\title{
GROWTH AND METABOLISM OF MESENCHYMAL STEM CELLS CULTIVATED ON MICROCARRIERS
}

Deborah Schop 


$\begin{array}{ll}\text { Promoters: } & \text { prof. dr. Joost D. de Bruijn } \\ & \text { prof. dr. Clemens A. van Blitterswijk } \\ \text { Assistant promoter: } & \text { dr. Riemke van Dijkhuizen-Radersma }\end{array}$

Copyright: 2010, Deborah Schop, Enschede, The Netherlands.

Neither this thesis nor its parts may be reproduced without written permission of the author. ISBN: 978-90-365-3018-7 


\title{
GROWTH AND METABOLISM OF MESENCHYMAL STEM CELLS CULTIVATED ON MICROCARRIERS
}

\author{
PROEFSCHRIFT
}

\author{
ter verkrijging van \\ de graad van doctor aan de Universiteit Twente, \\ op gezag van de rector magnificus, \\ prof. dr. H. Brinksma, \\ volgens besluit van het College voor Promoties \\ in het openbaar te verdedigen \\ op woensdag 19 mei 2010 om 15.00 uur
}

door

Deborah Schop

geboren op 28 november 1982

te Rotterdam 


\section{Members of the committee:}

Chairman: prof.dr. G. van der Steenhoven

Promoters: prof.dr. J.D. de Bruijn

prof.dr. C.A. van Blitterswijk

Ass promoter:

Referee:

Members: dr. D.E. Martens

dr. H.B.J. Karperien

prof.dr. L.W.M.M. Terstappen

prof.dr. A.J. van Zonneveld

prof.dr. W.J. van der Giessen
University of Twente, TNW

Queen Mary University of London /

Progentix / Xpand Biotechnology

Univ. Twente, TNW

Genmab

University of Wageningen

University of Twente, TNW

University of Twente, TNW

Leiden University Medical Centre

Erasmus University Medical Centre

\section{Deborah Schop}

\section{Growth and Metabolism of Mesenchymal Stem Cells}

\section{Cultivated on Microcarriers}

The research described in this thesis was financially supported by grant IS044112 from SenterNovem (Agency of Ministry of Economic Affairs), The Netherlands, by the Smart Mix Program of the Netherlands Ministry of Economic Affairs and the Netherlands Ministry of Education, Culture and Science and by the EU-funded FP7 project STEM EXPAND.

The publication of this thesis was supported by Xpand Biotechnology and Nederlandse vereniging voor Biomaterialen en Tissue Engineering
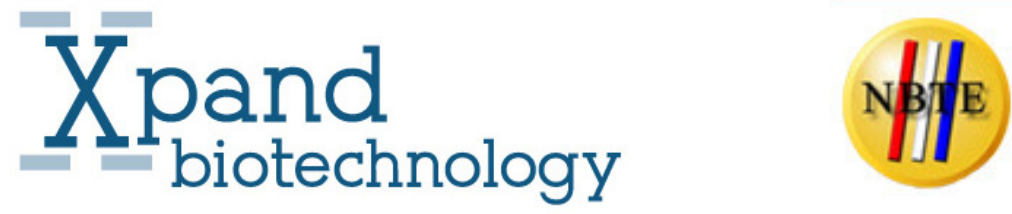

Printed by: Wörhmann Print Service, Zutphen, Nederland

Cover Design: Jan-Jacob Luijendijk 


\section{Table of contents}

List of publications

6.

$1 \quad$ General introduction and aims

9.

2 Growth, metabolism and growth Inhibitors of mesenchymal stem cells

37.

3 Expansion of mesenchymal stem cells using a microcarrier-based cultivation system: growth and metabolism

4 Expansion of human Mesenchymal Stromal Cells on Microcarriers: Growth and Metabolism

5 Effect of oxygen tension on metabolism, expansion and differentiation of human mesenchymal stromal cells

105.

Appendix: Effect of $\mathrm{pH}$ on metabolism and expansion of human mesenchymal stromal cells

6 Amino acid metabolism of human mesenchymal stromal cells during batch culture

$7 \quad$ Discussion and future perspectives

149.

Appendix - Use of MSCs in a porcine model of acute myocardial infarction; Feasibility in vitro results

160.

Summary

169.

Samenvatting

171.

Dankwoord

173.

Curriculum vitea

175. 


\section{List of publications}

\section{Publications related to this thesis}

- $\quad$ Schop D, FW Janssen, E Borgart, JD de Bruijn and R van Dijkhuizen-Radersma. (2008). Expansion of mesenchymal stem cells using a microcarrier-based cultivation system: growth and metabolism. J Tissue Eng Regen Med 02:126-135

- Schop D, FW Janssen, L van Rijn, H Fernandes, RM Bloem, JD de Bruijn, R van Dijkhuizen-Radersma. (2009). Growth, metabolism and growth inhibitors of mesenchymal stem cells. Tissue Eng part A, 15(8): 1877-1886

- Higuera-Sierra G, D Schop, F Janssen, R van Dijkhuizen-Radersma, A van Boxtel and C van Blitterswijk. (2009) Quantifying in vitro growth and metabolism kinetics of human mesenchymal stem cells using a mathematical model. Tissue Eng part A, 15(9): 26532663

- $\quad$ Schop D, R van Dijkhuizen-Radersma, E Borgart, FW Janssen, H Rozemuller, HJ Prins and JD de Bruijn. (2010). Expansion of human mesenchymal stem cells on microcarriers: Growth and metabolism. J Tissue Eng Regen Med, 4 (2): 131-140

- $\quad$ Schop D, R van Dijkhuizen-Radersma, G Brans, HJ Prins, H Rozemuller, D Martens, and JD de Bruijn. (2010) Effect of oxygen tension on metabolism, expansion and differentiation of human mesenchymal stem cells. Submitted

- $\quad$ Schop D, R van Dijkhuizen-Radersma, M Bracke, D Martens, and JD de Bruijn. Amino acid metabolism and flux analysis of human mesenchymal stromal cells during batch culture. In preparation

\section{Selected oral presentations}

- Schop D, R van Dijkhuizen-Radersma, E Borgart, FW Janssen and JD de Bruijn. (December 2006) Expansion of mesenchymal stem cells using a microcarrier-based cultivation system. Nederlandse vereniging voor Biomaterialen en Tissue engineering (NBTE), Lunteren, The Netherlands

6. 
- Higuera-Sierra G, D Schop, F Janssen, R van Dijkhuizen-Radersma and C van Blitterswijk. (January 2007) Mesenchymal Stem Cell Proliferation and Metabolic Profiling in Spinner Flasks Biomedical Engineering conference, Egmond aan Zee, The Netherlands

- Schop D, FW Janssen, E Borgart, JD de Bruijn and R van Dijkhuizen-Radersma. (September 2007) Successful 3D proliferation of human mesenchymal stem cells on microcarriers. Tissue Engineering International \& Regenerative Medicine Society (TERMIS), London, UK

- Higuera-Sierra G, D Schop, F Janssen, R van Dijkhuizen-Radersma, A van Boxtel and C van Blitterswijk. (September 2007) Mesenchymal Stem Cell Proliferation and Metabolic Profiling in Spinner Flasks. TERMIS, London, UK

- Higuera-Sierra G, D Schop, F Janssen, R van Dijkhuizen-Radersma, A van Boxtel and C van Blitterswijk. (November 2007) Modeling of Human Bone Marrow Mesenchymal Stem Cells Kinetics. Nederlandse verenging voor calcium- en botstofwisseling (NCVB), Zeist, The Netherlands

- Schop D, R van Dijkhuizen-Radersma, E Borgart, FW Janssen and JD de Bruijn. (December 2007) 3D proliferation of human mesenchymal stem cells on microcarriers. NBTE, Lunteren, The Netherlands

- Higuera-Sierra G, D Schop, F Janssen, R van Dijkhuizen-Radersma and C van Blitterswijk. (December 2007) Mesenchymal Stem Cell Proliferation and Metabolic Profiling in Spinner Flasks. NBTE, Lunteren, The Netherlands

- $\quad$ Schop D, FW Janssen, JD de Bruijn and R van Dijkhuizen-Radersma. (June 2008) Human mesenchymal stem cell proliferation on microcarriers by controlling $\mathrm{pH}$ and dissolved oxygen concentration. World Biomaterials Congress (WBC), Amsterdam, The Netherlands

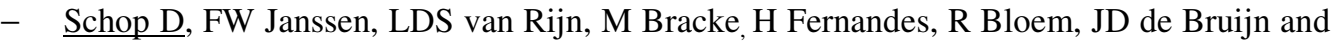
R van Dijkhuizen-Radersma. (December 2008) Growth, metabolism and growth inhibitors of mesenchymal stem cells. NBTE congress, Lunteren, The Netherlands

\section{Selected poster presentations}

- $\quad$ Schop D, FW Janssen, JD de Bruijn and R van Dijkhuizen-Radersma. (September 2008) Growth, metabolism and growth inhibitors of mesenchymal stem cells. Stem Cell Europe congress, Amsterdam, The Netherland 



\section{General introduction}

\section{and aims}

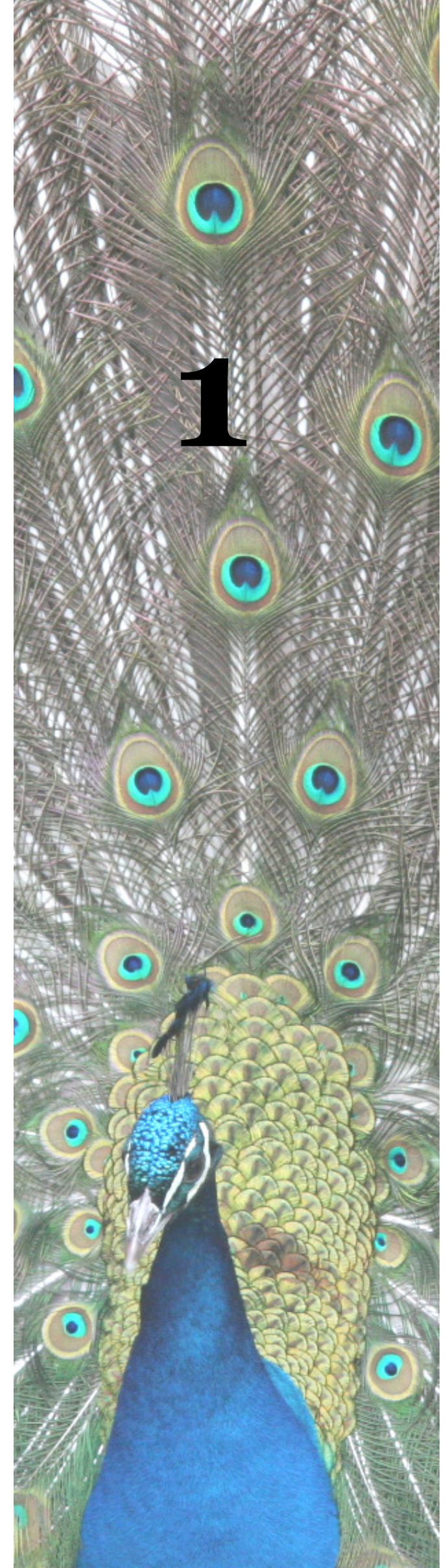





\section{Introduction}

This thesis focuses on the metabolism of mesenchymal stem cells during in vitro expansion. This introduction chapter provides the reader with an overview on both stem cells and metabolism. We first describe stem cells in general and mesenchymal stem cells in particular. As the majority of the expansion experiments have been performed using microcarriers in bioreactors, these subjects will be addressed as well. Thereafter, general background information on cell metabolism is given. Finally, the aims and outline of this thesis are described.

\section{Stem cells}

\section{What defines a stem cell?}

A stem cell is a cell in the human body or other multi-cellular organism that is characterized by the capacity of self-renewal and the ability to provide additional undifferentiated cells and differentiated cells towards a diverse range of specialized cell types and tissues (Figure 1).

Stem cells are maintained by symmetric cell division and asymmetric cell division. For symmetric cell division, two identical daughter cells are produced and for asymmetric cell division, one identical daughter cell and a non-identical daughter cell (progenitor cell or differentiating cell) are produced or two non-identical daughter cells are produced. A progenitor cell is a cell that is a precursor to differentiated cells towards a specific cell phenotype. These cells are assumed to have reduced self-renewal and a reduced ability to differentiate towards specialized cell types. In other words, progenitor cells have a different potency compared to undifferentiated stem cells. 


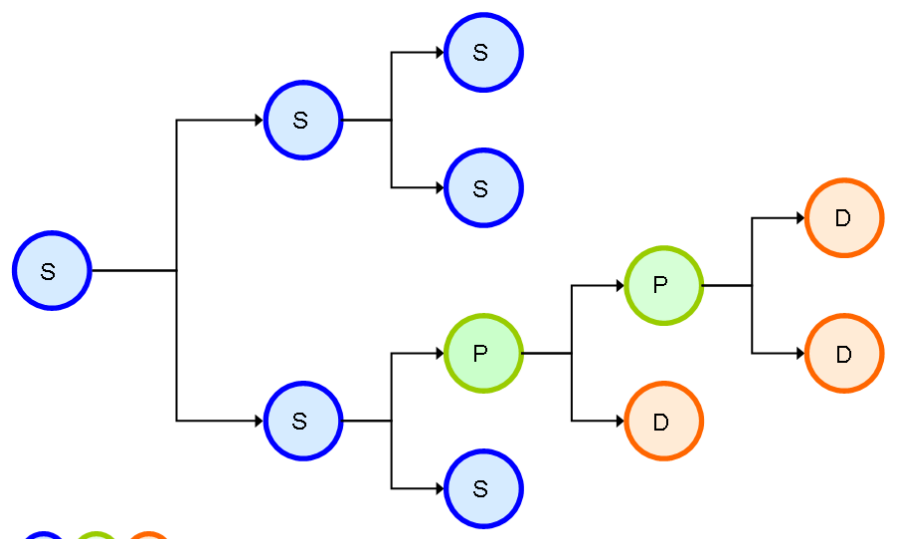

\section{(ㅇ) $P(1)$}

\section{Figure 1. Self-renewal and differentiation of a stem cell}

A: stem cell, B: progenitor cell, C: differentiated cell

The terms totipotent, pluripotent and multipotent are commonly used to describe the potency of stem cells to differentiate towards a range of specialized cell types and tissues;

- A totipotent cell has the capacity to form an entire organism. Totipotent cells have full potential. With regard to human development, a totipotent cell is formed by the fertilization of an egg by a sperm cell. The first hours after fertilization, identical totipotent cells are produced.

- A pluripotent cell has the capacity to develop into most, but not all, cell types and tissues. These cells are found in the inner cell mass of blastocyst 5 to 8 days after fertilization. They have the ability to develop cell and tissues of the three primary germ layers called ectoderm, mesoderm, and endoderm. These are the primary layers of cells in the embryo from which all tissues and organs develop.

- A multipotent cell has the capacity to form mature cells and tissues from multiple, but specific lineages from differentiated cells within a germ layer. For example, multipotent blood stem cells give rise to erythrocytes, white cells and platelets in the blood.

Stem cells can be subdivided into two main groups: embryonic and somatic stem cells. Embryonic stem cells (ESCs) are pluripotent cells that do not exist in the body. They are isolated from the inner cell mass of the blastocyst, a thin-walled hollow structure in early embryonic development from which the embryo arises, and can be massively expanded in vitro. In 1981, the first mouse ESCs were isolated ${ }^{1 ; 2}$ and in 1998 the first human ESCs were isolated ${ }^{3}$.

12. 
Somatic stem cells are multipotent cells that reside in differentiated tissues. The primary roles of adult stem cells in a living organism are to maintain and repair the tissue in which they are found. The trigger of differentiation and self maintenance of stem cells in vivo are controlled by a micro-environment described as the "niche ${ }^{4 ; 5}$. The first somatic stem cells were discovered in the bone marrow: haematopoietic stem cells that give rise to all red and white blood cells and the blood platelets ${ }^{6}$. Nowadays, it is known that somatic stem cells can be isolated from many animal and human tissues such as bone marrow, muscle, skin, liver, pancreas, dental pulp, fat, and the heart.

\section{Mesenchymal stem cells}

In addition to haematopoietic stem cells, Friedenstein discovered that the bone marrow also contains bone marrow stromal cells ${ }^{7}$. Currently these cells are referred to mesenchymal stem cells (MSCs), because of their ability to differentiate into cells of the mesodermal lineage (Figure 2). Initially, it was established that these cells could differentiate towards osteocytes, chondrocytes, adipocytes, and myoblast ${ }^{8-11}$, from the mesodermal lineage. However, more recent literature also showed differentiation towards neuronal ${ }^{12}$, $\operatorname{cardiac}^{13}$, hepatic ${ }^{14}$, endothelial $^{15}$, pancreatic ${ }^{16}$, and renal ${ }^{17}$ cell types. Differentiation towards cell types which do not belong to the mesodermal lineage is also described as stem cell plasticity. How plasticity occurs and if it is a tissue culture artifact is still under discussion ${ }^{18 ; 19}$.

MSCs are primarily enriched from the bone marrow. The bone marrow is normally harvested under local anaesthesia from the upper part of the hip, the iliac crest. Other populations of MSCs have been found from peripheral blood ${ }^{20}$, adipose tissue ${ }^{21}$, skin tissue ${ }^{22}$, thymus and spleen $^{23}$, trabecular bone ${ }^{24}$, umbilical cord blood ${ }^{25}$ and other sites ${ }^{26}$. MSCs can be easily enriched by their adherence ability to tissue culture plastic ${ }^{27}$. MSCs cannot be recognized and selected by expression of specific markers. Instead, they express a complex pattern of molecules including CD105, CD90, CD73, CD166, CD44, CD29, CD54, STRO-1 and show a negative expression for CD14, CD45 and CD34 ${ }^{8 ; 28 ;}$. MSCs are characterized by their fibroblast-like morphology, colony forming unit, and multipotency ${ }^{7}$. Moreover, they have high proliferation capacities, up to 40 population doublings and 25 for elderly donors ${ }^{30}$, which make them an interesting candidate for tissue engineering applications and cell therapy. 
Prolleraton

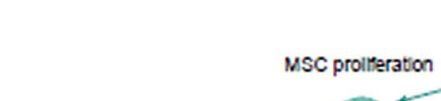

느 Mesenchymal stem cell

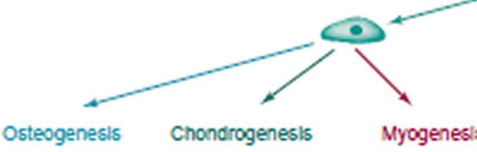

rogenes is

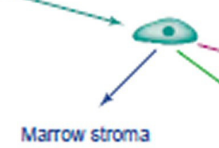

commitment
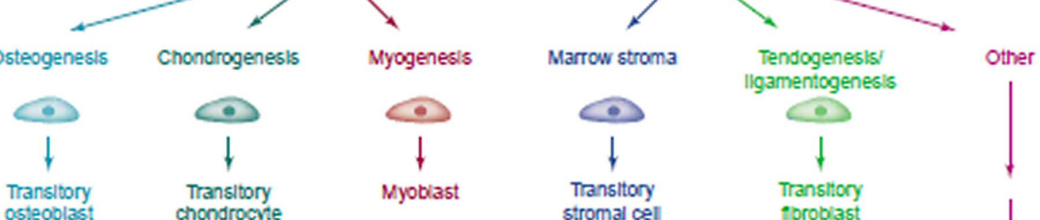

Lineage
progression osteoolast Transitory
chondrocyte (e)

(P)

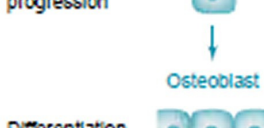

Dinerentation
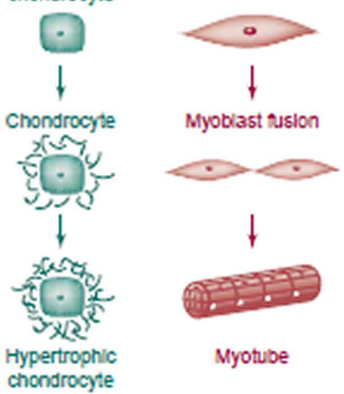

Maturation

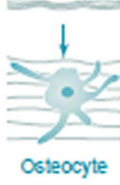

Cartllage

Myogenesis

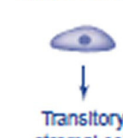

stromal cel

Transitory broblast
?
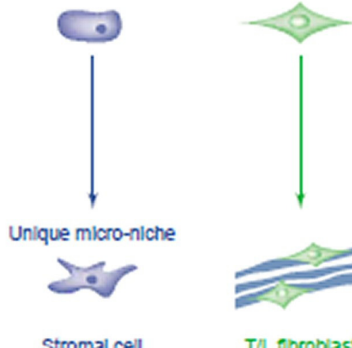

$T / L$ forodast

Marrow

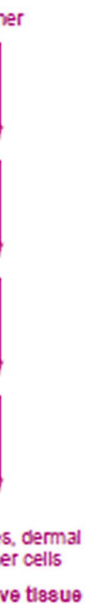

Muscle

\section{Figure 2. Multipotency of mesenchymal stem cell}

This scheme is a simplified depiction of the stepwise cellular transitions from the MSCs to differentiated phenotypes. Adapted from Caplan and Bruder ${ }^{31}$.

\section{Clinical applications}

Both ESCs and MSCs are interesting sources as regenerative medicine for clinical applications, using tissue engineering and cell therapy. However, MSCs are preferred because they are ethically non-controversial and present in every human body. When applying patient own MSCs as cell source, the graft-versus-host reaction is also prevented. On the other hands, allogenic MSCs could have immunomodulative properties, although clinical studies still need to verify this ${ }^{32 ; 33}$.

The term 'tissue engineering' is used for tissue which is ex vivo engineered using autologous or allogenic cells, and implanted back into the patient. A commonly applied definition of tissue engineering, as stated by Langer and Vacanti, is "an interdisciplinary field that applies the principles of engineering and life sciences toward the development of biological substitutes that restore, maintain, or improve tissue function or a whole organ" ${ }^{34}$. A commonly used technique for cell-based bone tissue engineering is shown in Figure 3. In addition to bone engineering ${ }^{35-37}$, other possible applications are possible using patient own

14. 
cells are, for example, the tissue engineering of cartilage ${ }^{38 ; 39}, \operatorname{skin}^{40-42}$, the nervous system ${ }^{43 ; 44}$, blood vessels ${ }^{45}$, cardiac tissue ${ }^{46}$, and organs ${ }^{47-49}$.

An example of tissue engineering that is already clinically applied is skin transplantation. A range of constructs are commercially available, such as Integra $^{\mathrm{TM}}$, Alloderm ${ }^{\mathrm{TM}}$ and Dermagraft $^{\mathrm{TM}}$. For example, Dermagraft ${ }^{\mathrm{TM}}$ is a cryopreserved human fibroblast-derived dermal substitute, which is composed of fibroblasts, extracellular matrix, and a bioabsorbable scaffold ${ }^{50}$

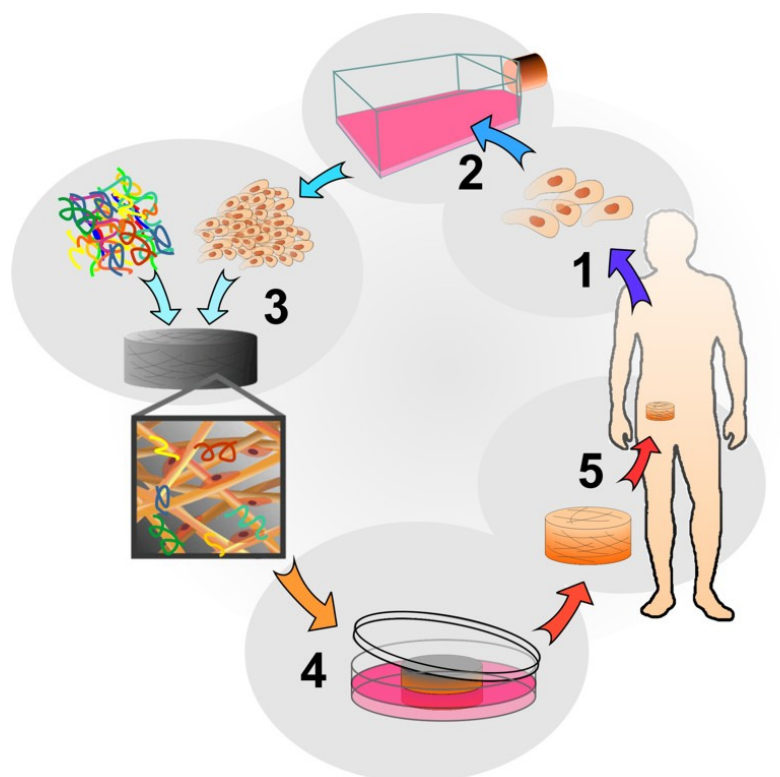

\section{Figure 3. The concept of cell-based bone tissue engineering}

1. Cell isolation from patient's bone marrow. 2. Cell expansion. 3. Cell seeding on suitable scaffold with or without presence of bioactive molecules. 4. Culture of the scaffold with cells expressing extracellular matrix. 5. Implantation of the construct in the defect of the patient. Adapted from Tissue Engineering book edited by CA van Blitterswijk ${ }^{51}$.

Cell therapy describes the process of introducing new cells into a damaged tissue in order to treat a disease or injury. For this, autologous or allogeneic stem cells can be used, but also mature, functional cells or transdifferentiated cells from patient own differentiated cells are used. With regard to stem cells, adult stem cells are isolated from the patient and expanded when necessary (step 1 and 2, Figure 3). Thereafter, they are injected back into the patient, either in the blood stream or at local sites. 
A cell therapy already used in the clinics for over 30 years is the transplantation of bone marrow, or more recently, umbilical cord blood stem cells, to treat cancer patient with conditions such as leukemia and lymphoma. During the chemotherapy, the haematopoietic stem cells within the bone marrow are killed. By reintroducing the functional stem cells after the chemotherapy, the patient regains the ability to produce healthy blood cells.

A number of other potential treatments are under investigation nowadays. Stem cells may be used to treat brain diseases, such as Parkinson ${ }^{52 ; 53}$ and Alzheimer ${ }^{54}$, or other neurological disorders, such as Huntington's disease ${ }^{55}$, multiple sclerosis ${ }^{56 ;} 57$ and spinal cord injury ${ }^{58 ;} 59$. Heart diseases, such as myocardial infarctions or heart failure, are another application for which stem cells are examined as cell therapy ${ }^{60-63}$. Other examples of cell therapy using mature, functional cells or transdifferentiated cells from patient own differentiated cells are replacements of cartilage ${ }^{64 ; 65}$, liver $^{66}$, and pancreas ${ }^{67-69}$.

A challenge for both tissue engineering and cell based therapy is the availability of sufficient functional cells for the application. It has been reported that the average amount of adult stem cells that can be differentiated into the osteogenic lineage from a patient is only about 1-10 per 100.000 cells present in the bone marrow ${ }^{70}$. For autologous tissue engineering, the cells are isolated from the patient and expanded in tissue culture flasks if necessary prior to seeding them on an appropriate scaffold. For cell-based therapy, millions, if not billion of cells are necessary. For example, for treatment of a spinal cord injury approximately $2 * 10^{8}-2 * 10^{9}$ bone marrow cells are injected ${ }^{58 ; 59}$, for chronic heart failure about between $28 * 10^{6}$ to $300 * 10^{6}$ bone marrow cells ${ }^{71-74}$ or till $6^{*} 10^{9} \mathrm{MSCs}^{75}$, and for successful liver transplantation it is hypothesized that $1 * 10^{10}$ hepatocytes are needed ${ }^{66}$. This numbers of cells are based on the methods used for several clinical trails. These cell numbers are not fixed yet, meaning that less or more cells are necessary for future clinical applications.

\section{Bioreactor technology}

To obtain sufficient cells for clinical applications, the cells or tissue need to be harvested from the patient and the required cells need to be isolated and expanded in vitro. In the case of MSCs, the MSCs are isolated from the source (e.g. the bone marrow) by plastic adhesion selection $^{27 ; 76 ; 77}$. The isolated population is heterogeneous and the number and population composition of adherent cells differs between patients ${ }^{78-80}$. The so called donor-to-donor variation makes it a challenge to develop a standard culture process.

16. 
The isolated cells can be in vitro expanded by monolayer culture on tissue culture treated plastic in the presence of culture medium supplemented with growth factors, serum, vitamins and other additives, such as the energy substrate glucose and amino acids. Examples of plastic culture systems are T-flasks, well-plates and Petri-dishes. After expansion, the cells can be seeded on a scaffold for tissue engineering applications, or administered to the patient for cellbased therapy.

The expansion of cells in these monolayer culture systems (2D) is far from optimal. It is labour intensive and susceptible to contaminations due to the number of necessary cell passages as a result of the limited availability of surface area and the manual medium refreshments. Furthermore, culture conditions are suboptimal due to the lack of monitoring and control of the cultivation ${ }^{81}$. Also in terms of logistics and costs, expansion of stem cells in 2D systems is unfavoured as this will possibly takes place in another location than in the hospital. This will bring in extra cost as the biopsy and the expanded cells need to be transported using protected transportation. In addition, extra costs are necessary for the labour needed to passage he cells. To expand stem cells in a controlled, reproducible, cost reducing and more efficient way, more and more research is being performed on the development of controlled bioreactors for both tissue engineering applications and cell therapy application ${ }^{81-86}$.

\section{Bioreactors for tissue engineering}

The most typical application of bioreactor technology in tissue engineering aims to optimize the quality of the engineered tissue construct to closely resemble patient own tissue and to limit handling between cell harvesting and implanting the tissue construct back into the patient. Another application of bioreactors in tissue engineering is to make tissue or a composition of cells and scaffolds that will be implanted as a catalyser that will transform to the proper tissue after implantation.

The tissue culture in bioreactors can be controlled for temperature, $\mathrm{pH}$, and oxygen and nutrients can be supplied optimally. In addition, mechanical stresses can be applied to improve the engineered construct based on the original tissue characteristics, for example for heart tissue $^{87}$ and cartilage ${ }^{88}$. Spinner flasks ${ }^{89}$, wavy-walled reactors ${ }^{90}$, and rotating wall vessels ${ }^{91}$ (schematically shown in Figure 4) are only a few examples of the numerous bioreactor devices found in the literature. A promising approach, enabling efficient and uniform seeding of different cell types in scaffolds of various morphologies and porosities, proved to be the perfusion bioreactor ${ }^{92-99}$. Homogeneous cell distribution throughout the whole three- 
dimensional scaffold is obtained due to the perfusion during the seeding phase. In addition, during expansion good mass transport of oxygen and nutrients to all the cells is obtained ${ }^{92-96 ; 98 ;}$ ${ }^{99}$. This principle of perfusion had been described for e.g. the engineering of bone ${ }^{94 ; 97}$ and heart valves $^{95}$.
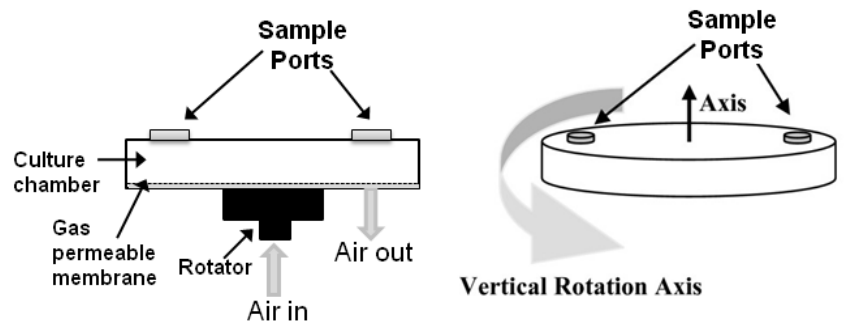

Figure 4. Simplified schematic depiction of a rotating wall vessel

This vessel is used as tissue engineering bioreactor and cell therapy bioreactor for a wide variety of cell types $^{91 ; 100 ; 101}$. Due to rotation of the chamber and the oxygenator, microgravity forces are generated in the culture, improving cell culture as minimal mechanical forces are generated and a high mass transfer is obtained.

\section{Bioreactors for cell therapy}

Cell expansion for cell therapy requires another bioreactor design. In contrast to the general tissue engineering approach, the cells only need to be expanded and harvested from an expansion surface and no scaffold containing cells is implanted. In addition, depending on the application the expanded cells should either be triggered or not to be triggered to differentiate by for example biological stimuli or bioreactor stimuli as used for tissue engineering.

In case of autologous use of cell therapy, cells need to be isolated from the patient, expanded, harvested and injected back into the patient, with or without cell differentiation prior to delivering the cells to the patient. For this application also numerous bioreactor devices are described in literature, such as packed and fluidized bed bioreactors (used for the expansion of hapatocytes, cardiomyocytes, cartilage cells and others, e.g. from Cesco Bioengineering Co. ${ }^{85}$, the rotating wall vessel (see Figure 4; used for expansion of haematopoietic stem cells, chondrocytes, cardiac cells and others, e.g. from Synthecon Inc.) ${ }^{100 ; 101}$, the Wave bioreactor (e.g. from GE Healthcare) ${ }^{102}$, and the stirred cultures in spinner flasks or stirred vessels, shown in Figure 5 (used for the expansion of MSCs, embryonic stem cells, various tumour cells and others ${ }^{103-108}$. The main difference in bioreactor designs are associated with mass transport, shear stresses and removal of metabolites ${ }^{109}$.

18. 


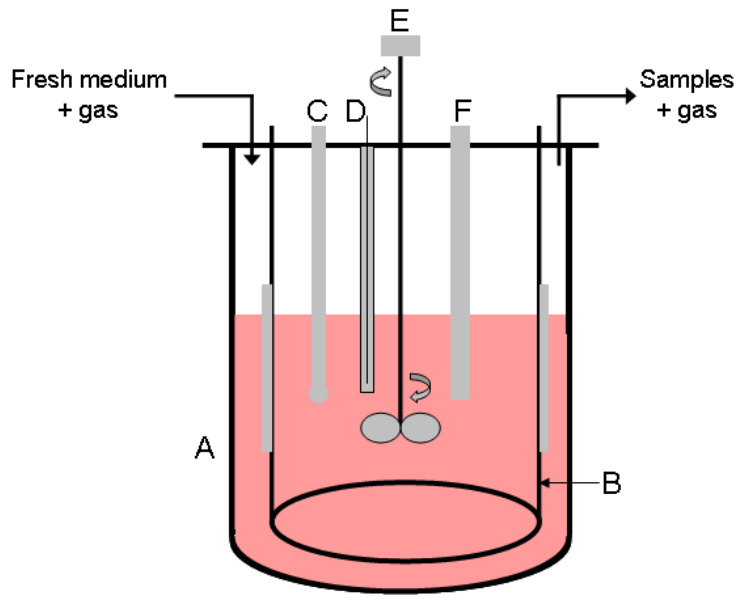

Figure 5. Schematic depiction of a stirred vessel bioreactor

A: reactor vessel, B: heat exchanger with baffles, C: $\mathrm{pH}$ sensor, D: temperature sensor, E: stirred with blades controlled with a stirrer motor, F: Oxygen probe

Being anchorage dependent cells, MSCs need to be attached to a surface for expansion. Independent of the bioreactor system, the expansion scaffold should have a large surface/volume ratio, not toxic for cells, inert, and able to release cells. As limited groups of expansion scaffolds are available, an obvious approach for stirred cultures of adherent cells would be the use of microcarriers. Microcarriers offer the advantage of providing a large surface area for monolayer cell growth during proliferation in a homogenous suspension culture. Since its introduction in 1967 by Van Wezel ${ }^{110}$, microcarrier culture has been applied successfully for growing primary cells and anchorage-dependent cell lines either for the production of vaccines or pharmaceuticals or for cell population expansion ${ }^{111}$. A variety of commercial microcarriers for cell expansion are available differing in chemical composition, charge, surface coatings and porosity ${ }^{112}$.

The Cytodex microcarriers, which are composed of cross-linked dextran matrix, are most commonly used for a wide range of cells, such as Chinese hamster ovary (CHO) cells ${ }^{113}$, Vero (African green monkey kidney) cells ${ }^{114}$, Madin-Darby canine kidney (MDCK) cells ${ }^{115}$, and for the expansion of animal derived stem cells ${ }^{116-119}$, these commercially available microcarriers have been used. Figure 6 depicts a schematic overview of a Cytodex 1 microcarrier, which is positively charged and attracts cells based on this charge yielding a higher initial attachment rate. Weather microcarriers can also be used for the expansion of human MSCs in a stirred culture system has not yet been investigated to date. 


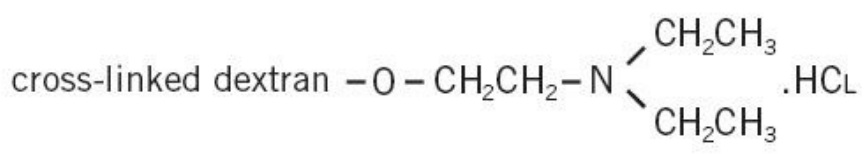

Figure 6. Schematic representative of Cytodex 1 microcarrier

These carriers have positively DEAE charges throughout the matrix

\section{Metabolism}

To optimize a bioreactor culture, with respect to $\mathrm{pH}$, oxygen tension and nutrient addition/metabolite removal for cell growth improvements, cellular metabolism should be evaluated. Cellular expansion and cell maintenance in cell culture requires energy. Energy, in the form of the storage molecule adenosine triphosphate (ATP), can be metabolized by animal cells using proteins, carbohydrates and fats as substrates (Figure 7).

Respiration involves glycolysis, the Krebs cycle, and electron transport ${ }^{120}$. The first two stages, glycolysis and Krebs cycle, are the catabolic pathways that decompose glucose and other organic fuels. Glycolysis, which occurs in the cytosol, starts the degradation by breaking glucose into two pyruvate molecules. The Krebs cycle, which takes place within the mitochondria, decomposes a derivate of pyruvate, Acetyl-CoA, to carbon dioxide $\left(\mathrm{CO}_{2}\right)$. In the third stage, the electron transport chain accepts the electrons from the breakdown of the first two stages (usually via NADH). With oxidative phosphorylation in the mitochondria, the energy from the transport of the electrons to the end of the chain is used to synthesis ATP.

With regard to the substrates, proteins are digested to amino acids, which are mainly used for building new proteins. However, excess amino acids are converted by enzymes to intermediates that can enter the glycolysis and the Krebs cycle. For cell culture, amino acids are important constituents of the culture medium. During the conversion of amino acids, the amino group of the amino acids must be removed, which is called deamination, yielding ammonia, urea, or other waste products.

Lipids are separated into glycerol and fatty acids by digestion. Afterwards, glycerol is concerted to an intermediate of glycolysis and fatty acids are broken down via the beta oxidation to two-carbon fragments, which enter the Krebs cycle.

20. 


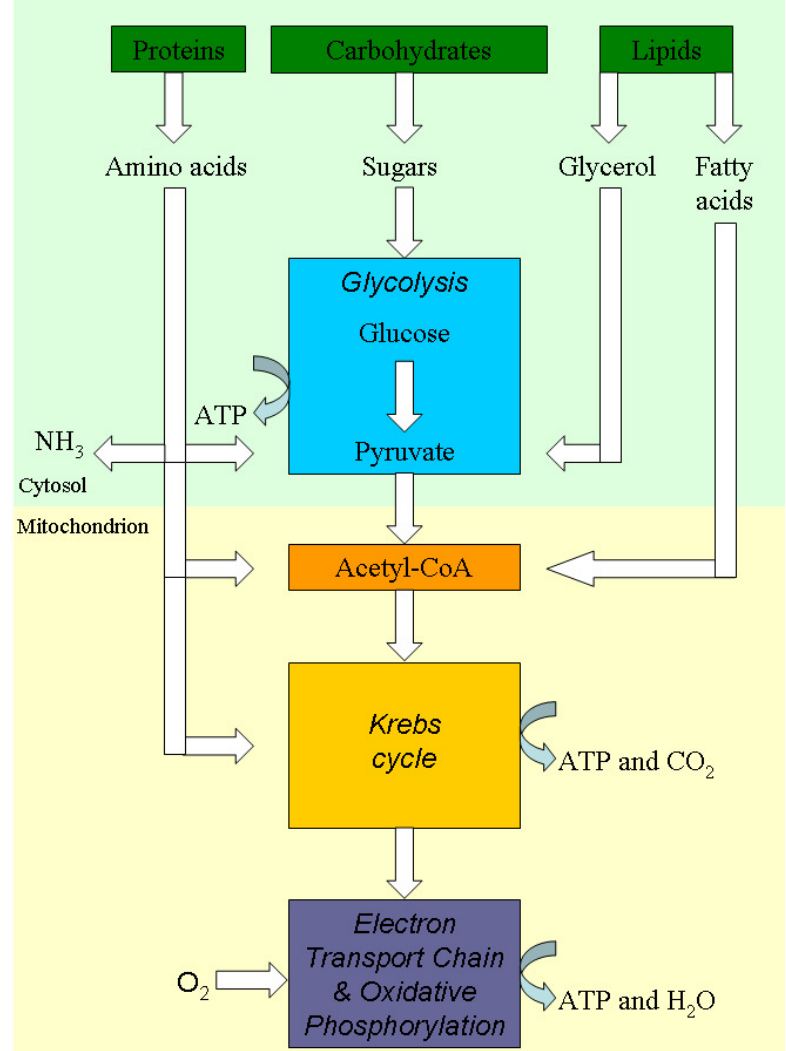

\section{Figure 7. Schematic diagram of cell respiratory catabolism}

Proteins, lipids and carbohydrates are digested into their respective subunits or monomers and are then processed by the cell to produce energy. Figure is based on information from Campbell et. al. ${ }^{120}$.

The main energy sources for cells are the carbohydrates. Starch, glycogen and other carbohydrates are hydrolysed to sugars, mainly glucose, which is then metabolized to energy by the glycolysis and the Krebs cycle. As in cell culture only hydrolysed carbohydrates can be utilized, glucose is commonly added to the culture medium for energy generation and is used as one of the main energy sources. Being one of the main energy sources, the metabolic routes from glucose to ATP are described in more detail in the following section. 


\section{Glucose metabolism}

\section{Glycolysis}

In glycolysis glucose, a six-carbon sugar, is broken down into two pyruvate molecules, a three-carbon sugar. The pathway of glucose to pyruvate consists of 10 enzymatic steps, but the most important steps are shown in Figure 8. During the first steps, energy is invested to obtain a 3-carbon sugar. The final steps generate energy, ATP and nicotinamide adenine dinucleotide in its reduced form (NADH). The net production of the glycolysis is 2 ATP molecules from 1 glucose molecule.

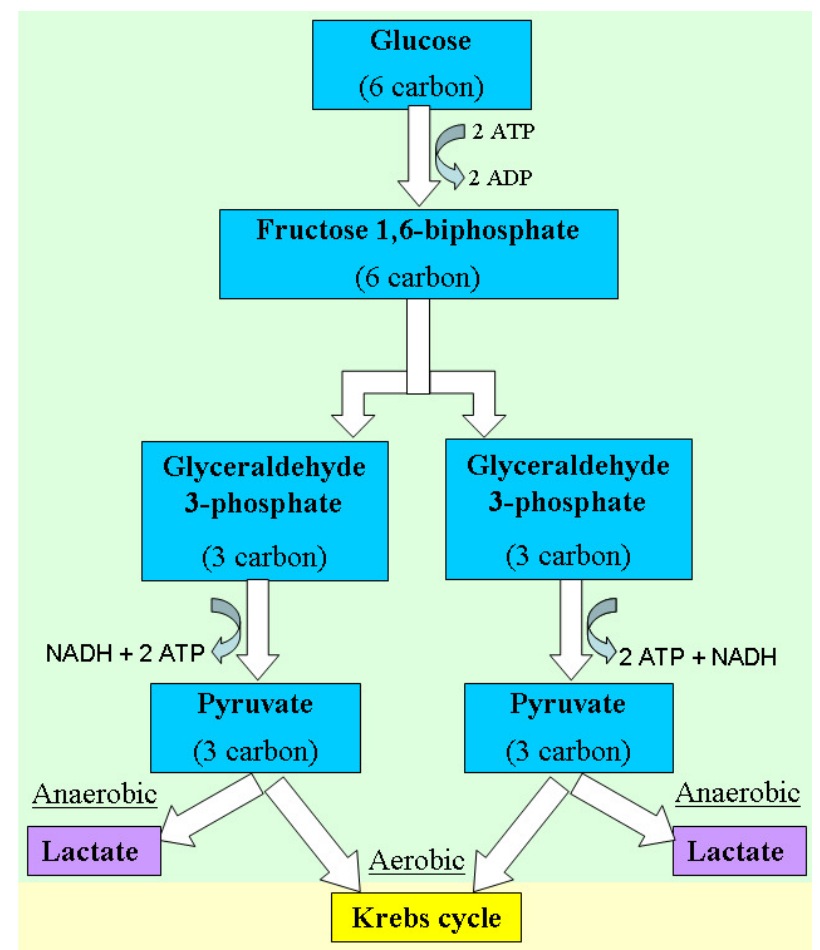

Figure 8. An overview of the glycolysis

Figure is based on information from literature ${ }^{120}$.

After glycolysis, pyruvate can be converted to acetyl-CoA, and ATP production continues in the Krebs cycle followed by oxidative phosphorylation. However, these pathways can only be used by the cells in presence of oxygen. When no oxygen is present or no oxygen is used by the cells, the fermentation to lactate, or also called the anaerobic glycolysis pathway, will be 
used. Per pyruvate molecule, one lactate molecule is produced and one NADH molecule is converted to $\mathrm{NAD}^{+}$. To generate equal amounts of ATP, a cell using the anaerobic pathway will consume far more glucose or at a higher rate than when using the aerobic pathways.

\section{The Krebs cycle}

The Krebs cycle, also known as the citric acid cycle or the tricarboxylic acid (TCA) cycle, is a series of enzymatic and chemical reactions which is essential for aerobic metabolism ${ }^{121}$. As shown in Figure 9, pyruvate from the glycolysis is converted into acetyl-CoA which is the start of the Krebs cycle. This step already yields $1 \mathrm{NADH}$ and $1 \mathrm{CO}_{2}$ molecule. The acetyl group of acetyl-CoA undergoes a series of oxidation reactions and transfers from citrate to oxaloacetate during one cycle before the process re-starts. The cycle consists of eight steps where $2 \mathrm{CO}_{2}$ molecules, 1 ATP molecule, $3 \mathrm{NADH}$ and 1 flavin adenine dinucleotide in its reduced form $\left(\mathrm{FADH}_{2}\right)$ are produced. As per glucose molecule two acetyl-CoA molecules are produced, the net production of the Krebs cycle is 2 ATP molecules.

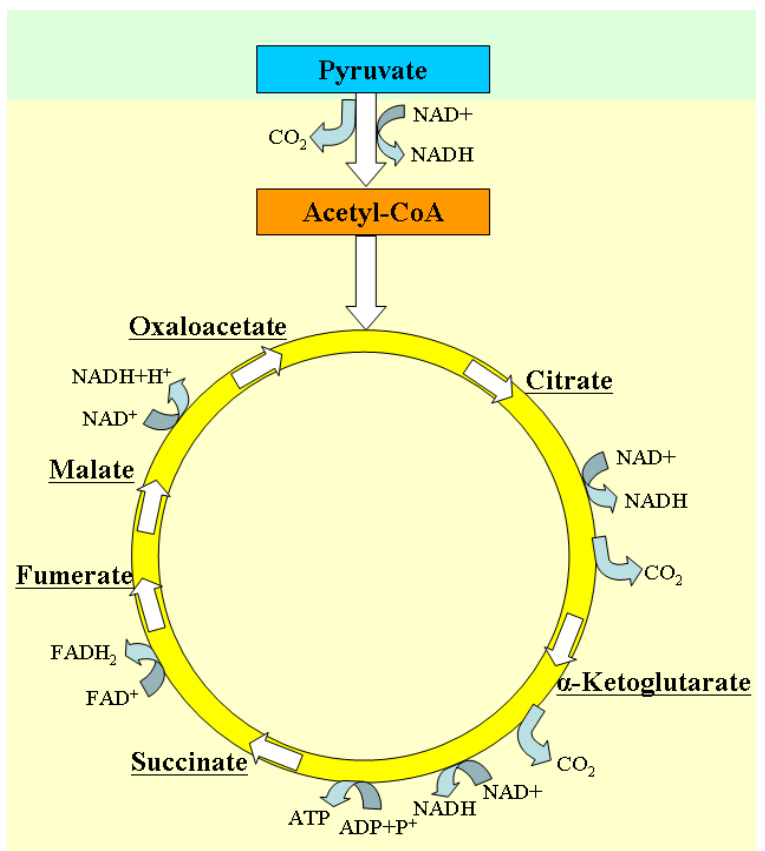

Figure 9. An overview of the Krebs cycle

Figure is based on information from literature ${ }^{120}$. 


\section{Electron transport chain and oxidative phosphorylation}

The electron transport chain is a collection of electron-carrier molecules (membrane proteins) embedded in the inner membrane of the mitochondrion that shuttle electrons during the redox reactions that release energy to make ATP ${ }^{120}$. For this, the FADH2 and NADH molecules yielded from the Krebs cycle are oxidized to release the electrons from the molecules and reform FAD+ and NAD+ that are recycled by the Krebs cycle. The electron carriers are composed of four complexes (I-IV) which transports protons $\left(\mathrm{H}^{+}\right)$to the intermembranous space, resulting in an electrochemical proton gradient. By re-entry of the protons through complex V, or ATP synthase, the free energy released from the gradient is used for ATP synthesis. This process is known as oxidative phosphorylation and yields 30-34 ATP molecules, depending on the activity and the type of the used electron shuttle complexes.

In total, the cellular respiration from glucose to ATP can produce 34-38 ATP molecules from 1 glucose molecule.

\section{Glutamine metabolism}

In addition to glucose metabolism, cellular energy can also be generated by the glutamine metabolism ${ }^{122}$. The nonessential amino acid, glutamine, is metabolically deaminated to glutamate. For this, the amino group of glutamine is hydrolysed by glutaminase yielding glutamate and ammonium. The glutamate is then converted to $\alpha$-ketoglutarate by either the transamination pathway yielding alanine or the deamination pathway using glutamate dehydrogenase (GDH) yielding an extra ammonium. $\alpha$-Ketoglutarate is then converted to pyruvate via the Krebs cycle and the malate aspartate shuttle. The conversion of glutamine to pyruvate is called the glutaminolysis. Pyruvate can next either be converted to lactate or alanine or is completely oxidized in the citric cycle to $\mathrm{CO}_{2}$ or partly oxidized to asparatate ${ }^{123}$.

Glutaminolysis can be either energy efficient or energy inefficient. The energy efficient catabolism, using GDH and complete oxidation to $\mathrm{CO}_{2}$, results in 27 moles of ATP and 2 moles of ammonia. Inefficient catabolism yields either 1 mole lactate, 1 mole ammonia and 9 moles ATP (using GDH) or yields 1 mole alanine, 1 mole ammonia and 9 moles ATP (using the transamination pathway) or yields 1 mole aspartate, 1 mole ammonia and 9 moles ATP $^{123-}$ 128 .

24. 


\section{Amino acid metabolism}

Although the glucose and glutamine metabolism are the most important metabolisms for energy generation, cells also have an amino acid metabolism. Amino acid metabolism is complex due to the number of amino acids (20 essential and nonessential amino acids) and metabolites involved ${ }^{129-131}$. Amino acids are not only used for protein biosynthesis but also as precursors for lipids, carbohydrates, signalling molecules, nucleic acids, and energy production. Amino acid metabolism consists of amino acid synthesis and amino acid catabolism. Figure 10 gives a schematic overview of amino acid metabolism, which is directly linked to the Krebs cycle.

Different metabolites are produced during the synthesis and catabolism of amino acids. The main waste product is ammonia $\left(\mathrm{NH}_{3}\right)$. During several amino acid conversions, e.g. mainly from glutamine to glutamate but also from serine to pyruvate, the amino group is removed and excreted as ammonia ${ }^{123}$. In addition, ammonia is also produced due to spontaneous decomposition of glutamine, as glutamine is chemically labile in a cell culture medium $^{132}$. Low levels of ammonia in the cell culture medium are known to inhibit cells growth $^{123}$

Other metabolites from amino acid metabolism are lactate (from incomplete oxidation of pyruvate) ${ }^{125 ; 135}$, alanine, aspartate, glutamate, and proline (from glutamine metabolism) ${ }^{125 ;}$ 136; ${ }^{137}$, and glycine (from serine metabolism) ${ }^{137}$. To overcome that these metabolites inhibit cell growth or that amino acids are limited in the culture medium, information on the amino acid metabolism for each cell type is required. At this stage, information on the amino acid metabolism (and energy metabolism in general) for (human) mesenchymal stem cells is lacking. 


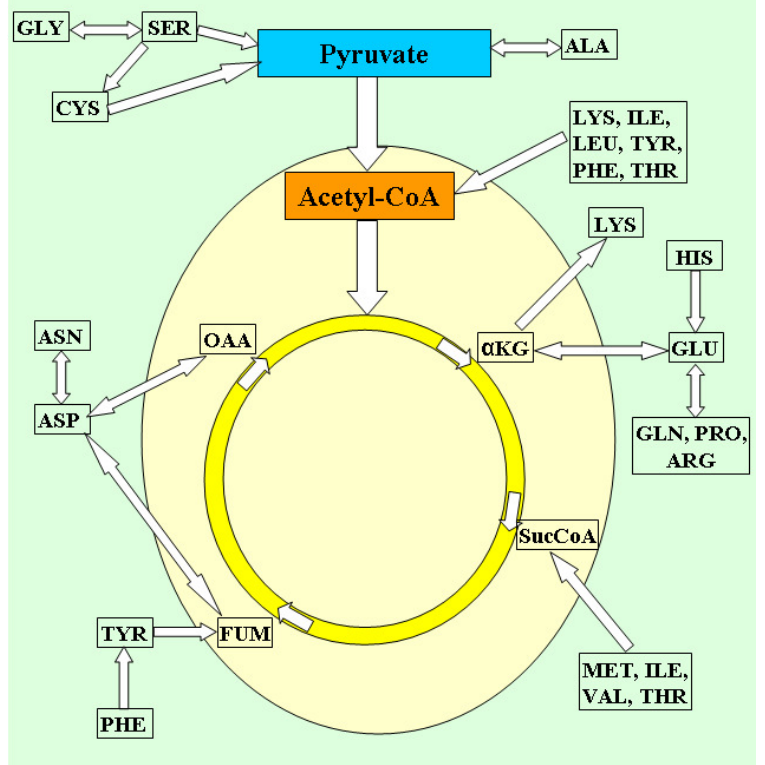

Figure 10. An overview of amino acid metabolism

This network is based on literature for mammalian cells ${ }^{133 ;} 134$ and the pathways described in the Kyoto Encyclopaedia of Genes and Genomes (KEGG). The general three-code abbreviations for the amino acids are used. Other abbreviations are $\alpha \mathrm{KG}$ : $\alpha$-ketoglutarate, SucCoA: succinate coenzyme A, FUM: fumerate, OAA: oxaloacetate.

\section{Metabolism and cell culture}

By having more knowledge on the metabolism of a cell line or cell type, cell culture can be improved in terms of expansion, viability, and productivity. For many years, the metabolism of a variety of cells has been investigated. By measuring the main nutrient and metabolite concentrations in the culture medium over time, the main metabolic routes of the cells for energy generation can be obtained and improved, based on the specific production and consumption rates $(\mathrm{q})$ and the yield of lactate from glucose $\left(\mathrm{Y}_{\text {lac/glc }}\right)$. A change in culture conditions or medium composition can redirect the preference metabolic route of the cells, resulting in better and more efficient results. For example, by maintaining the concentration of the C-sources glucose and glutamine at a defined level, metabolite production can be controlled and cell growth and productivity can be improved, as was shown for BKH cell by Cruz and coworkers ${ }^{137}$ and for hybridoma cell-lines by Ljunggren and Häggstörm ${ }^{126}$.

26. 
Another example is the replacement of nutrients to decrease the production of inhibiting metabolites. Genzel and co-workers investigated the effect of glutamine replacement by pyruvate to decrease the ammonia productions and thereby improving cell culture for several mammalian cell-lines ${ }^{138}$. By having information about the glutamine metabolism, action can be taken to decrease the production of metabolites, in this case ammonia, which is already inhibiting at low concentrations ${ }^{123 ; 135}$.

Culture conditions also have an influence on cellular metabolism and thereby the expansion, viability of productivity. An example is the dissolved oxygen concentration in the culture medium $^{128 ; 139}$. When enough oxygen is present in the medium, the cells can oxidize nutrients via the Krebs cycle. However, when oxygen is limiting, the anaerobic glycolysis to the metabolite lactate is used, where the maximum yield of lactate is 2 moles per mole glucose. High lactate concentrations can reduce the growth rate and cell viability, as was shown for multiple cell types ${ }^{135}$. To maintain the oxygen concentration at a percentage that the optimal metabolism is used by the cells, growth can be improved.

These are only a few examples how metabolic information can help improving a cell culture. By knowing more about the metabolism of stem cells and the effect of culture conditions on the metabolism of the stem cells, cell metabolism can be controlled ${ }^{140}$, resulting in improvement of the cell culture and the product quality (cell viability, multipotency).

\section{Oxygen and stem cells}

In the field of tissue engineering and regenerative medicine, oxygen is not only an important parameter for cell metabolism to improve cell culture but also to maintain stem cell multipotency. In vivo, the arterial bone marrow oxygen tension was measured to be $10-14 \%$, while MSCs reside within the bone marrow under hypoxic oxygen levels between $4-7 \%^{141}$. In addition, a developing embryo contains oxygen tension of $1.5-5.3 \%$ to develop the blastocytes and thus the embryonic stem cells ${ }^{142}$. When expanding MSCs in vitro under conventional culture conditions, air with $5 \% \quad \mathrm{CO}_{2}$ is normally used to provide oxygen for cellular metabolism and to control the medium $\mathrm{pH}$. However, it was shown when expanding stem cells at lower oxygen tensions, more population doublings were possible while maintaining stem cell differentiation potential ${ }^{143-152}$. It was shown that their growth rate can be improved by culturing under hypoxic $\left(5 \% \mathrm{O}_{2}\right)$ conditions. Moreover, when expanding the MSCs under hypoxic conditions, the multipotency was better maintained and less apoptosis was observed ${ }^{143}$ $147 ; 153 ; 154$. On the other hands, contradictory results regarding the effect of hypoxia on cell 
growth and MSC multipotency are also published ${ }^{145 ; 155 ; 156}$. In these studies no effect on cell growth was observed and no positive effects by hypoxia on multipotency of the MSCs.

It is suggested that more population doublings at low oxygen tensions are obtained because less and delayed cellular senescence occurs ${ }^{151 ; 157}$. Cellular senescence is induced by DNA damage and/or by telomerase shortening ${ }^{154}$ which may be caused by oxidative stress. When cells use the oxidative phosphorylation for energy generation, reactive oxygen species (ROS), such as oxygen free radicals $\left(\mathrm{O}_{2}^{-}\right)$and hydrogen peroxide $\left(\mathrm{H}_{2} \mathrm{O}_{2}\right)$, are produced ${ }^{151 ; 158}$. Normally, cells are protected against ROS by cellular anti-oxidants. However, cells can be damaged by the ROS production if insufficient anti-oxidants are present. Due to the production of ROS, premature aging of the cell can occur. However, when less ROS are produced by redirecting the cellular metabolism with lower oxygen tensions in the cell culture, the cellular senescence can be diminished ${ }^{159 ; 160}$ and cell expansion is prolonged.

At low oxygen tensions, in general the stem cell multipotency showed to be better maintained. An exact explanation why the stem cells better maintain their differentiation potential at hypoxic oxygen tension is not given in literature. Logically, when cells are expanded without DNA damage, the cells maintain their viability and stem cell characteristics. In addition, mimicking the in vivo conditions for bone marrow derived cells may also be an obvious explanation to increase the differentiation potential compared to culture the cells at different oxygen tensions in vitro. Despite the absence of an underlying mechanism, expanding stem cells at hypoxic oxygen tension might yield more population doublings, while maintaining and/or improving their stem cell characteristics.

\section{Aims and outline of this thesis}

Expansion of animal MSCs for multiple purposes has been shown in different types of bioreactor designs and on a number of scaffolds. However, most research is focussing on expansion of MSCs in the field of tissue engineering, i.e. expansion of MSCs on a scaffold prior to implantation of the engineered construct into the organism.

This thesis focuses on expansion of viable and multipotent MSCs for cell-based applications. It is hypothesized that MSCs can be expanded reproducibly in a process controlled bioreactor system while keeping their viability and multipotency. By unravelling the MSC cellular metabolism, a feeding regime can be defined and optimal culture conditions, such as $\mathrm{pH}$ control and hypoxic oxygen tension, can be selected.

28. 
As a first step, the expansion and energy metabolism of MSCs from several species in the conventional 2D culture systems, T-flasks, has been evaluated (Chapter $2^{161}$ ). Multiple donors per species were expanded and cellular metabolism was linked to cell growth. In addition, the effects of metabolic waste products, such as lactate from anaerobic glycolysis and ammonia from efficient glutamine metabolism, on growth rate were investigated. The inhibitory concentrations for these two waste products are important input for the optimization of culture conditions during expansion.

For clinical applications, the expansion of MSCs in a bioreactor is preferred over conventional 2D culture. In Chapter $3^{106}$ and $4^{107}$, MSCs are expanded in spinner flasks (a limited controlled bioreactor system) on microcarriers. Chapter 3 shows the reproducibility of goat MSC expansion and metabolism in a microcarrier-based cultivation system. Goat MSCs were selected for the first experiments as these cells grew significantly faster than human MSCs (concluded in Chapter 2). By using the goat MSCs, differences between cultures conditions (focussing on feeding regime) were more pronounced. Subsequently, the optimal feeding regime for goat MSCs was transferred to human MSCs in Chapter 4. After selecting the most suitable type of microcarriers for human MSCs, the feeding regime was fine-tuned to optimize the expansion rate. In addition, the human MSCs were characterized in detail to establish that these cells maintained their stem cell properties after expansion on microcarriers.

By using a stirred vessel bioreactor system, the culture could be controlled for several parameters, such as $\mathrm{pH}$ and dissolved oxygen concentrations (DO), to optimize the human MSCs expansion. Chapter $5^{162}$ describes the effect of pH and DO control on human MSCs expansion, metabolism and differentiation capacity. Both high oxygen concentrations (as used in standard in vitro culturing) and low oxygen concentrations (mimicking the natural environment of the MSCs) were evaluated. Based on the specific oxygen consumption, the glucose metabolism of the cells during expansion could be unravelled in more detail.

Besides the main energy metabolism, based on glucose and glutamine, the amino acid metabolism for human MSCs was investigated to further improve stem cell expansion. The consumption and production of the 20 essential and nonessential amino acids have been analyzed for human MSCs expanded under controlled conditions in a stirred vessel bioreactor. The findings are described in Chapter 6.

Finally, general conclusions drawn from the studies described in this thesis are discussed and future perspectives, including an in vitro feasibility study for in vivo implementation of expanded MSCs in a porcine model, are outlined in Chapter 7 and the Appendix chapter. 


\section{References}

1. Evans MJ, Kaufman MH (1981) Establishment in culture of pluripotential cells from mouse embryos. Nature 292:154-156

2. Martin GR (1981) Isolation of a pluripotent cell line from early mouse embryos cultured in medium conditioned by teratocarcinoma stem cells. Proc Natl Acad Sci U S A 78:7634-7638

3. Thomson JA, Itskovitz-Eldor J, Shapiro SS, Waknitz MA, Swiergiel JJ, Marshall VS, Jones JM (1998) Embryonic stem cell lines derived from human blastocysts. Science 282:1145-1147

4. Ohlstein B, Kai T, Decotto E, Spradling A (2004) The stem cell niche: theme and variations. Curr Opin Cell Biol 16:693-699

5. Schofield R (1978) The relationship between the spleen colony-forming cell and the haemopoietic stem cell. Blood Cells 4:7-25

6. Till JE, Mc CE (1961) A direct measurement of the radiation sensitivity of normal mouse bone marrow cells. Radiat Res 14:213-222

7. Friedenstein AJ, Chailakhjan RK, Lalykina KS (1970) The development of fibroblast colonies in monolayer cultures of guinea-pig bone marrow and spleen cells. Cell Tissue Kinet 3:393-403

8. Pittenger MF, Mackay AM, Beck SC, Jaiswal RK, Douglas R, Mosca JD, Moorman MA, Simonetti DW, Craig S, Marshak DR (1999) Multilineage potential of adult human mesenchymal stem cells. Science 284:143-147

9. Prockop DJ (1997) Marrow stromal cells as stem cells for nonhematopoietic tissues. Science 276:71-74

10. Caplan AI (1994) The mesengenic process. Clin Plast Surg 21:429-435

11. Lee JH, Kosinski PA, Kemp DM (2005) Contribution of human bone marrow stem cells to individual skeletal myotubes followed by myogenic gene activation. Exp Cell Res 307:174-182

12. Sanchez-Ramos J, Song S, Cardozo-Pelaez F, Hazzi C, Stedeford T, Willing A, Freeman TB, Saporta S, Janssen W, Patel N, Cooper DR, Sanberg PR (2000) Adult bone marrow stromal cells differentiate into neural cells in vitro. Exp Neurol 164:247-256

13. Toma C, Pittenger MF, Cahill KS, Byrne BJ, Kessler PD (2002) Human mesenchymal stem cells differentiate to a cardiomyocyte phenotype in the adult murine heart. Circulation 105:93-98

14. Weng YS, Lin HY, Hsiang YJ, Hsieh CT, Li WT (2003) The effects of different growth factors on human bone marrow stromal cells differentiating into hepatocyte-like cells. Adv Exp Med Biol 534:119-128

15. Oswald J, Boxberger S, Jorgensen B, Feldmann S, Ehninger G, Bornhauser M, Werner C (2004) Mesenchymal stem cells can be differentiated into endothelial cells in vitro. Stem Cells 22:377384

16. Moriscot C, de Fraipont F, Richard MJ, Marchand M, Savatier P, Bosco D, Favrot M, Benhamou PY (2005) Human bone marrow mesenchymal stem cells can express insulin and key transcription factors of the endocrine pancreas developmental pathway upon genetic and/or microenvironmental manipulation in vitro. Stem Cells 23:594-603

17. Chhabra P, Brayman KL (2009) The use of stem cells in kidney disease. Curr Opin Organ Transplant 14:72-78

18. Lakshmipathy U, Verfaillie C (2005) Stem cell plasticity. Blood Rev 19:29-38

19. Quesenberry PJ, Dooner G, Colvin G, Abedi M (2005) Stem cell biology and the plasticity polemic. Exp Hematol 33:389-394

20. Zvaifler NJ, Marinova-Mutafchieva L, Adams G, Edwards CJ, Moss J, Burger JA, Maini RN (2000) Mesenchymal precursor cells in the blood of normal individuals. Arthritis Res 2:477-488

21. Zuk PA, Zhu M, Mizuno H, Huang J, Futrell JW, Katz AJ, Benhaim P, Lorenz HP, Hedrick MH (2001) Multilineage cells from human adipose tissue: implications for cell-based therapies. Tissue Eng 7:211-228

22. Chunmeng S, Tianmin C (2004) Effects of plastic-adherent dermal multipotent cells on peripheral blood leukocytes and CFU-GM in rats. Transplant Proc 36:1578-1581

23. Krampera M, Marconi S, Pasini A, Galie M, Rigotti G, Mosna F, Tinelli M, Lovato L, Anghileri E, Andreini A, Pizzolo G, Sbarbati A, Bonetti B (2007) Induction of neural-like differentiation in human mesenchymal stem cells derived from bone marrow, fat, spleen and thymus. Bone 40:382-390

30. 
24. Sottile V, Halleux C, Bassilana F, Keller H, Seuwen K (2002) Stem cell characteristics of human trabecular bone-derived cells. Bone 30:699-704

25. Erices A, Conget P, Minguell JJ (2000) Mesenchymal progenitor cells in human umbilical cord blood. Br J Haematol 109:235-242

26. Jiang Y, Vaessen B, Lenvik T, Blackstad M, Reyes M, Verfaillie CM (2002) Multipotent progenitor cells can be isolated from postnatal murine bone marrow, muscle, and brain. Exp Hematol 30:896-904

27. Luria EA, Panasyuk AF, Friedenstein AY (1971) Fibroblast colony formation from monolayer cultures of blood cells. Transfusion 11:345-349

28. Jiang Y, Jahagirdar BN, Reinhardt RL, Schwartz RE, Keene CD, Ortiz-Gonzalez XR, Reyes M, Lenvik T, Lund T, Blackstad M, Du J, Aldrich S, Lisberg A, Low WC, Largaespada DA, Verfaillie CM (2002) Pluripotency of mesenchymal stem cells derived from adult marrow. Nature 418:41-49

29. Gronthos S, Graves SE, Ohta S, Simmons PJ (1994) The STRO-1+ fraction of adult human bone marrow contains the osteogenic precursors. Blood 84:4164-4173

30. Stenderup K, Justesen J, Clausen C, Kassem M (2003) Aging is associated with decreased maximal life span and accelerated senescence of bone marrow stromal cells. Bone 33:919-926

31. Caplan AI, Bruder SP (2001) Mesenchymal stem cells: building blocks for molecular medicine in the 21 st century. Trends Mol Med 7:259-264

32. Kode JA, Mukherjee S, Joglekar MV, Hardikar AA (2009) Mesenchymal stem cells: immunobiology and role in immunomodulation and tissue regeneration. Cytotherapy 11:377-391

33. Le Blanc K, Ringden O (2007) Immunomodulation by mesenchymal stem cells and clinical experience. J Intern Med 262:509-525

34. Langer R, Vacanti JP (1993) Tissue engineering. Science 260:920-926

35. Goshima J, Goldberg VM, Caplan AI (1991) Osteogenic potential of culture-expanded rat marrow cells as assayed in vivo with porous calcium phosphate ceramic. Biomaterials 12:253-258

36. Bruder SP, Kurth AA, Shea M, Hayes WC, Jaiswal N, Kadiyala S (1998) Bone regeneration by implantation of purified, culture-expanded human mesenchymal stem cells. J Orthop Res $16: 155-162$

37. Kruyt MC, de Bruijn JD, Wilson CE, Oner FC, van Blitterswijk CA, Verbout AJ, Dhert WJ (2003) Viable osteogenic cells are obligatory for tissue-engineered ectopic bone formation in goats. Tissue Eng 9:327-336

38. Caplan AI, Elyaderani M, Mochizuki Y, Wakitani S, Goldberg VM (1997) Principles of cartilage repair and regeneration. Clin Orthop Relat Res:254-269

39. Chen J, Wang C, Lu S, Wu J, Guo X, Duan C, Dong L, Song Y, Zhang J, Jing D, Wu L, Ding J, Li D (2005) In vivo chondrogenesis of adult bone-marrow-derived autologous mesenchymal stem cells. Cell Tissue Res 319:429-438

40. Rheinwald JG, Green H (1977) Epidermal growth factor and the multiplication of cultured human epidermal keratinocytes. Nature 265:421-424

41. Gallico GG, 3rd, O'Connor NE, Compton CC, Kehinde O, Green H (1984) Permanent coverage of large burn wounds with autologous cultured human epithelium. N Engl J Med 311:448-451

42. Metcalfe AD, Ferguson MW (2007) Tissue engineering of replacement skin: the crossroads of biomaterials, wound healing, embryonic development, stem cells and regeneration. J R Soc Interface 4:413-437

43. Dezawa M, Hoshino M, Nabeshima Y, Ide C (2005) Marrow stromal cells: implications in health and disease in the nervous system. Curr Mol Med 5:723-732

44. Ide C (1996) Peripheral nerve regeneration. Neurosci Res 25:101-121

45. Baguneid MS, Seifalian AM, Salacinski HJ, Murray D, Hamilton G, Walker MG (2006) Tissue engineering of blood vessels. Br J Surg 93:282-290

46. Zimmermann WH, Cesnjevar R (2009) Cardiac tissue engineering: implications for pediatric heart surgery. Pediatr Cardiol 30:716-723

47. Atala A, Bauer SB, Soker S, Yoo JJ, Retik AB (2006) Tissue-engineered autologous bladders for patients needing cystoplasty. Lancet 367:1241-1246

48. Yamzon J, Perin L, Koh CJ (2008) Current status of tissue engineering in pediatric urology. Curr Opin Urol 18:404-407 
49. Chen MK, Badylak SF (2001) Small bowel tissue engineering using small intestinal submucosa as a scaffold. J Surg Res 99:352-358

50. Hansbrough JF, Cooper ML, Cohen R, Spielvogel R, Greenleaf G, Bartel RL, Naughton G (1992) Evaluation of a biodegradable matrix containing cultured human fibroblasts as a dermal replacement beneath meshed skin grafts on athymic mice. Surgery 111:438-446

51. van Blitterswijk CA, Thomsen P, Lindahl A, Hubbell J, Wiliams D, Cancedda R, de Bruijn JD, Sohier J (2008) Tissue Engineering. Vol. 1. Elsevier

52. Lindvall O, Bjorklund A (2004) Cell therapy in Parkinson's disease. NeuroRx 1:382-393

53. Dezawa M, Kanno H, Hoshino M, Cho H, Matsumoto N, Itokazu Y, Tajima N, Yamada H, Sawada H, Ishikawa H, Mimura T, Kitada M, Suzuki Y, Ide C (2004) Specific induction of neuronal cells from bone marrow stromal cells and application for autologous transplantation. J Clin Invest 113:1701-1710

54. Sugaya K (2005) Possible use of autologous stem cell therapies for Alzheimer's disease. Curr Alzheimer Res 2:367-376

55. Clelland CD, Barker RA, Watts C (2008) Cell therapy in Huntington disease. Neurosurg Focus 24:E9

56. Windrem MS, Nunes MC, Rashbaum WK, Schwartz TH, Goodman RA, McKhann G, 2nd, Roy NS, Goldman SA (2004) Fetal and adult human oligodendrocyte progenitor cell isolates myelinate the congenitally dysmyelinated brain. Nat Med 10:93-97

57. Lindvall O, Kokaia Z (2006) Stem cells for the treatment of neurological disorders. Nature 441:10941096

58. Park HC, Shim YS, Ha Y, Yoon SH, Park SR, Choi BH, Park HS (2005) Treatment of complete spinal cord injury patients by autologous bone marrow cell transplantation and administration of granulocyte-macrophage colony stimulating factor. Tissue Eng 11:913-922

59. Yoon SH, Shim YS, Park YH, Chung JK, Nam JH, Kim MO, Park HC, Park SR, Min BH, Kim EY, Choi BH, Park H, Ha Y (2007) Complete spinal cord injury treatment using autologous bone marrow cell transplantation and bone marrow stimulation with granulocyte macrophage-colony stimulating factor: Phase I/II clinical trial. Stem Cells 25:2066-2073

60. Mazhari R, Hare JM (2007) Advances in cell-based therapy for structural heart disease. Prog Cardiovasc Dis 49:387-395

61. Strauer BE, Schannwell CM, Brehm M (2009) Therapeutic potentials of stem cells in cardiac diseases. Minerva Cardioangiol 57:249-267

62. Gersh BJ, Simari RD, Behfar A, Terzic CM, Terzic A (2009) Cardiac cell repair therapy: a clinical perspective. Mayo Clin Proc 84:876-892

63. Boyle AJ, Schulman SP, Hare JM, Oettgen P (2006) Is stem cell therapy ready for patients? Stem Cell Therapy for Cardiac Repair. Ready for the Next Step. Circulation 114:339-352

64. Brittberg M, Tallheden T, Sjogren-Jansson B, Lindahl A, Peterson L (2001) Autologous chondrocytes used for articular cartilage repair: an update. Clin Orthop Relat Res:S337-348

65. Gao J, Caplan AI (2003) Mesenchymal stem cells and tissue engineering for orthopaedic surgery. Chir Organi Mov 88:305-316

66. Selden C, Hodgson H (2004) Cellular therapies for liver replacement. Transpl Immunol 12:273-288

67. Kahn SE (2004) Engineering a new beta-cell: a critical venture requiring special attention to constantly changing physiological needs. Semin Cell Dev Biol 15:359-370

68. Song KH, Ko SH, Ahn YB, Yoo SJ, Chin HM, Kaneto H, Yoon KH, Cha BY, Lee KW, Son HY (2004) In vitro transdifferentiation of adult pancreatic acinar cells into insulin-expressing cells. Biochem Biophys Res Commun 316:1094-1100

69. Sutherland DE, Gruessner R, Kandswamy R, Humar A, Hering B, Gruessner A (2004) Beta-cell replacement therapy (pancreas and islet transplantation) for treatment of diabetes mellitus: an integrated approach. Transplant Proc 36:1697-1699

70. Aubin JE (1998) Bone stem cells. J Cell Biochem Suppl 30-31:73-82

71. Uitterdijk A, Groenendijk BC, van Der Giessen WJ (2009) Stem cell therapy for chronic heart failure. Hellenic J Cardiol 50:127-132

72. Ge J, Li Y, Qian J, Shi J, Wang Q, Niu Y, Fan B, Liu X, Zhang S, Sun A, Zou Y (2006) Efficacy of emergent transcatheter transplantation of stem cells for treatment of acute myocardial infarction (TCT-STAMI). Heart 92:1764-1767

73. Singh S, Arora R, Handa K, Khraisat A, Nagajothi N, Molnar J, Khosla S (2009) Stem cells improve left ventricular function in acute myocardial infarction. Clin Cardiol 32:176-180

32. 
74. Strauer BE, Brehm M, Zeus T, Kostering M, Hernandez A, Sorg RV, Kogler G, Wernet P (2002) Repair of infarcted myocardium by autologous intracoronary mononuclear bone marrow cell transplantation in humans. Circulation 106:1913-1918

75. Suarez de Lezo J, Herrera C, Pan M, Romero M, Pavlovic D, Segura J, Sanchez J, Ojeda S, Torres A (2007) [Regenerative therapy in patients with a revascularized acute anterior myocardial infarction and depressed ventricular function]. Rev Esp Cardiol 60:357-365

76. Jankowski RJ, Haluszczak C, Trucco M, Huard J (2001) Flow cytometric characterization of myogenic cell populations obtained via the preplate technique: potential for rapid isolation of muscle-derived stem cells. Hum Gene Ther 12:619-628

77. Both SK, van der Muijsenberg AJ, van Blitterswijk CA, de Boer J, de Bruijn JD (2007) A rapid and efficient method for expansion of human mesenchymal stem cells. Tissue Eng 13:3-9

78. Siddappa R, Licht R, van Blitterswijk C, de Boer J (2007) Donor variation and loss of multipotency during in vitro expansion of human mesenchymal stem cells for bone tissue engineering. $\mathrm{J}$ Orthop Res 25:1029-1041

79. Mendes SC, Tibbe JM, Veenhof M, Bakker K, Both S, Platenburg PP, Oner FC, de Bruijn JD, van Blitterswijk CA (2002) Bone tissue-engineered implants using human bone marrow stromal cells: effect of culture conditions and donor age. Tissue Eng 8:911-920

80. Phinney DG, Kopen G, Righter W, Webster S, Tremain N, Prockop DJ (1999) Donor variation in the growth properties and osteogenic potential of human marrow stromal cells. J Cell Biochem 75:424-436

81. Martin I, Wendt D, Heberer M (2004) The role of bioreactors in tissue engineering. Trends Biotechnol 22:80-86

82. Chen HC, Hu YC (2006) Bioreactors for tissue engineering. Biotechnol Lett 28:1415-1423

83. Freed LE, Guilak F, Guo XE, Gray ML, Tranquillo R, Holmes JW, Radisic M, Sefton MV, Kaplan D, Vunjak-Novakovic G (2006) Advanced tools for tissue engineering: scaffolds, bioreactors, and signaling. Tissue Eng 12:3285-3305

84. Placzek MR, Chung IM, Macedo HM, Ismail S, Mortera Blanco T, Lim M, Cha JM, Fauzi I, Kang Y, Yeo DC, Ma CY, Polak JM, Panoskaltsis N, Mantalaris A (2009) Stem cell bioprocessing: fundamentals and principles. J R Soc Interface 6:209-232

85. Portner R, Nagel-Heyer S, Goepfert C, Adamietz P, Meenen NM (2005) Bioreactor design for tissue engineering. J Biosci Bioeng 100:235-245

86. Wendt D, Riboldi SA, Cioffi M, Martin I (2009) Bioreactors in tissue engineering: scientific challenges and clinical perspectives. Adv Biochem Eng Biotechnol 112:1-27

87. Mertsching H, Hansmann J (2009) Bioreactor technology in cardiovascular tissue engineering. Adv Biochem Eng Biotechnol 112:29-37

88. Schumann D, Kujat R, Nerlich M, Angele P (2006) Mechanobiological conditioning of stem cells for cartilage tissue engineering. Biomed Mater Eng 16:S37-52

89. Vunjak-Novakovic G, Martin I, Obradovic B, Treppo S, Grodzinsky AJ, Langer R, Freed LE (1999) Bioreactor cultivation conditions modulate the composition and mechanical properties of tissueengineered cartilage. J Orthop Res 17:130-138

90. Bueno EM, Laevsky G, Barabino GA (2007) Enhancing cell seeding of scaffolds in tissue engineering through manipulation of hydrodynamic parameters. J Biotechnol 129:516-531

91. Freed LE, Vunjak-Novakovic G (1997) Microgravity tissue engineering. In Vitro Cell Dev Biol Anim 33:381-385

92. Chen JP, Lin CT (2006) Dynamic seeding and perfusion culture of hepatocytes with galactosylated vegetable sponge in packed-bed bioreactor. J Biosci Bioeng 102:41-45

93. Janssen FW, Oostra J, Oorschot A, van Blitterswijk CA (2006) A perfusion bioreactor system capable of producing clinically relevant volumes of tissue-engineered bone: in vivo bone formation showing proof of concept. Biomaterials 27:315-323

94. Janssen FW, van Dijkhuizen-Radersma R, Van Oorschot A, Oostra J, de Bruijn JD, Van Blitterswijk CA (2009) Human tissue-engineered bone produced in clinically relevant amounts using a semi-automated perfusion bioreactor system: a preliminary study. J Tissue Eng Regen Med

95. Karim N, Golz K, Bader A (2006) The cardiovascular tissue-reactor: a novel device for the engineering of heart valves. Artif Organs 30:809-814 
96. Kitagawa T, Yamaoka T, Iwase R, Murakami A (2006) Three-dimensional cell seeding and growth in radial-flow perfusion bioreactor for in vitro tissue reconstruction. Biotechnol Bioeng 93:947954

97. Sikavitsas VI, Bancroft GN, Lemoine JJ, Liebschner MA, Dauner M, Mikos AG (2005) Flow perfusion enhances the calcified matrix deposition of marrow stromal cells in biodegradable nonwoven fiber mesh scaffolds. Ann Biomed Eng 33:63-70

98. Wendt D, Marsano A, Jakob M, Heberer M, Martin I (2003) Oscillating perfusion of cell suspensions through three-dimensional scaffolds enhances cell seeding efficiency and uniformity. Biotechnol Bioeng 84:205-214

99. Zhao F, Ma T (2005) Perfusion bioreactor system for human mesenchymal stem cell tissue engineering: dynamic cell seeding and construct development. Biotechnol Bioeng 91:482-493

100. Hammond TG, Hammond JM (2001) Optimized suspension culture: the rotating-wall vessel. Am J Physiol Renal Physiol 281:F12-25

101. Liu Y, Liu T, Fan X, Ma X, Cui Z (2006) Ex vivo expansion of hematopoietic stem cells derived from umbilical cord blood in rotating wall vessel. J Biotechnol 124:592-601

102. Singh V (1999) Disposable bioreactor for cell culture using wave-induced agitation. Cytotechnology 30:149-158

103. Collins PC, Miller WM, Papoutsakis ET (1998) Stirred culture of peripheral and cord blood hematopoietic cells offers advantages over traditional static systems for clinically relevant applications. Biotechnol Bioeng 59:534-543

104. Frauenschuh S, Reichmann E, Ibold Y, Goetz PM, Sittinger M, Ringe J (2007) A microcarrier-based cultivation system for expansion of primary mesenchymal stem cells. Biotechnol Prog 23:187193

105. Lavery M, Kearns MJ, Price DG, Emery AN, Jefferis R, Nienow AW (1985) Physical conditions during batch culture of hybridomas in laboratory scale stirred tank reactors. Dev Biol Stand 60:199-206

106. Schop D, Janssen FW, Borgart E, de Bruijn JD, van Dijkhuizen-Radersma R (2008) Expansion of mesenchymal stem cells using a microcarrier-based cultivation system: growth and metabolism. J Tissue Eng Regen Med 2:126-135

107. Schop D, van Dijkhuizen-Radersma R, Borgart E, Janssen FW, Rozemuller H, Prins H-J, de Bruijn JD (2009) Expansion of human mesenchymal stromal cells on microcarriers: growth and metabolism. J Tissue Eng Regen Med in press

108. Schroeder M, Niebruegge S, Werner A, Willbold E, Burg M, Ruediger M, Field LJ, Lehmann J, Zweigerdt R (2005) Differentiation and lineage selection of mouse embryonic stem cells in a stirred bench scale bioreactor with automated process control. Biotechnol Bioeng 92:920-933

109. King JA, Miller WM (2007) Bioreactor development for stem cell expansion and controlled differentiation. Curr Opin Chem Biol 11:394-398

110. van Wezel AL (1967) Growth of cell-strains and primary cells on micro-carriers in homogeneous culture. Nature 216:64-65

111. Nilsson K (1988) Microcarrier cell culture. Biotechnol Genet Eng Rev 6:403-439

112. Malda J, Frondoza CG (2006) Microcarriers in the engineering of cartilage and bone. Trends Biotechnol 24:299-304

113. Raffoul T, Swiech K, Arantes MK, Sousa APBd, Mendonca RZ, Pereira CA, Suazo CAT (2005) Performance evaluation of CHO-K1 cell in culture medium supplemented with hemolymph. Braz Arch Biol Technol 48:58-95

114. Yokomizo AY, Antoniazzi MM, Galdino PL, Azambuja N, Jr., Jorge SA, Pereira CA (2004) Rabies virus production in high vero cell density cultures on macroporous microcarriers. Biotechnol Bioeng 85:506-515

115. Genzel Y, Behrendt I, Konig S, Sann H, Reichl U (2004) Metabolism of MDCK cells during cell growth and influenza virus production in large-scale microcarrier culture. Vaccine 22:22022208

116. Abranches E, Bekman E, Henrique D, Cabral JM (2007) Expansion of mouse embryonic stem cells on microcarriers. Biotechnol Bioeng 96:1211-1221

117. Fernandes AM, Fernandes TG, Diogo MM, da Silva CL, Henrique D, Cabral JM (2007) Mouse embryonic stem cell expansion in a microcarrier-based stirred culture system. J Biotechnol $132: 227-236$

34. 
118. Serra M, Brito C, Leite SB, Gorjup E, von Briesen H, Carrondo MJ, Alves PM (2009) Stirred bioreactors for the expansion of adult pancreatic stem cells. Ann Anat 191:104-115

119. Yang Y, Rossi FM, Putnins EE (2007) Ex vivo expansion of rat bone marrow mesenchymal stromal cells on microcarrier beads in spin culture. Biomaterials 28:3110-3120

120. Campbell NA, Reece JB, Mitchell LG (1999) Biology. Vol. 5. Benjamin/Cummings, California

121. Krebs HA (1948) The tricarboxylic acid cycle. Harvey Lect Series 44:165-199

122. Krebs HA, Bellamy D (1960) The interconversion of glutamic acid and aspartic acid in respiring tissues. Biochem J 75:523-529

123. Schneider M, Marison IW, von Stockar U (1996) The importance of ammonia in mammalian cell culture. J Biotechnol 46:161-185

124. Cruz HJ, Freitas CM, Alves PM, Moreira JL, Carrondo MJ (2000) Effects of ammonia and lactate on growth, metabolism, and productivity of BHK cells. Enzyme Microb Technol 27:43-52

125. Glacken MW (1988) Catabolic control of mammalian cell culture. Biotechnology (N Y) 6:10411050

126. Ljunggren J, Haggstrom L (1994) Catabolic control of hybridoma cells by glucose and glutamine limited fed batch cultures. Biotechnol Bioeng 44:808-818

127. Newsholme P, Newsholme EA (1989) Rates of utilization of glucose, glutamine and oleate and formation of end-products by mouse peritoneal macrophages in culture. Biochem J 261:211218

128. Ozturk SS, Palsson BO (1991) Growth, metabolic, and antibody production kinetics of hybridoma cell culture: 2. Effects of serum concentration, dissolved oxygen concentration, and medium $\mathrm{pH}$ in a batch reactor. Biotechnol Prog 7:481-494

129. Bonarius HP, Hatzimanikatis V, Meesters KP, de Gooijer CD, Schmid G, Tramper J (1996) Metabolic flux analysis of hybridoma cells in different culture media using mass balances. Biotechnol Bioeng 50:299-318

130. Doverskog M, Ljunggren J, Ohman L, Haggstrom L (1997) Physiology of cultured animal cells. J Biotechnol 59:103-115

131. Haggstrom L, Ljunggren J, Ohman L (1996) Metabolic engineering of animal cells. Ann N Y Acad Sci 782:40-52

132. Tritsch GL, Moore GE (1962) Spontaneous decomposition of glutamine in cell culture media. Exp Cell Res 28:360-364

133. Europa AF, Gambhir A, Fu PC, Hu WS (2000) Multiple steady states with distinct cellular metabolism in continuous culture of mammalian cells. Biotechnol Bioeng 67:25-34

134. Kontoravdi C, Wong D, Lam C, Lee YY, Yap MG, Pistikopoulos EN, Mantalaris A (2007) Modeling amino acid metabolism in mammalian cells-toward the development of a model library. Biotechnol Prog 23:1261-1269

135. Hassell T, Gleave S, Butler M (1991) Growth inhibition in animal cell culture. The effect of lactate and ammonia. Appl Biochem Biotechnol 30:29-41

136. Levintow L, Eagle H, Piez KA (1957) The role of glutamine in protein biosynthesis in tissue culture. J Biol Chem 227:929-941

137. Cruz HJ, Moreira JL, Carrondo MJ (1999) Metabolic shifts by nutrient manipulation in continuous cultures of BHK cells. Biotechnol Bioeng 66:104-113

138. Genzel Y, Ritter JB, Konig S, Alt R, Reichl U (2005) Substitution of glutamine by pyruvate to reduce ammonia formation and growth inhibition of mammalian cells. Biotechnol Prog 21:5869

139. Ozturk SS, Palsson BO (1990) Effects of dissolved oxygen on hybridoma cell growth, metabolism, and antibody production kinetics in continuous culture. Biotechnol Prog 6:437-446

140. Moreno-Sanchez R, Saavedra E, Rodriguez-Enriquez S, Olin-Sandoval V (2008) Metabolic control analysis: a tool for designing strategies to manipulate metabolic pathways. J Biomed Biotechnol 2008:597913

141. Grant JL, Smith B (1963) Bone marrow gas tensions, bone marrow blood flow, and erythropoiesis in man. Ann Intern Med 58:801-809

142. Fischer B, Bavister BD (1993) Oxygen tension in the oviduct and uterus of rhesus monkeys, hamsters and rabbits. J Reprod Fertil 99:673-679

143. Csete M (2005) Oxygen in the cultivation of stem cells. Ann N Y Acad Sci 1049:1-8 
144. Dellatore SM, Garcia AS, Miller WM (2008) Mimicking stem cell niches to increase stem cell expansion. Curr Opin Biotechnol 19:534-540

145. D'Ippolito G, Diabira S, Howard GA, Roos BA, Schiller PC (2006) Low oxygen tension inhibits osteogenic differentiation and enhances stemness of human MIAMI cells. Bone 39:513-522

146. Grayson WL, Zhao F, Bunnell B, Ma T (2007) Hypoxia enhances proliferation and tissue formation of human mesenchymal stem cells. Biochem Biophys Res Commun 358:948-953

147. Hung SC, Pochampally RR, Hsu SC, Sanchez C, Chen SC, Spees J, Prockop DJ (2007) Short-term exposure of multipotent stromal cells to low oxygen increases their expression of CX3CR1 and CXCR4 and their engraftment in vivo. PLoS One 2:e416

148. Krinner A, Zscharnack M, Bader A, Drasdo D, Galle J (2009) Impact of oxygen environment on mesenchymal stem cell expansion and chondrogenic differentiation. Cell Prolif 42:471-484

149. Lennon DP, Edmison JM, Caplan AI (2001) Cultivation of rat marrow-derived mesenchymal stem cells in reduced oxygen tension: effects on in vitro and in vivo osteochondrogenesis. J Cell Physiol 187:345-355

150. Ma T, Grayson WL, Frohlich M, Vunjak-Novakovic G (2009) Hypoxia and stem cell-based engineering of mesenchymal tissues. Biotechnol Prog 25:32-42

151. Moussavi-Harami F, Duwayri Y, Martin JA, Buckwalter JA (2004) Oxygen effects on senescence in chondrocytes and mesenchymal stem cells: consequences for tissue engineering. Iowa Orthop J 24:15-20

152. Ren H, Cao Y, Zhao Q, Li J, Zhou C, Liao L, Jia M, Cai H, Han ZC, Yang R, Chen G, Zhao RC (2006) Proliferation and differentiation of bone marrow stromal cells under hypoxic conditions. Biochem Biophys Res Commun 347:12-21

153. Lee JH, Jung KJ, Kim JW, Kim HJ, Yu BP, Chung HY (2004) Suppression of apoptosis by calorie restriction in aged kidney. Exp Gerontol 39:1361-1368

154. Parrinello S, Samper E, Krtolica A, Goldstein J, Melov S, Campisi J (2003) Oxygen sensitivity severely limits the replicative lifespan of murine fibroblasts. Nat Cell Biol 5:741-747

155. Malladi P, Xu Y, Chiou M, Giaccia AJ, Longaker MT (2006) Effect of reduced oxygen tension on chondrogenesis and osteogenesis in adipose-derived mesenchymal cells. Am J Physiol Cell Physiol 290:C1139-1146

156. Wang DW, Fermor B, Gimble JM, Awad HA, Guilak F (2005) Influence of oxygen on the proliferation and metabolism of adipose derived adult stem cells. J Cell Physiol 204:184-191

157. Digirolamo CM, Stokes D, Colter D, Phinney DG, Class R, Prockop DJ (1999) Propagation and senescence of human marrow stromal cells in culture: a simple colony-forming assay identifies samples with the greatest potential to propagate and differentiate. Br J Haematol 107:275-281

158. Kondoh H, Lleonart ME, Bernard D, Gil J (2007) Protection from oxidative stress by enhanced glycolysis; a possible mechanism of cellular immortalization. Histol Histopathol 22:85-90

159. Kondoh H, Lleonart ME, Gil J, Wang J, Degan P, Peters G, Martinez D, Carnero A, Beach D (2005) Glycolytic enzymes can modulate cellular life span. Cancer Res 65:177-185

160. Simon HU, Haj-Yehia A, Levi-Schaffer F (2000) Role of reactive oxygen species (ROS) in apoptosis induction. Apoptosis 5:415-418

161. Schop D, Janssen FW, van Rijn LD, Fernandes H, Bloem RM, de Bruijn JD, van DijkhuizenRadersma R (2009) Growth, metabolism, and growth inhibitors of mesenchymal stem cells. Tissue Eng Part A 15:1877-1886

162. Schop D, Van Dijkhuizen-Radersma R, Brans G, Prins H-J, Rozemuller H, Martens DE, de Bruijn JD (2010) Effect of oxygen tension on metabolism, expansion and differentiation of human mesenchymal stromal cells. Biotechnol Bioeng Submitted

36. 


\section{Growth, metabolism, and growth inhibitors of mesenchymal stromal cells}

This chapter is based on the published paper: Schop D, Janssen FW, Borgart E, van Rijn LDS, Fernandes H, Bloem RM, de Bruijn JD, van DijkhuizenRadersma R (2009) Tissue Eng Part A 15: 1877-1886

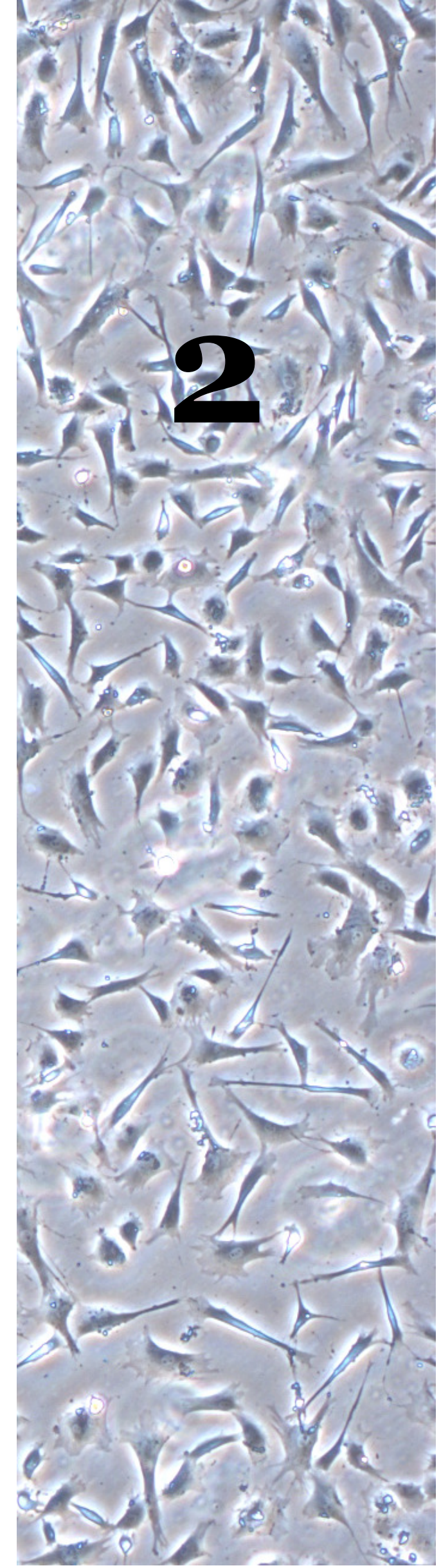





\section{Abstract}

Most therapeutic applications of bone marrow stromal cells (MSCs), or mesenchymal stem cells, require expansion of these cells. This study aimed to obtain more information about human MSCs regarding their expansion characteristics: growth, metabolism and growth inhibitors. In addition, the same expansion factors were examined for (model species) goat and rat MSCs to evaluate differences between MSCs of mammalian species. MSC proliferation, nutrient consumption and metabolite production were determined for five donors per species. In addition, the growth inhibitory concentrations of lactate and ammonia were established. Results showed that goat MSCs grew significantly faster than human and rat MSCs and that goat cells metabolized glucose more efficiently into energy $\left(\mathrm{Y}_{\mathrm{lac} / \mathrm{glc}}=0.8\right)$ than human $\left(\mathrm{Y}_{\text {lac/glc }}=2.0\right)$ and rat MSCs $\left(\mathrm{Y}_{\text {lac/glc }}=1.9\right)$. In addition, human $\left(\mathrm{qGlc}=-9.2 \mathrm{pmol} \mathrm{cell}^{-1} \mathrm{day}^{-1}\right)$ and rat MSCs $\left(\mathrm{qGlc}=-5.9 \mathrm{pmol} \mathrm{cell}^{-1} \mathrm{day}^{-1}\right)$ consumed more glucose than goat MSCs $(\mathrm{qGlc}=-2.6$ pmol cell ${ }^{-1}$ day $^{-1}$ ). Glutamine was shown not to be important as energy source for human, goat and rat MSCs. Regarding growth inhibition by metabolites, rat MSCs were more sensitive to lactate and ammonia (growth inhibiting at $16 \mathrm{mM}$ and ammonia at $1.9 \mathrm{mM}$ ) than goat (lactate: $28.4 \mathrm{mM}$, ammonia: $2.9 \mathrm{mM}$ ) and human MSCs (lactate: $35.4 \mathrm{mM}$, ammonia: $2.4 \mathrm{mM}$ ). Human MSCs did not loose their differentiation potential when their growth was inhibited by lactate or ammonia. 


\section{Introduction}

Adult bone marrow stomal cells (MSCs), also referred to as mesenchymal stem cells or progenitor cells, are multipotent cells. Their multipotency gives them the ability to differentiate into a variety of cell types from the mesodermal origin, such as cartilage, bone, muscle, tendon, ligament, and $\mathrm{fat}^{1-3}$. Because of these features, MSCs have emerged as a promising tool for clinical applications such as tissue engineering and cell-based therapy ${ }^{1 ; 3}$ and are therefore extensively evaluated for their properties and applications.

Although mesenchymal stem cells can be found in many tissues in the body, such as bone marrow, fat and muscle, they are mainly dormant and present in small quantities ${ }^{4}$. For clinical use, such as tissue engineering or cell-based therapies, most strategies require that adult MSCs are isolated and expanded to (tens of) million cells ${ }^{5 ; 6}$. To expand stem cells in a controlled, reproducible and cost-effective way, extensive research is being performed on the development of bioreactors $^{7-10}$. Essential parameters for the optimization of an expansion process in a bioreactor are growth, metabolism and growth inhibitors. To the best of our knowledge, the metabolism of human MSCs and the growth inhibition of human MSCs by metabolites have not been described in detail before.

For general cell culture, glucose and glutamine are the two most important nutrients for the generation of cellular energy (Adenosine 5'-triphosphate (ATP)) which is necessary for cell growth and maintenance. Glucose, the primary source of ATP for mammalian cells, is utilized either by oxidative phosphorylation (yielding about 30-38 moles of ATP per mole glucose) or by anaerobic glycolysis (yielding 2 moles of ATP and 2 moles of lactate per mole glucose). Both the glucose consumption and the lactate production indicate which metabolic route the cells use to produce energy from glucose ${ }^{11-14}$. Apart from a constituent of proteins (via protein biosynthesis), glutamine is also an important energy source for mammalian cell culture. Glutamine is metabolically deaminated to glutamate. The glutamate is then converted to $\alpha$ ketoglutarate by either the transamination pathway yielding alanine or the deamination pathway using glutamate dehydrogenase (GDH) yielding an extra ammonia. $\alpha$-Ketoglutarate is then converted to pyruvate. The conversion of glutamine to pyruvate is called the Glutaminolysis. Pyruvate can next either be converted to lactate or alanine or be completely broken down in the citric cycle. Glutaminolysis can be energy efficient or energy inefficient. The energy efficient catabolism, using GDH and complete oxidation to $\mathrm{CO}_{2}$, results in 27 moles of ATP and 2 moles of ammonia. Inefficient catabolism yields either 1 mole lactate, 1 40. 
mole ammonia and 9 mole ATP (using GDH) or yields 1 mole alanine, 1 mole ammonia and 9 mole ATP (using the transamination pathway) ${ }^{11-14}$. Glutamine consumption and ammonia production can indicate whether glutamine is used by the cells for either efficient or inefficient energy production or for protein biosynthesis only ${ }^{12 ; 15}$.

As cells consume glucose and glutamine to produce energy, they produce two toxic metabolites: lactate and ammonia, which could inhibit cell growth ${ }^{16}$. Part of the toxic effect of lactate and ammonia may be the result of $\mathrm{pH}$ disruption of electrochemical gradients affecting all membrane transport ${ }^{15 ; 17}$. Excessive accumulation of lactate can lower the $\mathrm{pH}$ of the medium, subsequently inhibiting cell growth ${ }^{15}$. The non-ionized ammonia $\left(\mathrm{NH}_{3}\right)$ can diffuse readily through the plasma membrane and inner membrane organelles causing the $\mathrm{pH}$ of acidic intracellular compartments to increase ${ }^{15}$. By fitting the cultivation regime to the optimal nutrient and metabolite concentrations, using for example refreshment or addition of cultivation medium, the expansion rate of the MSCs could be improved. Improvement of MSC expansion in controlled bioreactors may extent the clinical applications using MSCs.

This study investigated cell growth, cell metabolism, and cell growth inhibition by metabolites for human MSCs for five donors. During cultivation, the cell number and the nutrient (glucose and glutamine) and metabolite (lactate and ammonia) concentrations in the medium were monitored. Moreover, we evaluated the growth inhibitory effect of lactate and ammonia by addition of lactic acid or ammonium chloride to the proliferation medium. All conditions were evaluated in triplicate.

In addition, similar experiments have been performed on MSCs isolated from two other mammalian species: rat and goat. Frequently, these species are used as a model for human MSCs in tissue engineering and general stem cell research. It is, however, not clear if such a model species are directly comparable to human MSCs regarding expansion characteristics.

\section{Materials and Methods}

\section{MSC isolation and in vitro expansion}

For this study MSCs of three different species were used: human, goat and rat. After informed consent, human bone marrow aspirate (approximately $10 \mathrm{ml}$ ) was obtained from the iliac crest of 5 adult donors who were undergoing hip surgery. Per donor, nucleated cells were plated at 500000 cells $/ \mathrm{cm}^{2}$ in proliferation medium to purify MSCs by adhesion selection ${ }^{18 ; 19}$. Proliferation medium for human MSCs consisted of minimal essential medium ( $\alpha$-MEM, 
Invitrogen, The Netherlands) supplemented with $15 \%$ fetal bovine serum (FBS, Cambrex, Belgium), $100 \mathrm{U} / \mathrm{ml}$ penicillin (Invitrogen), $100 \mu \mathrm{g} / \mathrm{ml}$ streptomycin (Invitrogen), $2 \mathrm{mM} \mathrm{L-}$ glutamine (Invitrogen), $0.2 \mathrm{mM}$ L-ascorbic acid-2-phosphate (Sigma, The Netherlands), 1 $\mathrm{ng} / \mathrm{ml}$ basic fibroblast growth factor (AbD Serotec, UK) and $10 \mathrm{nM}$ dexamethason (Dex, Sigma). MSCs were cultured at $37^{\circ} \mathrm{C}$ in a humid atmosphere with $5 \% \mathrm{CO}_{2}$. After 6 days, the proliferation medium was replaced every 3 to 4 days. When near confluency was reached, cells were washed with PBS (Invitrogen) and enzymatically harvested with $0.25 \%$ trypsin in $1 \mathrm{mM}$ EDTA solution (Invitrogen) followed by replating at 500 cells $/ \mathrm{cm}^{2}$. Subsequently, MSC were cryopreserved at the end of passage 1 . Within twelve months the cryopreserved cells were thawed and replated in tissue culture flasks at 5,000 cells $/ \mathrm{cm}^{2}$. Cells were harvested and replated up to passage 2 to 3 .

Goat bone marrow aspirates (approximately $20 \mathrm{ml}$ ) from 5 donors were obtained from the iliac crest of 2- to 4-year-old adult Dutch milk goats. The MSCs per donor were purified and cryopreserved using the same procedure as described for human MSCs. Proliferation medium for goat MSCs consisted of $\alpha$-MEM supplemented with $10 \% \mathrm{FBS}, 100 \mathrm{U} / \mathrm{ml}$ penicillin, 100 $\mu \mathrm{g} / \mathrm{ml}$ streptomycin, $2 \mathrm{mM}$ L-glutamine, $0.2 \mathrm{mM}$ L-ascorbic acid-2-phosphate and $1 \mathrm{ng} / \mathrm{ml}$ basic fibroblast growth factor.

Rat bone marrow was obtained from the femur of five 6-week-old male Wistar (Harlan) rats. Per donor, whole bone marrow was placed in a tissue culture flask in aMEM (same proliferation medium composition as for human MSCs) to isolate MSC by adhesion selection. MSCs were cultured using the same procedure as for human MSCs. However, the rat MSCs were not cryopreserved but harvested and directly replated up to passage 2 to 3 .

\section{Cell growth and metabolism analysis}

To monitor cell growth and cell metabolism, passage 3 cells were plated in T-25 flasks with 1000 cells $/ \mathrm{cm}^{2}$ in proliferation medium. Destructive sampling was performed daily in triplets (three flasks were sacrificed per time point). Medium was removed from the cell culture and the cells were harvested using trypsin. Cell number was determined with a particle counter (Coulter-counter, Beckman Coulter, The Netherlands). Using the cell number, the specific growth rate (equation 1 and 2) and the generation time (equation 3) of the MSCs during the exponential growth phase were calculated with the following equations:

$$
C x(t)=C x(0) e^{\mu t}
$$

42. 
where $\mathrm{Cx}(0)$ and $\mathrm{Cx}(\mathrm{t})$ represent the cell numbers at the start and end of the exponential growth phase respectively, $\mu$ the specific growth rate $\left(h^{-1}\right)$ and $t$ the time $(h)$. This equation can be substituted to the following equation;

$\mu=\frac{\operatorname{Ln}(C x(t) / C x(0))}{\Delta t}$

$t_{d}=\frac{\ln 2}{\mu}$

where $t_{d}$ represents the generation time (h) and $\mu$ the specific growth rate $\left(h^{-1}\right)$.

The cultivation medium was analysed for glucose, lactate and ammonia concentrations with a VITROS DT60 II chemistry system (Ortho-Clinical Diagnostics, The Netherlands). Glucose and lactate concentrations were used to calculate the lactate yield from glucose $\left(\mathrm{Y}_{\text {lac/glc }}\right)$ and to calculate the cell-specific consumption rate of glucose (qGlc) (during the exponential growth phase) with the following equations:

$Y_{l a c / G l c}=\frac{\Delta[l a c]}{\Delta[G l c]}$

where $\Delta[\mathrm{lac}]$ represents the lactate production (mmol) in a certain time (t) interval and $\Delta[\mathrm{Glc}]$ the glucose consumption (mmol) in the same time interval.

$q G l c=\frac{\mu}{C x(0)} * \frac{\operatorname{Cglc}(t)-\operatorname{Cglc}(0)}{e^{\mu^{*} t}-1}$

where $\operatorname{Cglc}(\mathrm{t})$ and $\operatorname{Cglc}(0)$ represents the glucose concentration at the start and end of the exponential growth phase respectively, $\mathrm{Cx}(0)$ the cell number at the start of the exponential growth phase, $\mu$ the specific growth rate $\left(\right.$ day $\left.^{-1}\right)$ and $t$ the time (days). A negative $q$ means consumption and a positive $\mathrm{q}$ means production.

Furthermore, L-glutamine concentration in the medium was determined enzymatically with the Glutamine/Glutamate determination kit (GLN-1, Sigma). The yield of ammonia from glutamine $\left(\mathrm{Y}_{\mathrm{NH} / \mathrm{gln}}\right)$ and the cell-specific consumption rate of glutamine (qGln) were calculated using the same equations as for $\mathrm{Y}_{\mathrm{lac} / \mathrm{glc}}$ and qGlc (equations 4 and 5).

\section{Effects of ammonia and lactate on MSC growth}

To investigate the effect of ammonia $\left(\mathrm{NH}_{3}\right)$ on MSC growth, different concentrations of ammonium chloride $\left(\mathrm{NH}_{4} \mathrm{Cl}\right)$ were added to the proliferation medium. The examined $\mathrm{NH}_{3}$ concentrations in the medium varied from $0-4.5 \mathrm{mM} \mathrm{NH}_{3}$. To investigate the effect of lactate 
on MSC growth, different concentrations of $\mathrm{L}(+)$ lactic acid were added to the proliferation medium varying from 10 up to $47 \mathrm{mM}$ lactate. The cells were plated at day 0 with 1000 cells $/ \mathrm{cm}^{2}$ in standard proliferation medium. At day 3, medium was replaced with proliferation medium with extra $\mathrm{NH}_{3}$ or lactate. Four days after medium replacement (day 7 after seeding), the cell number was determined as described above. Growth inhibition was determined by calculating the difference in total cell numbers at the end of cultivation between the control cultivation and the cultivation with additional lactate or ammonia. MSC growth inhibition was defined as $>30 \%$ inhibition compared to the total cell number in the standard culture.

\section{Multipotency analyses of human MSCs}

Harvested human MSCs (cultivated with $35 \mathrm{mM}$ lactate or $4 \mathrm{mM} \mathrm{NH}_{3}$ concentrations) were examined for their differentiation potential using in vitro osteogenic, adipogenic and chondrogenic differentiation assays ${ }^{20}$. For osteogenic differentiation, human MSCs were seeded in 6-well plates at $10000 \mathrm{cells} / \mathrm{cm}^{2}$ and cultured for three weeks in osteogenic differentiation medium, which was composed of basic proliferation medium with $0.01 \mathrm{M}$ beta glycerol phosphate (Sigma). Mineralization of the extracellular matrix was verified by Alizarin red staining of the deposited calcium.

To induce adipogenic differentiation, human MSCs were seeded at $5000 \mathrm{cells} / \mathrm{cm}^{2}$ in 6well plates and cultured for three weeks in adipogenic medium. Adipogenic medium is composed of Dulbecco's Modified Eagle Medium (DMEM) with the following supplements: 10\% FBS, $100 \mathrm{U} / \mathrm{ml}$ penicillin, $100 \mu \mathrm{g} / \mathrm{ml}$ streptomycin, $0.05 \mathrm{M}$ 3-isobutyl-1-methylxanthine (Sigma), 0.02 M indomethacin (Sigma), $1 \mu \mathrm{M}$ Dex, and $0.1 \mathrm{nM}$ insulin (Sigma). Cells differentiated to adipocytes showed small fat droplets in their cytoplasm.

For chondrogenic differentiation, human MSCs were pelletted (3 min at $2000 \mathrm{rpm}$ ) and cultured for three weeks in chondrogenic medium, which was composed of DMEM with the following supplements: $100 \mathrm{U} / \mathrm{ml}$ penicillin, $100 \mu \mathrm{g} / \mathrm{ml}$ streptomycin, $0.1 \mathrm{nM}$ Dex, $40 \mu \mathrm{g} / \mathrm{ml}$ L-Proline (Sigma), $100 \mu \mathrm{g} / \mathrm{ml}$ Sodium Pyruvate (Sigma), 1x ITS+ (Sigma), and $0.01 \mu \mathrm{g} / \mathrm{ml}$ TGF $\beta 1$ (RnD Systems, UK). After three weeks, the pellets were embedded in Glycol Methacrylate (GMA, Sigma) and histological sections were made prior to Safranin O staining for Glycosaminoglycans (GAG).

44. 


\section{Statistical analysis}

Standard deviations per donor were obtained from triplets. Standard deviations per species were obtained from 5 donors. Statistical significance was assessed by analysing the data with the student $t$-test: significance was determined at a $p$ value less than 0.05 .

\section{Results and Discussion}

\section{MSC growth}

Human MSCs and goat and rat MSCs were cultured in tissue culture flasks for 7 days. During cultivation MSC growth was monitored (Figure 1). Expected growth curves of the MSCs were obtained for the three species, including a lag phase, an exponential phase and the beginning of the stationary phase. These three growth phases are characterized by cell attachment and cell acclimatization, increasing cell number, and ceased cell growth due to contact inhibition by monolayer formation.

Based on the cell numbers, we calculated the growth rate and generation time for the MSC of the 3 species and 5 donors per species. Table 1 shows the calculated parameters of the cultivations. Differences in growth rate and generation times were observed between MSCs of human, goat and rat. The average growth rate $(\mu)$ of 5 donors was $0.031( \pm 0.004) \mathrm{h}^{-1}$ for goat cells, whereas the growth rate for human cells was $0.020( \pm 0.004) \mathrm{h}^{-1}$ and for rat cells $0.025( \pm 0.002) \mathrm{h}^{-1}$. Goat MSCs grew significantly faster compared to human and rat MSCs (goat versus human $\mathrm{p}=0.0057$; goat versus rat $\mathrm{p}=0.04$ ), whereas no significant difference was observed between human and rat MSCs $(\mathrm{p}=0.06)$. The obtained growth rates are only valid for these donors cultivated under the tested conditions. For example, the use of more enriched medium, such as higher FBS concentrations or lower dissolved oxygen concentration ${ }^{21}$, may increase the growth rates of the MSCs. 


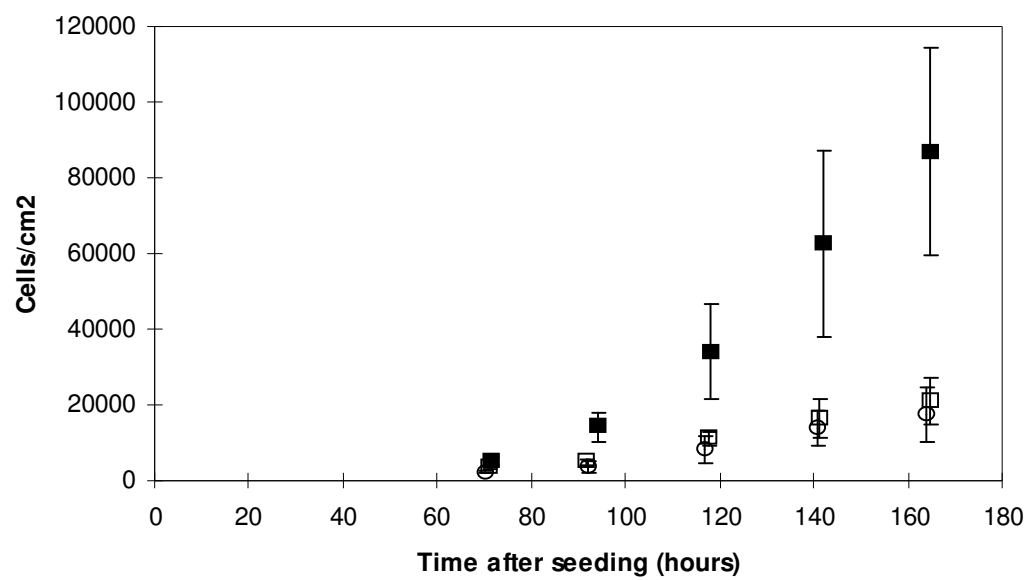

\section{Figure 1. MSC static growth over time}

Average growth of $(\square)$ human MSCs, ( $\bullet$ goat MSCs and (०) rat MSCs in tissue culture flasks of 5 donors per species. The standard deviations are obtained by averaging the results of five donors per species. The standard deviation per donor was below $5 \%$.

In addition to a variation in growth rate between species, a donor variation was observed. Many groups have already shown that there is a large donor variation for human MSCs in cell growth, differentiation and in vivo bone formation ${ }^{22-24}$. Our data confirmed a donor to donor variation for human MSCs regarding cell growth and showed similar donor variation for goat and rat.

46. 
Table 1.Growth and metabolic parameters obtained for human, goat and rat MSCs

Growth and metabolic parameters were calculated using the data obtained from the exponential growth phase. Five donors were analyzed per species.

\begin{tabular}{|c|c|c|c|c|c|c|c|c|c|c|c|c|c|c|c|c|c|c|}
\hline & \multicolumn{6}{|c|}{ Human } & \multicolumn{6}{|c|}{ Goat } & \multicolumn{6}{|c|}{ Rat } \\
\hline & 1 & 2 & 3 & 4 & 5 & Average & 1 & 2 & 3 & 4 & 5 & Average & 1 & 2 & 3 & 4 & 5 & Average \\
\hline $\boldsymbol{\mu}\left(\mathrm{h}^{-1}\right)$ & 0.027 & 0.019 & 0.016 & 0.017 & 0.021 & $0.020 \pm 0.004$ & 0.025 & 0.033 & 0.030 & 0.036 & 0.034 & $0.031 \pm 0.004$ & 0.024 & 0.027 & 0.028 & 0.019 & 0.020 & $0.025 \pm 0.002$ \\
\hline $\mathbf{t}_{d}(\mathrm{~h})$ & 25.7 & 36.1 & 42.6 & 40.5 & 32.7 & $35.5 \pm 6.00$ & 27.6 & 21.3 & 23.2 & 19.3 & 20.5 & $22.4 \pm 2.93$ & \begin{tabular}{|l}
28.4 \\
\end{tabular} & 24.4 & 25.1 & 36.4 & 35.1 & $28.1 \pm 2.63$ \\
\hline $\begin{array}{l}\mathbf{Y}_{\text {lac/glc }} \\
\left(\mathrm{mol} \mathrm{mol}^{-1}\right)\end{array}$ & 1.77 & 2.13 & 1.83 & 1.97 & 2.11 & $1.96 \pm 0.14$ & 1.00 & 0.29 & 0.9 & 0.82 & 1.00 & $0.80 \pm 0.26$ & 2.00 & 4.50 & 1.74 & 2.17 & 1.55 & $1.86 \pm 0.24$ \\
\hline $\begin{array}{l}\text { qGlc } \\
\left(\text { pmol cell }^{-1} \text { day }^{-1}\right)\end{array}$ & -8.04 & -10.73 & -11.47 & -8.63 & -7.10 & $-9.19 \pm 1.65$ & -2.72 & -1.79 & -3.27 & -2.35 & -2.80 & $-2.59 \pm 0.49$ & -10.17 & -2.51 & -7.56 & -3.63 & -5.57 & $-5.89 \pm 2.75$ \\
\hline $\begin{array}{l}\mathbf{Y}_{\mathrm{NH} 3 / \mathrm{gln}^{\prime}} \\
\left(\mathrm{mol} \mathrm{mol}^{-1}\right)\end{array}$ & 1.46 & 1.97 & 1.75 & 1.56 & 1.42 & $1.63 \pm 0.20$ & 2.31 & 1.25 & 1.12 & 0.96 & 1.14 & $1.35 \pm 0.49$ & 0.99 & 1.18 & 2.02 & 1.98 & 1.83 & $1.60 \pm 0.43$ \\
\hline $\begin{array}{l}\text { qGin } \\
\left(\text { pmol cell }^{-1} \text { day }^{-1}\right)\end{array}$ & -3.75 & -4.44 & -5.20 & -4.45 & -3.82 & $-4.48 \pm 0.52$ & -1.71 & -1.32 & -2.50 & -2.86 & -1.11 & $-1.95 \pm 0.68$ & $\mid-7.77$ & -13.81 & -3.09 & -4.77 & -3.91 & $-6.67 \pm 3.91$ \\
\hline $\begin{array}{l}\text { qGIn corrected } \\
\left(\text { pmol cell }^{-1} \text { day }^{-1}\right)\end{array}$ & -0.001 & -0.004 & -0.007 & -0.008 & -0.007 & $-0.007 \pm 0.002$ & 0.002 & -0.003 & -0.006 & -0.009 & 0.001 & $-0.003 \pm 0.004$ & 0.008 & -0.026 & -0.002 & -0.008 & -0.001 & $-0.006 \pm 0.011$ \\
\hline
\end{tabular}

(not corrected for spontaneous formation of $\mathrm{NH}_{3}$ and spontaneous decomposition of gln), qGln: average cell specific glutamine disappearance rate, qGln corrected: average

cell specific glutamine consumption rate (glutamine concentrations in the media were corrected for $10 \%$ spontaneous decomposition) 


\section{MSC metabolism}

During culture, cellular metabolism was evaluated for the MSCs of the three species. Nutrient (glucose, glutamine) and metabolite (lactate, ammonia) concentrations in the culture medium were monitored over time. Glucose concentrations decreased during growth for all cell cultures while lactate concentrations increased in the cultivation media (Figure 2). The decreasing glucose and increasing lactate concentrations correlated to the increasing cell numbers in the culture (Figure 1).
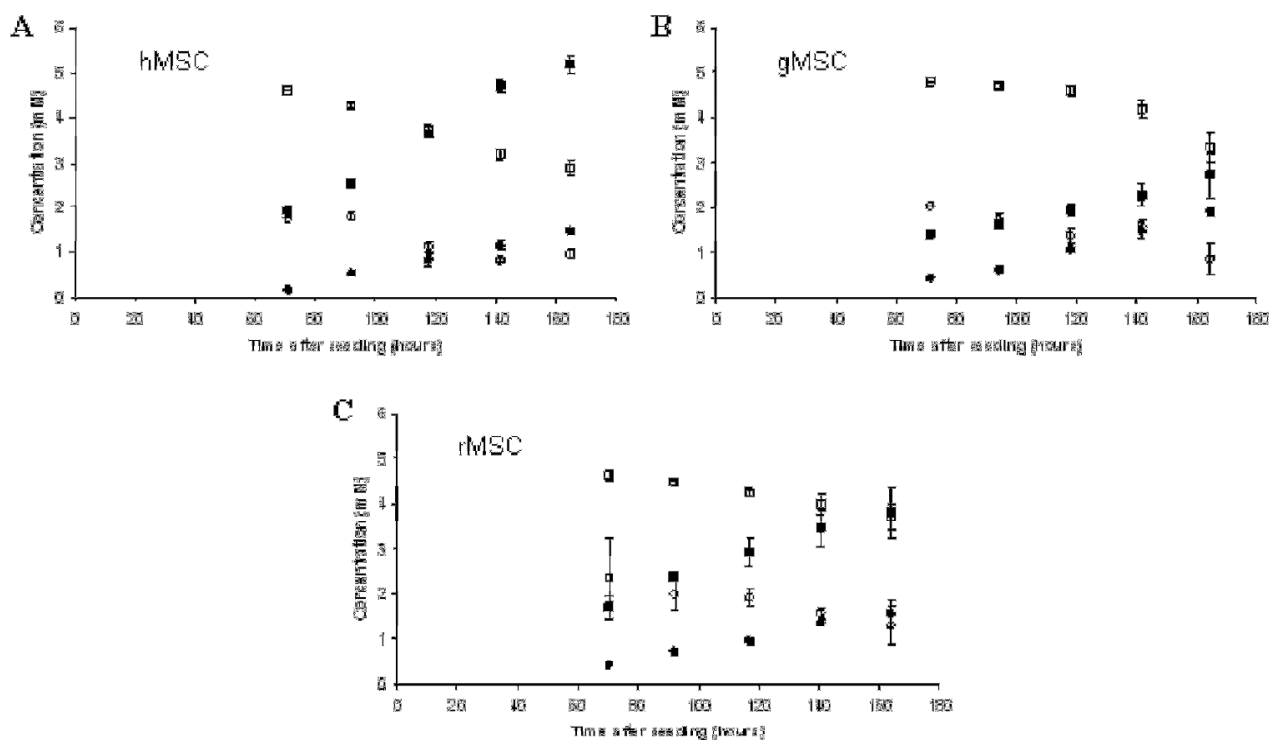

Figure 2. Consumption of glucose and glutamine and production of lactate and ammonia by MSCs over time

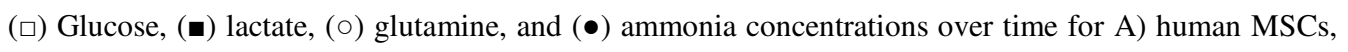
B) goat MSCs and C) rat MSCs. Average concentrations of 5 donors per species are shown. For all three species glucose and glutamine concentrations are decreasing over time and lactate and ammonia concentrations are increasing over time.

The yield of lactate from glucose $\left(\mathrm{Y}_{\text {lac/glc }}\right)$ and the cell specific glucose consumption rate (qGlc) were calculated from the glucose and lactate concentrations (Table 1). For $\mathrm{Y}_{\text {lac/glc }}$, significant higher yields were obtained for human $(\mathrm{p}=0.0001)$ and rat $(\mathrm{p}=0.021)$ MSCs compared to goat MSCs. Moreover, the qGlc differed between species, see Figure 3; significantly higher $q$ Glc were obtained for human $(\mathrm{p}=<0.0001)$ and rat $(\mathrm{p}=0.045)$ MSCs 48. 
compared to goat MSCs. Comparable to the results for MSC growth, a donor variation in glucose metabolism for all three species was observed ( $\pm 18 \%$ for human, $\pm 19 \%$ for goat and $\pm 47 \%$ for rat MSCs ).

The differences in $\mathrm{Y}_{\text {lac/glc }}$ and qGlc between species indicate that the MSCs of the three different species use different glucose metabolisms to gain energy for cell growth and cell maintenance. Compared to goat and rat MSCs, human MSCs consume relatively high amounts of glucose per cell ( $\pm-9.2 \mathrm{pmol} \mathrm{cell}^{-1} \mathrm{day}^{-1}$, see Table 1) and the lactate yield from glucose is also high $( \pm 2 \mathrm{~mol} / \mathrm{mol}$, see Table 1$)$. This indicates that the cells mainly metabolize glucose via the inefficient glycolytic pathway instead of the energy-efficient oxidative phosphorylation pathway. Regarding the rat MSC glucose metabolism, an inefficient use of glucose is also observed (qGlc \pm-5.9 pmol cell ${ }^{-1}$ day $^{-1}$ and a high $\mathrm{Y}_{\text {lac/glc }}$ of $\pm 1.9 \mathrm{~mol} / \mathrm{mol}$ ). Goat MSCs, however, metabolize glucose more efficiently to gain energy (relatively low qGlc of \pm-2.6 pmol cell ${ }^{-1}$ day $^{-1}$ and low $\mathrm{Y}_{\text {lac/glc }}$ of $\pm 0.8 \mathrm{~mol} / \mathrm{mol}$ ).

In addition to glucose, the glutamine concentrations were also decreasing in the medium during culture (Figure 2). Mainly as a result of glutamine conversion, the metabolite ammonia is produced (Figure 2). The cell specific glutamine consumption rate (qGln) and the yield of ammonia from glutamine $\left(\mathrm{Y}_{\mathrm{NH} 3 / \mathrm{Gln}}\right)$ were calculated from the glutamine and ammonia concentrations in the media (Table 1).

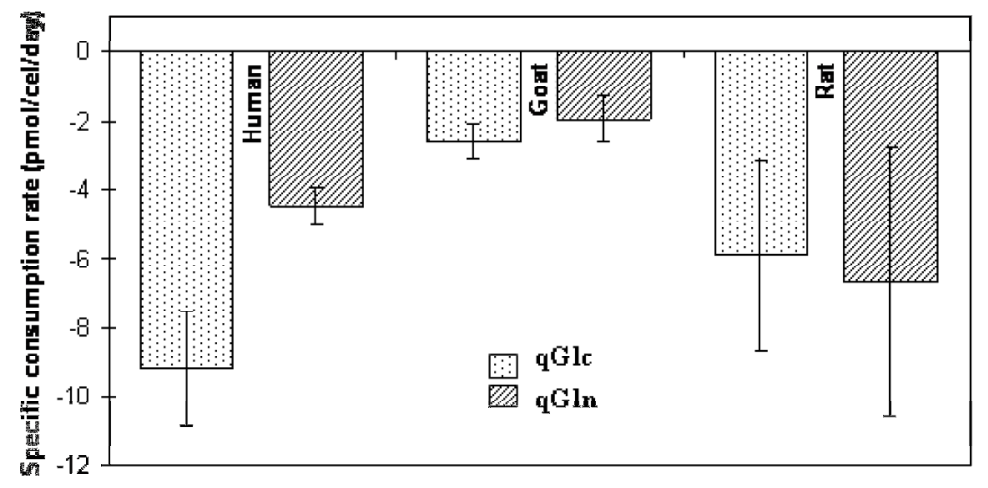

Figure 3. Average cell specific consumption rates of glucose and glutamine for human, goat and rat MSCs

The results are averages of five donors per species analysed in triplicate. These results show the differences in glucose consumption rates and glutamine disappearance rates for MSCs of the three examined species, indicating differences in cellular metabolism. The error bars are based on the variation between the donors. 
The obtained qGln differed between species, as presented in Figure 3. Less glutamine break down was observed in the culture with goat MSCs compared to the cultures with human and rat MSCs. However, during cultivation glutamine also decomposes spontaneously ${ }^{25}$. When correcting the glutamine concentrations in the medium with $\pm 10 \%$ per day ${ }^{25}$ (confirmed by own experiments), qGlc values of almost zero were obtained (see Table 1). This suggests that the rate with which glutamine disappears from the medium is more or less equal to the rate of spontaneous decomposition. Meaning that glutamine is not a major source for energy generation for the three species tested.

In addition, the obtained $\mathrm{Y}_{\mathrm{NH} / \mathrm{Gln}}$ for the three species were calculated (Table 1). The ammonia and the glutamine concentrations were used as measured in the medium, so not corrected for spontaneous decomposition of glutamine and spontaneous formation of $\mathrm{NH}_{3}$. The average yield of ammonia from glutamine was 1.6 for the three species. However, several factors may affect the calculation of the $\mathrm{Y}_{\mathrm{NH} 3 / \mathrm{Gln}}$. For example, ammonia is mainly a product from spontaneous glutamine decomposition and glutamine catabolism. However, it is also formed in several other amino acid metabolisms, such as glutamate and serine utilization ${ }^{15 ;} 26$. In addition, ammonia may have evaporated from the cultivation medium during the study ${ }^{27}$. Due to these factors and the low glutamine consumption, the $\mathrm{Y}_{\mathrm{NH} / \mathrm{G} \text { In }}$ cannot be ussed to draw a firm conclusion on the glutamine metabolism, based on these experiments. To prove the metabolic pathway used by the cells, studies with radioactive labelled glucose and glutamine should be performed or enzyme activities should be measured ${ }^{28}$ which are outside the scope of this paper. Nevertheless, the results indicate that the main C-source for MSC growth is not glutamine, but glucose.

Overall, human MSCs utilized glucose for generation of cellular energy using mainly the inefficient glycolysis pathway. Goat MSCs also utilized glucose for energy production, but were mainly using the efficient oxidative phosphorylation pathway. Rat MSCs consumed glucose for energy generation via the ineffective glycolysis pathway. Glutamine showed not to be a major source for energy generation for MSCs from the three species. These results proved the hypothesis that the cellular metabolism of MSCs, mainly regarding glucose, to generate energy for cell growth and cell maintenance is species dependent. Nevertheless, it should be taken into account that these results are obtained in these specific culture conditions (monolayer cultivation in tissue culture treated T-flasks using standard proliferation medium, incubated at $37^{\circ} \mathrm{C}$ in a humid atmosphere of air with $5 \% \mathrm{CO}_{2}$ ). The culture conditions may, however, influence the metabolism used by the cells to a large extent. For example, compared to their natural environment (e.g. in the bone marrow), the MSCs were cultivated in a 50 . 
hyperoxic condition $\left(20 \% \mathrm{O}_{2}\right)^{29}$. As oxygen concentrations may influence the cell metabolism $^{14 ; 30}$, other results, regarding glucose and glutamine metabolisms, may be obtained when the MSCs are cultivated at low oxygen concentrations (3-7\%). In addition, the medium concentrations of the C-sources glucose and glutamine may also have an influence on cell metabolism $^{11 ; 12}$. As these factors may change the cellular metabolism, the cell growth could also be altered.

\section{MSC growth inhibitors}

Lactate and ammonia $\left(\mathrm{NH}_{3}\right)$ are metabolites that are generally known to inhibit cell growth in mammalian cell culture. The sensitivity towards lactate and ammonia seems to be cell line specific and vary widely; cell growth inhibition by lactate ranging from $10 \mathrm{mM}$ to over $40 \mathrm{mM}$ and by ammonia between 0.5 up to $40 \mathrm{mM}$ has been described ${ }^{15 ; 16 ; 31}$. To investigate whether lactate and ammonia are also growth inhibiting for marrow stromal cells, the growth inhibitory concentrations of lactate and $\mathrm{NH}_{3}$, important parameters in the development of an optimized expansion process for MSCs, were investigated for human MSCs and goat and rat MSCs.

To obtain different ammonia concentrations, $\mathrm{NH}_{4} \mathrm{Cl}$ was added to the medium in various concentrations. Addition of $\mathrm{NH}_{4} \mathrm{Cl}$ did not have an influence on the buffered medium $\mathrm{pH}$. For different lactate concentrations lactic acid was added to the proliferation medium. The medium $\mathrm{pH}$ value dropped with $0.1-0.2$, which should not have an effect on the cell growth ${ }^{32}$. Table 2 shows the inhibitory concentrations for lactate and $\mathrm{NH}_{3}$ (defined as $>30 \%$ inhibition compared to growth in standard culture). $\mathrm{NH}_{3}$ growth inhibition was already observed at relatively low concentrations, whereas growth inhibition by lactate was observed at higher concentrations. The obtained results are in range with the in literature stated values for mammalian cell lines. Obtained growth inhibitory concentrations of lactate and $\mathrm{NH}_{3}$ showed a high donor variation per species. In addition, differences between the three species were observed. Rat MSCs appeared to be more sensitive to the metabolites than goat and human MSCs. 
Table 2. MSC growth inhibitory concentrations of lactate and $\mathrm{NH}_{3}$ for human, goat and rat

Growth inhibition was defined as $>30 \%$ inhibition compared to growth in standard culture. Five donors were analyzed per species. The average minimal growth inhibitory concentrations per species are shown.

\begin{tabular}{c|c|c|c}
\hline \multirow{5}{*}{ Human } & $\begin{array}{c}\text { Donor and } \\
\text { minimal average }\end{array}$ & $\begin{array}{c}\text { Lactate inhibitory } \\
\text { concentration (mmol/L) }\end{array}$ & $\begin{array}{c}\mathrm{NH}_{3} \text { inhibitory } \\
\text { concentration (mmol/L) }\end{array}$ \\
\hline \multirow{5}{*}{ Goat } & 1 & 24 & 3.0 \\
& 2 & 47 & 2.0 \\
& 3 & $>47$ & 2.0 \\
& 4 & 35 & 3.0 \\
& 5 & 24 & 2.0 \\
\cline { 2 - 4 } & Average & 35.4 & 2.4 \\
\hline \multirow{5}{*}{ Rat } & 1 & 13 & 2.5 \\
& 2 & 34 & 2.5 \\
& 3 & $>34$ & 4.5 \\
& 5 & 20 & 2.5 \\
& Average & $>34$ & 2.5 \\
\hline & 1 & 28.4 & 2.9 \\
\hline & 2 & 19 & 2.2 \\
& 3 & 19 & 2.2 \\
& 4 & 10 & 2.0 \\
\cline { 2 - 4 } & Average & 22 & 2.0 \\
\cline { 2 - 4 } & & 10 & 1.5 \\
\hline
\end{tabular}

Surprisingly, for 3 out of 5 human MSC donors and 4 out of 5 goat MSC donors, higher cell yields compared to the standard culture were obtained for lactate concentrations that were growth inhibiting for the other donors. Figure 4 shows the growth curve of MSCs from a goat donor cultured in normal proliferation medium and the final concentrations of cells cultured with different lactate concentrations. Growth inhibition was found for $20 \mathrm{mM}$ and $34 \mathrm{mM}$ lactate. For the lactate concentration of $13 \mathrm{mM}$, however, a higher cell yield was obtained compared to the control culture. This implies that the tested lactate concentration did not have a toxic effect of the cell growth. This phenomenon was also observed by Reuveny and coworkers $^{33}$ for a hybridoma cell line. Lao and Toth $^{27}$ discussed that this occurrence was probably due to a shift to a more favourable osmolarity of the cultivation. The osmolarity may also be altered by the addition of $\mathrm{NH}_{4} \mathrm{Cl}$, however, the amount added to the cultivation medium was small and probably had a negligible effect on the osmolarity and thus on cell growth.

52. 


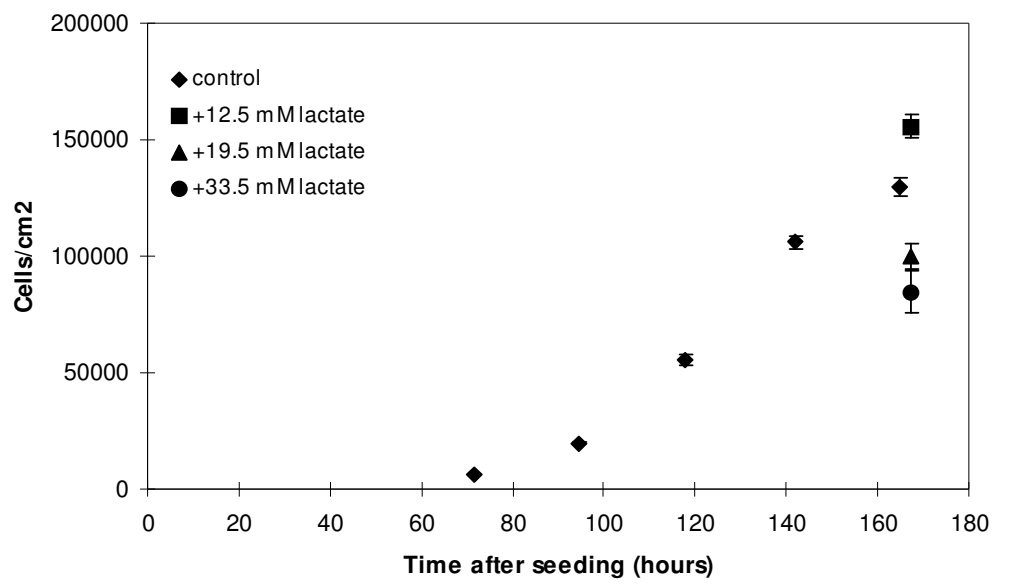

\section{Figure 4. Cell yields of goat MSCs (donor 2) at different lactate concentrations}

After 7 days of cultivation, the metabolite affected the cell number. This graph shows the influence of lactate on cells from goat donor 2, analysed in triplicate. These results were representative for MSCs of the other species and donors tested.

In addition to growth inhibition, high lactate and $\mathrm{NH}_{3}$ concentrations in the cultivation medium also affected the cell morphology. Figure 5 shows the changes in cell morphology for rat MSCs. When the cells were cultivated at high lactate concentrations, the cell morphology changed from fibroblast-like to more stretched cell morphology. Cells cultivated at high $\mathrm{NH}_{3}$ concentrations showed cubic cell morphology. Similar morphological changes were observed for human and goat MSCs. These morphological changes probably indicate that the cells were stressed by the metabolite concentrations. Elevated ammonia levels or lactate levels result in changes of the intracellular $\mathrm{pH}(\mathrm{pHi})$ values ${ }^{31}$. High ammonia levels induce acidification of the cytoplasm and an alkaline cytoplasm is obtained with high lactate levels. These differences in pHi may explain the observed differences in cell morphology.

Overall, it can be concluded that MSC growth is inhibited by the metabolites lactate and ammonia and that the growth inhibitory concentrations are species dependent. 


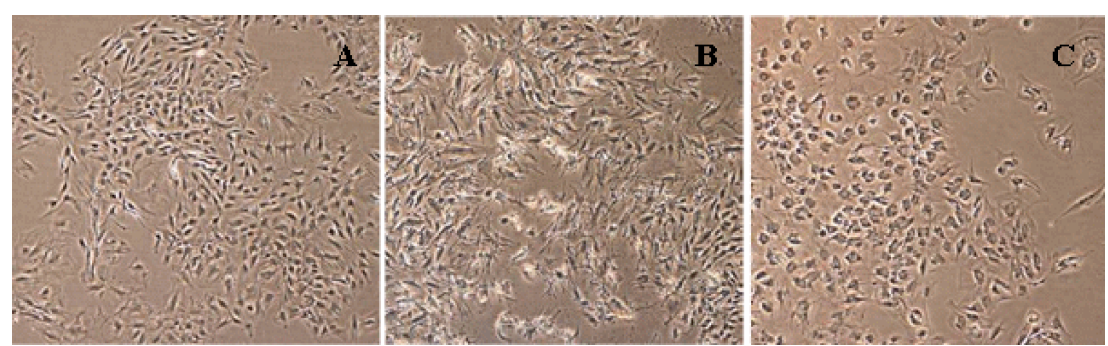

2 Figure 5. Cell morphologies of rat MSCs, donor 1, cultured in normal medium, high lactate medium or high $\mathrm{NH}_{3}$ medium

A) rat MSCs in normal proliferation medium, B) rat MSCs in medium containing $30 \mathrm{mmol} / \mathrm{L}$ lactate, C) rat MSCs in medium containing $4.0 \mathrm{mmol} / \mathrm{L} \mathrm{NH}_{3}$. Pictures taken 7 days after seeding, original magnification 40x.

\section{Effect of growth inhibitors on hMSC multipotency}

To evaluate if growth inhibition due to lactate or ammonia affects the differentiation potential of marrow stromal cells, multipotency assays were performed. Human MSCs were expanded in three culture conditions: 1) control (standard proliferation medium), 2) medium with addition of lactate, and 3) medium with addition of ammonia. Figure 6 shows the results of the multipotency assays of human donor 1 . Similar results were observed for the other donors. Expanded cells showed differentiation towards all tested lineages independent of the culture condition. This is also described for hematopoietic cells cultured with high lactate concentrations ${ }^{34}$.

Regarding the osteogenic differentiation, no differences were observed visually between the cells cultivated with or without extra lactate or $\mathrm{NH}_{3}$. Cells from all three conditions were able to produce mineralized extracellular matrix. Visually, no differences in mineralization rate and extent were observed. The human MSCs maintained the ability to form adipocytes for all three conditions. However, qualitative observation indicated that the cells cultivated at high lactate concentrations had a lower potential to differentiate to the adipogenic lineage. It is possible that during and after harvesting of the cells, more cells died in the lactate inhibited cultivations, resulting in a seeding density that was too low for the assay to be successful. No effect of $\mathrm{NH}_{3}$ on adipogenic differentiation was observed. The results for the chondrogenic differentiation assay were similar to the adipogenic assay. There was visually less formation of GAG in the extracellular matrix for the cells cultured with extra lactate, whereas no effect of the $\mathrm{NH}_{3}$ was observed.

54. 
Generally, human MSCs did not loose their differentiation potential when their growth is inhibited by lactate or ammonia.

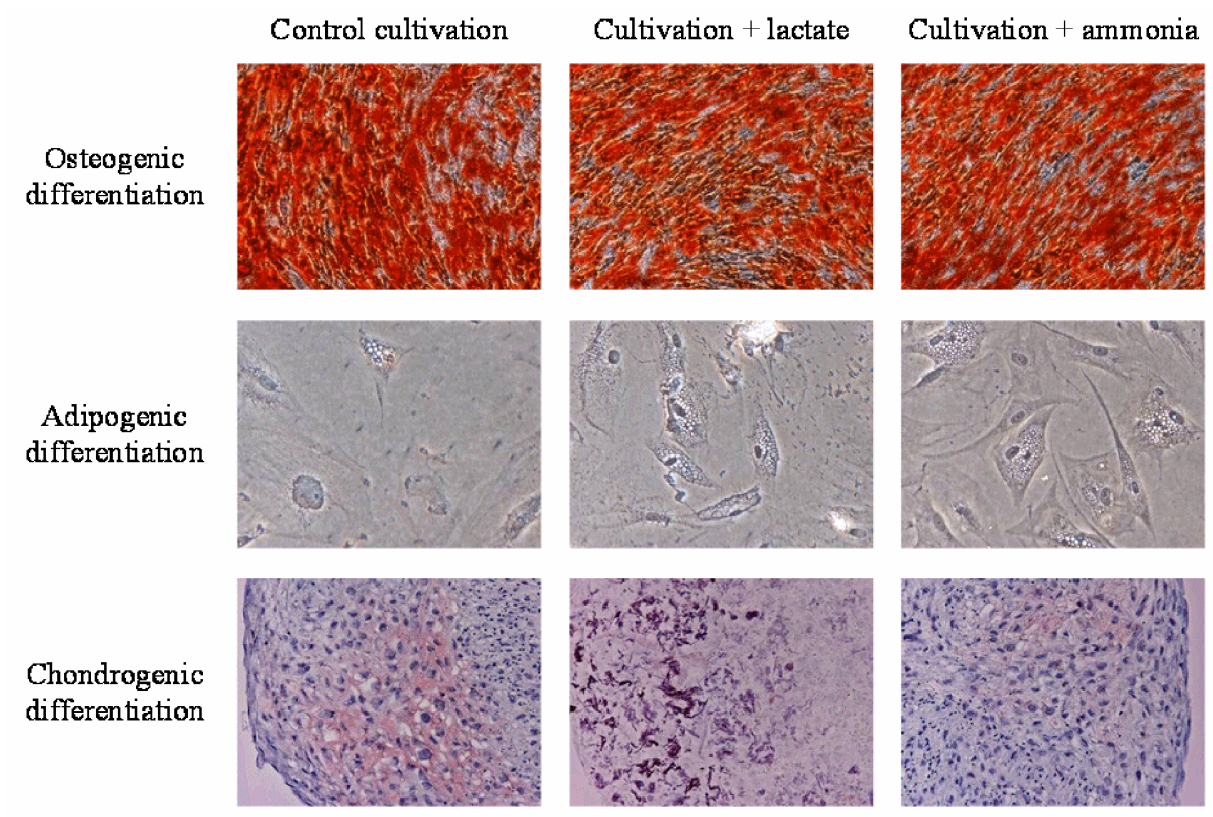

\section{Figure 6. Results multipotency assays for MSCs of Human donor 1}

Staining of the osteogenic differentiation shows the $\mathrm{Ca}^{2+}$ of the mineralized extracellular matrix. The adipogenic differentiation shows the formation of fat droplets in the cells. Staining of the chondrogenic differentiation shows the formation of GAG and the rounded (chondrogenic) cell morphology. Original magnifications are 100x for osteogenic differentiation and 200x for adipogenic and chondrogenic differentiation.

\section{Conclusions}

This study examined the in vitro growth, metabolism and growth inhibition by lactate and ammonia of human marrow stromal cells. In addition, the same growth characteristics were examined for goat and rat MSCs. Goat MSCs grew significantly faster when compared to human and rat MSCs. In addition, different metabolisms were used by the cells of the three species for growth and maintenance. Human MSCs utilized glucose for the generation of cellular energy using mainly the inefficient glycolysis pathway. Goat MSCs also utilized glucose for energy production, but are mainly using the efficient oxidative phosphorylation pathway. Rat MSCs consumed glucose for energy generation via the ineffective glycolysis 
pathway. Glutamine was shown not to be important as energy source for all three tested species. Finally, variations between the growth inhibitory concentrations for lactate and ammonia were observed between the three species. Rat MSCs are more sensitive to lactate and ammonia compared to human and goat MSCs. For several human and goat donors, increased expansion rates were obtained at elevated lactate levels. After cultivation of the cells at growth inhibitory lactate or ammonia concentrations, the human MSCs retained their in vitro differentiation potential.

In conclusion, these results show the differences in cell growth, cell metabolism and cell growth inhibition between MSCs of species. In addition, these results could lead to improvement of the expansion of MSC in bioreactors, which is important to decrease the total time of expansion prior to the therapeutic use of these cells.

\section{Acknowledgements}

The authors acknowledge the department of Orthopaedic surgery from the Reinier de Graaf Gasthuis for providing human bone marrow aspirates and Dr. R Licht and Dr. J de Boer, from Institute for Biomedical Technology, University of Twente for expert help with hMSC isolation from human bone marrow aspirates provided by the University Medical Center Utrecht. The work presented in this paper was supported by grant IS044112 from SenterNovem (Agency of Ministry of Economic Affairs), The Netherlands.

\section{References}

1. Caplan AI, Bruder SP (2001) Mesenchymal stem cells: building blocks for molecular medicine in the 21st century. Trends Mol Med 7:259-264

2. Pittenger MF, Mackay AM, Beck SC, Jaiswal RK, Douglas R, Mosca JD, Moorman MA, Simonetti DW, Craig S, Marshak DR (1999) Multilineage potential of adult human mesenchymal stem cells. Science 284:143-147

3. Prockop DJ (1997) Marrow stromal cells as stem cells for nonhematopoietic tissues. Science 276:71-74

4. Caplan AI (1991) Mesenchymal stem cells. J Orthop Res 9:641-650

5. Aubin JE (1998) Bone stem cells. J Cell Biochem Suppl 30-31:73-82

6. de Bruijn JD, van Blitterswijk CA (1998) New developments in implant coatings: biomimetics and tissue engineering. Biomaterials in Surgery. Georg Thieme Verlag, Stuttgart, pp 77-82

7. Frauenschuh S, Reichmann E, Ibold Y, Goetz PM, Sittinger M, Ringe J (2007) A microcarrier-based cultivation system for expansion of primary mesenchymal stem cells. Biotechnol Prog 23:187193

8. Martin I, Wendt D, Heberer M (2004) The role of bioreactors in tissue engineering. Trends Biotechnol 22:80-86

9. Portner R, Nagel-Heyer S, Goepfert C, Adamietz P, Meenen NM (2005) Bioreactor design for tissue engineering. J Biosci Bioeng 100:235-245

56. 
10. Schop D, Janssen FW, Borgart E, de Bruijn JD, van Dijkhuizen-Radersma R (2008) Expansion of mesenchymal stem cells using a microcarrier-based cultivation system: growth and metabolism. J Tissue Eng Regen Med 2:126-135

11. Glacken MW (1988) Catabolic control of mammalian cell culture. Biotechnology (N Y) 6:1041-1050

12. Ljunggren J, Haggstrom L (1995) Specific growth rate as a parameter for tracing growth-limiting substances in animal cell cultures. J Biotechnol 42:163-175

13. Newsholme P, Newsholme EA (1989) Rates of utilization of glucose, glutamine and oleate and formation of end-products by mouse peritoneal macrophages in culture. Biochem J 261:211218

14. Ozturk SS, Palsson BO (1991) Growth, metabolic, and antibody production kinetics of hybridoma cell culture: 2. Effects of serum concentration, dissolved oxygen concentration, and medium $\mathrm{pH}$ in a batch reactor. Biotechnol Prog 7:481-494

15. Schneider M, Marison IW, von Stockar U (1996) The importance of ammonia in mammalian cell culture. J Biotechnol 46:161-185

16. Hassell T, Gleave S, Butler M (1991) Growth inhibition in animal cell culture. The effect of lactate and ammonia. Appl Biochem Biotechnol 30:29-41

17. Dean RT, Jessup W, Roberts CR (1984) Effects of exogenous amines on mammalian cells, with particular reference to membrane flow. Biochem J 217:27-40

18. Both SK, van der Muijsenberg AJ, van Blitterswijk CA, de Boer J, de Bruijn JD (2007) A rapid and efficient method for expansion of human mesenchymal stem cells. Tissue Eng 13:3-9

19. de Bruijn JD, van den Brink I, Bovell YP, van Blitterswijk C (1998) Tissue engineering of goat bone: osteogenic potential of goat bone marrow cells. Bioceramics 11:497-500

20. Xiao Y, Peperzak V, van Rijn L, Borst J, de Bruijn JD Dexamethasone treatment during the expansion phase maintains stemness of bone marrow mesenchymal stem cells. J Tissue Eng Regen Med

21. D'Ippolito G, Diabira S, Howard GA, Roos BA, Schiller PC (2006) Low oxygen tension inhibits osteogenic differentiation and enhances stemness of human MIAMI cells. Bone 39:513-522

22. Mendes SC, Tibbe JM, Veenhof M, Bakker K, Both S, Platenburg PP, Oner FC, de Bruijn JD, van Blitterswijk CA (2002) Bone tissue-engineered implants using human bone marrow stromal cells: effect of culture conditions and donor age. Tissue Eng 8:911-920

23. Phinney DG, Kopen G, Righter W, Webster S, Tremain N, Prockop DJ (1999) Donor variation in the growth properties and osteogenic potential of human marrow stromal cells. J Cell Biochem 75:424-436

24. Siddappa R, Licht R, van Blitterswijk C, de Boer J (2007) Donor variation and loss of multipotency during in vitro expansion of human mesenchymal stem cells for bone tissue engineering. $\mathrm{J}$ Orthop Res 25:1029-1041

25. Tritsch GL, Moore GE (1962) Spontaneous decomposition of glutamine in cell culture media. Exp Cell Res 28:360-364

26. Capiaumont J, Legrand C, Carbonell D, Dousset B, Belleville F, Nabet P (1995) Methods for reducing the ammonia in hybridoma cell cultures. J Biotechnol 39:49-58

27. Lao MS, Toth D (1997) Effects of ammonium and lactate on growth and metabolism of a recombinant Chinese hamster ovary cell culture. Biotechnol Prog 13:688-691

28. Neermann J, Wagner R (1996) Comparative analysis of glucose and glutamine metabolism in transformed mammalian cell lines, insect and primary liver cells. J Cell Physiol 166:152-169

29. Grant JL, Smith B (1963) Bone marrow gas tensions, bone marrow blood flow, and erythropoiesis in man. Ann Intern Med 58:801-809

30. Wang DW, Fermor B, Gimble JM, Awad HA, Guilak F (2005) Influence of oxygen on the proliferation and metabolism of adipose derived adult stem cells. J Cell Physiol 204:184-191

31. Ozturk SS, Riley MR, Palsson BO (1992) Effects of ammonia and lactate on hybridoma growth, metabolism, and antibody production. Biotechnol Bioeng 39:418-431

32. McQueen A, Bailey JE (1990) Effect of ammonium ion and extracellular pH on hybridoma cell metabolism and antibody production. Biotechnol Bioeng 35:1067-1077

33. Reuveny S, Velez D, Macmillan JD, Miller L (1986) Factors affecting cell growth and monoclonal antibody production in stirred reactors. J Immunol Methods 86:53-59 
34. Patel SD, Papoutsakis ET, Winter JN, Miller WM (2000) The lactate issue revisited: novel feeding protocols to examine inhibition of cell proliferation and glucose metabolism in hematopoietic cell cultures. Biotechnol Prog 16:885-892

58. 


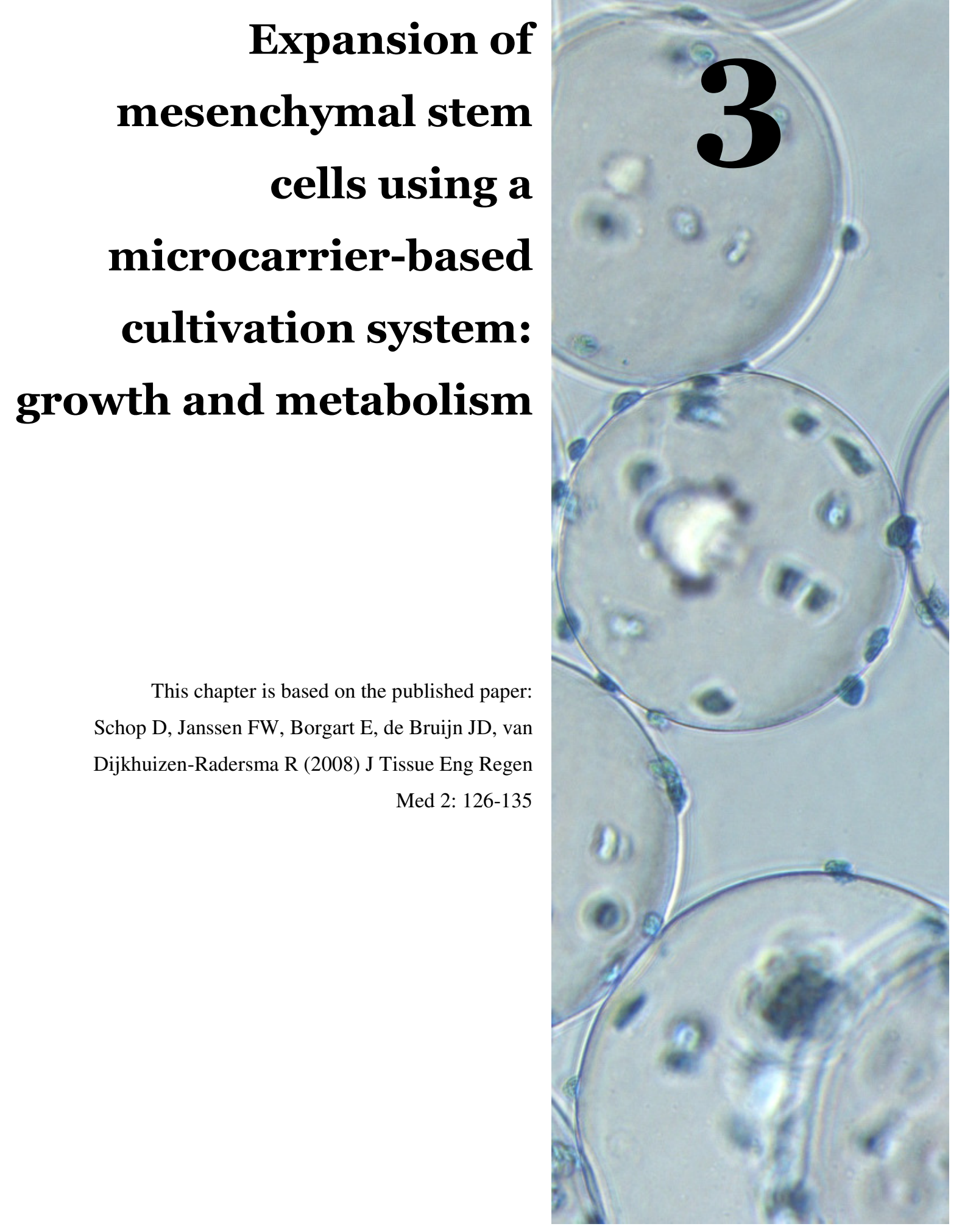





\section{Abstract}

For the continuous and fast expansion of mesenchymal stem cells (MSCs), microcarriers have gained increasing interest. The aim of this study was to evaluate the growth and metabolism profiles of MSCs, expanded in a microcarrier-based cultivation system. We investigated various cultivation conditions to expand goat mesenchymal stem cells on Cytodex 1 microcarriers. These conditions differed in feeding regime, i.e. the addition of fresh proliferation medium, with or without new microcarriers. For all conditions, cell attachment, cell proliferation, energy source consumption, metabolite production, and cell distribution on the microcarriers were studied. Attachment efficiencies of $40 \%$ were obtained followed by successful expansion up to 15 cultivation days. Depending on the feeding regime, an exponential growth, stationary growth, and decline growth phase could be distinguished. Addition of $30 \%$ fresh medium containing microcarriers every three days showed the longest continuous proliferation of goat MSCs on microcarriers. This feeding regime has the advantage that metabolites, such as ammonia, are diluted and that new energy sources, such as glucose and glutamine, and additional surface area are provided to the cells. In addition, by adding extra microcarriers a more homogenous cell distribution on the microcarriers is obtained as a result of bead-to-bead transfer. A correlation between nutrient consumption, metabolite production and cell growth was observed. The decreasing yield of lactate from glucose over time indicated a possible shift in cellular metabolism. 


\section{Introduction}

Adult mesenchymal stem cells, or MSCs, are self-renewal and multipotent stem cells present in e.g. the bone marrow. Their multipotency gives the ability to differentiate into a variety of cell types from the mesodermal origin, such as cartilage, bone, muscle, tendon, ligament, and $\mathrm{fat}^{1-3}$. Because of these features MSCs have strong potential as a tissue regenerative source $e^{1 ; 3}$.

For use as a tissue regenerative source, most strategies require that adult MSCs need to be isolated and expanded as they are only available in small numbers in the human body (e.g. in bone marrow). MSC multiplication is typically performed in 2D cultures, or plastic tissue culture flasks, which has some serious drawbacks. It is labour intensive and susceptible to contaminations due to the number of necessary cell passages as a result of the limited availability of surface area and the manual medium refreshments. Furthermore, culture conditions are suboptimal due to the lack of monitoring and control of the cultivation ${ }^{4}$. To expand stem cells in a controlled, reproducible and cost-effective way, more and more research is being done on the development of controlled bioreactors ${ }^{4-6}$.

Being anchorage dependent, MSCs require a large surface area for their expansion in a bioreactor. An obvious approach would be the use of microcarriers. Microcarriers offer the advantage of providing a large surface area for monolayer cell growth during proliferation in a homogenous suspension culture. Since its introduction in 1967 by Van Wezel ${ }^{7}$, microcarrier culture has been applied successfully for growing primary cells and anchorage-dependent cell lines either for the production of vaccines or pharmaceuticals or for cell population expansion ${ }^{8}$. A variety of commercial microcarriers for tissue engineering are available differing in chemical composition, charge, surface coatings and porosity ${ }^{9}$. The Cytodex microcarriers, which are composed of cross linked dextran matrix, are most commonly used for a wide range of cells, such as Chinese hamster ovary $(\mathrm{CHO})$ cells $^{10}$, Vero (African green monkey kidney) cells ${ }^{11}$ and Madin-Darby canine kidney (MDCK) cells ${ }^{12}$. Also for tissue engineering, such as cartilage and bone regeneration ${ }^{13}$ and the expansion of animal derived stem cells ${ }^{14-16}$, these commercially available microcarriers have been used. Frauenschuh and co-workers ${ }^{5}$ successfully applied Cytodex 1 microcarriers for the attachment and growth of porcine MSCs. They showed that 3D expansion of MSC on microcarriers represents a beneficial alternative to the conventional 2D monolayer cultivation system. However, cell metabolism was not investigated during cell expansion.

62. 
For the development of a bioreactor system it is important to know the demands of the cells for optimal cell growth. Cell growth could be inhibited by shortage of nutrients or by excess of metabolites. To obtain optimal culture conditions the feeding/refreshing regime is crucial $^{17-19}$. During cell growth nutrients such as glucose, glutamine and other amino acids are consumed. Meanwhile, metabolites such as lactate and ammonia are produced by the cells. These metabolites could inhibit cell growth at certain concentrations ${ }^{20-22}$. To prevent cell growth inhibition by metabolite production and/or nutrient deficiency the feeding regime should be optimal. In addition, as cell growth is correlated to nutrient consumption and metabolite production, the cell proliferation can be monitored in the reactor indirectly by monitoring metabolism ${ }^{19}$. A thorough investigation of the metabolism related to cell growth of MSCs in a microcarrier-based cultivation system has, to our best knowledge, not been published.

In this paper, we report the growth and metabolism of MSCs in microcarrier based spinner flask cultures to optimize the feeding/refreshing regime. The main goal is to optimize the expansion rate of the cells in a three-dimensional cultivation system. We evaluated various feeding and refreshing regimes for the expansion of goat MSCs. The goat MSCs were applied as a model for human MSCs. Since goat MSCs grow faster than human MSCs ${ }^{23}$, it was supposed that the effects of the feeding regime on cell growth and metabolism, being the focus of this paper, are more apparent. Here we describe three goat MSC cultivation conditions, varying in addition of fresh proliferation medium with or without microcarriers. All conditions were evaluated in triplicate. During cultivation, the nutrient (glucose and glutamine) and metabolite (lactate and ammonia) concentrations in the medium were monitored to establish the relation between growth, nutrient consumption and metabolite production. In addition, cell viability and cell distribution on the microcarriers were examined microscopically.

\section{Materials and Methods}

\section{Isolation of goat bone marrow derived mesenchymal stem cells (gMSCs)}

Goat bone marrow aspirate was obtained from the iliac crest of 2-4 year old adult Dutch milk goats. The MSC enriched population was isolated from the aspirates by using the adhesion selection ${ }^{24}$; plating the bone marrow with 500000 nucleated cells $/ \mathrm{cm}^{2}$ in $\alpha$-minimal 
essential medium $(\alpha M E M)$ for proliferation. $\alpha$ MEM proliferation medium consisted of minimal essential medium (Invitrogen, Breda, The Netherlands) supplemented with $10 \%$ fetal bovine serum (FBS, Cambrex, Verviers, Belgium), $100 \mathrm{U} / \mathrm{ml}$ penicillin (Invitrogen), $100 \mu \mathrm{g} / \mathrm{ml}$ streptomycin (Invitrogen), $2 \mathrm{mM} \mathrm{L}$-glutamine (Invitrogen), $0.2 \mathrm{mM} \mathrm{L}$-ascorbic acid-2phosphate (Sigma, Zwijndrecht, The Netherlands) and $1 \mathrm{ng} / \mathrm{ml}$ basic fibroblast growth factor (AbD Serotec, Oxford, UK). MSCs were cultured at $37^{\circ} \mathrm{C}$ in a humid atmosphere with $5 \%$ $\mathrm{CO}_{2}$. When near confluency was reached, cells were washed with PBS (Invitrogen) and enzymatically harvested by means of $0.25 \%$ trypsin in $1 \mathrm{mM}$ EDTA solution (Invitrogen) followed by replating with 500 cells $/ \mathrm{cm}^{2}$. Subsequently, MSC were cryopreserved at the end of passage 1.

\section{Monolayer pre-cultivation}

Defrosted cryopreserved MSC were plated with 2500 cells $/ \mathrm{cm}^{2}$ in $\alpha$ MEM proliferation medium. The medium was replaced every 3 to 4 days. At near confluency cells were subcultured until passage 4 as described above. The passage 4 harvested cells were used for the 3D microcarrier cultivation in spinner flasks.

\section{Microcarrier cultivation in spinner flasks}

\section{Preparation and seeding of the microcarriers}

Cytodex 1 microcarriers were prepared according to the manufacturer's instructions, which involves washing and swelling with PBS $\left(\mathrm{Ca}^{2+}\right.$ and $\mathrm{Mg}^{2+}$ free, Invitrogen), sterilization by autoclaving 30 minutes at $121^{\circ} \mathrm{C}$, and washing with medium. Siliconized (Sigmacote, Sigma) $100 \mathrm{ml}$ spinner flasks (Bellco, Nutacon, Leimuiden, The Netherlands) with a PTFE agitation paddle were used. The starting volume in the spinner flasks before seeding was $50 \mathrm{ml}$ proliferation medium containing a microcarrier surface area of $20 \mathrm{~cm}^{2} / \mathrm{ml}$ (based on manufacturer's instructions). The Cytodex 1 microcarriers have a surface area of $4400 \mathrm{~cm}^{2} / \mathrm{g}$, so $0.23 \mathrm{~g}$ Cytodex 1 was used per spinner flask. The microcarriers in the spinner flasks were seeded using passage $4 \mathrm{MSCs}$ from the monolayer precultivation. The total number of cells seeded per spinner flask was 2 million. The microcarrier cultures in spinner flasks were agitated using an external magnetic stirring system (VARIOMAG, Florida, USA) in a $37^{\circ} \mathrm{C}$ humid atmosphere containing $5 \% \mathrm{CO}_{2}$. The stirring regime comprised a 2 minute stirring phase at $30 \mathrm{rpm}$ followed by a rest phase $(0 \mathrm{rpm})$ for 30 minutes. After 18 hours seeding, the

64. 
microcarrier-cell complexes were settled by gravity and the proliferation medium was refreshed for $50 \%$. Subsequently, the agitation for the cultivation of MSCs on the microcarriers was set on continuously stirring at $30 \mathrm{rpm}$.

\section{gMSC cultivation on microcarriers}

Three different cultivation conditions were investigated in triplicate; I) with the addition of $30 \%$ fresh aMEM proliferation medium every three days during cultivation; II) with the addition of $30 \%$ fresh $\alpha \mathrm{MEM}$ proliferation medium containing freshly prepared Cytodex 1 microcarriers ( $20 \mathrm{~cm}^{2} / \mathrm{ml}$ and prepared as described before) every three days during cultivation; III) the control cultivation without any additions during cultivation. MSCs on microcarriers in spinner flasks were cultivated for 15 days at $37^{\circ} \mathrm{C}$ in a humid atmosphere with $5 \% \mathrm{CO}_{2}$, stirred at $30 \mathrm{rpm}$ by the external magnetic stirring system. To monitor cell growth, samples of $2 \mathrm{ml}$ of the microcarrier-cell complex suspensions were taken, starting at day 0 after seeding and refreshing. Every three days 2 samples were taken from the different cultivation conditions, except the control condition; one sample before and one sample after the addition of either fresh $\alpha$ MEM proliferation medium (condition I) or fresh $\alpha$ MEM proliferation medium containing freshly prepared microcarriers (condition II). By taking samples in this order, e.g. cellular consumptions can be calculated between the time points of additions. Samples were filtered using a $100 \mu \mathrm{m}$ cell strainer (BD Falcon, Alphen aan den Rijn, The Netherlands) resulting in two separate fractions; a medium fraction and a microcarrier-cell complexes fraction.

\section{Analyses}

\section{Cell proliferation}

Cell proliferation on the Cytodex 1 microcarriers was measured with the alamarBlue assay (BioSource, Etten-Leur, The Netherlands). The microcarrier-cell fraction is incubated for 4 hours with $3 \mathrm{ml} \mathrm{10 \%}$ alamarBlue solution in a humidified atmosphere containing $5 \% \mathrm{CO}_{2}$ at 37 ${ }^{\circ} \mathrm{C}$. During incubation the alamarBlue ${ }^{\mathrm{TM}}$ is reduced, caused by cellular activity, which was measured in triplicate by fluorescence. Fluorescence measurements of the reduced alamarBlue $^{\mathrm{TM}}$ were made by exciting at $535 \mathrm{~nm}$ and measuring emission at $595 \mathrm{~nm}$ using a plate reader (Anthos Labtec, Heerhugowaard, The Netherlands). The fluorescence emission intensity can be correlated to the cell number attached to the Cytodex 1 microcarriers using a 
donor specific calibration curve. Using the cell number attached on the microcarriers the specific growth rate and the generation time of the MSC can be calculated using the following equations:

$$
C(t)=C(0) * e^{\mu t}
$$

where $\mathrm{C}(0)$ and $\mathrm{C}(\mathrm{t})$ represent the cell numbers at time zero and $\mathrm{t}$ respectively, $\mu$ the specific growth rate $\left(\mathrm{h}^{-1}\right)$ and $\mathrm{t}$ the time $(\mathrm{h})$.

$$
t_{d}=\frac{\ln 2}{\mu}
$$

where $t_{d}$ represents the generation time $(h)$ and $\mu$ the specific growth rate $\left(h^{-1}\right)$.

\section{Medium analysis}

The medium fraction of the filtrated samples were analysed for glucose, lactate and ammonia using a VITROS DT60 II chemistry system (Ortho-Clinical Diagnostics, Tilburg, The Netherlands). Glucose and lactate concentrations were used for the calculation of the yield of lactate from glucose $\left(\mathrm{Y}_{\text {lac/glc }}\right)$ and for the calculation of the cell-specific consumption rate of glucose (qGlc) using the following equations:

$$
Y_{\text {lac /Glc }}=\frac{\Delta[\text { lac }]}{\Delta[G l c]}
$$

where $\Delta[\mathrm{lac}]$ represents the lactate production (mmol) in a certain time (t) interval and $\Delta[\mathrm{Glc}]$ the glucose consumption (mmol) in the same time interval.

$$
q G l c=\frac{\Delta[G l c] / \bar{C}}{\Delta t}
$$

where $\bar{C}$ represents the average cell number during a time interval, $\Delta$ t (days). Furthermore, Lglutamine concentration in the medium was determined enzymatically with the Glutamine/Glutamate determination kit (GLN-1) from Sigma. To determine cell death during seeding, the lactate dehydrogenase (LDH) activity in the medium after seeding was analysed by means of the enzymatic CytoTox-ONE ${ }^{\mathrm{TM}}$ Homogeneous Membrane Integrity Assay (Promega, Leiden, The Netherlands). LDH, released from death cells, was measured with a 10minute coupled enzymatic assay that results in the conversion of resazurin into the fluorescent resorufin. Fluorescence measurements of the resorufin were made by exciting at $535 \mathrm{~nm}$ and measuring emission at $595 \mathrm{~nm}$ using a plate reader (Anthos Labtec). The fluorescence emission 66. 
intensity could be correlated to the number of non attached dead cells using a donor specific calibration curve.

\section{Cell distribution, load and viability}

After 15 cultivation days the microcarrier-cell complexes were stained with a $1 \%$ methylene blue (MB) solution (Sigma) to examine cell distribution and loading on the microcarriers. The microcarriers with the attached cells were incubated 60 seconds in the MB solution and washed 3 times with PBS. Cells on the microcarriers were visualized using light microscopy (Nikon, Badhoevedorp, The Netherlands). For cell viability the microcarrier-cell complexes were incubated for 1.5 hours at $37^{\circ} \mathrm{C}$ in a humid atmosphere with $5 \% \mathrm{CO}_{2}$ in a $1 \%$ 3-(4,5-dimethylthiazol-2-yl)-2,5-diphenyltetrazolium bromide (MTT) solution (Merck, Amsterdam, The Netherlands). The viable cells on the microcarriers were visualized using light microscopy (Nikon).

\section{Statistical analysis}

Statistical significance was assessed by analysis data with the student $t$-test: significance was determined at a $p$ value less than 0.05 .

\section{Results}

Aim of this study was to evaluate growth and metabolism of MSCs, expanded in a microcarrier-based cultivation system. Three different microcarrier cultivation conditions in spinner flasks were monitored over time on cell growth and metabolism, in triplicate; I) with the addition of $30 \%$ fresh $\alpha$-MEM proliferation medium every three days during cultivation; II) with the addition of $30 \%$ fresh $\alpha$-MEM proliferation medium containing freshly prepared Cytodex 1 microcarriers $\left(20 \mathrm{~cm}^{2} / \mathrm{ml}\right)$ every three days during cultivation; III) the control cultivation without any additions during cultivation.

\section{Seeding}

MSCs were seeded directly into the spinner flasks using an intermitted stirring regime. The seeding efficiency was determined from the number of viable cells attached to the microcarriers and from the number of non-attached dead cells in the medium (Table 1). The three investigated cultivation conditions showed no significant difference in seeding efficiency, 
which was expected as the conditions during seeding were identical. The average seeding efficiency based on the number of viable attached cells was $41 \%$. Average ( $n=9)$ LDH activity in the medium resulted in a seeding efficiency of (100-44) $56 \%$.

\section{Microcarrier cultivation}

MSCs were cultured for 15 days in spinner flasks on Cytodex 1 microcarriers. During the cultivation of MSC on microcarriers, their growth was monitored over time for the three conditions in triplicate (Figure 1). Only small variations between the triplicates were observed, indicating that goat MSC cultivations in spinner flasks on cytodex 1 microcarriers are reproducible. Successful cell growth for all conditions was obtained. Up to 7 days, no significant difference $(p>0.05)$ between the three conditions was observed. The control condition showed an expected growth curve, including an exponential phase, a stationary phase and a death phase. These phases are characterized by an increasing viable cell number $(<$ day 6), a stable viable cell number (day 6 to day 11) and a decreasing viable cell number (> day 11). Condition I shows an extended stationary growth phase (from 6 to 14 days) in which the viable cell number remained stable. Cells died in a later cultivation stage compared to the control condition. Condition II shows an extended growth phase in which the total viable cell number is increasing linearly up to the end of the cultivation. These results show that by adding fresh medium to the microcarrier cultivation the decline phase is postponed (condition I vs. control). Apparently, the medium composition (nutrient and/or metabolite concentrations) is the growth inhibiting factor in the control spinner flasks. When adding fresh medium containing microcarriers the stationary growth phase is not reached at all during 15 days and therefore the proliferation of the MSCs on Cytodex 1 can be prolonged. This observation indicates that the availability of the surface area is the growth inhibiting factor in condition I (condition II vs. condition I).

68. 


\section{Table 1.Seeding efficiency of gMSCs on Cytodex 1 microcarriers}

The seeding efficiency, or amount of viable cells attached after 18 hours of seeding, was determined by means of the alamarBlue assay. Dead, non-attached cell numbers were obtained by measuring LDH activity in the medium. Seeding regime $\left(50 \mathrm{ml}, 20 \mathrm{~cm}^{2} / \mathrm{ml}, 2000 \mathrm{cells} / \mathrm{cm}^{2}\right.$, intermitted stirring) was identical for all three conditions.

\begin{tabular}{lllllll}
\hline \multirow{2}{*}{ Condition } & \multicolumn{2}{l}{ Seeded cells } & \multicolumn{2}{l}{ Viable, attached cells } & \multicolumn{2}{l}{ Dead, non-attached cells } \\
\cline { 2 - 7 } & No. & $\%$ & No. & $\%$ & No. & $\%$ \\
\hline I $(\mathrm{n}=3)$ & $2.0 * 10^{6}$ & 100 & $8.9 * 10^{5}$ & $44.4( \pm 4.9)$ & $8.6^{*} 10^{5}$ & $42.8( \pm 10.7)$ \\
II $(\mathrm{n}=3)$ & $2.0 * 10^{6}$ & 100 & $7.9^{*} 10^{5}$ & $39.6( \pm 6.1)$ & $9.3 * 10^{5}$ & $46.3( \pm 11.6)$ \\
Control $(\mathrm{n}=3)$ & $2.0 * 10^{6}$ & 100 & $8.1 * 10^{5}$ & $40.3( \pm 6.3)$ & $8.8^{*} 10^{5}$ & $44.0( \pm 9.6)$ \\
\hline Average $(\mathrm{n}=9)$ & $2.0 * 10^{6}$ & 100 & $8.3 * 10^{5}$ & $41.4( \pm 3.6)$ & $8.6^{*} 10^{5}$ & $43.8( \pm 11.3)$ \\
\hline
\end{tabular}

Based on the viable cell numbers, we calculated the growth rate and generation time. Table 2 shows the calculated parameters for time intervals during the 15 days of cultivation. The time intervals were chosen based on the feeding regime, as the addition of fresh medium resulted in increasing nutrient concentrations and dilution of metabolites. The calculated growth rate is the product of cell growth and cell death, which could also be described as the overall population growth rate. The calculated growth rates and generation times are in agreement with the observations in Figure 1. The growth phase corresponds to high growth rates $\left(\approx 0.02 \mathrm{~h}^{-1}\right)$. When cells were in the stationary growth phase a low growth rate $\left(<0.01 \mathrm{~h}^{-1}\right)$ was calculated. During the death phase a negative growth rate was observed, indicating that the death rate of the cells was larger than the growth rate. Furthermore, the total amount of population doublings was calculated. The total amount of population doublings obtained for the control condition was $2.6 \pm 0.18$ at day 6 ; for condition I, $3.0 \pm 0.18$ at day 12 ; and for condition II, $4.0 \pm 0.13$ at day 15 . For the calculation of these values the death rate was not taken into account, which means more population doublings occurred. At the end of the cultivation ( $\mathrm{t}=15$ days) the overall number of population doublings for the control condition, condition I and condition II were $1.4 \pm 0.22,2.8 \pm 0.20$, and $4.0 \pm 0.13$ respectively. These values are reflected by the total cell numbers at $t=15$ days in Figure 1. 


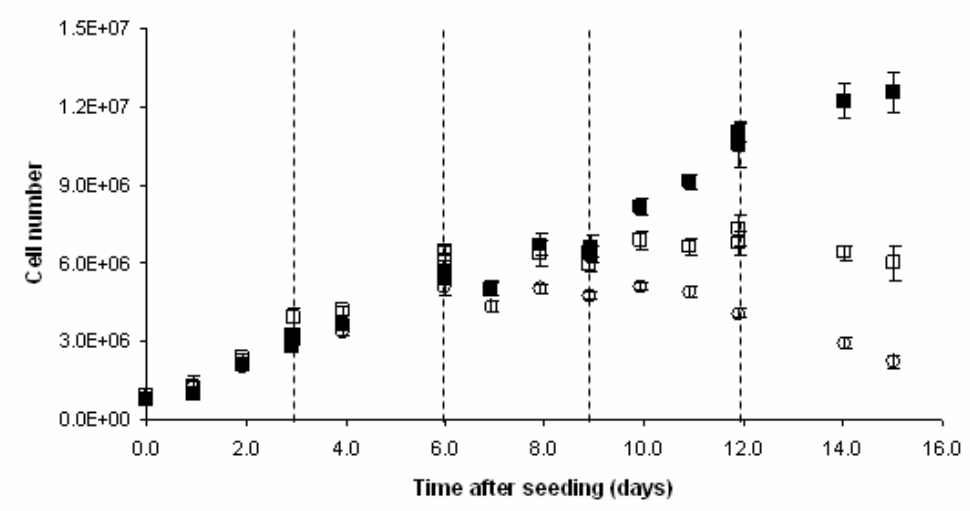

\section{Figure 1. MSC growth on microcarriers over time}

Cell numbers are based on alamarBlue results ( $n=3$ per condition). Dashed lines are the time points of culture medium additions (if applicable). At $\mathrm{t}=0$ days, a total of 2000 cells were seeded per $\mathrm{cm}^{2}$ microsphere surface in a total of $50 \mathrm{ml}$ culture medium containing $20 \mathrm{~cm}^{2} / \mathrm{ml}$ surface (totalling 2 million cells in each spinnerflask). ( $\square$ ) Condition I=addition of $30 \%$ medium every three days; ( $\square$ ) Condition $\mathrm{II}=$ addition of $30 \%$ medium containing microcarriers every three days; ( $($ ) Control=no additions.

\section{Table 2.Growth and metabolic parameters obtained during cultivation}

Growth and metabolic parameters were calculated in different time intervals, i.e. between time points of additions. Condition I) addition of $30 \%$ medium every three days; Condition II) addition of $30 \%$ medium containing microcarriers every three days; Control) no additions.

\begin{tabular}{lccccc}
\hline Condition & $\begin{array}{c}\text { Time } \\
\text { interval (days) }\end{array}$ & $\mu\left(\mathrm{h}^{-1}\right)$ & $\mathrm{t}_{\mathrm{d}}(\mathrm{h})$ & $\mathrm{Y}_{\text {lac } / \mathrm{glc}}$ & $\mathrm{qGlc}$ \\
\hline $\mathrm{I}(\mathrm{n}=3)$ & $0-3$ & 0.0208 & 33.4 & 2.00 & 7.35 \\
& $3-6$ & 0.0059 & 117.4 & 1.05 & 4.28 \\
& $6-9$ & 0.0014 & 495.9 & 0.96 & 4.05 \\
& $9-12$ & 0.0020 & 354.2 & 1.09 & 3.44 \\
& $12-15$ & -0.0004 & -1627.6 & 1.00 & 3.47 \\
II $(\mathrm{n}=3)$ & $0-3$ & 0.0209 & 33.1 & 2.00 & 8.37 \\
& $3-6$ & 0.0074 & 93.4 & 1.05 & 4.85 \\
& $6-9$ & 0.0044 & 158.0 & 1.00 & 4.17 \\
& $9-12$ & 0.0081 & 85.3 & 1.18 & 3.52 \\
Control & $12-15$ & 0.0040 & 174.5 & 1.31 & 2.55 \\
$(\mathrm{n}=3)$ & $0-3$ & 0.0206 & 33.6 & 2.18 & 8.51 \\
& $3-6$ & 0.0060 & 114.7 & 1.21 & 5.42 \\
& $6-9$ & 0.0020 & 353.4 & 1.31 & 5.50 \\
& $9-12$ & -0.0014 & -490.1 & 2.19 & 2.22 \\
& $12-15$ & -0.0044 & -156.0 & 1.10 & 1.66 \\
\hline
\end{tabular}

70. 


\section{Metabolism}

In addition to cell growth, the cellular metabolism was monitored for the three different culture conditions during the 15 days spinner flask cultivation. Nutrient (glucose, glutamine) and metabolite (lactate, ammonia) concentrations in the culture medium were monitored over time. With respect to the control condition, glucose concentrations decreased exponentially during cell growth (Figure 2A). Glucose concentrations for condition I and II decreased linearly in a slower rate, due to the additions of the nutrients. For the later time points $(>10$ days) the glucose concentration was lower for condition II compared to condition I. Directly opposite to the decreasing glucose concentration, the lactate concentration increases over time (Figure 2B); lactate was produced exponentially for the control condition and a linear increase of the lactate concentration was observed for condition I and II.
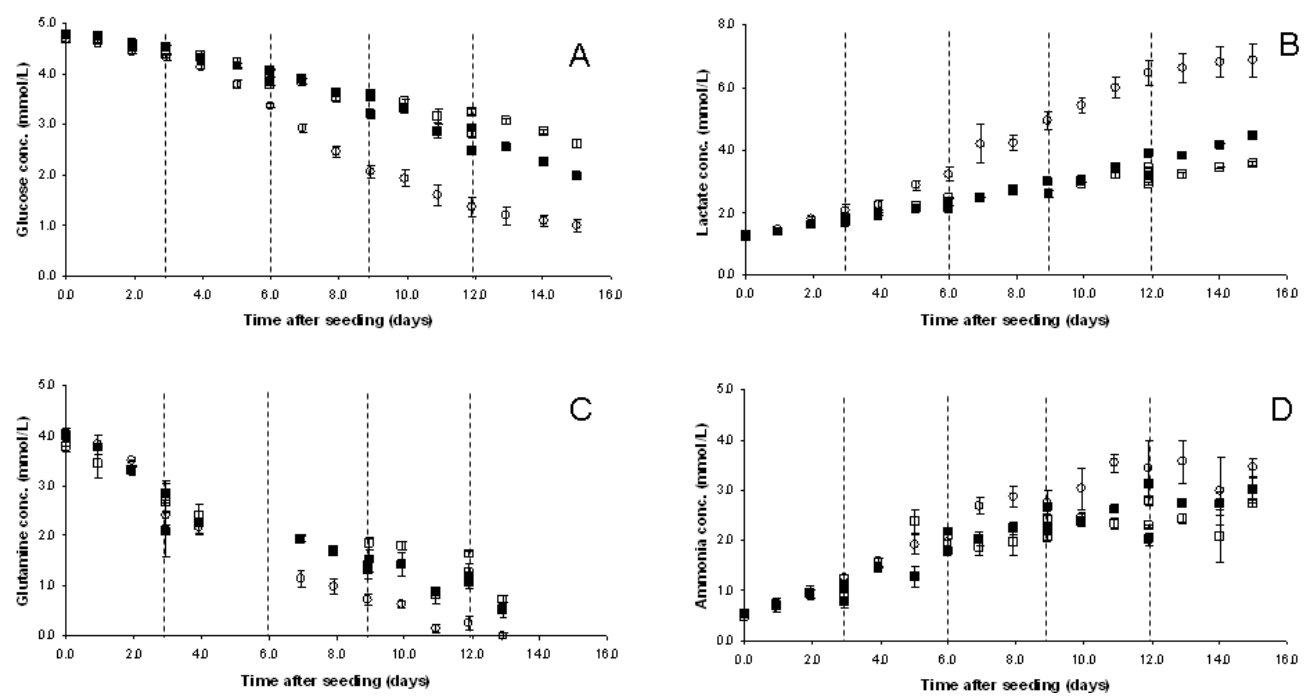

Figure 2. Consumption of glucose and glutamine and production of lactate and ammonia by MSCs on microcarriers over time

Dashed lines are the time points of culture medium additions (if applicable). ( $\square$ ) Condition I=addition of $30 \%$ medium every three days; (a) Condition II=addition of $30 \%$ medium containing microcarriers every three days; ( $\circ$ ) Control=no additions. ( $n=3$ per condition). Nutrient/metabolite profile of (A) glucose; (B) lactate; (C) glutamine; (D) ammonia

From the glucose and lactate concentrations, the yield of lactate from glucose $\left(\mathrm{Y}_{\text {lac/glc }}\right)$ and the cell specific glucose consumption rate (qGlc) was calculated for the three different culture conditions at different time intervals (Table 2). The $\mathrm{Y}_{\text {lac/glc }}$ varied between 1 and $2 \mathrm{~mol} \mathrm{~mol}^{-1}$ 
during culture. At the start of the cultivation (day 0 until day 3) the yield of lactate from glucose is around $2 \mathrm{~mol} \mathrm{~mol}^{-1}$ for every condition. With increasing cultivation times, however, the yield of lactate from glucose decreased to a $Y_{\text {lac/glc }}$ of $1 \mathrm{~mol} / \mathrm{mol}$. We did not observe any major differences between condition I and II, regarding $\mathrm{Y}_{\text {lac/glc. Initially, the glucose }}$ consumption of the cultivations is relatively high; around 8 pmol cell $^{-1}$ day $^{-1}$. Prolonged cultivation resulted in a decreasing qGlc over time. Similar results for qGlc were observed between the three different cultivation conditions.

Apart from glucose as energy source, glutamine was also utilized by the cells over time (Figure 2C). In the control condition, exponential glutamine uptake could be observed until day 3. From day 3 on, the glutamine concentration in the medium was decreasing slowly and linear. Glutamine, in the control condition, was totally exhausted after 11 days of cultivation. For condition I and II, glutamine uptake was comparable to the control condition during the first four days. However, due to medium additions, the glutamine concentrations in the medium for condition I and II decreased slower than for the control condition. For both condition I and II glutamine was not utilized completely during the spinner flask cultivations of 15 days. As a result of glutamine consumption the metabolite ammonia was produced by the cells (Figure 2D). In the control condition high ammonia concentrations were reached, around $3.5 \mathrm{mmol} \mathrm{NH} / \mathrm{L}$. Due to dilution by adding fresh medium lower ammonia concentrations, around $2.8 \mathrm{mmol} / \mathrm{L}$ for condition I and $3.1 \mathrm{mmol} / \mathrm{L}$ for condition II, were measured compared to the control condition.

\section{Characterization}

After 15 days of cultivation, Cytodex 1 microcarriers with attached MSCs were harvested from the three cultivation conditions and analysed microscopically for cell distribution, load and viability of the attached cells after MB and MTT staining. Figure 3 shows the distribution and load of the viable cells for the three conditions. Both the control condition (Figure $3 \mathrm{C} \& \mathrm{~F}$ ) and condition I (Figure $3 \mathrm{~A} \& \mathrm{D}$ ) showed heterogeneous cell distribution and cell aggregates on the microcarriers. Condition II (Figure 3 B\&E) showed a more homogeneous distribution of the cells on the microcarriers. Also the freshly added microcarriers were covered with MSCs, indicating that the cells were able to transfer from one bead to another during cultivation. Condition II showed the highest visual cell load on the carriers followed by condition I and the control, respectively. These microscopic observations confirmed the results obtained with alamarBlue (Figure 1). The comparison of the MTT stained samples with MB stained samples 
(data not shown) showed no differences for any of the conditions, proving the viability of the attached cells on the microcarriers.
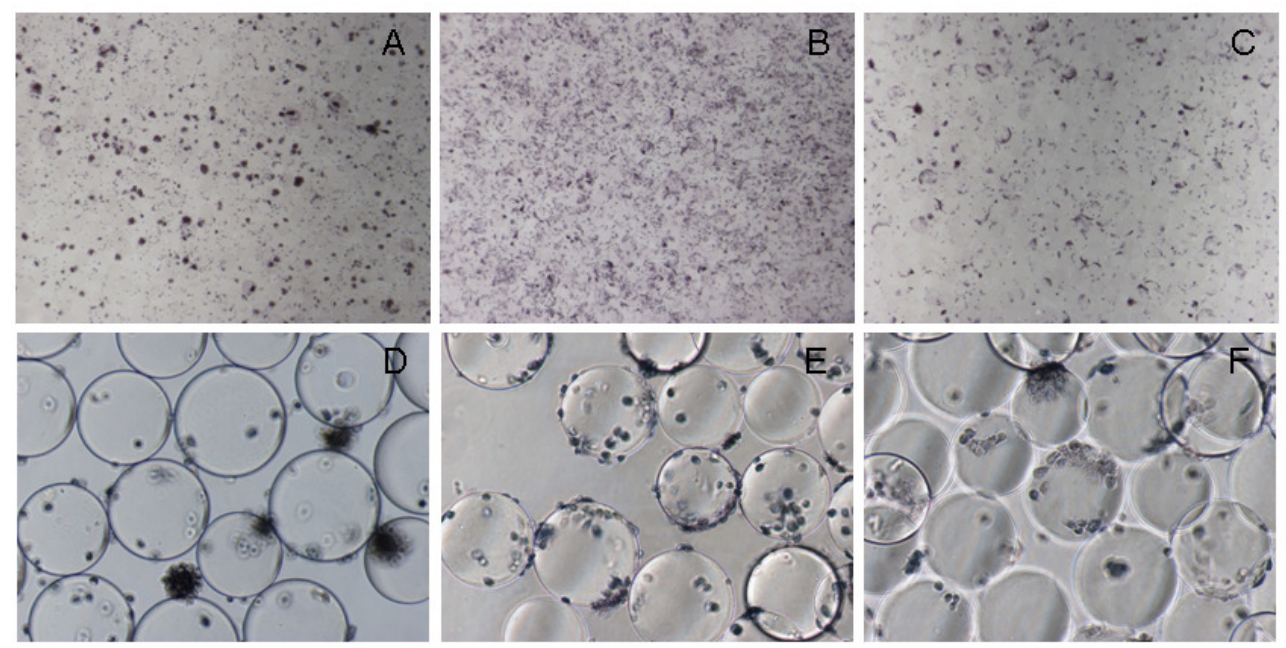

Figure 3. MSCs proliferated on Cytodex 1 microcarriers for 15 days stained with MTT

(A \& D) condition I, addition of 30\% fresh medium (Original magnification 20x \& 100x); (B \& E) condition II, addition of $30 \%$ fresh medium containing microcarriers (Original magnification 20x \& 100x); (C \& F) control condition (Original magnification 20x \& 100x).

\section{Discussion}

\section{Seeding}

The attachment efficiency obtained in this study for the MSCs to Cytodex 1 microcarriers of about $40 \%$ is relatively low compared to seeding efficiencies reported in other studies $5 ; 10 ; 11$; 13; 25-28. Seeding efficiencies between 75 and $100 \%$ were obtained in those studies. These differences in seeding efficiencies could be explained by the fact that other cell types were evaluated and/or other conditions during the initial attachment period were applied. An important parameter also affecting the attachment efficiency, however, is the verification method. Various methods have been reported to determine the number of attached cells to the microcarriers; 1 ) by counting the number of non-attached cells in filtrated (100 $\mu \mathrm{m})$ medium $^{10}$; $11 ; 13 ; 25 ; 27,2$ ) by microscopically counting the attached cells on the microcarriers ${ }^{26}, 3$ ) by using the Poisson distribution $\left.{ }^{5}, 4\right)$ by detaching cells using trypsin and counting detached cells ${ }^{28}$. 
Although all methods have their own drawbacks (e.g. representative sample, incomplete harvesting), the first method (counting non-attached cells in the medium) is overestimating the seeding efficiency. This evaluation method assumes that all cells absent in the medium have attached and is thereby not taking into account the number of dead cells. Most authors that applied this method indeed reported the highest attachment efficiencies. In our study we found a seeding efficiency of $41 \%$ based on viable attached cells (determined by alamarBlue) and $56 \%$ based on dead non-attached cells (calculated from LDH activity in the medium, Table 1). LDH measurements may overestimate the seeding efficiency, as the LDH activity in the medium decreases over time ( $\mathrm{t}_{0.5}=9$ hours). In contrast, analysis of the medium after seeding according to method 1 resulted in $80-90 \%$ seeding efficiency in our system (data not shown). Apparently, cells that did not attach to the microcarriers died during seeding (as proven by LDH activity) and could not be retrieved in the medium by counting.

Since the initial phase of a microcarrier culture is usually the most critical stage in the culture cycle $^{8 ; 29}$, the conditions for seeding of MSCs on microcarriers should be optimized to increase the attachment efficiency. Possible routes for improvement are varying the stirring regime, lowering the seeding volume, increasing the microcarrier concentration, varying the initial $\mathrm{pH}$ and/or serum concentrations $8 ; 25 ; 26$. Because the initial attachment of cells to a substrate will affect their proliferation ${ }^{13 ; 30}$, a higher seeding efficiency can then subsequently result in higher cell yields after expansion.

\section{Effect medium feeding regime on cell proliferation}

Glucose plays a central role as energy source in cellular metabolism; it is the primary source for ATP for mammalian cells utilizing glucose either by oxidative phosphorylation (yielding about 30-38 moles of ATP per mole glucose) or anaerobic glycolysis (yielding 2 moles of ATP and 2 molecules of lactate per mole glucose). The accumulation of lactate is therefore associated with inefficient metabolism of glucose ${ }^{31-33}$. Several publications correlated glucose and the lactate concentrations in the medium to cell numbers ${ }^{19 ; 34 ; 35}$. For the MSCs cultured on Cytodex 1 microcarriers, a correlation between cell growth and glucose and lactate concentrations is also observed. Increasing cell numbers (Figure 1) resulted in lower glucose concentrations (Figure 2A) and higher lactate concentrations (Figure 2B) in the medium. The metabolic parameters (Table 2) could also be correlated to the growth. Figure 4 presents the growth rates versus the specific glucose consumption rates for all cultivations. Similar linear correlations have been reported before for hybridoma cells ${ }^{34}$. Cells growing at a high rate,

74. 
consumed more glucose per cell than cells growing at a lower rate. However, growth rate depends not only on glucose consumption, but also on the efficiency of the glucose metabolism. Possibly, a metabolic shift form anaerobic glycolysis to oxidative phosphorylation occurred, as the yield of lactate from glucose changes over time ${ }^{34 ; 36}$. Initially a $\mathrm{Y}_{\text {lac/glc }}$ of 2 was obtained suggesting anaerobic glycolysis, followed by a combination of anaerobic glycolysis and oxidative phosphorylation, as the $\mathrm{Y}_{\text {lac/glc }}$ dropped towards 1 for every culture condition (Table 2). Apparently, at a low growth rate the cells consumed the glucose more efficiently for energy production. The energy produced by the cells is, however, not only used for growth, but also for cell maintenance ${ }^{37}$. For the control condition, the low qGlc values in the death phase may indicate that the consumed glucose is used for maintenance of the remaining living cells. At the end of the cultivation period, glucose was still present in the medium for all conditions, and therefore not limiting cell growth. In addition, the obtained lactate concentrations were below the growth inhibitory concentrations for goat MSCs $\left(>25 \mathrm{mmol} / \mathrm{L}^{23}\right)$.

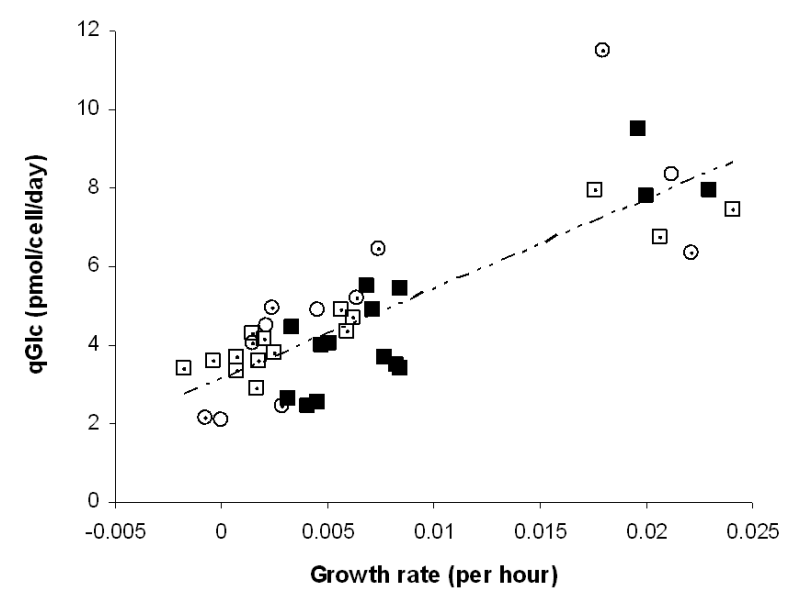

Figure 4. Specific glucose consumption rate versus growth rate of the MSCs

Data points of all conditions $(n=9)$ are shown. ( $\square$ ) Condition $I=$ addition of $30 \%$ medium every three days; (घ) Condition II=addition of $30 \%$ medium containing microcarriers every three days; ( $\circ$ ) Control=no additions.

Unlike glucose, glutamine was completely depleted in the control condition at day 11 and the cell growth ceased after depletion of glutamine. This indicates that the culture was nutritionally limited by glutamine. Apart from a constituent of proteins, glutamine is also an important energy source for mammalian cell culture $22 ; 32 ; 34$. Another reason why cells entered the stationary growth phase followed by the death phase could be the metabolite ammonia, 
$\mathrm{NH}_{3}$. Ammonia is mainly released by metabolic deamination of glutamine to glutamate and conversion of glutamate to $\alpha$-ketoglutarate. Also spontaneous decomposition of L-Glutamine releases ammonia ${ }^{22 ; 38}$. Ammonia can be growth inhibiting at low concentrations ${ }^{20 ; 22 ; 39}$. For goat MSCs, we found that the growth inhibitory $\mathrm{NH}_{3}$ concentration is around $3 \mathrm{mmol} / \mathrm{L}^{23}$. For the control condition, the inhibitory concentration of $3 \mathrm{mmol} / \mathrm{L}$ was reached at day 8 , increasing to $3.5 \mathrm{mmol} / \mathrm{L}$ at day 11 , which was also the starting point of the death phase. Therefore, both glutamine and/or ammonia could be the cause of growth inhibition and cell death in the control condition. Other possible causes could be e.g. shortage of essential amino acids and other deficiencies ${ }^{33 ;} 40$, accumulation of other waste products ${ }^{17 ;} 18$ or specific cultivation circumstances (sheer, $\mathrm{pH}$, oxygen).

Condition I and II shows extended linear growth compared to the control condition. During cultivation, both glucose and glutamine were not totally utilized in condition I and II due to the addition of nutrients every three days. Linear growth, also observed for murine MSCs by Da Silva Meirelles and Beyer Nardi ${ }^{41}$, indicates the presence of a growth inhibiting factor. In our case, it may be ammonia accumulations. Ammonia concentrations in condition I reached the growth inhibitory concentration at day 12 , similar to condition II. Condition II maintained the linear growth phase until the end of the cultivation period, whereas condition I reached the stationary growth phase after 6 days. This suggests a positive effect of the addition of microcarriers on cell growth. Overall, the addition of fresh nutrients prolongs growth for the MSCs grown on Cytodex 1 microcarriers. Feeding regimes keeping the nutrient concentration constant above a certain threshold may further prolong the exponential growth phase.

\section{Effect of surface area on cell proliferation}

In general, cells remain growing as long as nutrients are available, no accumulation of growth inhibitors occur, and sufficient surface area is available. Since the only difference between condition I and condition II is the addition of new microcarriers, the cells in condition II probably continued growing because new surface area is provided. Figure 5 presents the number of attached cells per square centimetre over time. For condition I a maximum cell load on the microcarriers, i.e. around 12000 cells per $\mathrm{cm}^{2}$, was observed (deduced from the situation seen in Figure 5). The maximum cell load was not reached for the control condition, due to the low total amount of cells in the culture. Moreover, for condition II the maximum cell load was also not reached, due to an increasing surface area by adding new microcarriers. So, by adding fresh microcarriers maximum loading of the microcarriers is prevented and cells can

76. 
continue growing. Interestingly, microscopic inspection showed no completely covered microcarriers in condition I (Figure 3D), but heterogeneous cell distribution and cell aggregates.

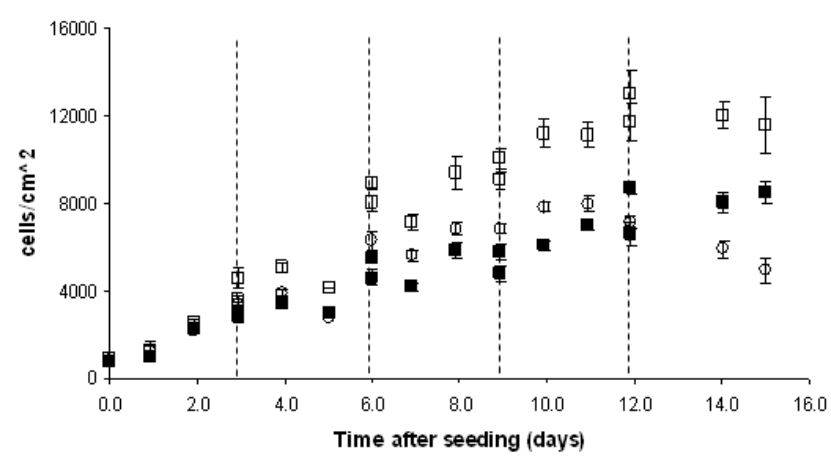

Figure 5. Number of MSCs per square centimetre versus time

Cell numbers are based on alamarBlue results ( $n=3$ per condition). Dashed lines are the time points of culture medium additions (if applicable). At $\mathrm{t}=0$ days, a total of 2000 cells were seeded per $\mathrm{cm}^{2}$ microsphere surface. ( $\square$ ) Condition I=addition of $30 \%$ medium every three days; (a) Condition $\mathrm{II}=$ addition of $30 \%$ medium containing microcarriers every three days; ( $)$ Control=no additions.

A more homogeneous cell distribution on the microcarriers was observed in condition II, as a results of bead-to-bead transfer of the MSCs. Cells transferring from carrier to carrier was shown for amongst others CHO cell-lines ${ }^{42 ;} 43$, bovine chondroprogenitor cells ${ }^{44}$, and recently for porcine mesenchymal stem cells ${ }^{5}$. By adding fresh microcarriers during cultivation, cell aggregates, as formed in condition I and the control, can be prevented. For all conditions, the cells kept rounded cell morphology on the microcarriers during the cultivation (Figure 3). This was also observed for porcine MSCs by Frauenschuh and co-workers ${ }^{5}$, although in their study the morphology changed to fibroblastoid shape during the adhesion process. As MSC are anchorage dependent, they attach to the positively charged Cytodex 1 microcarriers due to differences in charge ${ }^{8}$. Considering the rounded morphology, the dextran-based microcarriers do not supply the optimal surface characteristics for proper attachment of goat MSCs. Other types of microcarriers, as indicated by Nilsson ${ }^{8}$, may be more suitable for proper adhesion and expansion of goat MSCs.

Being a model for human MSC, the expanded goat MSC were not fully characterized for their "stemness" (FACS) and multipotency. The number of FACS antibodies for goat MSCs is limited and in vitro multipotency assays for goat MSCs are not standard as for human MSC. 
Other groups, however, have reported various studies with other animal derived stem cells showing the differentiation potential of the stem cells after expansion on (cytodex) microcarriers. Pluripotency was shown for mouse embryonic stem cells after expansion on cytodex $3^{14 ; 15}$ and multipotency was shown for porcine mesenchymal stem cells expanded on cytodex $1^{5}$. On the other hand, the cultivation on microcarriers may also induce differentiation during expansion ${ }^{9}$.

So far, no results on the expansion of human MSCs on microcarriers have been published. To evaluate the effect of feeding regime on the cell properties, including the stemness and multipotency, our future studies will focus on the expansion of human MSC on cytodex 1 microcarriers. The starting point for these studies with human MSCs will be condition II, being the preferred feeding regime for expansion of goat MSCs. However, human MSCs may behave differently compared to goat MSCs upon expansion on microcarriers and the feeding regime. Therefore, extensive characterization by FACS analyses and multipotency assays will be performed on the expanded human MSCs. If necessary, the feeding regime will be further optimized for human MSCs towards fast cell growth combined with efficient metabolism, homogenous cell distribution and maintained multipotency.

\section{Conclusions}

Herein, we have shown the successful expansion of goat mesenchymal stem cells by using a microcarrier-based cultivation system. The proliferation of goat MSCs can be prolonged by adding 30\% medium containing fresh nutrients and Cytodex 1 microcarriers to the cultivation system every three days. This feeding regime has the advantage that metabolites, such as ammonia, are diluted and that new energy sources, such as glucose and glutamine, and additional surface area are provided to the cells. In addition, by adding extra microcarriers a more homogenous cell distribution on the microcarriers is obtained as a result of bead-to-bead transfer. A correlation between nutrient consumption, metabolite production and cell growth was observed. However, the yield of lactate from glucose over time indicated a possible shift in cellular metabolism. As successful expansion of goat MSC was proven and correlated to cell metabolism, future studies will focus on human MSC expansion, including thorough investigation of the cellular metabolism and characterization of the cells.

78. 


\section{Acknowledgements}

This work was supported by grant IS044112 from SenterNovem (Agency of Ministry of Economic Affairs), The Netherlands. 


\section{References}

1. Caplan AI, Bruder SP (2001) Mesenchymal stem cells: building blocks for molecular medicine in the 21st century. Trends Mol Med 7:259-264

2. Pittenger MF, Mackay AM, Beck SC, Jaiswal RK, Douglas R, Mosca JD, Moorman MA, Simonetti DW, Craig S, Marshak DR (1999) Multilineage potential of adult human mesenchymal stem cells. Science 284:143-147

3. Prockop DJ (1997) Marrow stromal cells as stem cells for nonhematopoietic tissues. Science 276:71-74

4. Martin I, Wendt D, Heberer M (2004) The role of bioreactors in tissue engineering. Trends Biotechnol 22:80-86

5. Frauenschuh S, Reichmann E, Ibold Y, Goetz PM, Sittinger M, Ringe J (2007) A microcarrier-based cultivation system for expansion of primary mesenchymal stem cells. Biotechnol Prog 23:187193

6. Portner R, Nagel-Heyer S, Goepfert C, Adamietz P, Meenen NM (2005) Bioreactor design for tissue engineering. J Biosci Bioeng 100:235-245

7. van Wezel AL (1967) Growth of cell-strains and primary cells on micro-carriers in homogeneous culture. Nature 216:64-65

8. Nilsson K (1988) Microcarrier cell culture. Biotechnol Genet Eng Rev 6:403-439

9. Malda J, Frondoza CG (2006) Microcarriers in the engineering of cartilage and bone. Trends Biotechnol 24:299-304

10. Raffoul T, Swiech K, Arantes MK, Sousa APBd, Mendonca RZ, Pereira CA, Suazo CAT (2005) Performance evaluation of CHO-K1 cell in culture medium supplemented with hemolymph. Braz Arch Biol Technol 48:58-95

11. Yokomizo AY, Antoniazzi MM, Galdino PL, Azambuja N, Jr., Jorge SA, Pereira CA (2004) Rabies virus production in high vero cell density cultures on macroporous microcarriers. Biotechnol Bioeng 85:506-515

12. Genzel Y, Behrendt I, Konig S, Sann H, Reichl U (2004) Metabolism of MDCK cells during cell growth and influenza virus production in large-scale microcarrier culture. Vaccine 22:22022208

13. Malda J, van Blitterswijk CA, Grojec M, Martens DE, Tramper J, Riesle J (2003) Expansion of bovine chondrocytes on microcarriers enhances redifferentiation. Tissue Eng 9:939-948

14. Abranches E, Bekman E, Henrique D, Cabral JM (2007) Expansion of mouse embryonic stem cells on microcarriers. Biotechnol Bioeng 96:1211-1221

15. Fernandes AM, Fernandes TG, Diogo MM, da Silva CL, Henrique D, Cabral JM (2007) Mouse embryonic stem cell expansion in a microcarrier-based stirred culture system. J Biotechnol 132:227-236

16. Yang Y, Rossi FM, Putnins EE (2007) Ex vivo expansion of rat bone marrow mesenchymal stromal cells on microcarrier beads in spin culture. Biomaterials 28:3110-3120

17. Doverskog M, Ljunggren J, Ohman L, Haggstrom L (1997) Physiology of cultured animal cells. J Biotechnol 59:103-115

18. Godia F, Cairo JJ (2002) Metabolic engineering of animal cells. Bioprocess Biosyst Eng 24:289-298

19. Tsao YS, Cardoso AG, Condon RG, Voloch M, Lio P, Lagos JC, Kearns BG, Liu Z (2005) Monitoring Chinese hamster ovary cell culture by the analysis of glucose and lactate metabolism. J Biotechnol 118:316-327

20. Hassell T, Gleave S, Butler M (1991) Growth inhibition in animal cell culture. The effect of lactate and ammonia. Appl Biochem Biotechnol 30:29-41

21. Lao MS, Toth D (1997) Effects of ammonium and lactate on growth and metabolism of a recombinant Chinese hamster ovary cell culture. Biotechnol Prog 13:688-691

22. Schneider M, Marison IW, von Stockar U (1996) The importance of ammonia in mammalian cell culture. J Biotechnol 46:161-185

23. Schop D, Janssen FW, van Rijn LD, Fernandes H, Bloem RM, de Bruijn JD, van DijkhuizenRadersma R (2009) Growth, metabolism, and growth inhibitors of mesenchymal stem cells. Tissue Eng Part A 15:1877-1886

24. de Bruijn JD, van den Brink I, Bovell YP, van Blitterswijk C (1998) Tissue engineering of goat bone: osteogenic potential of goat bone marrow cells. Bioceramics 11:497-500

80. 
25. Chun BH, Chung SI (2001) Attachment characteristics of normal human cells and virus-infected cells on microcarriers. Cytotechnology 37:1-12

26. Forestell SP, Kalogerakis N, Behie LA, Gerson DF (1992) Development of the optimal inoculation conditions for microcarrier cultures. Biotechnol Bioeng 39:305-313

27. Ikonomou L, Drugmand JC, Bastin G, Schneider YJ, Agathos SN (2002) Microcarrier culture of lepidopteran cell lines: implications for growth and recombinant protein production. Biotechnol Prog 18:1345-1355

28. Varani J, Piel F, Josephs S, Beals TF, Hillegas WJ (1998) Attachment and growth of anchoragedependent cells on a novel, charged-surface microcarrier under serum-free conditions. Cytotechnology 28:101-109

29. Gebb C, Lundgren B, Clark J, Lindskog U (1983) Harvesting and subculturing cells growing on denatured-collagen coated microcarriers (Cytodex 3). Dev Biol Stand 55:57-65

30. Kong D, Chen M, Gentz R, Zhang J (1999) Cell growth and protein formation on various microcarriers. Cytotechnology 29:149-156

31. Campbell NA, Reece JB, Mitchell LG (1999) Biology. Vol. 5. Benjamin/Cummings, California

32. Newsholme P, Newsholme EA (1989) Rates of utilization of glucose, glutamine and oleate and formation of end-products by mouse peritoneal macrophages in culture. Biochem J 261:211218

33. Ozturk SS, Palsson BO (1991) Growth, metabolic, and antibody production kinetics of hybridoma cell culture: 2. Effects of serum concentration, dissolved oxygen concentration, and medium $\mathrm{pH}$ in a batch reactor. Biotechnol Prog 7:481-494

34. Ozturk SS, Palsson BO (1991) Growth, metabolic, and antibody production kinetics of hybridoma cell culture: 1. Analysis of data from controlled batch reactors. Biotechnol Prog 7:471-480

35. Ozturk SS, Thrift JC, Blackie JD, Naveh D (1997) Real-time monitoring and control of glucose and lactate concentrations in a mammalian cell perfusion reactor. Biotechnol Bioeng 53:372-378

36. Cruz HJ, Moreira JL, Carrondo MJ (1999) Metabolic shifts by nutrient manipulation in continuous cultures of BHK cells. Biotechnol Bioeng 66:104-113

37. Ozturk SS, Riley MR, Palsson BO (1992) Effects of ammonia and lactate on hybridoma growth, metabolism, and antibody production. Biotechnol Bioeng 39:418-431

38. Tritsch GL, Moore GE (1962) Spontaneous decomposition of glutamine in cell culture media. Exp Cell Res 28:360-364

39. Chen P, Harcum SW (2005) Effects of amino acid additions on ammonium stressed CHO cells. J Biotechnol 117:277-286

40. Ljunggren J, Haggstrom L (1995) Specific growth rate as a parameter for tracing growth-limiting substances in animal cell cultures. J Biotechnol 42:163-175

41. Meirelles Lda S, Nardi NB (2003) Murine marrow-derived mesenchymal stem cell: isolation, in vitro expansion, and characterization. Br J Haematol 123:702-711

42. Durrschmid M, Landauer K, Simic G, Bluml G, Doblhoff-Dier O (2003) Scalable inoculation strategies for microcarrier-based animal cell bioprocesses. Biotechnol Bioeng 83:681-686

43. Ohlson S, Branscomb J, Nilsson K (1994) Bead-to-bead transfer of Chinese hamster ovary cells using macroporous microcarriers. Cytotechnology 14:67-80

44. Melero-Martin JM, Dowling MA, Smith M, Al-Rubeai M (2006) Expansion of chondroprogenitor cells on macroporous microcarriers as an alternative to conventional monolayer systems. Biomaterials 27:2970-2979 



\section{Expansion of human mesenchymal Stromal cells: growth and metabolism}

This chapter is based on the published paper: Schop D, van Dijkhuizen-Radersma R, Borgart E, Janssen FW, Rozemuller H, Prins HJ, de Bruijn JD (2010) J Tissue Eng Regen Med 4: 131-140 



\section{Abstract}

Adult stem cells, or mesenchymal stromal cells (MSCs), are of great potential for cell therapy and tissue engineering applications. However, for therapeutic use, these cells need to be isolated from tissue or a biopsy and efficiently expanded as they cannot be harvested in sufficient quantities from the body. In our opinion, efficient expansion of MSCs can be achieved in a microcarrier-based cultivation system. This study selected a suitable microcarrier for human bone marrow derived stromal cells (human MSCs), optimized cell seeding strategies by varying serum concentrations, and optimized dynamic expansion of the human MSCs in a microcarrier-based spinner flask cultivation system by applying various feeding regimes. Cytodex 1 microcarriers in combination with a low serum concentration $0-5 \%$ in the medium resulted in the highest seeding efficiency for the human MSCs. Subsequently, significant expansion of the human MSCs on these carriers has been observed. The highest number of human MSCs population doublings (4.8 doublings) was obtained by a combination of $50 \%$ medium refreshment combined with addition of $30 \%$ medium containing microcarriers every three days. Exponential cell growth was observed for at least 9 days after seeding due sufficient nutrients (such as glucose) were present, metabolite concentrations (such as ammonia) were kept below growth inhibitory concentrations and adequate surface area was present for the cells. After dynamic expansion of the human MSCs, the cells retained their differentiation potential and their cell surface markers, indicating that human MSCs expansion on Cytodex 1 microcarriers did not alter phenotypic properties of the cells. 


\section{Introduction}

For most applications in tissue engineering and cell therapy, the use of adult stem cells (also referred to as mesenchymal stem cells, bone marrow stromal cells (MSCs) or progenitor cells) is preferred because of their ability to differentiate into many different cell types. When grown under appropriate conditions, adult stem cells can form various tissues such as bone, cartilage, muscle, tendon, ligament and other connective tissues ${ }^{1}$. As adult stem cells residue in virtually all tissues and organs, they can be isolated, expanded and used for therapeutic applications, such as bone and cartilage reconstitution or repair of infarcted heart tissue ${ }^{2 ; 3}$. From this perspective, it is interesting to use autologous adult stem cells to regenerate or replace missing or damaged body parts. However, the adult stem cells are present in small quantities in the body, such as bone marrow ${ }^{1 ; 4}$. One of the major challenges currently faced, is the lack of reproducible and cost-effective methods to isolate and expand sufficient numbers of adult stem cells so that they can be used for clinical applications.

Much research is performed to develop bioreactors for the creation of entire tissues (tissue engineering $)^{5-7}$, but only a few studies are focusing on the development of a bioreactor for adult stem cells expansion without differentiating them towards a certain lineage. This may be interesting for improvement of infarcted heart tissue or other body disorders after MSCs delivery ${ }^{3}$.

One way to expand adult stem cells in a controllable, reproducible and cost-effective manner is by using a microcarrier-based bioreactor system. Microcarriers offer the advantage of providing a large surface area for monolayer cell growth in a homogenously stirred suspension culture. Studies with porcine MSCs ${ }^{8}$, goat MSCs ${ }^{9}$, and rat $\mathrm{MSCs}^{10}$ already showed the possibility to expand MSCs on microcarriers. However, to our best knowledge no studies have been published showing significant expansion of human MSCs (human MSCs) on microcarriers. Previous studies by our group using conventional tissue culture flasks showed a different growth pattern and cellular metabolism of human MSCs compared to MSCs derived from other species ${ }^{11}$. Therefore, human MSCs expansion on microcarriers most probably also differ from goat or porcine MSCs expansion.

This paper reports the expansion of human bone marrow stromal cells (human MSCs) in a microcarrier based bioreactor system. Firstly, the seeding efficiency for human MSCs was evaluated on a wide variety of commercial available microcarriers. Further improvement of the seeding efficiency on the selected microcarriers was assessed by varying the serum concentration during seeding. Secondly, the expansion of the human MSCs on the selected 86. 
microcarriers was optimized by varying the feeding regimes. During expansion, the metabolism of the human MSCs was evaluated by monitoring nutrient consumption and metabolite production. After dynamic expansion, the differentiation potential and cell surface characteristics of the human MSCs were verified by multipotency assays and flow cytometry.

\section{Materials and Methods}

\section{Isolation of human MSCs}

After informed consent, human bone marrow aspirates (approximately $10 \mathrm{ml}$ ) was obtained from the iliac crest of adult donors who were undergoing hip surgery. The MSC population was isolated from the aspirates via adhesion selection ${ }^{12 ; 13}$ : plating the bone marrow at 500000 nucleated cells $/ \mathrm{cm}^{2}$ in $\alpha$-minimal essential medium $(\alpha \mathrm{MEM})$ for proliferation. $\alpha \mathrm{MEM}$ proliferation medium consisted of minimal essential medium (Invitrogen, Breda, The Netherlands) supplemented with 15\% foetal bovine serum (FBS, Cambrex, Verviers, Belgium), $100 \mathrm{U} / \mathrm{ml}$ penicillin (Invitrogen), $100 \mu \mathrm{g} / \mathrm{ml}$ streptomycin (Invitrogen), $2 \mathrm{mM}$ L-glutamine (Invitrogen), 0.2 mM L-ascorbic acid-2-phosphate (Sigma, Zwijndrecht, The Netherlands), 1 $\mathrm{ng} / \mathrm{ml}$ basic fibroblast growth factor (AbD Serotec, Oxford, UK) and $10 \mathrm{nM}$ dexamethason (Dex, Sigma) $)^{14}$. Human MSCs were cultured at $37^{\circ} \mathrm{C}$ in a humid atmosphere with $5 \% \mathrm{CO}_{2}$. When near confluency was reached (90\%), cells were washed with PBS (Invitrogen) and enzymatically harvested by means of $0.25 \%$ trypsin in $1 \mathrm{mM}$ EDTA solution (Invitrogen) followed by replating at 500 cells $/ \mathrm{cm}^{2}$. Subsequently, human MSCs were cryopreserved at the end of passage 2 .

\section{Monolayer pre-cultivation}

Defrosted cryopreserved human MSCs were plated at 2500 cells $/ \mathrm{cm}^{2}$ in $\alpha \mathrm{MEM}$ proliferation medium. The medium was replaced every 3 to 4 days. At near confluence, cells were sub-cultured until passage 5 as described above. The passage 5 harvested cells were used for the $3 \mathrm{D}$ microcarrier cultivation in spinner flasks. 


\section{Microcarrier cultivation in spinner flasks}

\section{Microcarrier selection}

Nine microcarrier types from different manufactures were examined for their human MSCs attachment properties. Cytodex type 1 and type 3 (GE Healthcare, Diegem, Belgium) ProNectin®F, Hillex II, Glass, Plastic, Plastic plus, FACT III, and Collagen (SoloHill Engineering, Michigan, United States) were prepared according to manufacturer's instructions. The microcarrier properties are shown in Table 1 . The microcarriers $\left(20 \mathrm{~cm}^{2} / \mathrm{ml}\right)$ were seeded using 24-well plates with 5000 cells $/ \mathrm{cm}^{2}$, shaken on a x-y-z-shaker (Heidolph polymax 1040, Salm en Kip BV, The Netherlands) at $37^{\circ} \mathrm{C}$ in a humid atmosphere with $5 \% \mathrm{CO}_{2}$. After an attachment period of 18 hours, the number of viable attached cells was determined with the alamarBlue assay (BioSource, Etten-Leur, The Netherlands) as described previously ${ }^{9}$. In short, the microcarrier-cell fraction is incubated for 4 hours with $3 \mathrm{ml} 10 \%$ alamarBlue solution. During incubation the alamarBlue ${ }^{\mathrm{TM}}$ is reduced, caused by cellular activity, which was measured in triplicate by fluorescence. The type of microcarrier showing the highest attachment of viable cells was selected for further development.

Table 1. General information microcarriers

\begin{tabular}{|c|c|c|c|c|c|}
\hline Microcarrier & Matrix & Surface coating & Charge & $\begin{array}{l}\text { Gravity } \\
\text { (g/ml) }\end{array}$ & Size $(\mu \mathrm{m})$ \\
\hline Cytodex 1 & DEAE-dextran & none & + & 1.03 & $131-220$ \\
\hline Cytodex 3 & DEAE-dextran & collagen & + & 1.04 & $133-215$ \\
\hline ProNectin $® F$ & polystyrene & fibronectin & none & 1.02 & $125-212$ \\
\hline FACT III & polystyrene & gelatin & + & 1.02 & $125-212$ \\
\hline Plastic plus & polystyrene & none & + & 1.02 & $125-212$ \\
\hline Collagen & polystyrene & gelatin & none & 1.02 & $125-212$ \\
\hline Plastic & polystyrene & none & none & 1.02 & $125-212$ \\
\hline Glass & polystyrene & high silica & - & 1.02 & $125-212$ \\
\hline Hillex II & polystyrene & $\begin{array}{l}\text { trimethyl } \\
\text { ammonium }\end{array}$ & + & 1.11 & $160-180$ \\
\hline
\end{tabular}

\section{Human MSCs seeding efficiency}

The effect of serum on the seeding efficiency of human MSCs on the selected microcarrier type was investigated in both 6-well plates and siliconized $100 \mathrm{ml}$ spinner flasks (Bellco, Nutacon, Leimuiden, The Netherlands). The microcarrier cultures $\left(20 \mathrm{~cm}^{2} / \mathrm{ml}\right.$, based on manufacturer's instructions) in 6-well plates were shaken on a x-y-z-shaker (Heidolph polymax 88. 
1040, Salm en Kip BV) in a $37^{\circ} \mathrm{C}$ humid atmosphere containing $5 \% \mathrm{CO}_{2}$. Passage 5 human MSCs, harvested from the monolayer pre-cultivation, were seeded in triplets at 2750 cells $/ \mathrm{cm}^{2}$ in $3 \mathrm{ml}$ proliferation medium containing different serum (FBS) concentrations; 0\%, 5\%, 10\%, and $15 \%$. During seeding, the culture was shaken continuously at $5 \mathrm{rpm}$. After an 3 hours attachment period, the cell seeding efficiency was determined with the alamarBlue assay.

The microcarrier cultures $\left(20 \mathrm{~cm}^{2} / \mathrm{ml}\right)$ in spinner flasks were agitated with a teflon (PTFE) agitation paddle and an external magnetic stirring system (VARIOMAG, Florida, USA) in a $37^{\circ} \mathrm{C}$ humid atmosphere containing $5 \% \mathrm{CO}_{2}$. With regard to the seeding in spinner flasks, passage 5 human MSCs were seeded at 4000 cells $/ \mathrm{cm}^{2}$ in $50 \mathrm{ml}$ proliferation medium containing either $0 \%, 5 \%$ or $15 \%$ serum. During seeding the culture was stirred continuously at $30 \mathrm{rpm}$. After an 18 hours attachment period, the cell seeding efficiency was determined with the alamarBlue assay. In addition, $\mathrm{pH}$ measurements of the different media were performed for both experiments.

\section{Human MSCs expansion on microcarriers}

After seeding the cells as described above, the microcarrier-cell complexes were settled by gravity and the proliferation medium was refreshed for $50 \%$ after the seeding phase before cells start multiplying (expansion phase). Human MSCs from two donors (both passage 5 cells) were expanded on microcarriers in spinner flasks for 9 days at $37{ }^{\circ} \mathrm{C}$ in a humid atmosphere with $5 \% \mathrm{CO}_{2}$, stirred at $40 \mathrm{rpm}$ continuously by the external magnetic stirring system. Several feeding regimes were tested to optimize the proliferation on the carriers. Table 2 depicts an overview of the experiments which are discussed in this paper.

Table 2. Used feeding regimes to optimize the expansion of human MSCs on microcarriers

\begin{tabular}{ccl}
\hline Run & Donor & Feeding regime (every three days) \\
\hline 1 & 2 & Refreshing 30\% medium \\
\hline 2 & 1 & Addition of $30 \%$ medium \\
\hline 3 & 1 & Addition of $30 \%$ medium containing microcarriers $\left(20 \mathrm{~cm}^{2} / \mathrm{ml}\right)$ \\
\hline 4 & 2 & Addition of $30 \%$ medium containing microcarriers $\left(20 \mathrm{~cm}^{2} / \mathrm{ml}\right)$ \\
\hline 5 & 1 & Addition of $30 \%$ medium \\
\hline 7 & 1 & Addition of $30 \%$ medium containing microcarriers $\left(20 \mathrm{~cm}^{2} / \mathrm{ml}\right)$ \\
\hline 8 & 1 & $\begin{array}{l}\text { Refreshing } 30 \% \text { medium followed by addition of } 30 \% \text { medium } \\
\text { containing microcarriers }\left(20 \mathrm{~cm}^{2} / \mathrm{ml}\right)\end{array}$ \\
\hline
\end{tabular}


To monitor cell growth, samples of $2 \mathrm{ml}$ of the microcarrier-cell complex suspensions were taken every three days, starting at day zero after seeding and refreshing, and analysed for cell number with the alamarBlue assay (BioSource, Etten-Leur, The Netherlands). Moreover, nutrients and metabolites (glucose, lactate and ammonia) in the medium were analysed using the VITROS DT60 II chemistry system (Ortho-Clinical Diagnostics, Tilburg, The Netherlands). L-glutamine concentration in the medium was determined enzymatically with the Glutamine/Glutamate determination kit (GLN-1, Sigma).

In addition to the measurements, samples were stained with $1 \%$ methylene blue (MB) solution (Sigma) to visualize the cell distribution and loading on the microcarriers using light microscopy. To verify the viability of the attached cells, the samples were stained with a $1 \% 3$ (4,5-dimethylthiazol-2-yl)-2,5-diphenyltetrazolium bromide (MTT) solution (Merck, Amsterdam, The Netherlands) and visualized using light microscopy. \\ Characterization of the human MSCs after expansion}

For characterization of the expanded human bone marrow stromal cells, cells were harvested from the microcarriers using the enzyme trypsin. Prior to enzymatic harvesting, the cell-microcarrier complexes were washed twice with PBS. The washed complexes were incubated for maximum 1 hour in $0.25 \% \mathrm{w} / \mathrm{v}$ trypsin/EDTA. Detachment of the cells from the microcarriers was confirmed by light microscopy. The detached cells were separated from the microcarriers using a $100 \mu \mathrm{m}$ filter.

\section{Multipotency analyses of human MSCs}

Harvested human MSCs from the optimal feeding regime(s) were examined for their differentiation potential using in vitro osteogenic and adipogenic differentiation assays. For osteogenic differentiation, human MSCs were seeded in 6-well plates at $10000 \mathrm{cells} / \mathrm{cm}^{2}$ and cultured for 21 days in osteogenic differentiation medium, which was composed of basic proliferation medium with $0.01 \mathrm{M}$ beta glycerol phosphate (Sigma). Mineralization of the extracellular matrix was verified by Alizarin red staining of the deposited calcium.

To induce adipogenic differentiation, human MSCs were seeded at $5000 \mathrm{cells} / \mathrm{cm}^{2}$ in 6well plates and cultured for 21 days in adipogenic medium. Adipogenic medium was composed of Dulbecco's Modified Eagle Medium (DMEM) with the following supplements: 10\% FBS, $100 \mathrm{U} / \mathrm{ml}$ penicillin, $100 \mu \mathrm{g} / \mathrm{ml}$ streptomycin, $0.5 \mathrm{mM}$ 3-isobutyl-1-methylxanthine (Sigma),

90. 
$0.02 \mathrm{M}$ indomethacin (Sigma), $1 \mu \mathrm{M}$ Dex, and $0.1 \mathrm{nM}$ insulin (Sigma). Cells differentiated to adipocytes were indentified by small fat droplets in their cytoplasm.

\section{Identification of human MSCs by flow cytometry}

To verify the phenotype of the harvested human MSCs, the cells were examined using flow cytometry on the markers shown in Table 3. Antibodies were purchased from Becton Dickinson (BD, Heidelberg, Germany), except for CD105 (Ancell Corp, Bayport, MN, USA). Labelled cells were measured using a FACS Calibur (BD) and data were analysed by using the CellQuest Pro software (BD).

Table 3. Cell markers used for HBMSCs characterization using flow cytometry

\begin{tabular}{rl|rl}
\hline Group & Marker & Group & Marker \\
\hline General markers & CD90 & MHC & HLA-ABC \\
& CD73 & B2 microglobulin \\
& CD105 & HLA-DR \\
\hline Adhesion markers & CD49 & Haematopoietic cells & GPA \\
& CD13 & CD31 \\
& CD117 & CD14 \\
& CD44 & CD3 \\
& CD55 & CD45 \\
& CD29 & CD19 \\
& CD166 & CD71 \\
& & CD34 \\
\hline
\end{tabular}

\section{Statistical analysis}

Statistical significance was assessed by analysis 2 groups of data with the student $t$-test and by analysis of 3 or more groups of data with the ANOVA test: significance was determined at a $p$ value less than 0.05 .

\section{Results and Discussion}

The aim of this study was to evaluate the expansion and metabolism of human mesenchymal stromal cells on microcarriers. Initially, an appropriate microcarrier was selected for the human MSCs. Subsequently, the expansion of human MSCs on the selected microcarrier was optimized and metabolism of the cells was monitored. Finally, the differentiation potential and cell surface characteristics of the expanded human MSCs were analyzed. 


\section{Microcarrier selection}

To select the most suitable microcarrier, human MSCs attachment on various microcarriers was investigated. After a seeding period of 18 hours, the cell number attached on the microcarriers was established with the alamarBlue assay. Significant differences in seeding efficiency between the tested microcarriers were obtained $(p<0.0001)$, see Figure 1. Cytodex type 1 showed the highest seeding efficiency (57\%) under these seeding conditions $(p=0.022$ compared to other groups).

Cytodex 1 was also shown to be the best microcarrier for porcine $\mathrm{MCSs}^{8}$ compared to Cytodex 2 and 3. A 80\% seeding efficiency, based on quantification by the Poisson distribution, was obtained. In addition, Cytodex 1 microcarriers were selected for chondrocyte expansion because high seeding efficiencies were obtained (85\%) by counting cells in suspension ${ }^{15}$. The higher seeding efficiencies obtained in these studies compared to the study performed for this paper may be caused by the different methods used to determine the seeding efficiency ${ }^{9}$. In addition, the current experimental conditions regarding e.g. stirring rate, serum concentrations, and microcarrier density were not optimized. Irrespective of the method and experimental conditions, Cytodex 1 microcarriers showed the highest seeding efficiency for the human MSCs (Figure 1) compared to the other microcarriers tested. Therefore, we selected this microcarrier type for further studies.

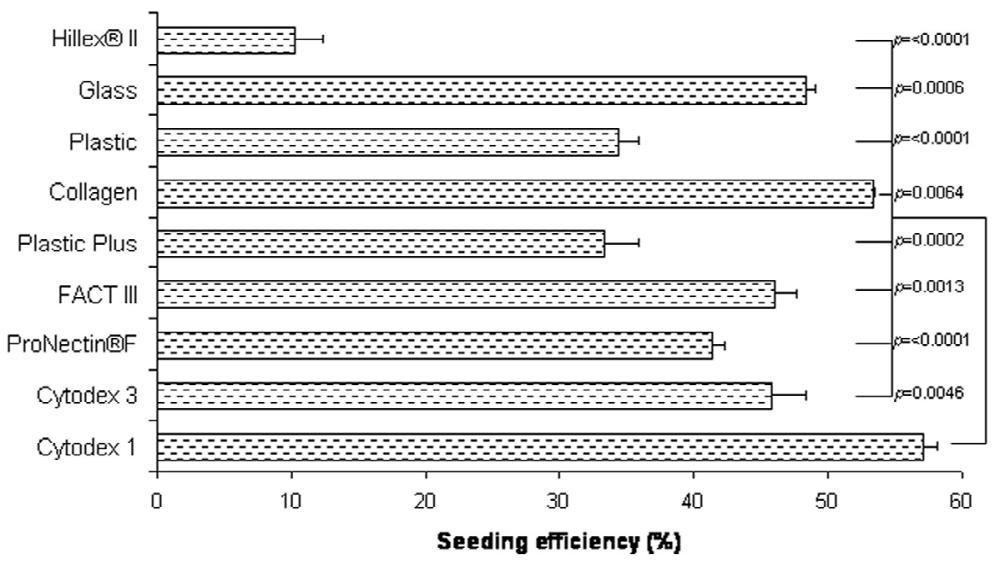

Figure 1. Human MSCs seeding efficiencies obtained for various microcarriers.

Each microcarrier type was seeded with 5000 cells per $\mathrm{cm}^{2}$. After 18 hours, the seeding efficiency per microcarrier was analysed in triplicate using the alamarBlue assay. $10 \%$ serum (of a different serum batch than used in the other experiments) was supplemented to the culture medium. Significant results between the groups were obtained $(p<0.0001)$.

92. 


\section{Human MSCs seeding efficiency - effect of serum}

Serum, the major supplement in cell culture media, contains cell attachment factors such as fibronectin which mediates in the cell adhesion process ${ }^{16}$. However, several studies showed that serum in the culture media during seeding inhibits cell attachment ${ }^{17 ;}$. To optimize cell attachment to the Cytodex 1 microcarriers, the effect of serum on seeding efficiency has been evaluated. Four serum concentrations in the standard proliferation medium were tested: $0 \%$, $5 \%, 10 \%$ and $15 \%$. Monolayer pre-cultured human MSCs were seeded on the microcarriers either in 6-well plates or spinner flasks.

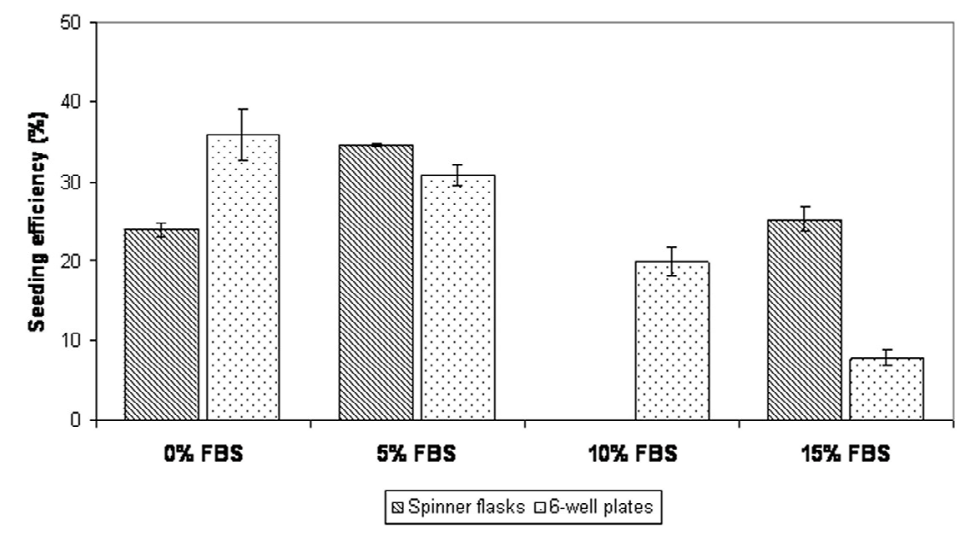

Figure 2. Seeding efficiency human MSCs - effect of serum.

HBMSCs were seeded on Cytodex 1 microcarriers into medium containing 0\%, 5\%, 10\% or 15\% serum (FBS). After the attachment period ( 3 hours for the 6-well plate experiments (seeded $2750 \mathrm{cells} / \mathrm{cm}^{2}$ ) and 18 hours for the spinner flask experiments (seeded $4000 \mathrm{cells} / \mathrm{cm}^{2}$ ), the seeding efficiency was determined using the alamarBlue assay. Significant differences between the groups were obtained $(p=0.0052)$.

Figure 2 shows the obtained seeding efficiencies for the human MSCs after the attachment period. Both the results of the 6-well plates and the spinner flask experiments are shown. Significant differences between the four groups of serum concentrations were obtained $(p=0.0052)$. Low serum concentrations, $0 \%-5 \%$, yielded in higher cell seeding efficiencies compared to the higher serum concentrations tested. Comparable results were obtained by Forestell and co-workers ${ }^{17}$ using human fetal lung fibroblasts, MRC-5 cells, on Cytodex 1 microcarriers. They discussed that the presence of serum lowers the surface hydrophobicity, resulting in a decreased cell attachment rate. They also postulated that cell attachment to the microcarrier surface is actually a two-stage process. The first step is cell adhesion to the 
carriers based on hydrophobic surface properties and the second step is cell attachment and spreading mediated by attachment proteins present in the serum. For non-ionic microcarriers, Nilsson ${ }^{19}$ indicated that fibronectin has also been found necessary for cell attachment. Our results, with human MSCs and positively charged Cytodex 1 microcarriers, indicated that serum is not necessary for initial cell attachment.

Besides the presence of attachment proteins, the initial $\mathrm{pH}$ may also affect the seeding efficiency. Initial media $\mathrm{pH}$, before equilibrium with $5 \% \mathrm{CO}_{2}$, was increasing with increasing serum concentrations; from $\mathrm{pH} 7.45$ at $0 \%$ serum to $\mathrm{pH} 7.65$ at $15 \%$ serum. After incubation in the $\mathrm{CO}_{2}$ incubator, the $\mathrm{pH}$ values were comparable for the four different media; 7.4, the standard $\mathrm{pH}$ for human MSCs growth currently used. The critical factor for cell attachment on a surface is its surface charge density. Nilsson ${ }^{19}$ proposed that this charge density is related to the interaction, the "van der Waals forces", between the attachment proteins of the cell and the charged surface. At physiological $\mathrm{pH}$, the hydrophobic surface of the Cytodex 1 microcarriers and the negative charge of the cells force the cells to attach to the microcarriers. However, when the medium $\mathrm{pH}$ is changed, the hydrophobicity of the microcarrier surface and the configuration of the cellular attachment proteins may be altered and influencing the attachment of the cells ${ }^{18 ; 20}$. Thus, the higher initial $\mathrm{pH}$ of medium with high serum concentrations (10$15 \%)$ may have reduced the seeding efficiency.

Overall, this study showed that low serum concentrations are beneficial for the seeding efficiency of human MSCs on Cytodex 1 microcarriers. However, for expansion higher serum percentages (10-15\%) are normally required ${ }^{12 ; 21}$. Therefore, for optimal expansion, additional serum should be added to the culture after the attachment period.

\section{Expansion and metabolism of human MSCs on microcarriers}

To optimize the expansion of human MSCs on Cytodex 1 microcarriers, various feeding regimes were evaluated in spinner flask experiments using 2 donors. Optimization of the feeding regime was mainly performed with donor 1 because comparable results were obtained between donor 1 and donor 2 when changing the feeding regime (data not shown). The following sections show and discuss the results per feeding regime tested.

94. 


\section{Effect of medium refreshment on human MSCs expansion}

Human MSCs from 2 donors were seeded on the Cytodex 1 microcarriers in spinner flasks and growth was monitored for 9 days. As a first step, a control run (no refreshment or addition of medium during cultivation) was performed for both donors to verify if human MSCs will grow on the Cytodex 1 microcarriers. Expansion of the human MSCs was observed for both donors (see Figure 3 for donor 1, data donor 2 not shown). However, cell growth was not optimal. Only three days of exponential cell growth on the microcarriers was observed for both donors. After 9 days, cells reached the stationary growth phase, were no growth is observed anymore.

Several factors can inhibit the exponential cell growth of the human MSCs, such as high metabolite concentrations ${ }^{11 ; 22}$ low nutrient concentrations and/or shear ${ }^{20 ;}$. Measurements of the main metabolites (lactate and ammonia) and nutrients (glucose and glutamine) in the culture medium revealed that inhibiting ammonia concentrations $\left(2.4 \mathrm{mmol} / \mathrm{l}^{11}\right)$ are reached at day 9 for the control cultivations of both donors (data not shown). Moreover, glucose concentrations were zero, or almost zero, between day 6 and day 9 after seeding. These two inhibiting factors may explain why the cells did not grow exponentially anymore after 3 days of culture. Obviously, more factors may play a role in cell growth inhibition.

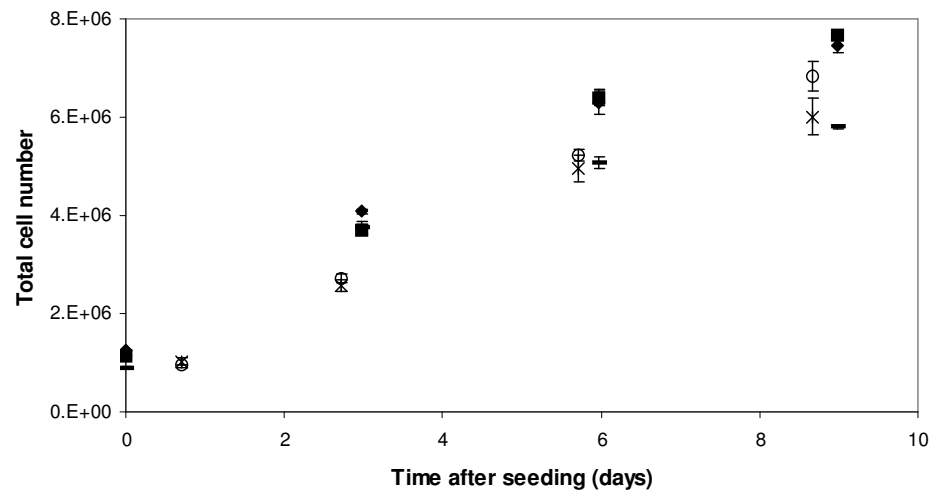

Figure 3. Human MSCs expansion on microcarriers with or without the addition of extra microcarriers during culture.

$\downarrow=$ Run 3 (addition of medium with microcarriers every three days); $\mathbf{n}=$ Run 2 (addition of medium every three days); $\mathrm{x}=$ Run 6 (addition of medium with microcarriers every three days); o=Run 5 (addition of medium every three days); $=$ =control (no additions or refreshments every three days), donor 1 . 
High ammonia concentrations and low glucose concentrations may be overcome by medium refreshment, similar to the conventional T-flasks cultivation. However, $100 \%$ medium refreshment of microcarrier cultivation is practically impossible because the microcarriers should stay in suspension. Previous expansion experiments with goat MSCs on Cytodex 1 microcarriers ${ }^{9}$ showed that exponential cell growth was obtained when the feeding regime comprises the addition of $30 \%$ fresh medium containing $20 \mathrm{~cm}^{2} / \mathrm{ml}$ microcarriers every three days. To examine the effect of only medium refreshment on the human MSCs growth on microcarriers, $30 \%$ medium of the microcarrier culture was refreshed every three days for 9 days long. The results showed no difference in cell growth compared to control, i.e. 3 days exponential cell growth followed by a decline in total cell number. Regarding the growth rates of the cells during the cultivation also no differences were obtained between the control run and the $30 \%$ medium refreshment run. Glucose concentrations were finished for both the control and 30\% medium refreshments runs at day 9 and ammonia concentrations were both growth inhibiting (2.4 mM for the $30 \%$ refreshment run and $2.7 \mathrm{mM}$ for the control run). As there were no differences obtained in cell growth and the glucose and ammonia concentrations in the medium between the runs, it can be concluded that $30 \%$ medium refreshment every three days is not sufficient to improve cell growth for human MSCs.

\section{Effect of carrier addition on human MSCs expansion}

As refreshing only did not improve human MSCs growth on microcarriers, the effect of $30 \%$ medium addition, either with or without extra microcarriers, was examined. Two experiments with 1 donor were performed to examine the effect of $30 \%$ medium addition every three days, with or without $20 \mathrm{~cm}^{2} / \mathrm{ml}$ Cytodex 1 microcarriers (run 2, 3, 5, and 6). Figure 3 shows the growth curves of the cells in the separate experiments, including a control run without additions or refreshments. As former experiments with goat MSCs showed no significant variation between triplets ${ }^{11}$, not every run with the human MSCs was performed in duplets/triplets.

Cell growth in all conditions showed the normal growth curve, including lag, exponential and stationary growth phase. No effect of adding medium with or without microcarriers was observed regarding cell growth, which is opposite to what was expected, namely better cell growth when adding medium containing microcarriers because extra nutrients and surface area is provided to the cells ${ }^{11}$. Nevertheless, when examining the cell distribution on the microcarriers, cell-microcarrier aggregates were obtained when no extra microcarriers were

96. 
added (Figure 4A). These aggregates were not observed in the culture where extra microcarriers were added (Figure 4B). The human MSCs seem to adhere preferably to newly added microcarriers. Hu et $a l^{24}$ also observed that mammalian cells attached to new microcarriers with a significant faster rate. Himes and $\mathrm{Hu}^{18}$ published that a higher attachment rate is, among others, mainly caused by the ion exchange capacity. A higher exchange capacity resulted in a higher cell attachment rate. A decreasing exchange capacity of the microcarriers on which cells had previously grown could be caused by serum proteins adsorbed on the carrier surface $^{25}$.
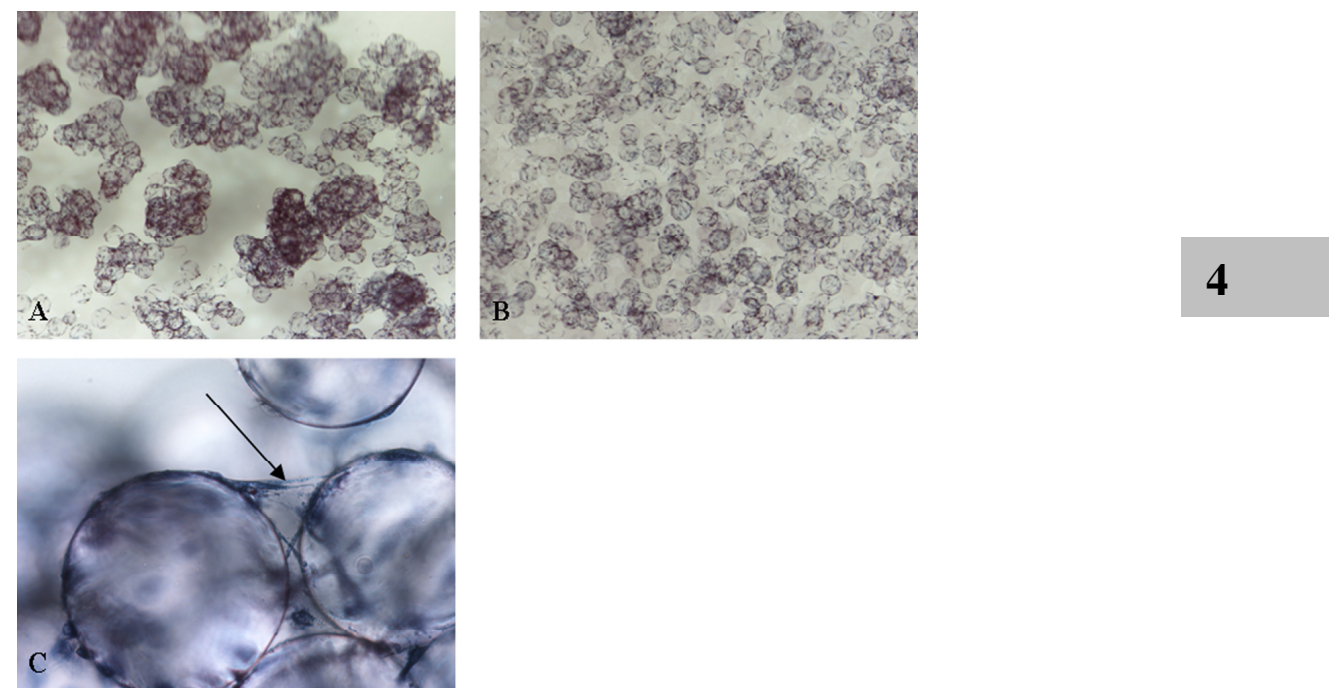

Figure 4. $\quad$ Effect of a feeding regime with or without microcarrier addition on cell distribution.

A) Run 2 (without the addition of microcarriers), original magnification 20x; B) Run 3 (with the addition of microcarriers), original magnification 20x; C) Run 2, original magnification 200x, arrow indicates the cellular bridge between the microcarriers. Cells were stained with $1 \%$ MTT solution.

Another explanation for the formation of aggregates, when no new microcarriers are added to culture, is the cell density (i.e. number of cells/microcarrier). If no new surface area is provided, the cells will search for any place left for attachment. For example, they will adhere partly on one microcarrier and partly on another microcarrier causing cell bridges between the carriers, see Figure 4C. When enough surface area is present, by adding new microcarriers, fewer cell bridges between the carriers and cell-microcarrier aggregates will be formed. In addition, by using higher stirring rates, the formation of cell bridges will be reduced ${ }^{20}$. 
By adding 30\% medium with and without extra microcarriers, significant higher cell numbers were obtained compared to the control condition of donor 1 (Figure 3). This indicates that by adding extra nutrients to the culture the cell growth is prolonged. Medium analysis indeed showed that glucose was not fully consumed at day 9 (2-3 mM glucose left at day 9) and ammonia levels were slightly lower for the $30 \%$ addition conditions. However, cell growth is prolonged linearly and not exponentially. This may still be caused by the production of metabolites, lactate and ammonia, which can inhibit cell growth ${ }^{11 ; 22}$. Medium analysis showed that ammonia and lactate concentrations were increasing over time. Especially ammonia reached relatively high levels $( \pm 2.0 \mathrm{mM})$ ) that can inhibit cell growth ${ }^{11}$. To overcome the effect of metabolites on the cell growth, metabolites should be removed by, for example, refreshing the culture medium. As was shown, $30 \%$ medium refreshment alone is not enough to improve MSCs growth on microcarriers. Subsequently, a combination of medium addition with extra microcarriers and medium refreshment was examined.

\section{Combination of medium refreshment and microcarrier addition}

Three feeding regimes were compared to determine the effect of a combination of medium refreshment and medium addition with microcarriers. The regime in which $30 \%$ medium containing microcarriers was added every three days (without refreshments, run 6) was compared to two cultures in which, prior to the addition of $30 \%$ medium (with microcarriers) also $30 \%$ (run 7) and 50\% (run 8) of the medium was refreshed every three days. Figure 5 shows the growth curves obtained for these three cultures. With regard to the total cell number after 9 days, no positive effect was obtained when $30 \%$ of the medium was refreshed combined with the addition of medium with microcarriers (run 7, 2.9 population doublings) compared to run 6 (without refreshments, 2.6 population doublings) ( $p=0.056$ ). The lack of effect was also reflected by the doubling times $\left(t_{d}\right.$, see Table 4$)$. These results indicate that the combination of $30 \%$ medium refreshment and 30\% addition of medium containing microcarriers were not sufficient to improve human MSC expansion. However, when refreshing $50 \%$ of the medium combined with $30 \%$ addition of medium containing microcarriers (run 8), higher total cell numbers were obtained $(p<0.0001)$ and up to day 9 exponential cell growth was obtained (see Figure 5, 4.8 population doublings). Moreover, after the initial growth phase, day 0 to day 3 , a constant cell growth rate ( $t_{d}=70$ hours) was obtained until day 9 (see Table 4 ). The growth rate obtained, however, is relatively slow for human MSCs compared to standard 2D culture in

98. 
tissue culture flasks. Therefore, future studies will focus on further optimization of the culture conditions to improve the cell growth rates.

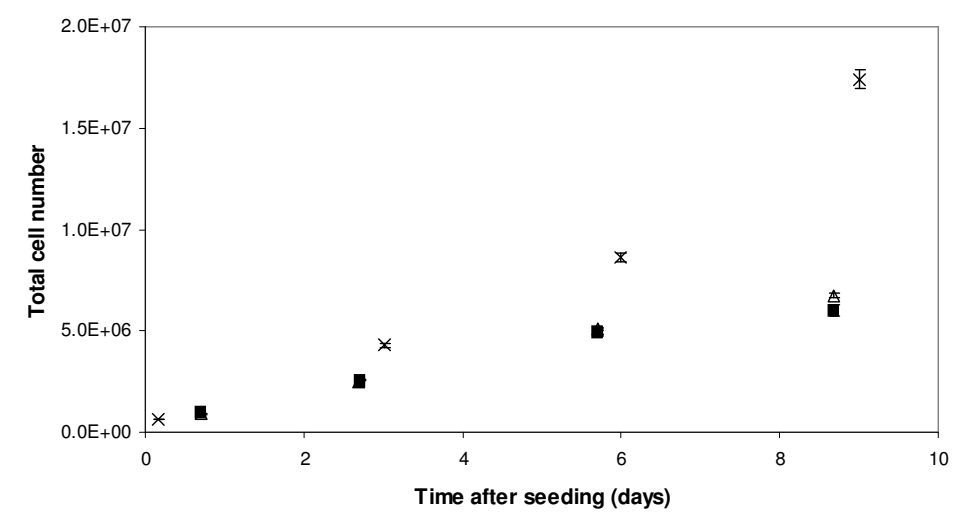

Figure 5. Human MSCs expansion on microcarriers; effect of a combination of both refreshing medium and adding medium with microcarriers.

a=Run 6 (30\% addition of medium with carriers every three days); $\Delta=$ Run 7 (30\% medium refreshment + $30 \%$ addition of medium with carriers every three days); $\mathrm{x}=$ Run 8 (50\% medium refreshment $+30 \%$ addition of medium with carriers every three days). At day 9, no significant difference between run 6 and run 7 was obtained $(p=0.056)$. A significant difference between run 8 and run 6 or run 7 was obtained $(p<0.0001)$ after 9 days of culture.

During expansion in run 8, a more efficient metabolism was used by the cells for cell growth. Lower specific glucose consumption rates $(\mathrm{qGlc})$ were obtained while the yield of lactate from glucose $\left(\mathrm{Y}_{\text {lac/glc }}\right)$ remained constant around 1.5 (Table 4). Glucose is either efficiently metabolised by oxidative phosphorylation (yielding about 30-38 moles of ATP per mole glucose) or inefficiently metabolised by anaerobic glycolysis (yielding 2 moles of ATP and 2 molecules of lactate per mole glucose). The accumulation of lactate up to a $Y_{\text {lac/glc }}$ of 2 is therefore associated with inefficient metabolism of glucose ${ }^{26}$. $Y_{\text {lac/glc }}$ higher than 2 can be explained by the fact that lactate can also be produced from glutamine and other amino acids ${ }^{26}$. The partly efficient glucose metabolism and constant growth observed in run 8 may be explained by the favourable nutrient and metabolite concentrations present in the culture medium during expansion. Adequate glucose levels, the main nutrient for human MSCs growth $^{11}$, were present in the medium during the expansion over 9 days (Figure 6). Even when the cells were growing faster compared to the other conditions, comparable glucose levels were maintained in the medium due to the $50 \%$ medium refreshment. Due to the optimized feeding 
regime, glucose concentrations stabilised around $3 \mathrm{mM}$ during expansion in run 8 . As reported previously ${ }^{11}$, minimal glutamine consumption by the human MSCs was observed (data not shown) for all conditions. Glutamine is therefore not considered to be growth rate limiting.

Table 4. Metabolic and growth parameters obtained for human MSCs cultures using different feeding regimes.

Run $6=30 \%$ addition of medium with carriers; Run $7=30 \%$ medium refreshment $+30 \%$ addition of medium with carriers; Run $8=50 \%$ medium refreshment $+30 \%$ addition of medium with carriers.

\begin{tabular}{l|l|lll}
\hline \multicolumn{1}{l}{ Time periods (days) } & \multicolumn{1}{l}{$\mathbf{0 - 3}$} & $\mathbf{3 - 6}$ & $\mathbf{6 - 9}$ \\
\hline $\mathbf{t}_{\mathbf{d}}(\mathrm{h})$ & Run 6 & 38.3 & 85.9 & 153.9 \\
& Run 7 & 31.7 & 67.7 & 201.5 \\
& Run 8 & 24.5 & 70.5 & 70.8 \\
\hline $\mathbf{q G l c}$ & Run 6 & 9.3 & 7.6 & 6.3 \\
pmol cell $^{-1}$ day $\left.^{-1}\right)$ & Run 7 & 6.4 & 8.4 & 6.6 \\
& Run 8 & 10.8 & 6.2 & 3.9 \\
\hline $\mathbf{Y}_{\text {lac/glc }}$ & Run 6 & 2.8 & 1.6 & 1.4 \\
& Run 7 & 6.5 & 1.9 & 1.7 \\
& Run 8 & 1.6 & 1.6 & 1.4 \\
\hline
\end{tabular}

$\mathrm{qGlc}=$ average specific glucose consumption rate; $\mathrm{Y}_{\text {lac/glc }}=$ yield of lactate from glucose; $\mathrm{t}_{\mathrm{d}}=$ doubling time

By refreshing $50 \%$ of the medium, metabolites, such as lactate and ammonia, are removed from the human MSCs culture. As these metabolites may be growth inhibiting, already at concentrations reach during culture without refreshment ${ }^{11}$, removing half of the metabolites every three days has a significant effect (see Figure 5, $p<0.0001$ ). Figure 6 shows that lactate concentrations increased for the first 6 days and remained constant up to day 9 due to the refreshment. Higher lactate levels for run 8 were measured compared to run 6 and 7, because more cells were present. Nevertheless, the lactate levels reached during expansion in all the conditions were not growth limiting, according to previously reported growth inhibitory concentrations $^{11}$. Ammonia concentrations, which were already inhibiting for the donor tested at $2.0 \mathrm{mM}$, increased for the first three days to $1.3 \mathrm{mM}$ and remained stable up to day 9 . Nevertheless, initial cell growth (day 0-3) is faster compared to the growth between day 3 and day 9. This indicates that there is still an unknown factor that inhibits/limits cell growth.

100. 

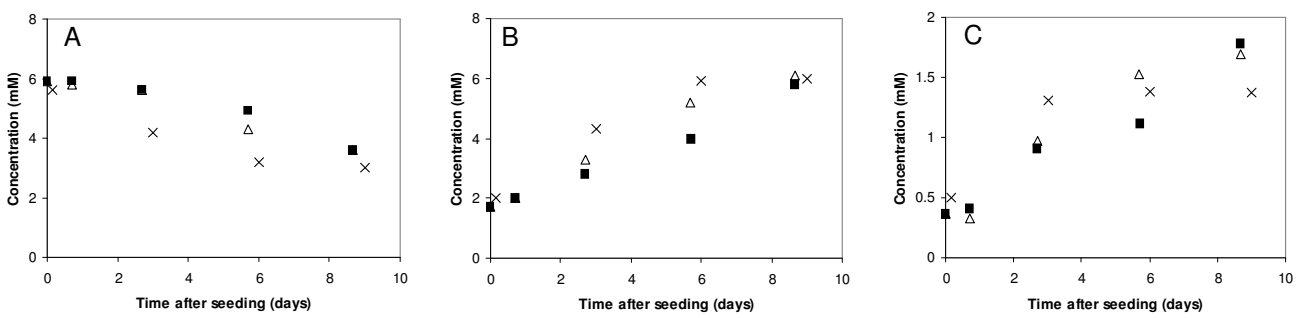

Figure 6. Nutrient and metabolite concentrations during human MSCs expansion using different feeding regimes.

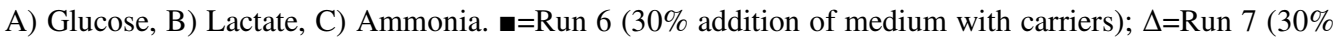
medium refreshment + addition of medium with carriers); $\mathrm{x}=$ Run 8 (50\% medium refreshment + addition of medium with carriers).

Overall, our results indicate that with a combination of 50\% medium refreshment and $30 \%$ medium addition with microcarriers, every three days, an exponential growth of the human MSCs on Cytodex 1 microcarriers is feasible (for the tested time period).

\section{Human MSCs characterization}

To verify if the dynamically expanded human MSCs retained their differentiation capacity and their phenotypic properties, multipotency assays and FACS analyses were performed. Figure 7 shows the results of the multipotency assays. Expanded cells showed the capacity to differentiate towards both tested lineages, adipo- and osteogenic, independent of the culture conditions. These results show that human MSCs did not lose their differentiation potential when expanded dynamically on Cytodex 1 microcarriers.

Besides multipotency assays, the cells were also analysed on their phenotypic properties using flow cytometry (FACS). Based on the marker intensities, the expanded cells were positive for the markers that should be present on human MSCs (the general markers shown in Table 3), for the adhesion markers, and HLA-ABC and $\beta 2$ microglobulin. Lack of expression was observed for the haematopoietic markers and HLA-DR (for markers see Table 3). 

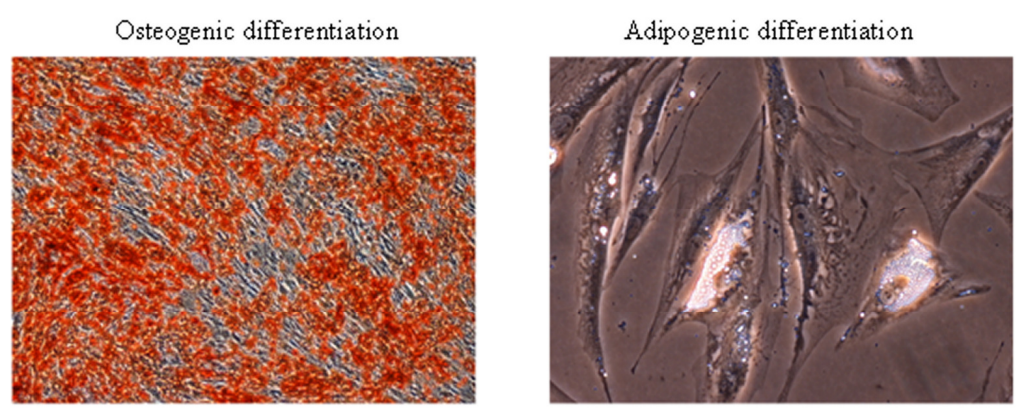

Figure 7. Results multipotency assays for dynamically expanded human MSCs

On Cytodex 1 microcarriers expanded cells, feeding regime 50\% refreshment combined with 30\% addition of medium containing microcarriers every three days (run 8), were harvested and used for stem cell differentiation.

Staining of the osteogenic differentiation shows the $\mathrm{Ca}^{2+}$ of the mineralized extracellular matrix. The adipogenic differentiation shows the formation of fat droplets in the cells. Original magnifications are 40x for osteogenic differentiation and 200x for adipogenic differentiation.

Overall, the results showed that the cells also retained their phenotypical properties after dynamic cultivation on Cytodex 1 microcarriers in spinner flasks. Although, to our best knowledge, this is the first time that significant expansion of human MSCs on Cytodex 1 microcarriers has been shown, further optimization to improve the cell growth rates will be required prior to clinical application. Therefore, we are currently performing experiments using stirred vessel bioreactors in which temperature, $\mathrm{pH}$ and dissolved oxygen concentration $\left(\mathrm{DO}_{2}\right)$ can be monitored and controlled. In this system, besides the feeding regime (including amino acid metabolism analyses) also the $\mathrm{pH}$ and $\mathrm{DO}_{2}$ will be optimized for human MSC expansion.

\section{Conclusions}

This study showed for the first time significant expansion of human MSCs on microcarriers. Cytodex 1 microcarriers were selected as most suitable carrier based on seeding efficiency. Using low serum concentrations $(0 \%-5 \%)$ the seeding efficiency of human MSCs on Cytodex 1 microcarriers was improved in comparison with higher serum concentrations $(10 \%-15 \%)$. For expansion of human MSCs on Cytodex 1 microcarriers, several feeding regimes were evaluated. The highest number of population doublings was obtained by using a combination of $50 \%$ medium refreshment followed by $30 \%$ medium addition containing microcarriers every three days. Exponential cell growth was obtained for at least 9 days after 102. 
seeding since sufficient nutrients (glucose, glutamine and others) were present, metabolite concentrations $\left(\mathrm{NH}_{3}\right.$, lactate and others) were kept below growth inhibitory concentrations and adequate surface area was available for the cells. After dynamic expansion of the Human MSCs, the cells maintained their differentiation potential and their cell surface markers, indicating that human MSCs expansion on Cytodex 1 microcarriers did not alter the phenotypic properties of the cells.

\section{Acknowledgements}

The authors acknowledge Dr. R Licht and Dr. J de Boer, from Institute for Biomedical Technology, University of Twente for their help with human MSCs isolation from human bone marrow aspirates provided by the University Medical Center Utrecht. The work presented in this paper was supported by grant IS044112 from SenterNovem (Agency of Ministry of Economic Affairs), The Netherlands. In addition, the authors gratefully acknowledge the support of the Smart Mix Program of the Netherlands Ministry of Economic Affairs and the Netherlands Ministry of Education, Culture and Science and the authors acknowledge the support from EU-funded FP7 project STEM EXPAND.

\section{References}

1. Pittenger MF, Mackay AM, Beck SC, Jaiswal RK, Douglas R, Mosca JD, Moorman MA, Simonetti DW, Craig S, Marshak DR (1999) Multilineage potential of adult human mesenchymal stem cells. Science 284:143-147

2. Barry FP, Murphy JM (2004) Mesenchymal stem cells: clinical applications and biological characterization. Int J Biochem Cell Biol 36:568-584

3. Spitkovsky D, Hescheler J (2008) Adult mesenchymal stromal stem cells for therapeutic applications. Minim Invasive Ther Allied Technol 17:79-90

4. Caplan AI (1991) Mesenchymal stem cells. J Orthop Res 9:641-650

5. Chen P, Harcum SW (2005) Effects of amino acid additions on ammonium stressed CHO cells. J Biotechnol 117:277-286

6. Martin I, Wendt D, Heberer M (2004) The role of bioreactors in tissue engineering. Trends Biotechnol 22:80-86

7. Portner R, Nagel-Heyer S, Goepfert C, Adamietz P, Meenen NM (2005) Bioreactor design for tissue engineering. J Biosci Bioeng 100:235-245

8. Frauenschuh S, Reichmann E, Ibold Y, Goetz PM, Sittinger M, Ringe J (2007) A microcarrier-based cultivation system for expansion of primary mesenchymal stem cells. Biotechnol Prog 23:187193

9. Schop D, Janssen FW, Borgart E, de Bruijn JD, van Dijkhuizen-Radersma R (2008) Expansion of mesenchymal stem cells using a microcarrier-based cultivation system: growth and metabolism. J Tissue Eng Regen Med 2:126-135

10. Yang Y, Rossi FM, Putnins EE (2007) Ex vivo expansion of rat bone marrow mesenchymal stromal cells on microcarrier beads in spin culture. Biomaterials 28:3110-3120 
11. Schop D, Janssen FW, van Rijn LD, Fernandes H, Bloem RM, de Bruijn JD, van DijkhuizenRadersma R (2009) Growth, metabolism, and growth inhibitors of mesenchymal stem cells. Tissue Eng Part A 15:1877-1886

12. Both SK, van der Muijsenberg AJ, van Blitterswijk CA, de Boer J, de Bruijn JD (2007) A rapid and efficient method for expansion of human mesenchymal stem cells. Tissue Eng 13:3-9

13. de Bruijn JD, van den Brink I, Bovell YP, van Blitterswijk C (1998) Tissue engineering of goat bone: osteogenic potential of goat bone marrow cells. Bioceramics 11:497-500

14. Xiao Y, Peperzak V, van Rijn L, Borst J, de Bruijn JD Dexamethasone treatment during the expansion phase maintains stemness of bone marrow mesenchymal stem cells. J Tissue Eng Regen Med

15. Malda J, van Blitterswijk CA, Grojec M, Martens DE, Tramper J, Riesle J (2003) Expansion of bovine chondrocytes on microcarriers enhances redifferentiation. Tissue Eng 9:939-948

16. Yamada KM, Olden K (1978) Fibronectins--adhesive glycoproteins of cell surface and blood. Nature 275:179-184

17. Forestell SP, Kalogerakis N, Behie LA, Gerson DF (1992) Development of the optimal inoculation conditions for microcarrier cultures. Biotechnol Bioeng 39:305-313

18. Himes VB, Hu WS (1987) Attachment and growth of mammalian cells on microcarriers with different ion exchange capacities. Biotechnol Bioeng 29:1155-1163

19. Nilsson K (1988) Microcarrier cell culture. Biotechnol Genet Eng Rev 6:403-439

20. Koller MR, Papoutsakis ET (1995) Cell adhesion in animal cell culture: physiological and fluidmechanical implications. Bioprocess Technol 20:61-110

21. Sotiropoulou PA, Perez SA, Salagianni M, Baxevanis CN, Papamichail M (2006) Characterization of the optimal culture conditions for clinical scale production of human mesenchymal stem cells. Stem Cells 24:462-471

22. Hassell T, Gleave S, Butler M (1991) Growth inhibition in animal cell culture. The effect of lactate and ammonia. Appl Biochem Biotechnol 30:29-41

23. Papoutsakis ET (1991) Fluid-mechanical damage of animal cells in bioreactors. Trends Biotechnol 9:427-437

24. Hu WS, Giard DJ, Wang DI (1985) Serial propagation of mammalian cells on microcarriers. Biotechnol Bioeng 27:1466-1476

25. Mukhopadhyay A, Mukhopadhyay SN, Talwar GP (1993) Influence of serum proteins on the kinetics of attachment of Vero cells to cytodex microcarriers. J Chem Technol Biotechnol 56:369-374

26. Glacken MW (1988) Catabolic control of mammalian cell culture. Biotechnology (N Y) 6:1041-1050

104. 



\section{Abstract}

Most therapeutic applications of bone marrow stromal cells, or mesenchymal stem cells (MSCs), require expansion of these cells. This paper describes the effect of low and normal oxygen tension on human MSC metabolism, growth and multipotency in both microcarrierbased cell cultures and in tissue flask cultures. Human MSCs were expanded on tissue culture plastic in T-flasks or on Cytodex 1 microcarriers in a stirred vessel bioreactor at 3-4\% $\mathrm{O}_{2}$ (hypoxic) or $20 \% \mathrm{O}_{2}$ (normoxic). The cell number, cell viability, cellular apoptosis, nutrient and metabolite concentrations were measured over time. To obtain more specific knowledge on the metabolism of human MSCs, metabolic inhibitors were used and the oxygen consumption was measured. Oxygen tension had a significant effect on the metabolism of human MSCs. A higher rate of the glycolytic metabolism was obtained when the cells were cultured at a hypoxic atmosphere compared to air atmosphere (normoxic). It was calculated that the cells used for $28-30 \%$ the efficient oxidative phosphorylation pathway and for $70-72 \%$ the inefficient glycolytic pathway to generate energy from glucose. No effect of oxygen tension was shown on human MSC growth rate in tissue culture flasks or on Cytodex 1 microcarriers. We observed more cellular senescence and apoptosis during expansion at $20 \% \mathrm{O}_{2}$. Regarding multipotency, the expansion of human MSCs at a hypoxic atmosphere on microcarriers resulted in a higher potency of chondrogenic differentiation, but did not influence osteogenesis and adipogenesis. Moreover, FACS analysis showed that surface marker expression was not influenced by oxygen tension. 


\section{Introduction}

Mesenchymal stromal cells (MSCs) have the ability to differentiate into bone, cartilage, fat, muscle and other connective tissues ${ }^{1}$. Due to this multipotency, MSCs have a great potential as tissue regenerative source. A major limitation is the lack of reproducible and costeffective methods to isolate and expand sufficient numbers of MSCs, making them useful for clinical applications. Therefore, various types of bioreactors are in development to automate and optimize MSC expansion.

One way to expand MSCs is to grow them on microcarriers, which offers the advantage of a large surface area for monolayer cell growth in a homogenously stirred suspension culture ${ }^{2}$. Several papers have described the possibility of expanding MSCs from different species on microcarriers, such as porcine $\mathrm{MSCs}^{3}$, rat $\mathrm{MSCs}^{4}$, goat $\mathrm{MSCs}^{5}$, and recently for human $\mathrm{MSCs}^{6}$. Our previous study showed that expansion of human MSCs on Cytodex 1 microcarriers is supported when every three days $50 \%$ of the culture medium is refreshed and an extra of $30 \%$ fresh medium with microcarriers is added ${ }^{6}$. However, in none of these experiments, the culture conditions (e.g. pH and dissolved oxygen, DO) were monitored or controlled. If culture conditions are controlled, cell expansion and viability may be improved and optimal growth conditions can be selected and maintained.

The oxygen tension of the culture medium during expansion of MSCs may play an important role, as MSCs reside in vivo within the bone marrow under hypoxic oxygen levels between $4-7 \%^{7}$. When expanding MSCs in vitro on conventional tissue culture plastic, it was shown that their growth can be improved by culturing under hypoxic $\left(5 \% \mathrm{O}_{2}\right)$ conditions ${ }^{8-13}$. Moreover, when expanding the MSCs under hypoxic conditions, the multipotency was better maintained $^{8 ; 14 ; 15}$ and less apoptosis was observed ${ }^{16-19}$. Nevertheless, also contradictory results regarding a positive effect of hypoxia on growth and multipotency are reported ${ }^{20 ; 21}$.

Another important factor for culture optimization is cellular metabolism, which may have an influence on cellular senescence and apoptosis. Depending on the metabolic route used to generate energy from the main $\mathrm{C}$-source glucose, i.e. the glycolysis or the oxidative phosphorylation, the cells may be harmed on DNA level which can induce cellular senescence and apoptosis ${ }^{22 ; 23}$. As indicated by previous research, human MSCs prefer the glycolytic metabolic pathway, yielding lactate, to gain cellular energy (Adenosine-5'-triphosphate, ATP) 6

In this study we have investigated the effect of 3-4\% oxygen (hypoxic) and $20 \% \mathrm{O}_{2}$ oxygen (normoxic) tension on human MSCs growth, metabolism and differentiation potential 108. 
in both microcarrier-based cell cultures and in static cultures on cell culture plastic. Due to the physiological environment in which bone marrow derived MSCs reside, we hypothesize that hypoxic culture conditions allow faster growth of the MSCs in vitro and maintain/improve the differentiation potential compared to in vitro expansion at $20 \% \mathrm{O}_{2}$.

\section{Materials and Methods}

\section{Isolation and monolayer pre-cultivation of human MSCs}

After informed consent, human bone marrow aspirates (approximately $10 \mathrm{ml}$ ) were obtained from the acetabulum of adult donors who were undergoing hip surgery (donor 1; female, age 68 years and donor 2; female, age 38 years). The human MSC population was enriched from the aspirates via adhesion selection as described previously ${ }^{6 ; 24}$. Prior to cell culture on the microcarriers, the MSCs were cultivated in T-flasks up to passage 1 as described previously ${ }^{6}$. Culture medium used consisted of $\alpha$-MEM (Invitrogen, Breda, The Netherlands) supplemented with 15\% FBS (FBS, Cambrex, Verviers, Belgium), $100 \mathrm{U} / \mathrm{ml}$ penicillin (Invitrogen), $100 \mu \mathrm{g} / \mathrm{ml}$ streptomycin (Invitrogen), $2 \mathrm{mM}$ L-glutamine (Invitrogen), $0.2 \mathrm{mM} \mathrm{L-}$ ascorbic acid-2-phosphate (Sigma, Zwijndrecht, The Netherlands), 1 ng/ml bFGF (AbD Serotec, Oxford, UK), and $10 \mathrm{nM}$ dexamethason (Sigma).

\section{Cell culture on microcarriers}

For the expansion of human MSCs on microcarriers, 1 liter round-bottomed stirred vessel bioreactors (Applikon Biotechnology BV, Schiedam, The Netherlands) were used. During the 11 days of cultivation, the following conditions were regulated with an ez-Control (Applikon Biotechnology): temperature, agitation speed, $\mathrm{pH}$ and dissolved oxygen. Temperature was set at $37^{\circ} \mathrm{C}$. The cell-microcarrier suspension was stirred with a marine impeller at 45-90 rpm, depending on the medium level. The dissolved oxygen tension was controlled at 4 or $21 \% \mathrm{O}_{2}$ saturation by adjusting the oxygen fraction (using $\mathrm{N}_{2}$ and/or air gasses) in the headspace of the cultures. The $\mathrm{pH}$ was regulated at 7.2/7.3 using 0.25 $\mathrm{M} \mathrm{NaOH}$ and $\mathrm{CO}_{2}$ gas. Cytodex type 1 microcarriers (GE Healthcare, Diegem, Belgium) were used for expansion of human MSCs at a density of $20 \mathrm{~cm}^{2} / \mathrm{ml}(4.5 \mathrm{~g} / \mathrm{l})$. 
Following detachment from T-flasks using $0.25 \%$ (w/v) trypsin-EDTA, The human MSCs were seeded on the microcarriers at 3000 cells $/ \mathrm{cm}^{2}$ in $325 \mathrm{ml}$ proliferation medium without FBS $^{6}$. The suspension was stirred at $45 \mathrm{rpm}$ for 4 hours. After the seeding period, the medium was refreshed for 50\% and FBS was added to obtain a final concentration of 15\% FBS. During the proliferation phase, the culture was stirred at $60 \mathrm{rpm}$. Every three days, the medium was refreshed for $50 \%$ and, secondly, $30 \%$ fresh medium containing fresh microcarriers at 20 $\mathrm{cm}^{2} / \mathrm{ml}$ was added to the cell culture. Because the medium level increased over time, the stirring rate was increased to maximal $90 \mathrm{rpm}$ to maintain a homogeneous microcarrier suspension. For this study, 4 separate experiments were performed $(n=4)$.

\section{Oxygen tension experiments $-2 D$ and $3 D$}

The effect of a low oxygen tension during expansion on human MSCs was investigated both on the microcarriers in the stirred vessel and on tissue culture plastic in 6-well plates. In the stirred vessels, the cells were seeded on the microcarriers using a dissolved oxygen concentration of $20 \% \mathrm{O}_{2}$. After the seeding period, the oxygen tension was set on $4 \% \mathrm{O}_{2}$ in one vessel and kept between $16-20 \% \mathrm{O}_{2}$ for the other vessel. Samples were taken at least every three days.

In the 6-well plates, the cells were seeded at $1000 \mathrm{cells} / \mathrm{cm}^{2}$ and placed in $\mathrm{CO}_{2}$ controlled incubators with an oxygen tension of $20 \% \mathrm{O}_{2}$. After 2 days, the medium was refreshed and the plates were either incubated with air and $5 \% \mathrm{CO}_{2}\left(\mathrm{CO}_{2}\right.$ incubator) or with $5 \% \mathrm{CO}_{2}$ and $3 \% \mathrm{O}_{2}$ $\left(\mathrm{N}_{2}\right.$ diluted air) for 5 more days. Daily, a 6-wellplate was taken from the incubator and sacrificed for sample analysis.

\section{Sample analysis}

Microcarrier-cell samples $( \pm 10 \mathrm{ml})$ were taken aseptically from the cell cultures in the stirred vessels. Viable cell numbers were measured using the AlamarBlue assay (BioSource, Breda, The Netherlands) and the CellTiter-Glo assay (Promega, Leiden, The Netherlands), which are based on metabolic activity of the cell. For both assays, a donor specific calibration curve was prepared based on cell number in tissue culture plates and their read-out. Cell viability was measured with the CytoTox-Fluor assay, which is based on protease activity and cellular apoptosis was determined using the Caspase-Glo assay (both from Promega). Cellular senescence was assessed by staining for $\beta$-galactosidase activity (Sigma).

110. 
For the cell cultures on tissue culture plastic, he cell number was determined by means of enzymatic harvesting using 0.25 (w/v) trypsin/EDTA (Invitrogen, The Netherlands) and cell counting with a particle counter (Coulter-counter, Beckman Coulter, The Netherlands).

Nutrients and metabolites (glucose, lactate and ammonia) in the medium were analyzed using the VITROS DT60 II chemistry system (Ortho-Clinical Diagnostics, Tilburg, The Netherlands). L-glutamine concentration in the medium samples was determined with the enzymatic Glutamine/Glutamate determination kit (GLN-1, Sigma).

\section{Oxygen consumption and metabolism human MSCs}

To measure the specific oxygen consumption rate per cell, the $\mathrm{BD}^{\mathrm{TM}}$ Oxygen Biosensor System, 96-well, (BD OBS, BD Biosciences, Belgium) was used. A sample from a hypoxic microcarrier culture in a stirred vessel at day 6 after seeding, with a cell concentration of 4500 cells $/ \mathrm{cm}^{2}\left(3.9 * 10^{4}\right.$ cells/well, $312 \mu \mathrm{l}$ per well), was transferred into the sealed BD OBS system. For 330 minutes, every 10 to 30 minutes, the fluorescence (excitation at $485 \mathrm{~nm}$ and emission at $625 \mathrm{~nm}$ ) of the wells was measured to follow oxygen consumption by the cells.

To evaluate which metabolic route the human MSCs use for energy generation, the BD OBS system was used in combination with metabolic inhibitors that completely shut down specific metabolic routes of the cell; sodium azide (Sigma) at $10 \mathrm{mM}$, and 2-deoxy-D-glucose (Fluka, The Netherlands) at $50 \mathrm{mM}$. Sodium azide is an oxidative phosphorylation inhibitor ${ }^{25}$ and 2-deoxy-D-glucose is a glycolytic inhibitor ${ }^{26}$. By calculating the specific oxygen consumption of the cell using a specific metabolic route, the metabolism used by the human MSCs expanded on the microcarriers can be verified. For comparison, the inhibitors were also used during human MSC expansion on 2D tissue culture plastic. Consumption rates and production rates from glucose and lactate were used from 2D cell cultures, as the BD OBS system does not allow sampling for medium analyses due to the sample volumes necessary.

\section{Characterization of the human MSCs after expansion}

Prior to characterization of the expanded human MSCs, the cell-microcarrier complexes were washed twice with PBS. The washed complexes were incubated for maximum 1 hour in 0.015\% Collagenase type II (Worthington Biochem, Lakewood NJ, USA) followed by 5 minutes incubation in $0.25 \% \mathrm{w} / \mathrm{v}$ trypsin/EDTA. Detachment of the cells from the microcarriers was confirmed by light microscopy. The detached cells were separated from the microcarriers using a $100 \mu \mathrm{m}$ filter. 


\section{Multipotency analysis of human MSCs}

Harvested human MSCs (passage 2 to 3 ) expanded at the two different $\mathrm{O}_{2}$ concentrations were examined for their differentiation potential using in vitro osteogenic, adipogenic and chondrogenic differentiation assays. The osteogenic differentiation and staining and adipogenic differentiation were performed as described before ${ }^{6}$. Cells differentiated to adipocytes were qualified by Oil Red O staining of the fat droplets in their cytoplasm. Quantification of the adipocytes was performed by lysing the stained cells using Ipegal (Sigma) and measuring the absorbance of the released Oil Red O at 450nm.

To induce chondrogenic differentiation, $5 * 10^{5}$ human MSCs were centrifuged $(500 \mathrm{~g}$, $3 \mathrm{~min}$ ) and cultured in a pellet for 21 days in chondrogenic medium. Chondrogenic medium was composed of DMEM with the following supplements: $100 \mathrm{U} / \mathrm{ml}$ penicillin, $100 \mu \mathrm{g} / \mathrm{ml}$ streptomycin, $40 \mu \mathrm{g} / \mathrm{ml}$ L-proline (Sigma), $100 \mu \mathrm{g} / \mathrm{ml}$ sodium pyruvate (Sigma), 1x ITS solution (Sigma), and $0.01 \mu \mathrm{g} / \mathrm{ml}$ TGF $\beta 1$ (R\&D Sytems, Abington UK). Chondrogenic matrix composed of glycosaminoglycans (GAG) was qualified by SafraninO (Merck) staining after glycol methacrylate (GMA) imbedding and sectioning of the pellets $(6 \mu \mathrm{m})$. Chondrogenic matrix was quantified by determining the amount of GAG (DMMB-based assay) per DNA (Cyquant DNA Assay, Invitrogen) after Proteinase K (Sigma) digestion of the pellets.

\section{Identification of human MSCs by flow cytometry}

To verify the immunophenotype of the harvested human MSCs, the cells were examined, using flow cytometry, on their antigen expression profile for CD90, CD73, HLA class I, HLA class II, $\beta 2$-microglobulin, CD49, CD13, CD117, CD44, CD55, CD29, CD166, glycophorin A, CD31, CD14, CD3, CD45, CD19, CD71, CD34 and CD105, as described by Prins et al. ${ }^{27}$. In addition, the cells were analyzed on number of Alkaline Phosphatase (ALP) positive cells using the non-conjugated antibody ALP (DSHB, Iowa city, Iowa, USA) which was stained with secondary antibody IgG1-FITC goat anti-mouse antisera (Southern Biotechnology Associates, Inc, Birmingham, USA).

\section{Statistical analysis}

Statistical significance was assessed by analyzing 2 groups of data with the student $t$-test and by analyzing 3 or more groups of data with the ANOVA test: significance was determined at a $p$ value less than 0.05 .

112. 


\section{Results}

\section{Effect of oxygen tension on human MSC growth, viability and stem cell characteristics}

\section{Cell growth}

Cell expansion on tissue culture plastic (2D) with either $20 \% \mathrm{O}_{2}$ or $3-4 \% \mathrm{O}_{2}$ resulted in no significant difference $(p=0.89, \mathrm{n}=3)$, as the cell growth rates in the exponential growth phase were $0.47 \pm 0.050$ day $^{-1}\left(20 \% \mathrm{O}_{2}\right)$ and $0.46 \pm 0.053$ day $^{-1}(3-4 \% \mathrm{O} 2)$ (Figure $\left.1 \mathrm{~A}\right)$. Between day 6 and 7, cells were over confluent causing a drop in cell number at day 7 .

Expansion of human MSCs on Cytodex 1 microcarriers (3D) at $20 \% \mathrm{O}_{2}$ and $3-4 \% \mathrm{O}_{2}$, also resulted in no significant difference in cell growth $(p=0.82)$ (Figure 1B). The exponential growth rate of donor $1(\mathrm{n}=4)$ at $20 \% \mathrm{O}_{2}$ was $0.24 \pm 0.036$ day $^{-1}$ and at $3-4 \% \mathrm{O}_{2} 0.23 \pm 0.051$ day $^{-}$ 1 . For donor $2\left(\mathrm{n}=1\right.$, growth trend not shown) a growth rate of $0.31 \mathrm{day}^{-1}$ was obtained at $20 \%$ $\mathrm{O}_{2}$ and 0.30 day $^{-1}$ at 3-4\% $\mathrm{O}_{2}$. Based on the growth rates, the cells in the 2D system grew twice as fast.
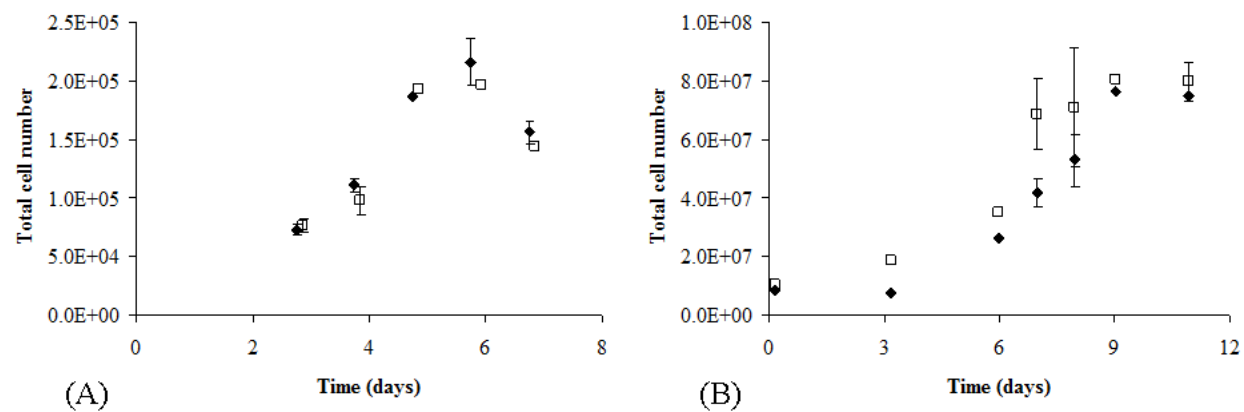

Figure 1. Effects of oxygen tension on human MSCs growth

Tissue culture plastic (A) and Cytodex 1 microcarriers (B). 3-4\% $\mathrm{O}_{2}(\bullet)$ and $20 \% \mathrm{O}_{2}(\square)$ were evaluated. Results for donor 1 are shown in A ( $\mathrm{n}=3$ separate experiments) and B ( $\mathrm{n}=4$ separate experiments). Standard deviations larger then $5 \%$ are indicated using error bars. 


\section{Cell viability and apoptosis}

Figure $2 \mathrm{~A}$ and $2 \mathrm{C}$ show the cell viability and apoptosis during expansion in T-flasks at $20 \% \mathrm{O}_{2}$. Cell viability was maintained around $90 \%$ and apoptosis levels were low up to day 9 after seeding. At confluency, apoptosis was significantly increased $(p<0.0001)$ to a signal of $1.6^{*} 10^{5}$ at day 11. Cell viability and apoptosis levels when cultured on Cytodex 1 microcarriers at $3-4 \%$ or $20 \% \mathrm{O}_{2}$ are shown in Figure $2 \mathrm{~B}$ and $2 \mathrm{D}$. At both oxygen tensions, cell viability was around $62 \%$ for the first 6 days and subsequently maintained at $80 \%$ (except for the $3-4 \% \mathrm{O}_{2}$ culture at day 3 , which was caused by an error in $\mathrm{pH}$ control). Apoptosis levels increased slightly over time (compared to 2D signal).
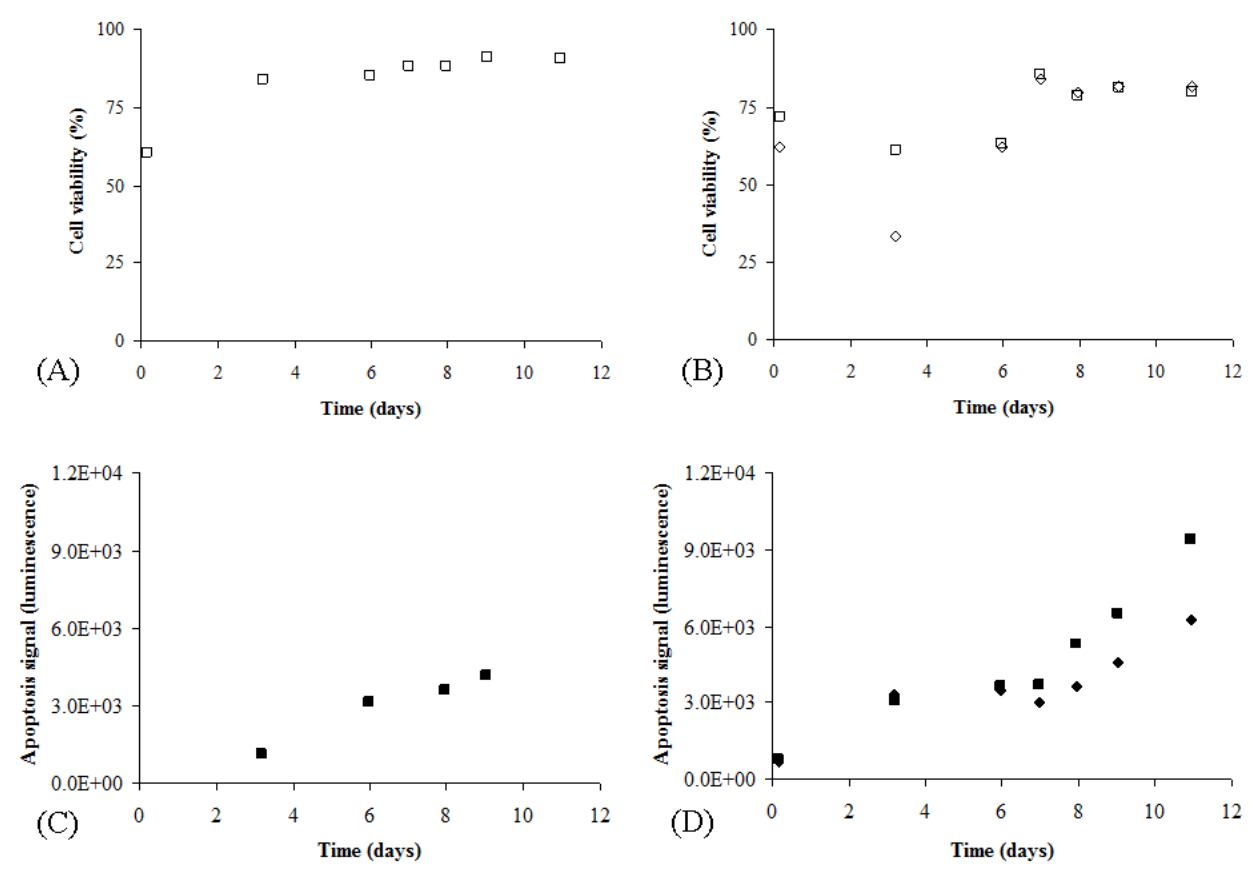

Figure 2. $\quad$ Apoptosis and necrosis signals during expansion of human MSCs

On tissue culture plastic (A, C) and on Cytodex 1 microcarriers (B, D). Cell viability at $20 \% \mathrm{O}_{2}(\square)$ and 3$4 \% \mathrm{O}_{2}(\diamond)$ is shown in the upper two graphs (A, B). Apoptosis signal (in luminescence) at $20 \% \mathrm{O}_{2}(\mathbf{m})$ and $3-4 \% \mathrm{O}_{2}(\bullet)$ is shown in the lower two graphs $(C, D)$. Apoptosis signal in tissue culture plastic culture increased to $1.6 \mathrm{E}+05$ at day 11 (not shown in figure A). Related growth curves for expansion on Cytodex 1 microcarriers are shown in figure $1 \mathrm{~B}$. Related growth curve for $2 \mathrm{D}$ culture is not shown, however, is comparable to the trend shown in Figure 1A.

114. 


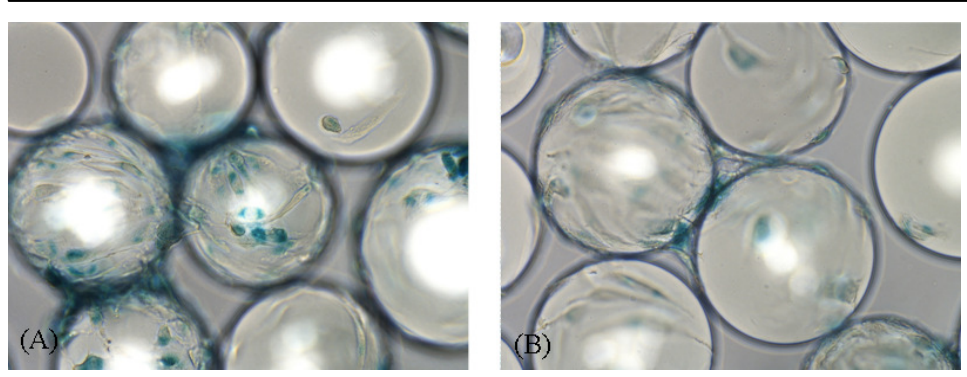

Figure 3. Senescence cell staining of human MSCs expanded on Cytodex 1 microcarriers.

$20 \% \mathrm{O}_{2}(\mathrm{~A})$ and $3-4 \% \mathrm{O}_{2}(\mathrm{~B})$. Blue stained cells are positive for cellular senescence. Original magnification was 200x.

In Figure 3 it is shown that more cells displayed cellular senescence when expanded with $20 \% \mathrm{O}_{2}$ compared to $3-4 \% \mathrm{O}_{2}$ on Cytodex 1 microcarriers. Cells expanded at $20 \% \mathrm{O}_{2}$ in $\mathrm{T}$ flasks also showed a high number of senescence positive cells $( \pm 80 \%)$.

\section{Human MSCs characterization}

Following expansion on tissue culture plastic or Cytodex 1 microcarriers, passage 2 to 3 human MSCs were able to differentiate in vitro towards the adipogenic, osteogenic and chondrogenic lineages. Figure 4 shows representative pictures for all conditions after differentiation, except that fewer GAG matrix was observed for the chondrogenic differentiation of 2D expanded cells and cells expanded at $20 \% \mathrm{O}_{2}$. Visual observations revealed that the oxygen tension did not influence the differentiation rate and quality for adipogenic and osteogenic differentiation.

Quantitatively, it was shown that significantly more GAG/DNA was present after chondrogenic differentiation when the cells were expanded at hypoxic conditions (Table I). This was shown both for 2D and 3D expanded cells. In addition, significantly more adipocytes were formed after 2D expansion irrespective of the oxygen tension. No differences in osteogenic differentiation were seen between $3-4 \% \mathrm{O}_{2}$ and $20 \% \mathrm{O}_{2}$ culture conditions, in both 2D and 3D. Regarding the cell marker ALP which is related to osteogenesis, $100 \%$ positive staining was shown for the human MSCs after 2D expansion with flow cytometry, irrespectively of the oxygen tension (Table II). In contrast, human MSCs expanded on the Cytodex 1 microcarriers were less than $100 \%$ positive for ALP. 


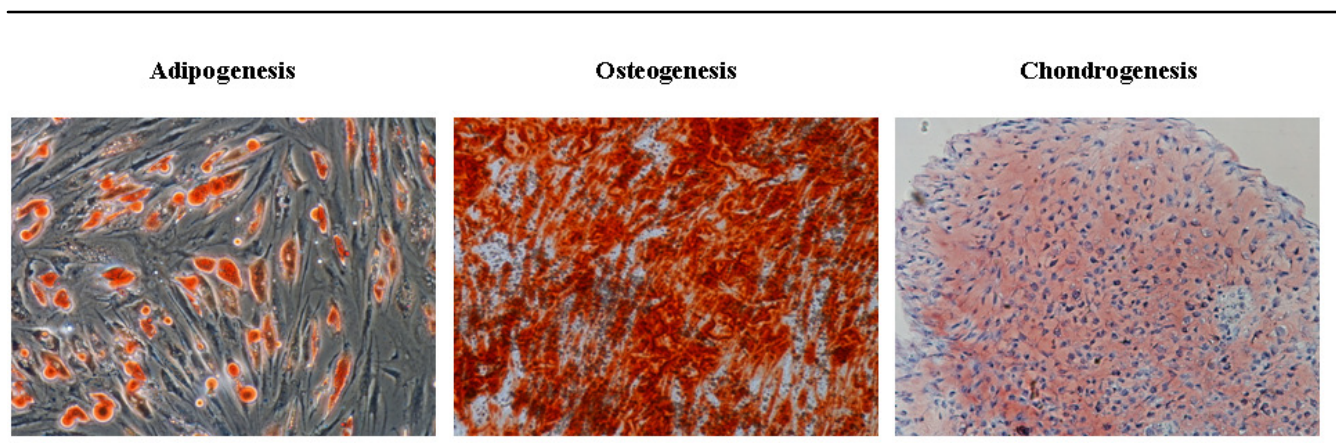

Figure 4. Qualitative results human MSCs differentiation after expansion on microcarriers at hypoxic conditions.

Original magnification was $100 x$.

Table I. Quantitative results multipotency assays after expansion human MSCs

Expanded either with 3-4\% $\mathrm{O}_{2}$ or $20-21 \% \mathrm{O}_{2}$ in T-flasks (2D for 7 days) and on microcarriers (3D for 11 days). Values corrected for negative controls, undifferentiated cells.

\begin{tabular}{|c|c|c|c|c|}
\hline & \multicolumn{2}{|c|}{ 2D expansion } & \multicolumn{2}{|c|}{ 3D expansion } \\
\hline & $3 \% \mathrm{O}_{2}$ & $20 \% \mathrm{O}_{2}$ & $4 \% \mathrm{O}_{2}$ & $21 \% \mathrm{O}_{2}$ \\
\hline Adipogenesis & & & & \\
\hline $\begin{array}{l}\text { In Oil Red O } \\
\text { absorbance per well } \\
\text { Osteogenesis }\end{array}$ & $0.296 \pm 0.021 *$ & $0.372 \pm 0.014^{*}$ & $0.200 \pm 0.004$ & $0.203 \pm 0.009$ \\
\hline $\begin{array}{l}\text { In mg } \mathrm{Ca} 2+ \\
\text { deposition per well }\end{array}$ & $0.45 \pm 0.035$ & $0.43 \pm 0.036$ & $0.41 \pm 0.032$ & $0.43 \pm 0.020$ \\
\hline $\begin{array}{l}\text { Chondrogenesis } \\
\text { In GAG/DNA }\end{array}$ & $3.18 \pm 0.20^{*}$ & $1.88 \pm 0.18^{*}$ & $11.01 \pm 0.94^{*}$ & $4.12 \pm 0.93^{*}$ \\
\hline
\end{tabular}

* Significant difference between the oxygen tensions; $\mathrm{p}<0.0001$

Besides in vitro differentiation of the expanded human MSCs, the cells were characterized on their phenotypic properties using flow cytometry. Based on the marker intensities, the expanded cells were positive for the markers that should be present on human MSCs (CD90, CD73, and CD105), for the adhesion markers (CD49e, CD13, CD117, CD44, CD55, CD29, and CD166), and HLA class I and $\beta 2$ microglobulin. Lack of expression was observed for the haematopoietic markers (GpA, CD31, CD14, CD3, CD45, CD19, CD71, and CD34) and HLA class II as previously described ${ }^{27}$. Down regulation in expression of the following adhesion factors was observed for 3D expanded cells compared to 2D expanded cells; CD13, CD29, CD44, CD49e, CD105. No effect of the oxygen tension on the surface marker expressions was observed.

116. 
Table II. ALP positive cells after expansion human $\mathrm{MSCs}$ with $3-4 \% \mathrm{O}_{2}$ or $20 \% \mathrm{O}_{2}$.

\begin{tabular}{l|c|cc}
\hline & 2D & \multicolumn{2}{c}{ 3D } \\
& Donor 1 & Donor 1 & Donor 2 \\
\hline $\mathbf{3 - 4 \%} \mathbf{O}_{\mathbf{2}}$ & $100 \%$ & $82.8 \%$ & $41.5 \%$ \\
$\mathbf{2 0 \%} \mathbf{O}_{\mathbf{2}}$ & $100 \%$ & $66.4 \%$ & $78.5 \%$ \\
\hline
\end{tabular}

\section{Effect of oxygen tension on metabolism of human MSCs}

Figure $5 \mathrm{~B}$ and $5 \mathrm{D}$ shows that glutamine concentrations in the medium decrease and ammonia concentrations increase over time. The oxygen tension does not influence the glutamine metabolism of the cells. As shown by Figure 5A and 5C, the decrease in glucose and increase in lactate concentrations is more rapid when the human MSCs were expanded on tissue culture plastic at $3-4 \% \mathrm{O}_{2}$ compared to $20 \% \mathrm{O}_{2}$. The specific glucose consumption rate (qGlc) and specific lactate production rate (qLac) differ significantly between the cultures ( $p=0.004$ and $p=0.0004$, respectively) (Table III), whereas the yield of lactate from glucose $\left(\mathrm{Y}_{\text {lac/glc }}\right)$ does not differ significantly $(p=0.24)$.

Expansion of human MSCs on Cytodex 1 microcarriers at $4 \% \quad \mathrm{O}_{2}$ and $20 \% \mathrm{O}_{2}$ gives similar results. The ratio between the $4 \% \mathrm{O}_{2}$ and $20 \% \mathrm{O}_{2}$ conditions in the production and consumption rates for donor 1 (Table III) indicates that $1.54 \pm 0.20$ times more glucose is consumed and $1.32 \pm 0.30$ times more lactate is produced at hypoxia. Donor 2 shows an even larger difference in production (3.27 \pm 0.92 times more) and consumption $(3.73 \pm 1.23$ times more) rates between $4 \% \mathrm{O}_{2}$ and $20 \% \mathrm{O}_{2}$ tensions, but the trend is comparable to donor 1 . Independent of the donor, culture system and the oxygen tension, the yield of lactate from glucose does not differ significantly between the two cultures $(p=0.23)$. 

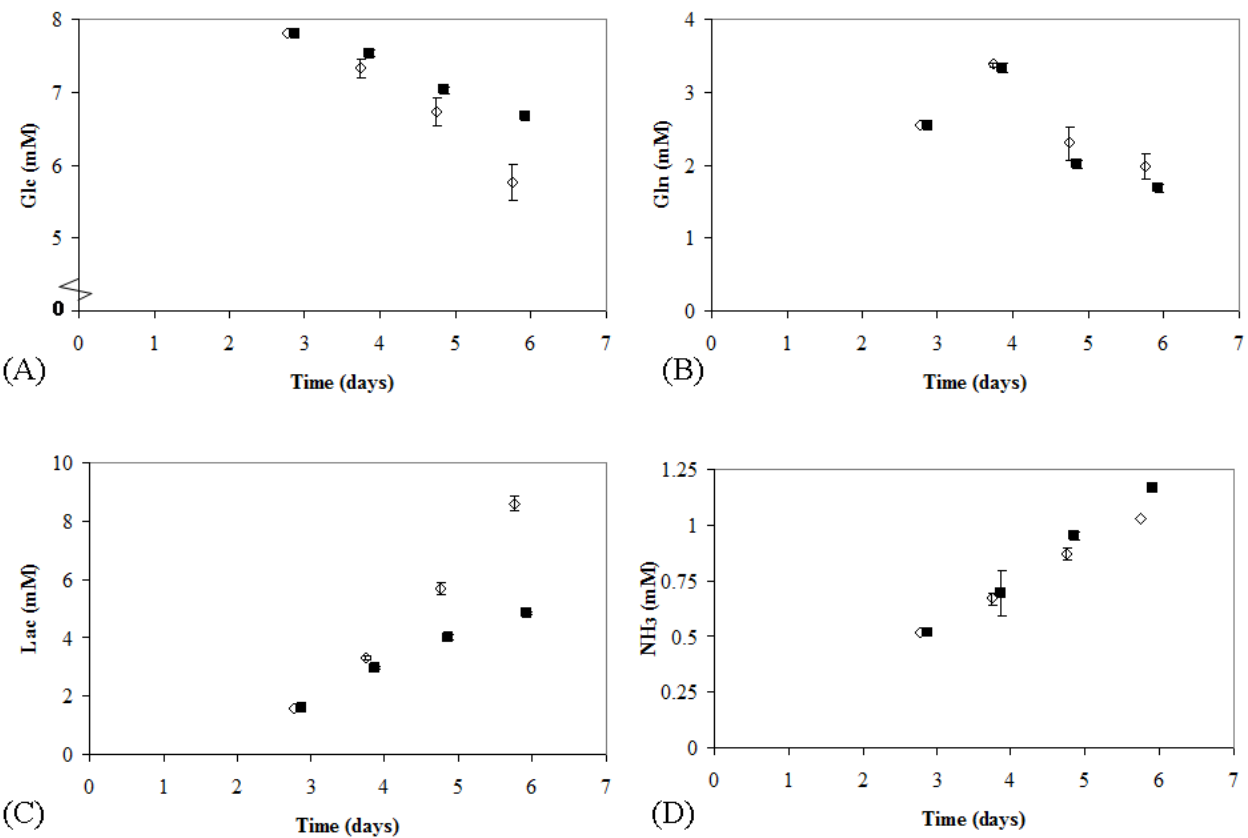

Figure 5. Nutrient and metabolite concentrations during human MSCs expansion in tissue culture flasks.

A) Glucose, B) Glutamine, C) Lactate, D) Ammonia concentrations in the medium when expanded with $3 \% \mathrm{O}_{2}(\diamond)$ and with $20 \% \mathrm{O}_{2}(\mathbf{m})$

Table IV shows the growth rates, the glucose production rates and the yield of lactate from glucose for the cells expanded at both oxygen tensions per metabolic inhibitor. Addition of the two selected metabolic inhibitors resulted in a decrease in growth rate compared to the standard culture without inhibitors. Addition of 2-deoxy-D-glucose, inhibiting the glycolysis and glucose uptake, resulted in a higher growth rate for the human MSCs expanded at $20 \% \mathrm{O}_{2}$ $(p=0.0059)$ compared to the expansion at $3-4 \% \mathrm{O}_{2}$. In contrast, when adding sodium azide, inhibiting the oxidative phosphorylation pathway, cell growth was more inhibited at $20 \% \mathrm{O}_{2}$ $(p=0.025)$. Regarding the glucose metabolism, significantly more lactate was produced when culturing the human MSCs with sodium azide compared to the cells cultures with 2-deoxy-Dglucose $(p<0.0001)$ because the cells were forced to use the glycolytic pathway. Human MSCs expanded without inhibitor showed a comparable qLac to the cells expanded with sodium azide.

118. 
Table III. Metabolic rates human MSCs on tissue culture plastic (2D) and on Cytodex 1 microcarriers (3D) at different oxygen tensions.

The statistical error of the values is below $20 \%$ and mainly caused by the differences between separate cultures. The measurement error per sample is below $5 \%$.

\begin{tabular}{|c|c|c|c|c|c|c|}
\hline \multicolumn{7}{|c|}{$20 \% \mathrm{O}_{2}-3 \mathrm{D}$} \\
\hline $\begin{array}{l}\text { Time } \\
\text { period }\end{array}$ & $\begin{array}{c}\text { Donor 1* } \\
\mathrm{qGlc}^{\Delta}\end{array}$ & $\mathrm{qLac}^{\Delta}$ & Ylac/glc & $\begin{array}{c}\text { Donor } 2^{*} \\
\mathrm{qGlc}^{\Delta}\end{array}$ & $\mathrm{qLac}^{\Delta}$ & Ylac/glc \\
\hline $0-3$ & -7.76 & 27.33 & 3.59 & -4.36 & 14.18 & 3.25 \\
\hline $3-6$ & -8.56 & 16.26 & 1.94 & -7.39 & 10.11 & 1.37 \\
\hline $6-9$ & -8.70 & 16.34 & 1.82 & -3.61 & 5.87 & 1.63 \\
\hline \multicolumn{7}{|c|}{$3-4 \% O_{2}-3 D$} \\
\hline $\begin{array}{l}\text { Time } \\
\text { period }\end{array}$ & $\begin{array}{c}\text { Donor 1* } \\
\mathrm{qGlc}^{*}\end{array}$ & $\mathrm{qLac}^{\Delta}$ & Ylac/glc & $\begin{array}{c}\text { Donor } 2^{*} \\
\mathrm{qGlc}^{\Delta}\end{array}$ & $\mathrm{qLac}^{\Delta}$ & Ylac/glc \\
\hline $0-3$ & -14.40 & 24.37 & 1.86 & -23.19 & 32.68 & 1.41 \\
\hline $3-6$ & -12.78 & 23.15 & 1.80 & -16.91 & 30.11 & 1.78 \\
\hline $6-9$ & -11.19 & 19.94 & 1.74 & -13.06 & 26.53 & 1.92 \\
\hline \multicolumn{7}{|c|}{$20 \% \mathrm{O}_{2}-2 \mathrm{D}$} \\
\hline $\begin{array}{l}\text { Time } \\
\text { period }\end{array}$ & $\begin{array}{c}\text { Donor 1* } \\
\mathrm{qGlc}^{\Delta}\end{array}$ & $\mathrm{qLac}^{\Delta}$ & Ylac/glc & & & \\
\hline $3-6$ & -6.20 & 19.42 & 3.14 & & & \\
\hline \multicolumn{7}{|c|}{$3-4 \% \mathrm{O}_{2}-2 \mathrm{D}$} \\
\hline $\begin{array}{l}\text { Time } \\
\text { period }\end{array}$ & $\begin{array}{c}\text { Donor 1* } \\
\text { qGlc }^{\Delta}\end{array}$ & $\mathrm{qLac}^{\Delta}$ & Ylac/glc & & & \\
\hline $3-6$ & -9.56 & 34.61 & 3.66 & & & \\
\hline
\end{tabular}




\section{Table IV. $\quad$ Effect of metabolic inhibitors on growth and metabolism human MSCs}

Data obtained from 2D cultures in controller incubators except for the $\mathrm{qO}_{2}$, which was determined in the BD OBS system using cells on microcarriers in 3D culture (no medium samples were possible in the BD OBS system, thereby data from $2 \mathrm{D}$ cultures were used). qATP from glucose was calculated using the following equation: qATP $=2 *(\mathrm{P} / \mathrm{O}) * \mathrm{qATP}\left(\mathrm{O}_{2}\right)+\mathrm{qATP}(\mathrm{lac})$, where qATP is the net production rate of ATP and $\mathrm{qATP}\left(\mathrm{O}_{2}\right)$ and qATP(lac) are the net production rates of oxygen and lactate (maximum $\mathrm{Y}_{\text {lac/glc }}$ of 2 was used for calculation). P/O is the ration of ATP generation from electron pair transfer from NADH to oxygen (=2-3 ATP, assumed 2.5 ATP).

\begin{tabular}{|c|c|c|c|c|c|}
\hline \multirow[b]{2}{*}{ O2 tension } & \multicolumn{2}{|c|}{$\begin{array}{c}50 \mathrm{mM} \\
\text { 2-deoxy-D-glucose }\end{array}$} & \multicolumn{2}{|c|}{$\begin{array}{c}10 \mathrm{mM} \\
\text { sodium azide }\end{array}$} & \multirow{2}{*}{$\begin{array}{c}\text { Without } \\
\text { inhibitor } \\
3-4 \%\end{array}$} \\
\hline & $3-4 \%$ & $20 \%$ & $3-4 \%$ & $20 \%$ & \\
\hline$\mu\left(\right.$ day $\left.^{-1}\right)$ & $0.094 *$ & $0.183^{*}$ & $0.246^{*}$ & $0.139 *$ & 0.540 \\
\hline qGIc (pmol cell ${ }^{-1}$ day $\left.^{-1}\right)$ & ND & ND & $-10.09 *$ & $-7.51 *$ & -12.05 \\
\hline qLac (pmol cell ${ }^{-1}$ day $\left.^{-1}\right)$ & 5.44 & 4.68 & 22.70 & 22.54 & 21.15 \\
\hline $\mathbf{Y}_{\text {lac/glc }}$ & ND & ND & 2.25 & 3.00 & 1.76 \\
\hline $\mathrm{qO}_{2}\left(\mathrm{pmol}\right.$ cell $^{-1}$ day $\left.^{-1}\right)$ & -2.40 & ND & 0 & 0 & -1.85 \\
\hline qATP (pmol cell ${ }^{-1}$ day $\left.^{-1}\right)$ & 11.98 & ND & 20.18 & 15.02 & 30.39 \\
\hline
\end{tabular}

*: Significant different between $3-4 \% \mathrm{O}_{2}$ and $20 \% \mathrm{O}_{2}$

ND: not determined

Figure 6 shows the $\mathrm{O}_{2}$ consumption by the human MSCs, which were expanded for 6 days on Cytodex 1 microcarriers, with or without inhibitor to determine the metabolic route used by the cells for energy generation. Table IV shows the specific oxygen consumption rates $\left(\mathrm{qO}_{2}\right)$ for these human MSCs. Maximum $\mathrm{qO}_{2}$ was obtained with 2-deoxy-D-glucose and minimum $\mathrm{qO}_{2}$ with sodium azide. We calculated the net production of ATP (qATP) using the theoretically value of 30 (to maximum 38) ATP molecules per glucose produced using the oxidative phosphorylation compared to only 2 ATP molecules per glucose produced through glycolysis ${ }^{28}$ (Table IV). Based on the net production of ATP from glucose to lactate (21.15 pmol cell ${ }^{-1}$ day $^{-1}$ ) and the total ATP production by the human MSCs $\left(30.39\right.$ pmol cell $^{-1}$ day $\left.^{-1}\right)$, it was calculated that the human MSCs used for $70 \%$ the glycolysis and for $30 \%$ the oxidative phosphorylation to generate energy from glucose when expanded at 3-4\% $\mathrm{O}_{2}$.

120. 


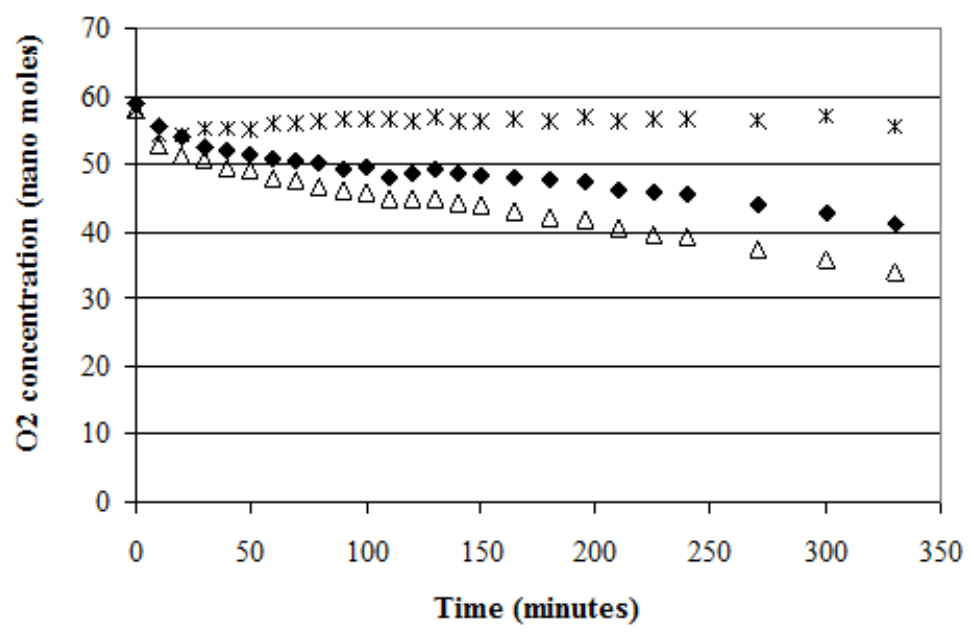

Figure 6. Oxygen consumption human MSCs on Cytodex 1 microcarriers in BD OBS plates

Normal cell culture $(\Delta)$ and the effect of the metabolic inhibitors 2-deoxy-D-glucose $(\diamond)$ and sodium azide $(*)$.

A comparable calculation of the ratio, using qGlc and $\mathrm{qO}_{2}$ and the fact that six molecules $\mathrm{O}_{2}$ are necessary to metabolize 1 molecule glucose, showed that the human MSCs used for $72 \%$ the glycolysis and for $28 \%$ the oxidative phosphorylation;

Oxidative phosphorylation

$$
\begin{aligned}
& =\mathrm{qO} 2 / 6 * 30 \mathrm{ATP}=9.25 \mathrm{ATP} \mathrm{cell}^{-1} \mathrm{day}^{-1}=28 \% \\
& =\mathrm{qGlc}-(\mathrm{qO} 2 / 6) * 2 \text { ATP }=23.48 \mathrm{ATP}^{\mathrm{A}} \mathrm{cell}^{-1} \mathrm{day}^{-1}=72 \%
\end{aligned}
$$

Glycolysis

Either way, both estimations show that human MSCs have a preference for glycolytic metabolism for energy generation from glucose when expanded at hypoxic conditions.

\section{Discussion and conclusions}

In this study, we have shown that oxygen tension has a significant influence on the metabolism of human MSCs expanded in tissue culture flasks and on Cytodex 1 microcarriers. A higher rate of glycolysis was obtained when the cells were cultured at an oxygen tension of $3-4 \%$ compared to a tension of $20 \% \mathrm{O}_{2}$. It is estimated that the cells used for $28-30 \%$ the oxidative phosphorylation pathway and for $70-72 \%$ the glycolytic pathway to generate energy from glucose when expanded at 3-4\% $\mathrm{O}_{2}$. No effect of the oxygen tension was observed on the human MSCs growth rate in tissue culture flasks and on Cytodex 1 microcarriers. However, 
more senescence and apoptosis was observed for the cells expanded at 20-21\% $\mathrm{O}_{2}$. Regarding stem cell characteristics, no influence of the oxygen tension was observed, except that more chondrogenic matrix was obtained during chondrogenic differentiation after expansion in a hypoxic atmosphere.

\section{Effect of oxygen tension on cell growth and metabolism}

In contrast to results of other groups ${ }^{8 ; 14 ; 21 ; 29}$, no effect of oxygen tension on the human MSCs growth rate was observed in our study. For example, the group of D'Ippolito ${ }^{14}$ showed that human MSCs from bone marrow grew twice as fast at hypoxic $\left(3 \% \mathrm{O}_{2}\right)$ compared to $20 \%$ $\mathrm{O}_{2}$. However, the isolated subpopulation could have been another subpopulation than studied in our experiment because the cells were isolated from the biopsy using fibronectin-coated dishes, whereas we isolated the cells directly on tissue culture plastic. Another study by Grayson et al.

${ }^{8}$ showed faster expansion of human MSCs at hypoxic atmospheres $\left(2 \% \mathrm{O}_{2}\right)$. Nevertheless, the effect of the oxygen tension was only visible at the end of the cultures (>day 7 after seeding). This may indicate that the cells proliferate longer at hypoxia, which is also observed in our cultures based on cell viability. Despite the fact that Wang et al. ${ }^{21}$ used another cell type, human adipose-derived populations, they observed no positive effect of hypoxia on proliferation, like in our study. These contradictory results described in literature show that different experimental steps, such as MSCs isolation, may influence the results.

The viability status of the expanded cells showed that the cells were more viable when expanded on tissue culture plastic in a static culture compared to expansion on Cytodex 1 microcarriers in a stirred culture. Initially, apoptosis levels were comparable between the culture on tissue culture plastic and on Cytodex 1 microcarriers, which may indicate that cell death in $3 \mathrm{D}$ cultures is mainly due to necrosis, i.e. cell death induced by external factors ${ }^{30}$. Necrosis may be caused by the shear in the bioreactor system due to stirring of the culture ${ }^{30}$ which is absent in the $2 \mathrm{D}$ cultures. This may also explain why human MSCs grew twice as fast in the $2 \mathrm{D}$ system compared to the cells in the bioreactor system (based on obtained growth rates).

With regard to the effect of oxygen tension on the apoptosis, levels increased faster for the culture with $20 \% \mathrm{O}_{2}$. Moreover, more cellular senescence was observed for the cells expanded with $20 \% \mathrm{O}_{2}$. It has been described that when cells use cellular metabolism in the mitochondria, i.e. the oxidative phosphorylation of glucose, at high oxygen tension, Reactive Oxygen Species (ROS) are formed which can cause cellular senescence ${ }^{23}$. DNA damage due 
to ROS can initiate the apoptotic pathway ${ }^{31}$. Therefore, if the cellular metabolism is changed by the oxygen tension, it may affect the cellular senescence and apoptosis. In our experiments, oxygen tension affected the cell metabolism to a large extent. Human MSCs consumed more glucose when expanded with $3-4 \% \mathrm{O}_{2}$ compared to $20 \% \mathrm{O}_{2}$ to obtain sufficient ATP for cell growth and maintenance, both in 2D and 3D expansion systems. Apparently, the human MSCs are induced to gain their energy via the inefficient glycolysis upon hypoxia, most probably via the activation of the transcriptional hypoxia-inducible complex-1 (HIF-1) ${ }^{32 ;} 33$. An enhanced glycolysis by the cells can diminish the effect of oxidative stress by ROS ${ }^{22}$ and can possibly explain why fewer human MSCs were in senescence and apoptosis at the hypoxic atmosphere compared to the standard used atmosphere ${ }^{31}$. To verify this, future studies should be performed with a HIF inhibitor.

We found that human MSCs expanded in a hypoxic atmosphere mainly gained their energy from glucose by using the glycolysis pathway. Moreover, by evaluating growth, qGlc, qLac, and qO2 for the human MSCs cultures with or without inhibition with 2-deoxy-Dglucose or sodium azide, the same conclusion can be drawn. As the metabolism for the non inhibited cell culture is almost comparable to the cell culture inhibited by sodium azide, it can be concluded that the human MSCs are preferably glycolytic to gain cellular energy for growth and maintenance. These results confirm observations in our previous studies with human MSCs ${ }^{6 ; 34}$.

\section{Effect of oxygen tension on stem cell characteristics}

The enhanced chondrogenic differentiation after expansion at hypoxic conditions may be due to the fact that the hypoxic conditions mimics the natural habitat in chondrogenic tissue ${ }^{35}$, stimulating chondrogenic differentiation afterwards. Wang et al. ${ }^{21}$ also found an enhanced chondrogenic phenotype under $5 \% \mathrm{O}_{2}$ for human adipose-derived populations, whereas contradictory results were described for e.g. murine-adipose derived MSCs, which showed reduced chondrogenesis at $2 \% \mathrm{O}_{2}$ compared to $20 \% \mathrm{O}_{2}{ }^{20}$. However, the contradictory results were obtained with cells from another species, which can have a significant effect on the results ${ }^{34}$.

Regarding adipogenesis, more adipocytes were formed when the cells were expanded with $20 \% \mathrm{O}_{2}$, which was also observed by Csete and co-workers ${ }^{36}$. However, when expanding the cells on the microcarriers, no difference was observed in adipocyte differentiation between the two oxygen tensions. The difference between 2D and 3D in adipogenesis may be explained by 
the fact that the cells are expanded on different surfaces ${ }^{37 ; 38}$ and under different shear stresses ${ }^{39 ; 40}$. In addition, the expansion time may also be of influence, as the cells were expanded for 7 days on tissue culture plastic and for 11 days on Cytodex 1 microcarriers.

Regarding osteogenesis, no differences between the oxygen tensions were obtained for both $2 \mathrm{D}$ and 3D expansion of the human MSCs. Fehrer et al. ${ }^{41}$ also showed that there was no difference in osteogenic differentiation when the human MSCs were expanded at hypoxia or $20 \% \mathrm{O}_{2}$. However, also contradictory results are described in literature regarding osteogenic differentiation. For example, Lennon et al. ${ }^{10}$ found that primary rate MSCs enhanced osteoblast differentiation characteristics when grown at $5 \% \mathrm{O}_{2}$, whereas D'Ippolito et al. ${ }^{14}$ found that osteogenesis was blocked for a subpopulation of human MSCs at $3 \% \mathrm{O}_{2}$. In addition, Malladi and co-workers ${ }^{20}$ found reduction of osteogenesis for murine-adipose derived MSCs at $2 \% \mathrm{O}_{2}$ compared to $20 \% \mathrm{O}_{2}$. However, these results can be explained as well by the usage of cells from different species or that MSCs isolation differed from our methods. Regarding ALP labeling, which is a marker for differentiation towards the osteogenic lineage ${ }^{42}$, no consistent results were obtained between $3-4 \% \mathrm{O}_{2}$ and $20 \% \mathrm{O}_{2}$ between the two donors examined. The donor-to-donor variation regarding ALP expression has been observed before 43. Nevertheless, a significant difference between 2D and 3D expanded cells was observed ( $p=0.012$ ), which may be caused by for example the culture surface difference or the shear difference.

Finally, no effect of oxygen tension was observed on the immunophenotype of the expanded cells either in 2D and 3D. However, down regulation in expression of a set of adhesion factors was observed for 3D expanded cells compared to 2D expanded cells. We speculate that this down regulation can be due to the different culture surfaces of the microcarriers (positively charged cross-linked dextran matrix with DEAE-groups) compared to the uncharged tissue culture treated plastic surface ${ }^{37}$. In addition, to harvest the cells from the microcarriers and to prevent cell aggregates, collagenase was used in combination with trypsin, where only trypsin was used to harvest the cells from the tissue culture plastic. As collagenase cleavage sites ${ }^{44}$ are different from the trypsin cleavage sites ${ }^{45}$, additional attachment proteins may be dissociate by the collagenase enzyme.

In conclusion, we observed a significant effect by the oxygen tension on the metabolism of human MSCs, as a higher rate of the glycolytic metabolism was used at 3-4 \% $\mathrm{O}_{2}$. No effect of oxygen tension was shown on human MSC growth rate in tissue culture flasks or on Cytodex 1 microcarriers, which was not expected as described in the hypothesis. However, less apoptosis and cellular senescence was obtained at 3-4\% $\mathrm{O}_{2}$. Regarding multipotency, the expansion of 124. 
human MSCs at a hypoxic atmosphere on microcarriers resulted in a higher potency of chondrogenic differentiation, but did not influence osteogenesis and adipogenesis.

Since inconsistent data is described in literature, we used defined conditions to study growth, metabolism, differentiation potential and cell surface characteristics of human MSCs. Overall, expanding human MSCs in a hypoxic atmosphere on Cytodex 1 microcarriers is preferred for clinical applications as cell viability is better maintained and cellular senescence and apoptosis is limited. Since human MSCs are mainly glycolytic, the glucose level in the culture medium is an important parameter to maintain cell growth in a bioreactor system.

\section{Acknowledgements}

The authors acknowledge P. Pilot and Dr R.M. Bloem, from Reinier de Graaf Gasthuis dept. Orthopaedic surgery, Delft, The Netherlands, for providing human bone marrow aspirates. The work presented in this paper was supported by grant IS044112 from SenterNovem (Agency of Ministry of Economic Affairs), The Netherlands. In addition, the authors gratefully acknowledge the support of the Smart Mix Program of the Netherlands Ministry of Economic Affairs and the Netherlands Ministry of Education, Culture and Science and the authors acknowledge the support from EU-funded FP7 project STEM EXPAND.

\section{References}

1. Pittenger MF, Mackay AM, Beck SC, Jaiswal RK, Douglas R, Mosca JD, Moorman MA, Simonetti DW, Craig S, Marshak DR (1999) Multilineage potential of adult human mesenchymal stem cells. Science 284:143-147

2. Nilsson K (1988) Microcarrier cell culture. Biotechnol Genet Eng Rev 6:403-439

3. Frauenschuh S, Reichmann E, Ibold Y, Goetz PM, Sittinger M, Ringe J (2007) A microcarrier-based cultivation system for expansion of primary mesenchymal stem cells. Biotechnol Prog 23:187193

4. Yang Y, Rossi FM, Putnins EE (2007) Ex vivo expansion of rat bone marrow mesenchymal stromal cells on microcarrier beads in spin culture. Biomaterials 28:3110-3120

5. Schop D, Janssen FW, Borgart E, de Bruijn JD, van Dijkhuizen-Radersma R (2008) Expansion of mesenchymal stem cells using a microcarrier-based cultivation system: growth and metabolism. J Tissue Eng Regen Med 2:126-135

6. Schop D, van Dijkhuizen-Radersma R, Borgart E, Janssen FW, Rozemuller H, Prins H-J, de Bruijn JD (2009) Expansion of human mesenchymal stromal cells on microcarriers: growth and metabolism. J Tissue Eng Regen Med in press

7. Grant JL, Smith B (1963) Bone marrow gas tensions, bone marrow blood flow, and erythropoiesis in man. Ann Intern Med 58:801-809

8. Grayson WL, Zhao F, Bunnell B, Ma T (2007) Hypoxia enhances proliferation and tissue formation of human mesenchymal stem cells. Biochem Biophys Res Commun 358:948-953 
9. Moussavi-Harami F, Duwayri Y, Martin JA, Buckwalter JA (2004) Oxygen effects on senescence in chondrocytes and mesenchymal stem cells: consequences for tissue engineering. Iowa Orthop J 24:15-20

10. Lennon DP, Edmison JM, Caplan AI (2001) Cultivation of rat marrow-derived mesenchymal stem cells in reduced oxygen tension: effects on in vitro and in vivo osteochondrogenesis. J Cell Physiol 187:345-355

11. Ren H, Cao Y, Zhao Q, Li J, Zhou C, Liao L, Jia M, Cai H, Han ZC, Yang R, Chen G, Zhao RC (2006) Proliferation and differentiation of bone marrow stromal cells under hypoxic conditions. Biochem Biophys Res Commun 347:12-21

12. Krinner A, Zscharnack M, Bader A, Drasdo D, Galle J (2009) Impact of oxygen environment on mesenchymal stem cell expansion and chondrogenic differentiation. Cell Prolif 42:471-484

13. Dellatore SM, Garcia AS, Miller WM (2008) Mimicking stem cell niches to increase stem cell expansion. Curr Opin Biotechnol 19:534-540

14. D'Ippolito G, Diabira S, Howard GA, Roos BA, Schiller PC (2006) Low oxygen tension inhibits osteogenic differentiation and enhances stemness of human MIAMI cells. Bone 39:513-522

15. Ma T, Grayson WL, Frohlich M, Vunjak-Novakovic G (2009) Hypoxia and stem cell-based engineering of mesenchymal tissues. Biotechnol Prog 25:32-42

16. Hung SC, Pochampally RR, Hsu SC, Sanchez C, Chen SC, Spees J, Prockop DJ (2007) Short-term exposure of multipotent stromal cells to low oxygen increases their expression of CX3CR1 and CXCR4 and their engraftment in vivo. PLoS One 2:e416

17. Lee JH, Jung KJ, Kim JW, Kim HJ, Yu BP, Chung HY (2004) Suppression of apoptosis by calorie restriction in aged kidney. Exp Gerontol 39:1361-1368

18. Csete M (2005) Oxygen in the cultivation of stem cells. Ann N Y Acad Sci 1049:1-8

19. Parrinello S, Samper E, Krtolica A, Goldstein J, Melov S, Campisi J (2003) Oxygen sensitivity severely limits the replicative lifespan of murine fibroblasts. Nat Cell Biol 5:741-747

20. Malladi P, Xu Y, Chiou M, Giaccia AJ, Longaker MT (2006) Effect of reduced oxygen tension on chondrogenesis and osteogenesis in adipose-derived mesenchymal cells. Am J Physiol Cell Physiol 290:C1139-1146

21. Wang DW, Fermor B, Gimble JM, Awad HA, Guilak F (2005) Influence of oxygen on the proliferation and metabolism of adipose derived adult stem cells. J Cell Physiol 204:184-191

22. Kondoh H, Lleonart ME, Gil J, Wang J, Degan P, Peters G, Martinez D, Carnero A, Beach D (2005) Glycolytic enzymes can modulate cellular life span. Cancer Res 65:177-185

23. Kondoh H, Lleonart ME, Bernard D, Gil J (2007) Protection from oxidative stress by enhanced glycolysis; a possible mechanism of cellular immortalization. Histol Histopathol 22:85-90

24. de Bruijn JD, van den Brink I, Bovell YP, van Blitterswijk C (1998) Tissue engineering of goat bone: osteogenic potential of goat bone marrow cells. Bioceramics 11:497-500

25. Ishikawa T, Zhu BL, Maeda H (2006) Effect of sodium azide on the metabolic activity of cultured fetal cells. Toxicol Ind Health 22:337-341

26. Barban S, Schulze HO (1961) The effects of 2-deoxyglucose on the growth and metabolism of cultured human cells. J Biol Chem 236:1887-1890

27. Prins HJ, Rozemuller H, Vonk-Griffioen S, Verweij VG, Dhert W, Slaper-Cortenbach I, Martens AC (2009) Bone Forming Capacity of Mesenchymal Stromal Cells when Cultured in the Presence of Human Platelet Lysate as Substitute for Fetal Bovine Serum. Tissue Eng Part A

28. Campbell NA, Reese JB, Mitchell LG (1999) Biology. Benjamin/Cummings, Menlo Park, CA

29. King JA, Miller WM (2007) Bioreactor development for stem cell expansion and controlled differentiation. Curr Opin Chem Biol 11:394-398

30. Al-Rubeai M, Singh RP, Goldman MH, Emery AN (1995) Death mechanisms of animal cells in conditions of intensive agitation. Biotechnol Bioeng 45:463-472

31. Simon HU, Haj-Yehia A, Levi-Schaffer F (2000) Role of reactive oxygen species (ROS) in apoptosis induction. Apoptosis 5:415-418

32. Bartrons R, Caro J (2007) Hypoxia, glucose metabolism and the Warburg's effect. J Bioenerg Biomembr 39:223-229

33. Semenza GL, Roth PH, Fang HM, Wang GL (1994) Transcriptional regulation of genes encoding glycolytic enzymes by hypoxia-inducible factor 1. J Biol Chem 269:23757-23763

126. 
34. Schop D, Janssen FW, van Rijn LD, Fernandes H, Bloem RM, de Bruijn JD, van DijkhuizenRadersma R (2009) Growth, metabolism, and growth inhibitors of mesenchymal stem cells. Tissue Eng Part A 15:1877-1886

35. Lee RB, Urban JP (1997) Evidence for a negative Pasteur effect in articular cartilage. Biochem J 321 ( Pt 1):95-102

36. Csete M, Walikonis J, Slawny N, Wei Y, Korsnes S, Doyle JC, Wold B (2001) Oxygen-mediated regulation of skeletal muscle satellite cell proliferation and adipogenesis in culture. J Cell Physiol 189:189-196

37. Engler AJ, Sen S, Sweeney HL, Discher DE (2006) Matrix elasticity directs stem cell lineage specification. Cell 126:677-689

38. Winer JP, Janmey PA, McCormick ME, Funaki M (2009) Bone marrow-derived human mesenchymal stem cells become quiescent on soft substrates but remain responsive to chemical or mechanical stimuli. Tissue Eng Part A 15:147-154

39. Stolberg S, McCloskey KE (2009) Can shear stress direct stem cell fate? Biotechnol Prog 25:10-19

40. Kreke MR, Huckle WR, Goldstein AS (2005) Fluid flow stimulates expression of osteopontin and bone sialoprotein by bone marrow stromal cells in a temporally dependent manner. Bone 36:1047-1055

41. Fehrer C, Brunauer R, Laschober G, Unterluggauer H, Reitinger S, Kloss F, Gully C, Gassner R, Lepperdinger $\mathrm{G}$ (2007) Reduced oxygen tension attenuates differentiation capacity of human mesenchymal stem cells and prolongs their lifespan. Aging Cell 6:745-757

42. Turksen K, Aubin JE (1991) Positive and negative immunoselection for enrichment of two classes of osteoprogenitor cells. J Cell Biol 114:373-384

43. Siddappa R, Licht R, van Blitterswijk C, de Boer J (2007) Donor variation and loss of multipotency during in vitro expansion of human mesenchymal stem cells for bone tissue engineering. $J$ Orthop Res 25:1029-1041

44. Barrett AJ, Knight CG, Brown MA, Tisljar U (1989) A continuous fluorimetric assay for clostridial collagenase and Pz-peptidase activity. Biochem J 260:259-263

45. Brown WE, Wold F (1973) Alkyl isocyanates as active-site-specific reagents for serine proteases. Reaction properties. Biochemistry 12:828-834 


\title{
Appendix
}

\section{Effect of pH on metabolism and expansion of human mesenchymal stromal cells}

\author{
D Schop, R van Dijkhuizen-Radersma, JD de Bruijn \\ Xpand Biotechnology, Bilthoven, The Netherlands
}

\begin{abstract}
Subsequent to oxygen tension, this study investigated the effect of $\mathrm{pH}$ control on human MSC expansion and metabolism in a microcarrier-based cultivation system. Two stirred vessel bioreactors were used simultaneously, were one reactor was controlled at $\mathrm{pH} 7.2$ and the other was not controlled for the $\mathrm{pH}$. When controlling the $\mathrm{pH}$, cell growth is prolonged, more glucose is consumed per cell and more lactate is produced per cell. Cell metabolism, with regard to glucose and glutamine, is not altered when the $\mathrm{pH}$ decreased in the non-controlled bioreactor culture.
\end{abstract}




\section{Introduction}

In addition to the influence of oxygen tension on metabolism, expansion and differentiation of human mesenchymal stromal cells (MSCs), the effect of $\mathrm{pH}$ on expansion and metabolism of human MSCs was investigated.

As described in the main introduction and discussion of chapter 5, controlling the culture conditions can improve cell expansion and alter cellular metabolism. By controlling the oxygen tension at hypoxia, cell viability was increased, metabolism was changed to mainly glycolysis for energy generation from glucose, and the MSCs maintained their multipotency, with better results for chondrogenic differentiation. In addition to oxygen tension, $\mathrm{pH}$ of the culture medium is another important cell culture parameter. Without controlling the $\mathrm{pH}$, culture medium will get acid due to production of lactate by the cells, with the result that cell growth will cease ${ }^{1}$. Previous spinner flask experiments showed that the carbonate buffer present in culture medium is not strong enough to maintain the $\mathrm{pH}$ in a physiological range for human MSCs culture (data not shown). So, by maintaining the $\mathrm{pH}$ set point, the $\mathrm{pH}$ needs adjustments by addition of base to the medium. In addition, the production of lactate can also increase the osmolality of the medium, which could inhibit cell growth ${ }^{2 ; 3}$. This appendix describes the effect of $\mathrm{pH}$ control on metabolism and growth of human MSCs in a microcarrier-based cell culture.

\section{Material and Methods}

This experiment was performed according to the cell culture on microcarriers described in the materials and methods section in chapter 5. The effect of $\mathrm{pH}$ control at 7.2 on cell growth was verified by performing two stirred vessel runs simultaneously; one with online $\mathrm{pH}$ control (with $0.25 \mathrm{M} \mathrm{NaOH}$ and $\mathrm{CO}_{2}$ gas) and the other one without online $\mathrm{pH}$ control but with $5 \%$ $\mathrm{CO}_{2}$ present in the gas mixture for the carbonate buffer present in the medium. The latter condition resembles experiments performed in spinner flasks. During cell culture, the online $\mathrm{pH}$ was monitored, viable cell numbers were determined using the CellTiter-Glo assay (Promega, Leiden, The Netherlands) and glucose, lactate and ammonia levels were measured with the VITROS DT60 II chemistry system (Ortho-Clinical Diagnostics, Tilburg, The Netherlands). 


\section{Results and Discussion}

\section{Effects of pH on cell growth}

Figure 1 shows the cell growth over time and the online monitored $\mathrm{pH}$ of the culture medium during human MSC expansion on the Cytodex 1 microcarriers.
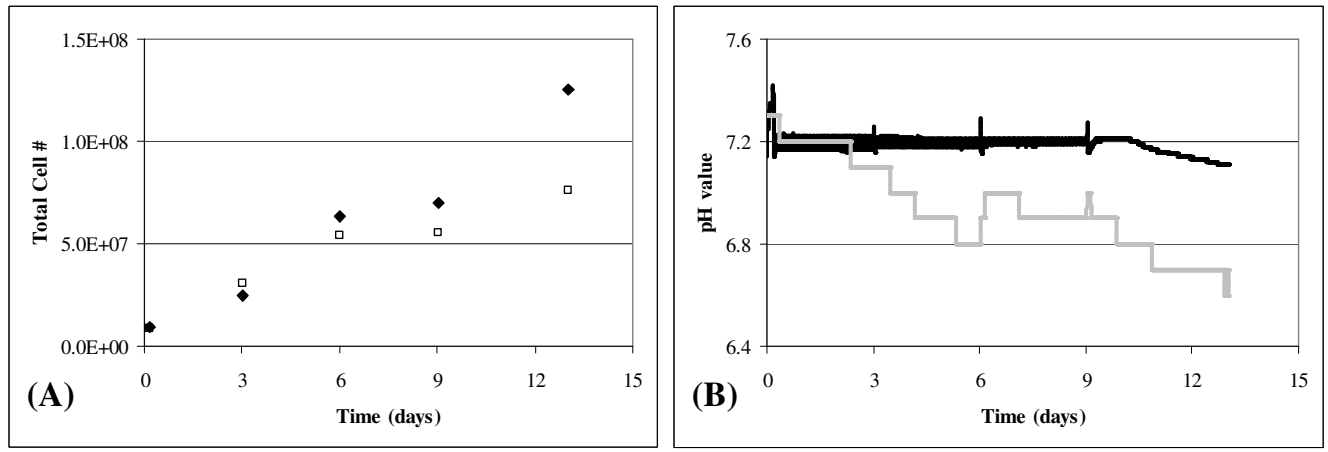

Figure 1. Cell growth and the pH trend during culture

Cell growth (A) and online pH (B) trend during expansion with ( $\downarrow$ and black line) or without ( $\square$ and gray line) online $\mathrm{pH}$ control.

Linear growth was obtained up to day 6 in both the $\mathrm{pH}$ controlled $(\mathrm{pH}$ 7.2) and the non $\mathrm{pH}$ controlled reactor. During cultivation, $\mathrm{pH}$ in the non-controlled reactor dropped to 6.6 at day 13. Most probably, the low $\mathrm{pH}$ inhibited cell growth due to accumulation of lactic acid. At day 13, the $\mathrm{pH}$ controlled reactor contained 1.6x more cells than the non $\mathrm{pH}$ controlled reactor. These results confirm that by controlling the $\mathrm{pH}$ with online monitoring and control, significant better growth was obtained compared to the culture that was controlled with $\mathrm{CO}_{2}$ and the carbonate buffer $(\mathrm{p}<0.0001$ at day 13). This indicates that the buffer capacity of the standard media used for MSCs expansion is too low to maintain a physiological $\mathrm{pH}$ during culture and should be evaluated further in the future.

An explanation why linear cell growth is observed for the controlled culture and no exponential growth could be the osmolality increase due to controlling the $\mathrm{pH}$ with base $\mathrm{e}^{1 ; 3}$. However, this was not measured during the experiment.

130. 


\section{Effects of pH on cell metabolism}

Subsequently to growth, the cellular energy metabolism was monitored by measuring glucose, lactate, and ammonia concentrations in the culture medium. Based on the medium concentrations and cell numbers, it was found that the decreasing $\mathrm{pH}$ of the medium slightly influenced glucose uptake rates and lactate production rate. During the final culture period (day 9 to 13), the qGlc decreased from $3.1 \mathrm{pmol} \mathrm{cell}^{-1} \mathrm{day}^{-1}$ in the controlled culture to 2.4 pmol cell

${ }^{1}$ day $^{-1}$ in the culture with the decreasing $\mathrm{pH}$. The qLac decreased from $7.1 \mathrm{pmol}$ cell $^{-1} \mathrm{day}^{-1}$ in the controlled culture to $4.8 \mathrm{pmol} \mathrm{cell}^{-1} \mathrm{day}^{-1}$ in the culture with the decreasing $\mathrm{pH}$. However, the yield of lactate from glucose remained similar around 2. This indicates that the metabolic route remains the same when the $\mathrm{pH}$ is decreasing, but the rate that the pathway was used for energy generation decreased. The decrease in glucose uptake rates and lactate production rates due to a decreasing $\mathrm{pH}$ were also found by Ozturk and Palsson with hybridoma cells ${ }^{1}$.

Regarding the inhibitor ammonia, the production rates did not differ between the cultures, mainly because glutamine spontaneously decomposed from the culture medium instead that glutamine is consumed by the cells, as was shown before ${ }^{4 ; 5}$.

\section{Conclusion}

$\mathrm{pH}$ control is necessary for the expansion of human MSCs in a microcarrier-based cultivations system, as non controlled cultures result in acidified culture medium that inhibit cell growth. A decrease in $\mathrm{pH}$ results in slower cell growth and a decreased consumption rate of glucose per cell, however, glucose and glutamine metabolism did not change.

\section{References}

1. Ozturk SS, Palsson BO (1991) Growth, metabolic, and antibody production kinetics of hybridoma cell culture: 2. Effects of serum concentration, dissolved oxygen concentration, and medium $\mathrm{pH}$ in a batch reactor. Biotechnol Prog 7:481-494

2. Lao MS, Toth D (1997) Effects of ammonium and lactate on growth and metabolism of a recombinant Chinese hamster ovary cell culture. Biotechnol Prog 13:688-691

3. Omasa T, Higashiyama K, Shioya S, Suga K (1992) Effects of lactate concentration on hybridoma culture in lactate-controlled fed-batch operation. Biotechnol Bioeng 39:556-564

4. Tritsch GL, Moore GE (1962) Spontaneous decomposition of glutamine in cell culture media. Exp Cell Res 28:360-364

5. Schop D, Janssen FW, van Rijn LD, Fernandes H, Bloem RM, de Bruijn JD, van Dijkhuizen-Radersma R (2009) Growth, metabolism, and growth inhibitors of mesenchymal stem cells. Tissue Eng Part A 15:1877-1886 



\section{Amino acid \\ metabolism of human mesenchymal stromal cells during batch}

culture

This chapter is based on a paper to be submitted: Schop D, van Dijkhuizen-Radersma R, Bracke M, Martens DE, de Bruijn JD 



\section{Abstract}

Insight in the amino acid metabolism of multipotent human mesenchymal stromal cells (human MSCs) can improve their expansion, which is a requirement for certain clinical applications. This study focussed on amino acid metabolism during a batch microcarrier based cell culture. During six days of batch culture, a variety of amino acids, essential and nonessential, was consumed by human MSCs, either for energy generation via the Krebs cycle or for protein synthesis. For all amino acids, at least $40 \%$ of the initial amount was still present when growth stopped, making growth inhibition by amino acids not likely. 


\section{Introduction}

Autologous mesenchymal stromal cells (MSCs), also called adult mesenchymal stem cells or progenitor cells, are an interesting source for clinical applications because of their multipotent characteristics. For effective therapy, it is postulated that MSCs need to be expanded in vitro as they are only present in small quantities in the body ${ }^{1}$. Previously reported research showed that MSCs can be expanded on microcarriers in a stirred culture, while maintaining their differentiation capacity ${ }^{2-5}$. However, after a linear/exponential growth phase, MSC growth is inhibited by unknown factors. So far, a maximum of five population doublings has been obtained ${ }^{4}$, while it is reported that MSCs are capable to have 25-40 population doublings in vitro ${ }^{6}$.

To optimize MSCs expansion, the energy metabolism from glucose and glutamine has been investigated previously by our group ${ }^{4 ;} 7$. We showed that glucose is the main energy source for MSCs, which confirms the necessity of glucose in the culture medium for cell expansion. For the energy generation from glucose, the inefficient glycolysis pathway is mainly used by human MSCs, which produces lactate as waste product. It is known that waste products, such as lactate and ammonia, can inhibit cell growth ${ }^{8-10}$ and limit MSC expansion ${ }^{11}$. Inhibiting concentrations for MSC expansion are on average $35 \mathrm{mM}$ for lactate and in the range of 2-4 $\mathrm{mM}$ for ammonia ${ }^{11}$. In addition, also other factors could inhibit cell growth, such as depletion of energy sources, amino acid deficiency, exhaustion or inactivation of growth factors, lipid and trace element deficiency, or external factors such as shear stress ${ }^{12-15}$. This study investigated in more detail if one of these factors, amino acid deficiency, is inhibitory for MSC expansion.

Analysis of free amino acids in human mesenchymal stromal cell (human MSCs) culture media can give valuable information on the metabolism of expanding human MSCs. Analysis of spent culture media could indicate limiting nutrients or metabolites that may inhibit cell growth.

In this paper we report on batch experiments with human MSCs expanded on Cytodex 1 microcarriers in a stirred vessel bioreactor to obtain general insight in the amino acid metabolism and possible amino acid deficiencies that could inhibit cell growth. Analysis over the whole culture period enables a kinetic approach to allow understanding of amino acid uptake and potential strategies to improve media design.

136. 


\section{Materials and Methods}

\section{Isolation and monolayer pre-cultivation of human MSCs}

After informed consent, human bone marrow aspirates (approximately $10 \mathrm{ml}$ ) were obtained from the acetabulum of adult donors undergoing hip surgery (donor 1; female, age 68 years and donor 2; female, age 38 years). The human MSC population was isolated from the aspirates via adhesion selection as described previously ${ }^{4 ;} 16$. In short, whole bone marrow was plated at 500.000 mononucleated cells per $\mathrm{cm}^{2}$. After 6 days, the bone marrow is removed by refreshing the medium and the attached MSCs are expanded. Prior to cell culture on the microcarriers, the isolated cells were cultivated in T-flasks up to passage 1 as described previously ${ }^{4}$. Culture medium used consisted of $\alpha$-MEM (Invitrogen, Breda, The Netherlands) supplemented with 15\% FBS (FBS, Cambrex, Verviers, Belgium), $100 \mathrm{U} / \mathrm{ml}$ penicillin (Invitrogen), $100 \mu \mathrm{g} / \mathrm{ml}$ streptomycin (Invitrogen), $2 \mathrm{mM} \mathrm{L-glutamine} \mathrm{(Invitrogen),} 0.2 \mathrm{mM} \mathrm{L-}$ ascorbic acid-2-phosphate (Sigma, Zwijndrecht, The Netherlands), 1 ng/ml bFGF (AbD Serotec, Oxford, UK), and $10 \mathrm{nM}$ dexamethason (Sigma).

\section{Cell culture on microcarriers}

For the expansion of human MSCs on microcarriers, 1 liter round-bottomed stirred vessel bioreactors (Applikon Biotechnology BV, Schiedam, The Netherlands) were used. During cultivation, the following conditions were regulated with an ez-Control (Applikon

Biotechnology):

- $\quad$ temperature controlled at $37^{\circ} \mathrm{C}$,

- $\quad$ agitation speed controlled at $50 \mathrm{rpm}$ during seeding and at max $70 \mathrm{rpm}$ during expansion using a marine impeller,

- $\quad$ pH regulated at 7.3 using $0.25 \mathrm{M} \mathrm{NaOH}$ and $\mathrm{CO}_{2}$ gas,

- $\quad$ dissolved oxygen concentration (DO) controlled at $4 \% \mathrm{O}_{2}$ saturation $^{7}$ (20\% air saturation) by adjusting the oxygen fraction (using $\mathrm{N}_{2}$ and/or air gasses) blown over the surface of the cultures.

Cytodex type 1 microcarriers (GE Healthcare, Diegem, Belgium) were used at a density of 20 $\mathrm{cm}^{2} / \mathrm{ml}$ (4.5 g/l), for expansion of human MSCs. 
The human MSCs were seeded on the microcarriers at 3000 cells $/ \mathrm{cm}^{2}$ in $400 \mathrm{ml}$ proliferation medium without $\mathrm{FBS}^{4}$. The suspension was stirred at $50 \mathrm{rpm}$ for 4 hours. After the seeding period, the medium was refreshed for $50 \%$ and FBS was added to obtain a final concentration of $15 \%$ FBS. The total working volume was $400 \mathrm{ml}$. During 7 days of cell expansion, the culture was stirred at $70 \mathrm{rpm}$. Samples were taken daily for cell analysis and medium analysis. Because the medium level decreased over time, the stirring rate was decreased stepwise to $60 \mathrm{rpm}$ to maintain a homogeneous microcarrier suspension with comparable shear forces. For this study, two separate experiments were performed $(n=2)$ in the bioreactor system.

\section{Microcarrier sample analysis}

Daily, 10-20 ml microcarrier-cell samples were taken aseptically from the cell cultures in the stirred vessels. Viable cell numbers were measured using the CellTiter-Glo assay (Promega, Leiden, The Netherlands), which is based on metabolic activity of the cell. Cell viability was defined with the CytoTox-Fluor assay, by measuring protease activity and cellular apoptosis was determined using the Caspase-Glo assay (both from Promega).

To visualize the cell load and cell distribution on the microcarriers, cells were stained either with $1 \%$ methylene blue (MB) solution (Sigma) or 1\% 3-(4,5-dimethylthiazol-2-yl)-2,5diphenyltetrazolium bromide (MTT) solution (Merck, Schiphol-Rijk, The Netherlands).

Moreover, nutrients and metabolites (glucose, lactate, ammonia and urea) in the medium were analyzed using the VITROS DT60 II chemistry system (Ortho-Clinical Diagnostics, Tilburg, The Netherlands). Free amino acid concentrations in the medium samples were determined by HPLC chromatography, performed by Ansynth Service B.V. (Roosendaal, The Netherlands). Control medium, medium incubated in the humidified $\mathrm{CO}_{2}$ incubator at $37^{\circ} \mathrm{C}$ without cells, was also analyzed for the same nutrients/metabolites and amino acid, to correct for spontaneous formation and decomposition.

\section{Statistical analysis}

Statistical significance was assessed by analyzing 2 groups of data with the student $t$-test and by analyzing 3 or more groups of data with the ANOVA test: significance was determined at a $p$ value less than 0.05

138. 


\section{Results}

Figure 1 shows the growth curves of the human MSCs for the two duplet experiments in the stirred vessels. Linear growth is obtained between day 1 and day 5, where cells grew with an average specific growth rate of $0.48 \pm 0.007$ day $^{-1}$, which equals a doubling time of $34 \mathrm{hr}$.

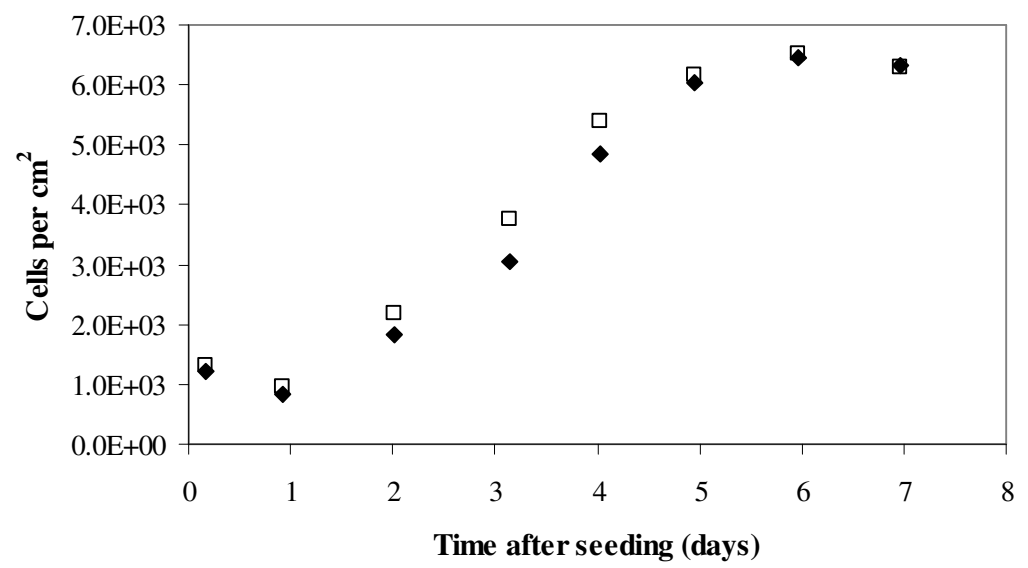

Figure 1. Growth human MSCs in a batch microcarrier culture

The symbols $\square$ and $\diamond$ represents cell numbers per $\mathrm{cm}^{2}$ surface area in the two duplet cultures. A seeding efficiency of $37 \%$ was obtained.

The cell viability of the cultures is shown in Figure 2A. During the Linear growth phase, an average cell viability of $75.3 \pm 5.9 \%$ was obtained. Apoptosis, indicated by the caspase activity in the cell culture, increased during day 1 and day 5 (see Figure 2B), however, the signal per cell stabilized between day 2 and day 6 .

Results from the control medium (data not shown) showed significant spontaneous decomposition of glutamine and arginine. Glutamine spontaneously decomposed with a rate of $0.06 \mathrm{mM}$ per day into ammonia and pyrollidone-carboxilic acid and Arginine decomposed with a rate of $0.01 \mathrm{mM}$ per day into ornithine and ureum. Other amino acids and nutrients measured remained stable in the control medium.

Figures $3 \mathrm{~A}$ and 3B show the concentrations of the main nutrients, glucose and glutamine, and their metabolites, lactate and ammonia in the culture medium over time. During the linear growth period, a $\mathrm{Y}_{\text {lac/glc }}$ of $1.736 \pm 0.014$ was obtained indicating a more anaerobic glucose metabolism towards lactate. A $\mathrm{Y}_{\mathrm{NH} 3 / \mathrm{gln}}$ of $2.108 \pm 0.043$ was obtained, which is caused by spontaneous decomposition of glutamine and the use of amino acids for energy generation. The 
measured medium concentrations of the amino acids which were produced or consumed with the highest rates during culture are shown in Figures 3C and 3D. Over time, none of the amino acids were fully depleted from the culture medium.

The specific consumption and production rates, during the linear growth phase, of the main energy sources, the amino acids, and their metabolites are shown in Figure 4. The rates for glutamine, ammonia, arginine, and ornithine have been corrected for spontaneous decomposition. From this figure it can be observed that glucose is the main C-source for energy metabolism of the cells as a high consumption rate was obtained compared to the consumption rate of glutamine.
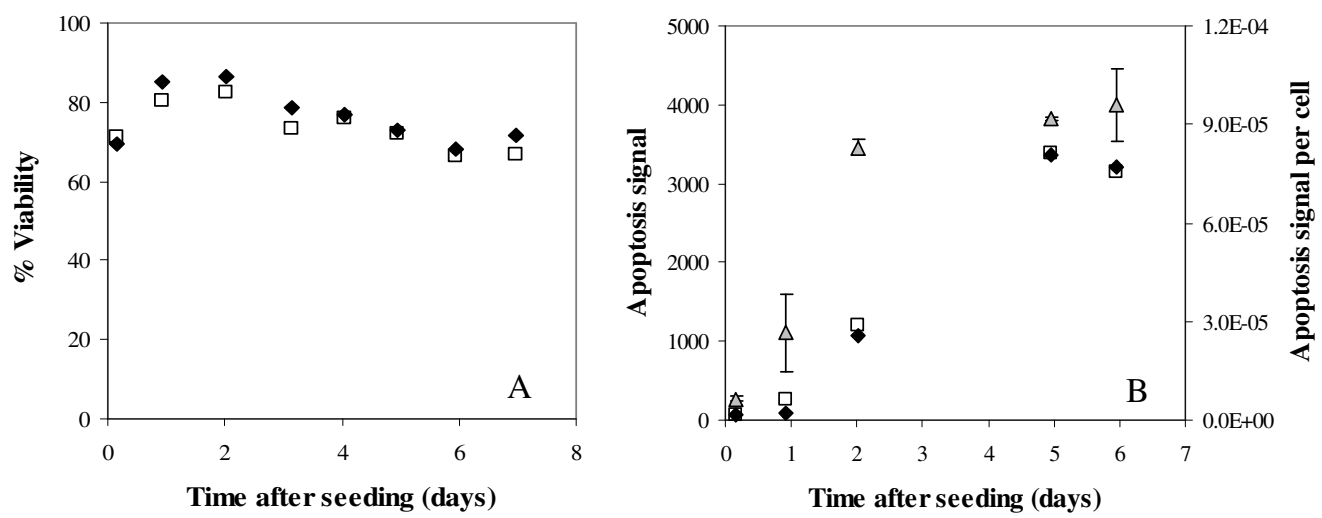

Figure 2. Cell viability and apoptosis signals during the expansion

$2 \mathrm{~A}$ shows cell viability and 2B the apoptosis signal for the two experiments. Symbols $\square$ and $\diamond$ represents the data for the two duplet cultures and symbol $\triangle$ indicates the average apoptosis signal per cell for the two experiments.

140. 

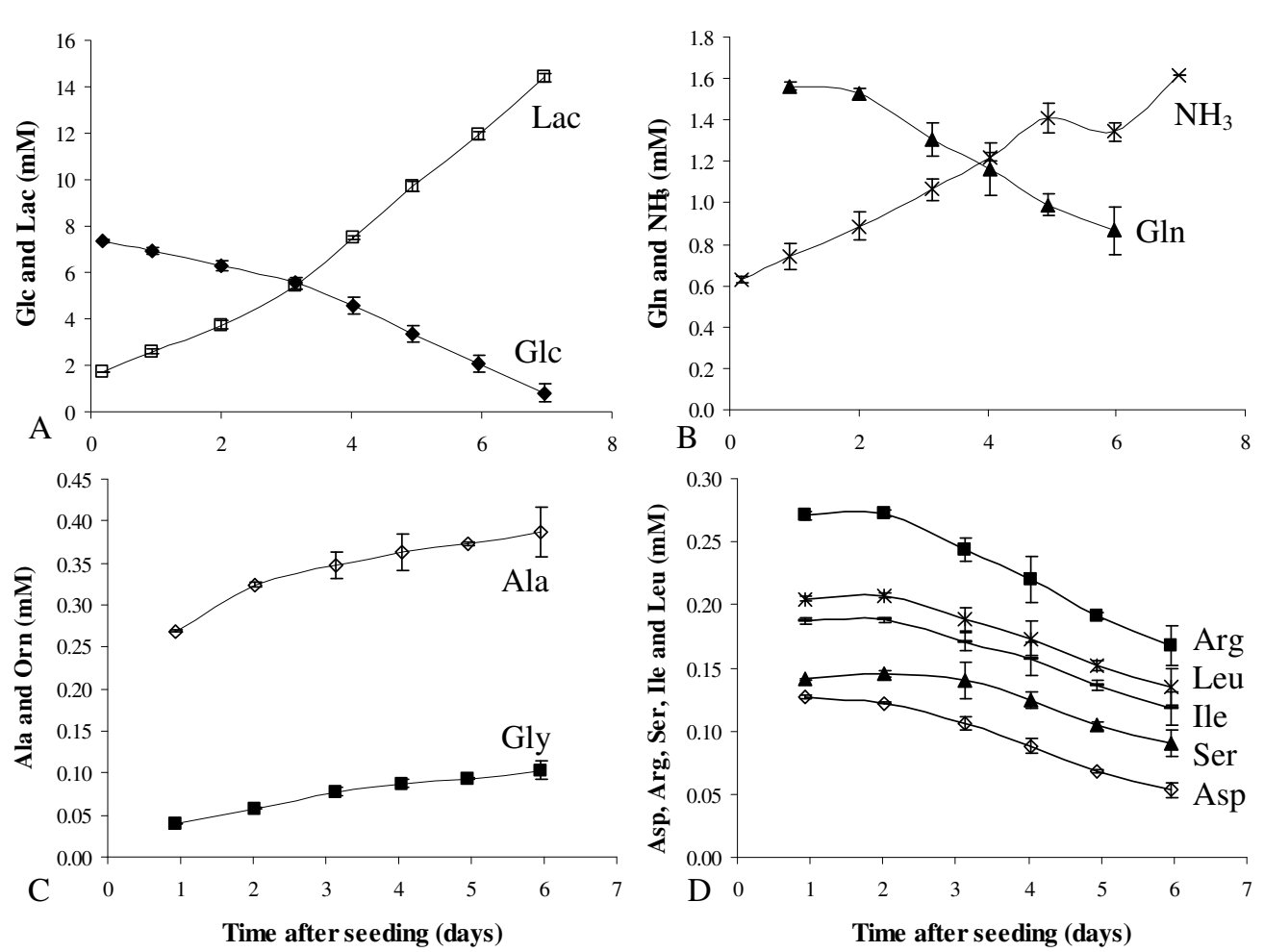

Figure 3. Main nutrient and metabolite and amino acid profiles

The average concentrations in the culture media are shown over time. The concentrations are not corrected for spontaneous decomposition in this figure. Error bars are the standard deviations between the two experiments. The general three-code for the amino acids are used (see appendix). 
Amino acid metabolism human MSCs

Specific production rate $(\mathrm{pmol} / \mathrm{cell} / \mathrm{day})$

Specific production rate (pmol/cell/day)

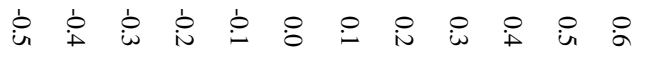

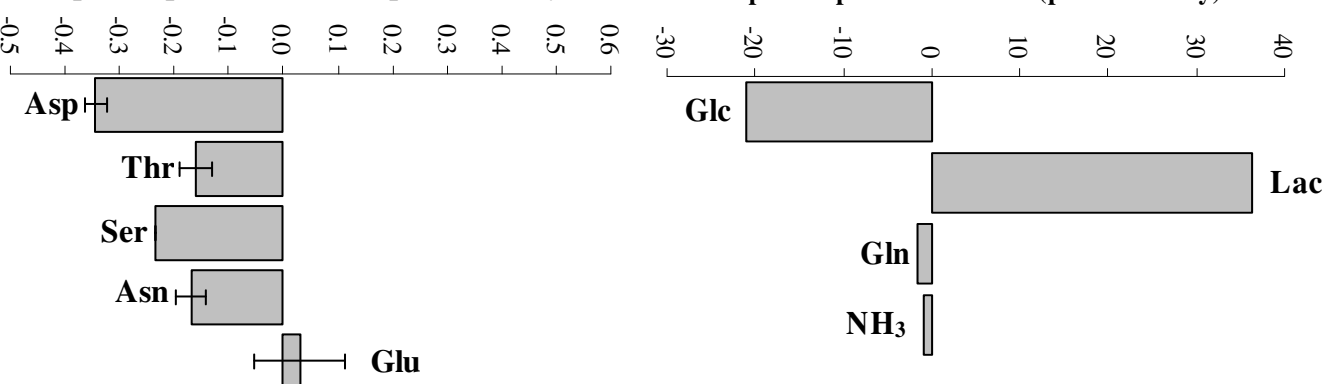

Pror

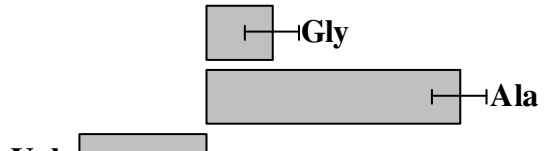

Valम

Cys

Met

Ile

Leu
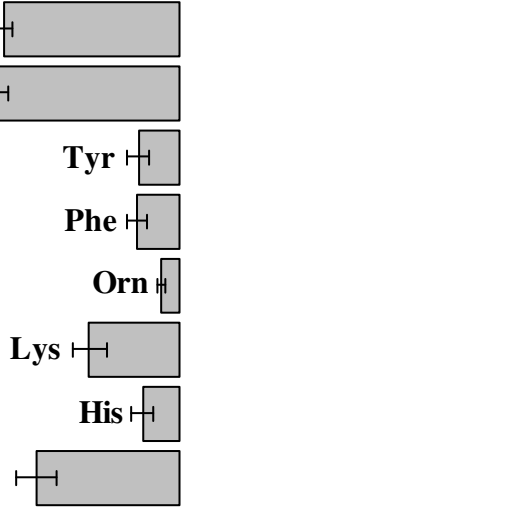

\section{la}

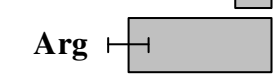

Figure 4. Specific rates for the batch culture of human MSCs

The specific rates are calculated for the linear growth phase between day 1 and day 5 . The specific rates of Orn, Arg, Gln, and $\mathrm{NH}_{3}$ are corrected for spontaneous formation and decomposition in control medium. A negative rate means consumption and a positive rate means production. Error bars are the standard deviations between the two experiments. If no error bar is shown, than this is too small to observe. The general three-code for the amino acids are used (see appendix).

The corrected specific rate for ammonia shows that ammonia is slightly consumed by the cells for protein synthesis. Glycine and alanine are the only two amino acids produced by the MSCs during expansion. Alanine is produced by glutaminolysis ${ }^{17}$, indicating that glutamine was also slightly used for energy generation, as shown in Figure 4.

142. 


\section{Discussion and Conclusions}

In this study we have gained insight in the amino acid metabolism of human MSCs expanded on microcarriers during a batch culture in stirred vessels. For the expansion and maintenance of the cells, glucose and to a lesser extent glutamine are the major nutrients consumed for energy. This is in agreement with other mammalian cell lines ${ }^{18 ;} 19$, but in contradiction with our previous results, where almost no consumption of glutamine was observed. However, in the previous study a correction for the spontaneous decomposition of glutamine of $10 \%$ per day was assumed based on literature ${ }^{20}$ and own experimental data measured with a less precise analyzing method (enzymatic kit GLN-1, Sigma). In this study, glutamine analysis with the HPLC method resulted in a spontaneous decomposition of 5.6\% per day, which is substantially less. This may explain why higher glutamine consumption rates by the cells are calculated for this study.

Amino acids that were consumed with a relatively high rate are isoleucine, leucine, valine, arginine, and aspartate. Besides being used for protein synthesis these amino acids can all be converted to intermediates of the Krebs cycle, and thus for the generation of energy.

Important waste products of nitrogen metabolism are ammonia, urea and alanine. Ammonia is formed in the catabolism of amino acids, while it can be converted to urea in the urea cycle. In addition ammonia can be taken up by glutamate dehydrogenase when it operates in from alfa-ketoglutarate to glutamate. Glutamate can next be transaminated with pyruvate to alfa-ketoglutarate and alanine through alanine aminotransferase ${ }^{17}$. The ammonia present is mostly coming from spontaneous decomposition of glutamine, while the production rate by the cells is very low. Also the production of urea by the cells is very low. The levels of alanine produced in cell culture vary between cell type and medium composition. Ljunggren and Haggstrom showed that by using reduced glucose and glutamine concentrations in substrate limited fed-batch cultures, the production of the by-products, including alanine, is suppressed $^{21}$. Here there is some formation of alanine, which may indicate the use of amino acids for energy generation. However, in order to determine whether amino acids are used for energy generation and in what amount a more extensive study using metabolic flux analysis including measurement of biomass composition and labelling studies should be performed.

In addition to alanine, also glycine was generated during the human MSCs expansion. Glycine, which is formed from serine, is incorporated into proteins and is used as a precursor for DNA and RNA, by the formation of purines ${ }^{24}$. It is generally considered as a waste product from serine metabolism and linked to the central metabolism. For example, Hansen et. al. 
correlated an increase in glycine excretion with a lower glucose consumption rate and lower lactate yield, indicating an increased ATP yield from glutaminolysis ${ }^{25 ; 26}$.

At day 5, the growth of the MSCs stops. At this time point ammonia and lactate concentrations are below their toxic levels $(35.4 \mathrm{mM} \text { for lactate and 2-4 } \mathrm{mM} \mathrm{NH})^{11}$. However, ammonia levels measured at day 7 were close to the inhibitory concentration for the evaluated donor $(2 \mathrm{mM})$. Alanine and glycine, which are in general less toxic then ammonia and lactate, are also not toxic. Furthermore, none of the amino acids is depleted and all concentrations are above $40 \%$ of the initial concentration. Consequently, growth inhibition by an amino acid is also not likely. Finally also glucose was present in sufficient amounts at this point and not limiting. However, after 7 days of culture, the glucose was almost depleted from the culture medium, which could explain that at day 7 the total cell number present in the bioreactor decreased, i.e. cells were dying.

However, whether these factors are the main cause for the ceasing cell growth is not clear. External factors, such as shear, may also play a role, as cell viability is decreasing slowly due to necrosis as apoptosis remained stable. Contact inhibition of the cells as a cause for the stopping of cell growth ${ }^{22}$, seems unlikely since the microcarriers were not fully covered with cells, as shown in Figure 5. Moreover, other medium components that were not studied in this work, such as fatty acids or growth factors, may influence the cell growth ${ }^{15}$. These factors could be studied in future research to optimize the expansion of human MSCs.

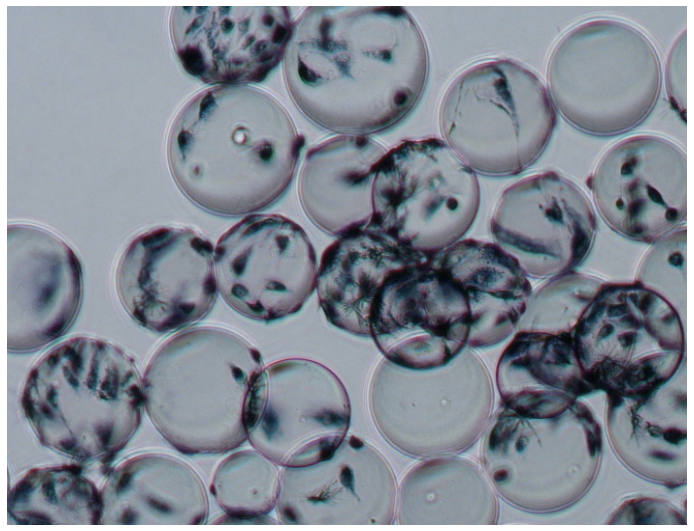

Figure 5. Cell load on the microcarriers after 6 days of culture

Cell were stained with MTT, original magnification 40x

Overall, it was shown that a variety of amino acids, essential and non-essential, were consumed by the human MSCs, either for energy generation via the Krebs cycle or for protein 144. 
synthesis. After 6 days of batch culture, no amino acids were depleted from the culture medium and all concentrations were above $40 \%$ of the initial level. Although amino acids may become limiting before they are depleted, it seems unlikely that amino acids deficiencies were the growth inhibiting factor. Fed-batch or perfusion culture seems a good way to optimise the growth of MSCs. In this way nutrient concentrations can be maintained at constant and optimal levels. By lowering the glutamine concentration also ammonia formation through spontaneous decomposition of glutamine can be minimised. Perfusion culture has the additional advantage that toxic products are washed out ${ }^{3 ; 4}$.

\section{Acknowledgements}

The authors acknowledge P. Pilot and Dr R.M. Bloem, from Reinier de Graaf Gasthuis dept. Orthopaedic surgery, Delft, The Netherlands, for providing human bone marrow aspirates. The work presented in this paper was supported by grant IS044112 from SenterNovem (Agency of Ministry of Economic Affairs), The Netherlands. In addition, the authors gratefully acknowledge the support of the Smart Mix Program of the Netherlands Ministry of Economic Affairs and the Netherlands Ministry of Education, Culture and Science and the authors acknowledge the support from EU-funded FP7 project STEM EXPAND.

\section{Appendix}

\section{Conversions of the amino acid metabolism:}
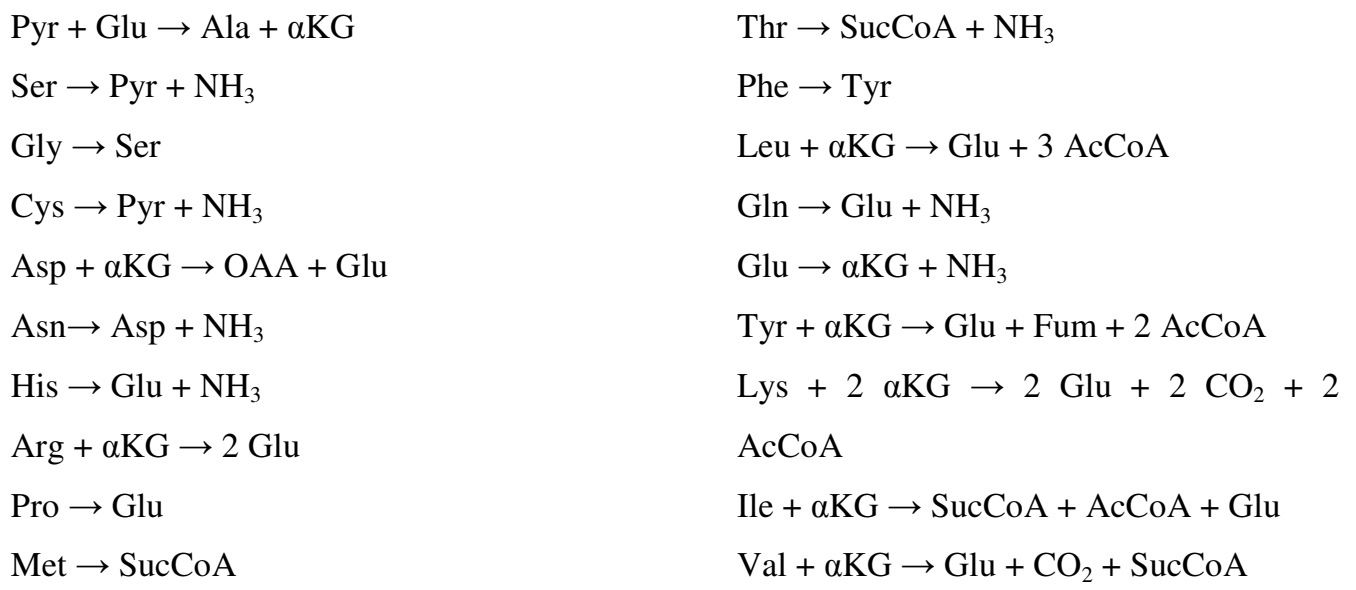


\section{Central metabolic pathways:}

$$
\begin{aligned}
& \mathrm{Glc} \rightarrow 2 \mathrm{Pyr}+\mathrm{H}_{2} \mathrm{O} \\
& \mathrm{Pyr} \rightarrow \mathrm{Lac} \\
& \mathrm{Pyr} \rightarrow \mathrm{AcCoA}+\mathrm{CO}_{2} \\
& \mathrm{AcCoA}+\mathrm{OAA}+\mathrm{H} 2 \mathrm{O} \rightarrow \alpha \mathrm{KG}+\mathrm{CO}_{2}+\mathrm{CoA} \\
& \alpha \mathrm{KG} \rightarrow \mathrm{SucCoA}+\mathrm{CO}_{2} \\
& \mathrm{SucCoA}+\mathrm{H}_{2} \mathrm{O} \rightarrow \mathrm{Fum} \\
& \mathrm{Fum}+\mathrm{H}_{2} \mathrm{O} \rightarrow \mathrm{Mal} \\
& \mathrm{Mal} \rightarrow \mathrm{OAA} \\
& \mathrm{Mal} \rightarrow \mathrm{Pyr}+\mathrm{CO}_{2}
\end{aligned}
$$

\section{Abbreviations:}

$\begin{array}{llll}\text { AcCoA } & \text { Acetyl Coenzyme A } & \text { Ile } & \text { Isoleuline } \\ \alpha \mathrm{KG} & \alpha \text {-ketoglutarate } & \text { Lac } & \text { Lactate } \\ \text { Ala } & \text { Alanine } & \text { Leu } & \text { Leucine } \\ \text { Arg } & \text { Arginine } & \text { Lys } & \text { Lysine } \\ \text { Asn } & \text { Asparagine } & \text { Mal } & \text { Malate } \\ \text { Asp } & \text { Aspartate } & \text { Met } & \text { Methionine } \\ \text { Cys } & \text { Cysteine } & \mathrm{NH}_{3} & \text { Ammonia } \\ \text { CO } & \text { Carbon Dioxide } & \text { OAA } & \text { Oxaloacetate } \\ \text { Fum } & \text { Fumarate } & \text { Phe } & \text { Phenylalanine } \\ \text { Glc } & \text { Glucose } & \text { Pro } & \text { Proline } \\ \text { Gln } & \text { Glutamine } & \text { Pyr } & \text { Pyruvate } \\ \text { Glu } & \text { Glutamate } & \text { Ser } & \text { Serine } \\ \text { Gly } & \text { Glycine } & \text { SucCoA } & \text { Succinate Coenzyme A } \\ \text { His } & \text { Histidine } & \text { Thr } & \text { Threonine }\end{array}$

146. 


\section{References}

1. Aubin JE (1998) Bone stem cells. J Cell Biochem Suppl 30-31:73-82

2. Frauenschuh S, Reichmann E, Ibold Y, Goetz PM, Sittinger M, Ringe J (2007) A microcarrier-based cultivation system for expansion of primary mesenchymal stem cells. Biotechnol Prog 23:187193

3. Schop D, Janssen FW, Borgart E, de Bruijn JD, van Dijkhuizen-Radersma R (2008) Expansion of mesenchymal stem cells using a microcarrier-based cultivation system: growth and metabolism. J Tissue Eng Regen Med 2:126-135

4. Schop D, van Dijkhuizen-Radersma R, Borgart E, Janssen FW, Rozemuller H, Prins H-J, de Bruijn JD (2009) Expansion of human mesenchymal stromal cells on microcarriers: growth and metabolism. J Tissue Eng Regen Med in press

5. Yang Y, Rossi FM, Putnins EE (2007) Ex vivo expansion of rat bone marrow mesenchymal stromal cells on microcarrier beads in spin culture. Biomaterials 28:3110-3120

6. Stenderup K, Justesen J, Clausen C, Kassem M (2003) Aging is associated with decreased maximal life span and accelerated senescence of bone marrow stromal cells. Bone 33:919-926

7. Schop D, Van Dijkhuizen-Radersma R, Brans G, Prins H-J, Rozemuller H, Martens DE, de Bruijn JD (2010) Effect of oxygen tension on metabolism, expansion and differentiation of human mesenchymal stromal cells. Biotechnol Bioeng Submitted

8. Hassell T, Gleave S, Butler M (1991) Growth inhibition in animal cell culture. The effect of lactate and ammonia. Appl Biochem Biotechnol 30:29-41

9. Schneider M, Marison IW, von Stockar U (1996) The importance of ammonia in mammalian cell culture. J Biotechnol 46:161-185

10. Lao MS, Toth D (1997) Effects of ammonium and lactate on growth and metabolism of a recombinant Chinese hamster ovary cell culture. Biotechnol Prog 13:688-691

11. Schop D, Janssen FW, van Rijn LD, Fernandes H, Bloem RM, de Bruijn JD, van DijkhuizenRadersma R (2009) Growth, metabolism, and growth inhibitors of mesenchymal stem cells. Tissue Eng Part A 15:1877-1886

12. Papoutsakis ET (1991) Fluid-mechanical damage of animal cells in bioreactors. Trends Biotechnol 9:427-437

13. Bailey JM, Dunbar LM (1973) Essential fatty acid requirements of cells in tissue culture: a review. Exp Mol Pathol 18:142-161

14. Butler M, Huzel N, Barnabe N (1997) Unsaturated fatty acids enhance cell yields and perturb the energy metabolism of an antibody-secreting hybridoma. Biochem J 322 ( Pt 2):615-623

15. Mizrahi A, Lazar A (1988) Media for cultivation of animal cells: and overview. Cytotechnology 1:199-214

16. de Bruijn JD, van den Brink I, Bovell YP, van Blitterswijk C (1998) Tissue engineering of goat bone: osteogenic potential of goat bone marrow cells. Bioceramics 11:497-500

17. Doverskog M, Ljunggren J, Ohman L, Haggstrom L (1997) Physiology of cultured animal cells. J Biotechnol 59:103-115

18. Genzel Y, Ritter JB, Konig S, Alt R, Reichl U (2005) Substitution of glutamine by pyruvate to reduce ammonia formation and growth inhibition of mammalian cells. Biotechnol Prog 21:58-69

19. Glacken MW (1988) Catabolic control of mammalian cell culture. Biotechnology (N Y) 6:1041-1050

20. Tritsch GL, Moore GE (1962) Spontaneous decomposition of glutamine in cell culture media. Exp Cell Res 28:360-364

21. Ljunggren J, Haggstrom L (1995) Specific growth rate as a parameter for tracing growth-limiting substances in animal cell cultures. J Biotechnol 42:163-175

22. Abercrombie M (1970) Contact inhibition in tissue culture. In Vitro 6:128-142 



\section{General discussion,}

conclusions and future perspectives 

MSCs are a potentially promising source of regenerative cells for several clinical applications, i.e. cell therapy and tissue engineering. For most applications it is postulated that not enough MSCs can be harvested whereby MSCs need to be multiplied to a sufficient number, while maintaining their multipotency and viability prior to use. Nowadays, more and more groups are developing a process to efficiently expand stem cells, derived either from the adult body or embryonic tissue ${ }^{1-12}$. Efficient expansion of these cells in a closed bioreactor system is preferred, as a bioreactor cell culture can be controlled for several parameters, such as $\mathrm{pH}$ and medium composition, which results in reproducible cultures. Moreover, an automated bioreactor system is less susceptible for contaminations compared to expansion in open tissue culture flasks, as no cell passaging may be necessary because of sufficient availability of surface area and no transport of the cells to the patient is required because the bioreactor system can be placed within the hospital area.

To efficiently expand cells, more information about the cells is necessary, such as their growth and metabolism, so enough nutrients will be present, growth inhibiting metabolites can be removed from the culture, and optimal culture conditions, such as oxygen tension, can be defined. But also the surface area for anchorage-dependent cells, such as MSCs, is important ${ }^{13}$. Enough surface area and characteristics of the surface composition are factors that influence cell expansion in a bioreactor system.

In this thesis we have shown the possibility to expand viable and multipotent MSCs, isolated from bone marrow from several species, in a process controlled bioreactor system on microcarriers. By investigating different feeding regimes, based on cellular metabolism, and culture conditions, such as $\mathrm{pH}$ and low dissolved oxygen tension, the expansion and cell quality based on cellular senescence and apoptosis was improved. It was found that by refreshing the medium for $50 \%$ every three days in combination with the addition of $30 \%$ fresh medium containing microcarriers, linear cell growth for the human MSCs was obtained (chapter 4). By controlling the $\mathrm{pH}$ at 7.2 and the dissolved oxygen concentration at $4 \%$ (hypoxia), growth was improved and cell viability was increased (chapter 5). In addition, data about MSCs metabolism is reported and more details about the amino acid metabolism during expansion of the MSCs in a batch culture were obtained. Results showed that the human MSCs are mainly glycolytic regarding their glucose metabolism, almost do not use glutamine for energy generation, and that ammonia is a metabolite produced during the expansion which is already inhibiting at low concentrations (chapter 2).

Using these results, we are a few steps closer to efficient expansion of MSCs for clinical $\underline{\text { applications and more knowledge about the effects of } \mathrm{pH} \text {, oxygen tension, amino acids, feeding }}$ 
regime, and metabolites on MSC growth, metabolism, and differentiation potential is gained. When transferring the obtained data to a stand-alone disposable bioreactor system that is developed according to Good Manufacturing Practices (GMP) guidelines, this system can be used within the hospital to expand patient own stem cells. Moreover, when cell growth within the bioreactor system can be linked to either oxygen consumption (see chapter 5) or glucose consumption (see chapter 4 and chapter 2 shows no significant difference between donors on qGlc), the expansion of these cells can be monitored and controlled automatically. In other words, the system will be a stand-alone expansion device, without the input of a doctor or another person at the hospital facilities that can misunderstand read-outs of the bioreactor system. After efficient expansion in this controlled bioreactor system, the MSCs can be used for a specific application to cure a patient.

\section{Species dependency}

We performed experiments with MSCs from several species to select an appropriate microcarrier and to optimize growth using feeding regimes and cell culture conditions. Chapter 3 and 4 investigated the influence of microcarrier surface characteristics on human MSC attachment and the effect of feeding regimes on cell growth and cell metabolism for goat and human MSCs. Differences in cell morphology on the Cytodex 1 microcarriers, in growth and in metabolism between goat and human MSCs were observed. Regarding growth and metabolism, goat MSCs grew twice as fast compared to human MSCs while using a larger proportion of the oxidative phosphorylation pathway for energy generation. Human MSCs mainly used the glycolytic pathway to consume glucose, which is less efficient. This difference in growth and metabolism was also observed in 2D tissue culture flasks as described in chapter

2. Regarding cell morphology, human MSCs were more elongated on the microcarriers compared to the goat MSCs.

In addition, less bead-to-bead transfer was observed for the human MSCs compared to goat MSCs, which could either be due to the attachment strength of the cells on the microcarriers or due to the lower growth rate of the human MSCs. The attachment strength of the cells could also explain the more elongated cell morphology for the human MSCs. Nevertheless, the fact that the MSCs are capable to jump from one microcarrier to another microcarrier is a unique finding which allows expansion of the cells without passaging the cells using dissociation enzymes. Next to species dependency, several other factors may have triggered differences in the bead-to-bead transfer. For example, the cellular charge, attachment 
molecules expressed on the cells, and FBS concentrations in the medium (10\% for goat MSC medium and $15 \%$ for human MSC medium, which contains attachment proteins such as fibronectin ${ }^{14}$ ), may have influenced the differences.

Overall, it was concluded that direct extrapolation of results obtained using models to the human situation is not always possible. Based on these results we decided to perform future experimental studies using human MSCs only.

\section{Balance between culture conditions and medium compositions}

Another conclusion from the work described in this thesis is that a MSC culture can not only be improved by optimizing the medium composition or by optimizing the culture conditions, such as $\mathrm{pH}$ and DO. A balance between these critical factors is necessary to obtain the most efficient culture process for the expansion of cells, while maintaining the stem cell characteristics.

From chapter 2 and 4, it can be concluded that glucose is the main C-source for human MSCs, so glucose levels should be adequate for energy generation by the cells. From chapter 1, it can be concluded that ammonia production should be kept as low as possible or removed from the medium, as it inhibits cell growth already at low levels (2 mM). Moreover, $\mathrm{pH}$ control and DO control at hypoxic concentrations showed to have an impact on the cell growth and quality. By maintaining the $\mathrm{pH}$ at the optimal level, cell growth was continued (appendix chapter 5). In addition, by expanding the cells at a hypoxic DO of $4 \%$, the mainly glycolytic cells (chapter 5) are more viable and are better able to maintain their multipotency. For clinical application of these expanded cells it is then expected that a hypoxic DO during MSC expansion is preferred.

Nevertheless, cell growth obtained in our defined conditions in the bioreactor cultures maintained linear and not exponential, which is preferred to expand the cells in a short time period. This may be an indication that the cells are still limited or inhibited in their growth by unknown factors. From the results described in chapter 6 , it seems that amino acids are not limiting or inhibiting during batch culture. Nevertheless, other factors, not investigated during this thesis, such as shear stress by agitation ${ }^{15 ; 16}$, osmolality increase due to $\mathrm{pH}$ control and lactate production by the cells ${ }^{17 ; 18}$, fatty acid $^{19 ; 20}$ or growth factor ${ }^{21}$ concentrations, may have an influence on the cell culture quantity and quality. By increasing the agitation rate, more harmful eddies may be formed, but the cell-microcarrier clumps formed during the culture 
could be prevented ${ }^{15}$. Initial experiments, with human MSCs in a stirred vessel, showed that when the agitation rate is increased to a speed close to the theoretical speed at which harmful eddies are formed, faster growth and a more homogeneous cell distribution was obtained. This indicates that there is an optimal mixing speed for the expansion of the human MSCs in a bioreactor system. By performing future experiments focussing on the optimal mixing speed in the bioreactor system, the expansion of the human MSCs may be improved.

Next to culture conditions, such as DO and agitation rate, the medium composition may have a major effect on human MSC growth and metabolism. In chapters 2, 4, 5 and 6, we have shown that the main $\mathrm{C}$-source glucose is used for growth and that glutamine is almost not consumed by the cells for energy generation, but mostly as a protein constituent. This indicates that glutamine concentrations can be decreased in the medium, thereby also decreasing the spontaneous formation of ammonia. Other solutions to obtain an efficient metabolism without high production of the metabolites lactate and ammonia is by replacing the glucose and/or glutamine by another $\mathrm{C}$-source, such as pyruvate. For example, Genzel and co-workers ${ }^{22}$ showed that by replacing glutamine with pyruvate for expansion of several mammalian cell lines, less ammonia and lactate was produced due to a change in metabolism. Results showed that the cells were not inhibited in their growth by the metabolites due to the glutamine substitute. Future studies to optimize the medium composition for the expansion of human MSCs may focus on the replacement of either glucose or glutamine, to diminish ammonia production.

Another medium component that is important for the expansion of human MSCs is serum $^{23 ; 24}$. Serum contains a whole collection of important components for cell growth, such as growth factors, vitamins, proteins (e.g. attachment proteins), and mineral ions ${ }^{25}$. However, most sera are from animal origin. When the expanded stem cells will be used for clinical application, an animal free expansion process is favourable. Because serum is an undefined medium substitute, finding a serum replacement is a real challenge. During the experimental period for thesis, several commercial serum substitutes were examined (CellProtex, CellProsper, LiforCell, Platelet Lysate) either in tissue culture flasks or in a microcarrier culture. None of the tested substitutes resulted in comparable growth of the human MSCs when expanded with serum. Also cell attachment to the microcarriers appeared to depend on the serum in the medium (as described in chapter 4). Initial cell attachment to the microcarriers is based on the charge density of the microcarriers and the cells, but tight cell attachment and spreading is initiated by attachment proteins either present in the serum or produced by the cells $^{13 ; 14 ; 26}$. We performed experiments with serum substitutes (data not shown), where results 154. 
showed no or low cell attachment efficiency on the microcarriers. To find a proper serum substitute for human MSC expansion on Cytodex 1 microcarriers, more additional experiments are required.

Other components in the medium that may influence expansion, which have not yet been investigated, are e.g. fatty acids, vitamins, or components that can trigger stem cell differentiation such as growth factors. Most fatty acid can be produced by the cells themselves and will be used by the cells to store energy, as precursors for other molecules, and as a constituent of cell structures such as cell membranes. However, there are also essential fatty acids which cannot be produced by the cells such as arachidonic acid and linoleic acid ${ }^{27}$. Concentrations present in the cell culture will influence growth and metabolism ${ }^{19 ; 20 ; 28}$. Upon limited availability of the essential fatty acids, growth will cease. This will also be the case for other medium components as vitamins and growth factors. When more information about these components is available for human MSC expansion, growth and metabolism can be optimized to a clinical relevant situation in which the cells remain their stem cell characteristics and are expanded to substantial cell numbers needed for clinical application.

\section{Direct MSCs enrichment from the bone marrow on microcarriers}

In the experiments described in the previous chapters, we used MSCs that were precultured in 2D on tissue culture plastic after adhesion selection from the bone marrow aspirates. For clinical application, it would be ideal to attach the MSCs directly from the biopsy on the microcarriers, followed by expansion of the attached MSCs in the same system. This reduces the number of steps necessary for the whole process, minimizing the risk of errors, contaminations, and time necessary for the whole process. We evaluated several methods; 1) direct seeding the untreated biopsy to the microcarrier suspension, 2) pre-treating the biopsy with red blood cell lysis buffer, gradient centrifugation, RosetteSep ${ }^{\mathrm{TM}}$ (enrichments method of MSCs from bone marrow using antibodies and density centrifugation, from Stem Cell Technologies) MSC enrichment, or filtration, prior to placing the biopsy in a microcarriers suspension. Several problems occurred; 1) Cell yields decreased 2) Cells attached to the microcarriers, but no growth was observed. However, by filtrating the biopsy using a $8 \mu \mathrm{m}$ filter, the MSCs attached and proliferate. Initial results, performed with a porcine bone marrow biopsy shown in the appendix, showed that the enrichment steps on tissue culture plastic can be skipped while maintaining the differentiation potential of the attached and expanded cells on 
the Cytodex 1 microcarriers. As these are preliminary results with another species than human, experiments should be performed using several human bone marrow biopsies to confirm these observations and to compare the cell yield when direct enrichments or indirect enrichment method is used.

\section{Applications of the expanded human MSCs and the challenges}

A critical prerequisite for the successful implementation of a bioreactor system for stem cell expansion is the timely delivery if the expanded cells. The time of expansion before the MSCs can be used for a patient will depend on the application, as different cell numbers may be required. A lot of different applications are investigated nowadays, such as neurological disorders and heart diseases, as described in the introduction of this dissertation. Also different numbers of multipotent stem cells or stem cells which are already triggered to differentiate towards a specific lineage are used for clinical trails. To take cardiac repair as an example, more than 100 clinical trails have already been performed which uses different approaches to deliver stem cells to the patient after a myocardial infarction ${ }^{29 ; 30}$. To give some examples, Ge et. al. administered about 40 million bone marrow cells ${ }^{31}$ and Suarez de Lezo et. al. administered about 900 million ficol separated bone marrow cells ${ }^{32}$. Both observed a positive significant effect by administering these cell fractions to the patient. Another study by Janssens et. al., administered approximately 300 million ficol separated bone marrow cells but did not observe a positive effect ${ }^{33}$.

For most clinical trails using bone marrow cells, either the whole biopsy or the mononucleated fraction was used. However, it is postulated that by administering an enriched fraction of MSCs, better results could be obtained ${ }^{34}$. A small-scale study by Chen et. al. showed the positive effect of administering $6 \mathrm{ml}$ with 800 to 1000 million bone marrow mesenchymal stem cells per $\mathrm{ml}^{35}$. This is a high number of cells and more clinical trails should be performed to find the optimal cell number of MSCs that should be administered to the patient after a myocardial infarction or for another clinical application. The challenge before using the microcarrier-based bioreactor system for clinical application will be to obtain the required cell numbers in time while maintaining viability and multipotency of the cells. Before using the system in clinical trails for several applications, the expansion process needs therefore further improvement.

156. 
Next to the timely delivery of the expanded cells, the costs of the development and production of the bioreactor for stem cell expansion is a crucial factor for the successful implementation. The bioreactor system will have to be designed and developed according to the relevant guidelines and produced under GMP using approved disposable materials. The part of the bioreactor which will be in direct contact with patient material should be disposable to avoid the risk of contamination and expensive validated cleaning procedures. The control system should probably be able to control multiple cultures in parallel to be cost effective. Furthermore this system should be easy to operate, avoid the risk of (human) errors and require general lab facilities (regarding gasses, current etc) to be implemented in the hospital facilities and departments.

\section{In conclusion}

We showed that it is possible to expand human MSCs on Cytodex 1 microcarriers in the stirred vessel bioreactor. Improved expansion of the cells was obtained by taking a closer look to the metabolisms of the cells during multiplication en the control of $\mathrm{pH}$ and $\mathrm{DO}$ in the microcarrier-based bioreactor system. Overall, we have gained scientific knowledge on the growth and metabolism of MSCs and obtained knowledge on the effects of feeding regime, metabolic inhibitors, and $\mathrm{pH}$ and oxygen tension control on the expansion and metabolism of MSCs.

Before using expanded human MSCs for several applications in the clinic, more research should be performed to optimise growth of the cells on the microcarriers in the bioreactor system by evaluating the medium composition, the culture parameters and the bioreactor design. We showed that MSCs can be efficiently expanded in a microcarrier-based bioreactor system at hypoxic oxygen tensions, while maintaining the differentiation potential and cell viability As postulated, the medium composition can be optimized by evaluating for example the fatty acids, vitamins or growth factors. The culture conditions can be improved by finding the optimal mixing speed to obtain a homogenous cell distribution without cell damaging levels of shear. Before the MSCs expanded using this process can be used in the clinics, an automated and disposable bioreactor design according to GMP guidelines and a GMP process must be developed. 


\section{References}

1. Abranches E, Bekman E, Henrique D, Cabral JM (2007) Expansion of mouse embryonic stem cells on microcarriers. Biotechnol Bioeng 96:1211-1221

2. Brayfield CA, Marra KG, Rubin JP (2009) Adipose Tissue Regeneration. Curr Stem Cell Res Ther

3. Fernandes AM, Fernandes TG, Diogo MM, da Silva CL, Henrique D, Cabral JM (2007) Mouse embryonic stem cell expansion in a microcarrier-based stirred culture system. J Biotechnol $132: 227-236$

4. Frauenschuh S, Reichmann E, Ibold Y, Goetz PM, Sittinger M, Ringe J (2007) A microcarrier-based cultivation system for expansion of primary mesenchymal stem cells. Biotechnol Prog 23:187193

5. Kehoe DE, Jing D, Lock LT, Tzanakakis EM (2009) Scalable Stirred-suspension Bioreactor Culture of Human Pluripotent Stem Cells. Tissue Eng Part A

6. King JA, Miller WM (2007) Bioreactor development for stem cell expansion and controlled differentiation. Curr Opin Chem Biol 11:394-398

7. Krawetz R, Taiani JT, Liu S, Meng G, Li X, Kallos MS, Rancourt D (2009) Large-Scale Expansion of Pluripotent Human Embryonic Stem Cells in Stirred Suspension Bioreactors. Tissue Eng Part C Methods

8. Schop D, Janssen FW, Borgart E, de Bruijn JD, van Dijkhuizen-Radersma R (2008) Expansion of mesenchymal stem cells using a microcarrier-based cultivation system: growth and metabolism. J Tissue Eng Regen Med 2:126-135

9. Schop D, van Dijkhuizen-Radersma R, Borgart E, Janssen FW, Rozemuller H, Prins H-J, de Bruijn JD (2010) Expansion of human mesenchymal stromal cells on microcarriers: growth and metabolism. J Tissue Eng Regen Med in press

10. Serra M, Brito C, Leite SB, Gorjup E, von Briesen H, Carrondo MJ, Alves PM (2009) Stirred bioreactors for the expansion of adult pancreatic stem cells. Ann Anat 191:104-115

11. Yang Y, Rossi FM, Putnins EE (2007) Ex vivo expansion of rat bone marrow mesenchymal stromal cells on microcarrier beads in spin culture. Biomaterials 28:3110-3120

12. Yu Y, Li K, Bao C, Liu T, Jin Y, Ren H, Yun W (2009) Ex vitro expansion of human placentaderived mesenchymal stem cells in stirred bioreactor. Appl Biochem Biotechnol 159:110-118

13. Nilsson K (1988) Microcarrier cell culture. Biotechnol Genet Eng Rev 6:403-439

14. Yamada KM, Olden K (1978) Fibronectins--adhesive glycoproteins of cell surface and blood. Nature 275:179-184

15. Koller MR, Papoutsakis ET (1995) Cell adhesion in animal cell culture: physiological and fluidmechanical implications. Bioprocess Technol 20:61-110

16. Papoutsakis ET (1991) Fluid-mechanical damage of animal cells in bioreactors. Trends Biotechnol 9:427-437

17. Lao MS, Toth D (1997) Effects of ammonium and lactate on growth and metabolism of a recombinant Chinese hamster ovary cell culture. Biotechnol Prog 13:688-691

18. Omasa T, Higashiyama K, Shioya S, Suga K (1992) Effects of lactate concentration on hybridoma culture in lactate-controlled fed-batch operation. Biotechnol Bioeng 39:556-564

19. Bailey JM, Dunbar LM (1973) Essential fatty acid requirements of cells in tissue culture: a review. Exp Mol Pathol 18:142-161

20. Butler M, Huzel N, Barnabe N (1997) Unsaturated fatty acids enhance cell yields and perturb the energy metabolism of an antibody-secreting hybridoma. Biochem J 322 ( Pt 2):615-623

21. Mizrahi A, Lazar A (1988) Media for cultivation of animal cells: and overview. Cytotechnology 1:199-214

22. Genzel Y, Ritter JB, Konig S, Alt R, Reichl U (2005) Substitution of glutamine by pyruvate to reduce ammonia formation and growth inhibition of mammalian cells. Biotechnol Prog 21:58-69

23. Both SK, van der Muijsenberg AJ, van Blitterswijk CA, de Boer J, de Bruijn JD (2007) A rapid and efficient method for expansion of human mesenchymal stem cells. Tissue Eng 13:3-9

24. Sotiropoulou PA, Perez SA, Salagianni M, Baxevanis CN, Papamichail M (2006) Characterization of the optimal culture conditions for clinical scale production of human mesenchymal stem cells. Stem Cells 24:462-471

158. 
25. Maurer H (1986) Towards chemically-defined, serum free media for mamalian cell culture. In: Freshney R (ed) Animal cell culture: A practical approach. IRL Press, Oxford

26. Forestell SP, Kalogerakis N, Behie LA, Gerson DF (1992) Development of the optimal inoculation conditions for microcarrier cultures. Biotechnol Bioeng 39:305-313

27. Grammatikos SI, Subbaiah PV, Victor TA, Miller WM (1994) Diversity in the ability of cultured cells to elongate and desaturate essential (n-6 and n-3) fatty acids. Ann N Y Acad Sci 745:92-105

28. Rosenthal MD (1987) Fatty acid metabolism of isolated mammalian cells. Prog Lipid Res 26:87-124

29. Singh S, Arora R, Handa K, Khraisat A, Nagajothi N, Molnar J, Khosla S (2009) Stem cells improve left ventricular function in acute myocardial infarction. Clin Cardiol 32:176-180

30. Giordano A, Galderisi U, Marino IR (2007) From the laboratory bench to the patient's bedside: an update on clinical trials with mesenchymal stem cells. J Cell Physiol 211:27-35

31. Ge J, Li Y, Qian J, Shi J, Wang Q, Niu Y, Fan B, Liu X, Zhang S, Sun A, Zou Y (2006) Efficacy of emergent transcatheter transplantation of stem cells for treatment of acute myocardial infarction (TCT-STAMI). Heart 92:1764-1767

32. Suarez de Lezo J, Herrera C, Pan M, Romero M, Pavlovic D, Segura J, Sanchez J, Ojeda S, Torres A (2007) [Regenerative therapy in patients with a revascularized acute anterior myocardial infarction and depressed ventricular function]. Rev Esp Cardiol 60:357-365

33. Janssens S, Dubois C, Bogaert J, Theunissen K, Deroose C, Desmet W, Kalantzi M, Herbots L, Sinnaeve P, Dens J, Maertens J, Rademakers F, Dymarkowski S, Gheysens O, Van Cleemput J, Bormans G, Nuyts J, Belmans A, Mortelmans L, Boogaerts M, Van de Werf F (2006) Autologous bone marrow-derived stem-cell transfer in patients with ST-segment elevation myocardial infarction: double-blind, randomised controlled trial. Lancet 367:113-121

34. Joggerst SJ, Hatzopoulos AK (2009) Stem cell therapy for cardiac repair: benefits and barriers. Expert Rev Mol Med 11:e20

35. Chen SL, Fang WW, Ye F, Liu YH, Qian J, Shan SJ, Zhang JJ, Chunhua RZ, Liao LM, Lin S, Sun JP (2004) Effect on left ventricular function of intracoronary transplantation of autologous bone marrow mesenchymal stem cell in patients with acute myocardial infarction. Am J Cardiol 94:92-95 


\title{
Appendix
}

\section{Use of MSCs in a porcine model of acute myocardial infarction; Feasibility in vitro results}

\author{
D Schop $^{1}$, A Uitterdijk $^{2}$, M Bracke $^{1}$, BCW Groenendijk $^{2}$, WJ van der Giessen ${ }^{2,3}$, JD de Bruijn ${ }^{1}$ \\ ${ }^{1}$ Xpand Biotechnology, Bilthoven, The Netherlands \\ ${ }^{2}$ Department of Cardiology, Erasmus MC, Rotterdam, The Netherlands \\ ${ }^{3}$ Interuniversity Cardiology Institute, ICIN-KNAW, Utrecht, The Netherlands
}

\begin{abstract}
Prior to evaluate the effect of porcine MSCs in a porcine model of acute myocardial infarction, the feasibility of enriching porcine MSCs from a bone marrow aspirate and the expansion of these MSCs in a microcarrier-based cultivation system was investigated. Several enrichment methods were examined and expansion on Cytodex 1 microcarriers in a spinner flask culture was evaluated. After expansion, either in tissue culture flasks or in the microcarrier culture, the multipotency of these cells was evaluated. Erythrocyte depleted $(8 \mu \mathrm{m}$ filtering) crude bone marrow-derived MSCs attached directly to microcarriers. Subsequently, MSCs were able to multiply on the microcarriers and multipotency assays showed a higher differentiating potency for the cells enriched and expanded in the microcarrier-based cultivation system compared to cells enriched and expanded in tissue culture flasks. This study shows that it is feasible to expand porcine MSCs to substantial cell numbers within a clinically relevant therapeutical window.
\end{abstract}

160. 


\section{Introduction}

Several studies have shown that damage to infarcted heart tissue can be diminished by injecting the infarcted tissue with a (mono nucleated) subpopulation of the bone marrow ${ }^{1-4}$. However, the exact mechanism behind this repair is not yet known. It has been postulated that tissue repair could be due to introduction of a cocktail of the bone marrow cells, or only one cell type (e.g. the MSCs). Alternatively, paracrine regulation, or factors produced by the injected fraction of cells may be active to preserve the infarct borderzone tissue ${ }^{5-7}$. Contradictory results regarding improvement of myocardial function after cell therapy are also reported ${ }^{8-10}$. For example, Chen and co-workers reported a significant effect of cell therapy on the improvements of the left ventricular ejection fraction after acute myocardial infarction ${ }^{4}$, whereas Janssens et. al., did not found a significant improvement of the left ventricular ejection fraction after cell therapy ${ }^{10}$.

To investigate if MSCs enriched from bone marrow can play a role in the repair of damaged heart tissue, a porcine model for acute myocardial infarction will be used. In this model, MSCs will be enriched from the bone marrow of the animal, expanded to obtain 2$3 * 10^{6}$ MSCs per $\mathrm{kg}$ bodyweight ${ }^{3}$ and finally readministered transcoronary into infarct borderzone tissue of the pig one week after myocardial infarction ${ }^{11}$. By studying this porcine model, the clinical application of human autologous adult stem cell expansion will be investigated.

A feasibility study was set up to investigate the possibility to enrich porcine MSCs, either on tissue culture plastic or directly onto microcarriers, and to expand the enriched cells in a microcarrier-based cultivation system. To perform this study, the spinner flasks culture conditions designed for the human MSCs (chapter 4) have been used. Preliminary in vitro results, regarding enrichments and growth of porcine MSCs, are shown in this appendix.

\section{Materials and Methods}

All animal experiments were conducted in compliance with the "Guide for the Care and Use of Laboratory Animals" and after approval of the Animal Care Committee of the Erasmus MC. Bone marrow aspirates $(20-30 \mathrm{ml})$ were taken aseptically from the proximal femur of four, 5-6 months old (25-35 kg), Yorkshire x Landrace pigs of either sex. Bone marrow was collected in heparin, EDTA or sodium citrate anticoagulation tubes (Becton Dickinson, 
Vacutainer, Breda, The Netherlands) and transported at room temperature within 6 hours to the cell culture facility. Different experiments were performed using the aspirates.

Culture medium consisted of $\alpha$-MEM (Invitrogen, Breda, The Netherlands) supplemented with 10\% FBS (Cambrex, Verviers, Belgium), $100 \mathrm{U} / \mathrm{ml}$ penicillin (Invitrogen), $100 \mu \mathrm{g} / \mathrm{ml}$ streptomycin (Invitrogen), $2 \mathrm{mM}$ L-glutamine (Invitrogen), $0.2 \mathrm{mM}$ L-ascorbic acid-2phosphate (Sigma, Zwijndrecht, The Netherlands), and $1 \mathrm{ng} / \mathrm{ml}$ bFGF (AbD Serotec, Oxford, UK).

The MSC population was enriched from some aspirates either on tissue culture plastic or directly onto Cytodex 1 microcarriers in spinner flasks $\left(20 \mathrm{~cm}^{2} / \mathrm{ml}\right)$ using adhesion selection ${ }^{12}$

${ }^{13}$. Different pre-treatments of the aspirates were examined on cell yield after enrichment;

1) no pre-treatments,

2) washing the aspirate twice with PBS by centrifugation (5 minutes at $300 \mathrm{~g}$ ), and

3) filtration of the aspirate biopsy through an $8 \mu \mathrm{m}$ filter of PET membrane (Becton and Dickinson Labware, Breda, The Netherlands).

For expansion of the MSC population, either the directly seeded microcarriers were used or the microcarriers were incubated with porcine MSCs that were isolated by initial adhesion to tissue culture plastic. Expansion of the porcine MSCs was performed in $100 \mathrm{ml}$ spinner flasks (as described in chapter 4). Between day 6 and day 16, 50\% of the medium was refreshed and $30 \%$ medium with microcarriers was added every three days. Expansion of the porcine MSCs was assessed by the CellTiter-Glo assay (Promega, Leiden, The Netherlands) or by staining a sample with $1 \%$ methylene blue (MB) solution (Sigma).

After expansion of the porcine MSCs enriched from one aspirate, the differentiation potential, with regard to osteogenesis and chondrogenesis, was evaluated. For this, the protocols used to differentiate human MSCs were used (described in chapter 4 and 5).

\section{Results and Discussion}

\section{Enrichment of porcine MSCs from raw aspirate}

With regard to enrichment of the MSC population on tissue culture plastic, washing the biopsy with PBS yielded 2 times more cells compared to the untreated biopsy. After 13 days, $1.59 * 10^{4}$ cells $/ \mathrm{cm}^{2}$ were obtained from the untreated aspirate and $3.18 * 10^{4}$ cells $/ \mathrm{cm}^{2}$ were obtained from the washed aspirate. These differences are most probably caused by the lower number of erythrocytes present after washing the aspirate. Erythrocytes may have consumed 162. 
and exhausted nutrients from medium, leaving lower nutrient levels for the adherent fraction of the aspirate.

The first two enrichment methods failed to isolate MSCs directly onto Cytodex 1 microcarriers. An elastic aggregate was formed when the untreated aspirate was incubated with a microcarrier suspension. The aggregate did not include all microcarriers. It is speculated that the heparin present in the biopsy reacts with the microcarriers in the culture due to the electrogradient. Heparin is a highly-sulfated glycosaminoglycan, which is widely used as an injectable anticoagulant and has the highest negative charge density of any known biological molecule ${ }^{14}$. As the Cytodex 1 microcarriers are positively charged, the heparin might attach to the microcarriers and may not be functional. In case heparin is absent or dysfunctional in a culture containing blood platelets, the blood will coagulate and form an aggregate. We evaluated alternative anti-coagulation agents, such as EDTA and sodium citrate, in order to rule out the effect of charge neutralisation. However, bone marrow received in containers pretreated with aforementioned antiocoagulants resulted in even lower numbers of isolated MSCs (data not shown). An alternative solution to intercept the problem of coagulation is to eliminate the blood platelets from the heparin aspirate, either by washing the aspirate or by filtration.

The washing pre-treatment of the biopsy resulted in attached cells to the Cytodex 1 microcarriers. However, many red blood cells remained present in the medium and they attached to the microcarriers as well, which is undesirable as they may consume nutrients and use surface area dedicated for the MSC population. Alternatively, the biopsy was $8 \mu \mathrm{m}$ filtrated yielding an enriched cell population of which the MSC fraction could directly be adhered to the Cytodex 1 microcarriers (Figure 1A). Isolation of stem cells using filtration was also shown by Hung and co-workers ${ }^{15}$. They used a $3 \mu \mathrm{m}$ filter and placed the filter with the mono nucleated fraction of the bone marrow in a tissue culture flask for MSC enrichment. However, direct enrichment of MSCs onto microcarriers has not been shown before, to our best knowledge. 


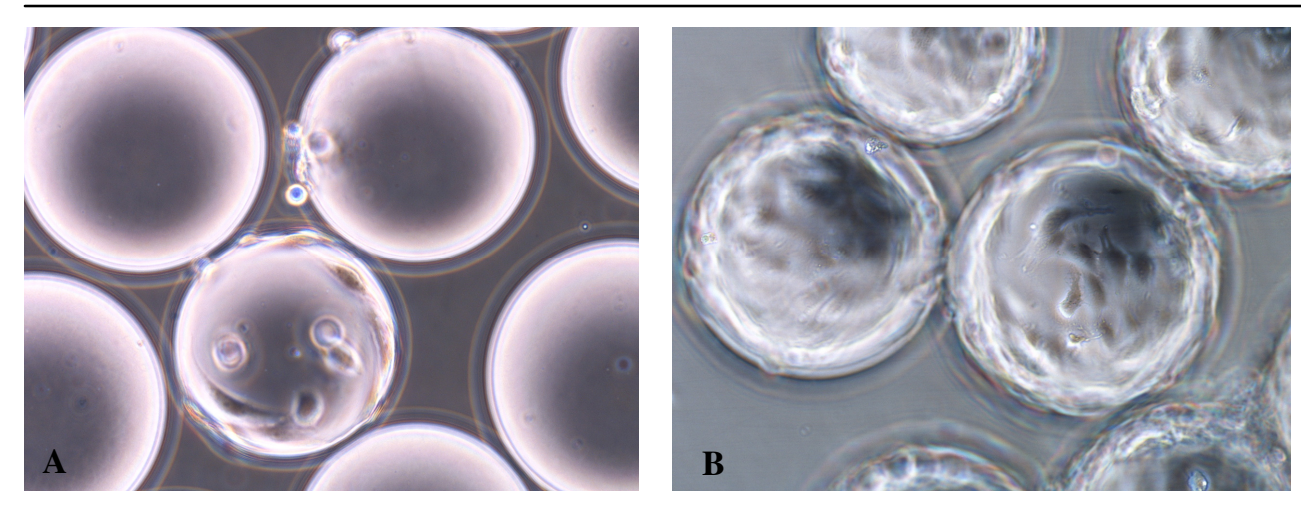

Figure 1. Direct seeding and growth of porcine MSCs on microcarriers

A filtered bone marrow biopsy was incubated with a Cytodex 1 microcarrier suspension in spinner flasks. A) Attached cells at day 6 after seeding B) Expanded cells after 16 days.

\section{Expansion of porcine MSCs on microcarriers}

Expansion of porcine MSCs was shown for passage 0 cells (after direct MSC-isolation onto the microcarriers, Figure 1B), and passage 1 cells (isolated on tissue culture plastic and reseeded onto microcarriers (Figure 2). Comparable to goat and human MSCs ${ }^{13 ;}{ }^{16}$, bead-tobead jumping of the porcine MSCs was observed after addition of fresh microcarriers.

During expansion, $\mathrm{p} 1$ cells grew with a population doubling time of 2 hours. Moreover, glucose and lactate were measured. The p1 porcine MSC culture in the spinner flask showed a glucose to lactate conversion rate $\left(\mathrm{Y}_{\text {lac/glc }}\right)$ of 2.5 and a specific glucose consumption rate (qGlc) of -3.3 pmol cell $^{-1}$ day $^{-1}$. These are results of only one culture and from one donor, and may therefore not be representative but it gives an indication about the metabolism of porcine MSCs. Based on these data, porcine MSCs expanded on microcarriers used glycolytic metabolism to generate energy from glucose. Growth and metabolism may change when expansion is upscaled to the stirred vessel bioreactor using optimized culture conditions as defined for the expansion of human MSCs (see chapter 4 and 5).

164. 


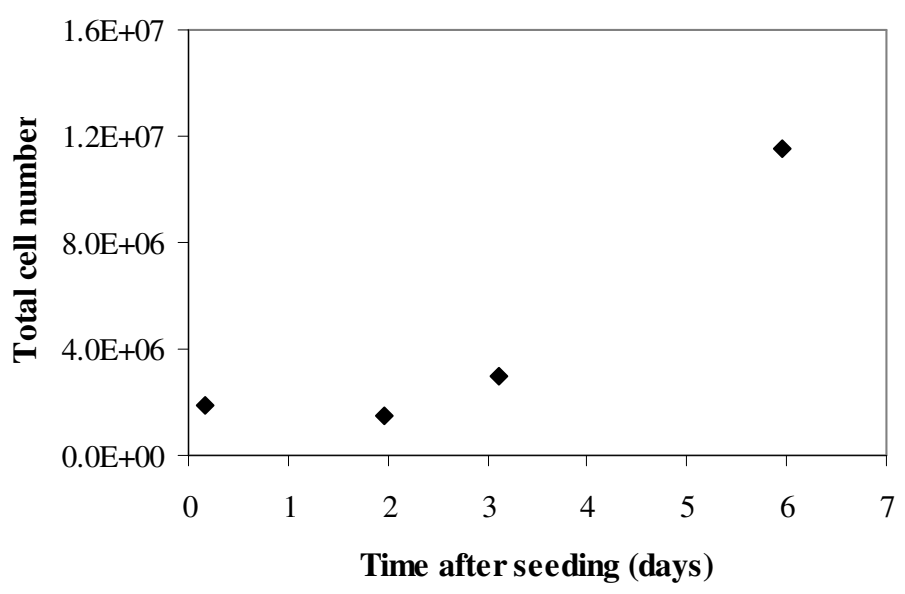

Figure 2. $\quad$ Expansion of porcine MSCs on Cytodex 1 microcarriers

$(\bullet)$ passage 1 cells expanded on microcarriers in a spinner flask.

\section{Multipotency of expanded porcine MSCs}

The directly enriched and expanded porcine MSCs on cytodex 1 microcarriers and tissue culture plastic were verified for their differentiation potential, with regard to adipogenesis, osteogenesis and chondrogenesis. Adipogenesis of the porcine MSCs, using the selected protocol which is also used for differentiation of human MSCs, did not yield fat globules in the cytoplasm. This may be an indication that the expanded porcine MSCs were not multipotent or that the selected protocol to stimulate adipogenesis was not suitable for porcine MSCs.

With regard to the osteogenesis and chondrogenesis, differentiation of the expanded cells was observed (Figure 3). More calcium deposits and more GAG matrix was formed with p0 cells that were isolated and expanded on Cytodex 1 microcarriers, compared to the p2 cells isolated and expanded on tissue culture plastic. These results indicate that by isolating and expanding the MSCs directly using microcarriers and the filtration method, MSCs maintain their differentiation potential better than when isolating and expanding the cells on tissue culture plastic. As this experiment was only performed with one donor, this study should be repeated with several donors and passage numbers, as this may influence the results ${ }^{17-19}$. 


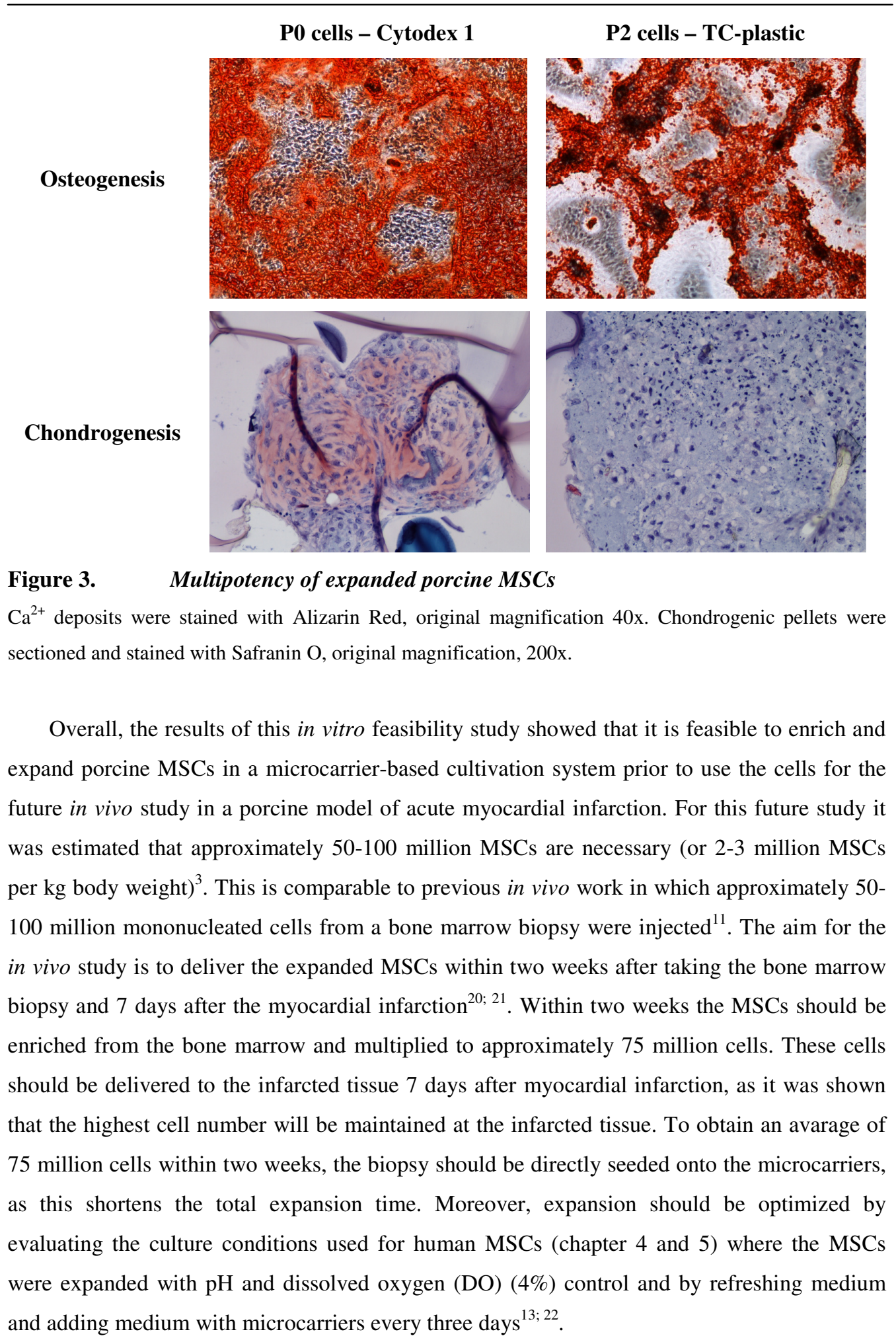

166. 


\section{Conclusions}

Most optimal enrichments of porcine MSCs from the bone marrow on the Cytodex 1 microcarriers was obtained after $8 \mu \mathrm{m}$ filtration of the biopsy. In addition, cells were able to grow on the microcarriers and showed to be more multipotent than when enriched and expanded on tissue culture plastic. For future in vivo experiments, it should be feasible to expand the MSCs up to an average of 75 million cells within a clinically relevant therapeutical window.

\section{References}

1. Assmus B, Schachinger V, Teupe C, Britten M, Lehmann R, Dobert N, Grunwald F, Aicher A, Urbich C, Martin H, Hoelzer D, Dimmeler S, Zeiher AM (2002) Transplantation of Progenitor Cells and Regeneration Enhancement in Acute Myocardial Infarction (TOPCARE-AMI). Circulation 106:3009-3017

2. Wollert KC, Meyer GP, Lotz J, Ringes-Lichtenberg S, Lippolt P, Breidenbach C, Fichtner S, Korte T, Hornig B, Messinger D, Arseniev L, Hertenstein B, Ganser A, Drexler H (2004) Intracoronary autologous bone-marrow cell transfer after myocardial infarction: the BOOST randomised controlled clinical trial. Lancet 364:141-148

3. Giordano A, Galderisi U, Marino IR (2007) From the laboratory bench to the patient's bedside: an update on clinical trials with mesenchymal stem cells. J Cell Physiol 211:27-35

4. Chen SL, Fang WW, Ye F, Liu YH, Qian J, Shan SJ, Zhang JJ, Chunhua RZ, Liao LM, Lin S, Sun JP (2004) Effect on left ventricular function of intracoronary transplantation of autologous bone marrow mesenchymal stem cell in patients with acute myocardial infarction. Am J Cardiol 94:92-95

5. Gnecchi M, Zhang Z, Ni A, Dzau VJ (2008) Paracrine mechanisms in adult stem cell signaling and therapy. Circ Res 103:1204-1219

6. Korf-Klingebiel M, Kempf T, Sauer T, Brinkmann E, Fischer P, Meyer GP, Ganser A, Drexler H, Wollert KC (2008) Bone marrow cells are a rich source of growth factors and cytokines: implications for cell therapy trials after myocardial infarction. Eur Heart J 29:2851-2858

7. Ziebart T, Yoon CH, Trepels T, Wietelmann A, Braun T, Kiessling F, Stein S, Grez M, Ihling C, Muhly-Reinholz M, Carmona G, Urbich C, Zeiher AM, Dimmeler S (2008) Sustained persistence of transplanted proangiogenic cells contributes to neovascularization and cardiac function after ischemia. Circ Res 103:1327-1334

8. Lunde K, Solheim S, Aakhus S, Arnesen H, Abdelnoor M, Forfang K (2005) Autologous stem cell transplantation in acute myocardial infarction: The ASTAMI randomized controlled trial Intracoronary transplantation of autologous mononuclear bone marrow cells, study design and safety aspects. Scand Cardiovasc J 39:150-158

9. Meyer GP, Wollert KC, Lotz J, Pirr J, Rager U, Lippolt P, Hahn A, Fichtner S, Schaefer A, Arseniev L, Ganser A, Drexler H (2009) Intracoronary bone marrow cell transfer after myocardial infarction: 5-year follow-up from the randomized-controlled BOOST trial. Eur Heart J 30:29782984

10. Janssens S, Dubois C, Bogaert J, Theunissen K, Deroose C, Desmet W, Kalantzi M, Herbots L, Sinnaeve P, Dens J, Maertens J, Rademakers F, Dymarkowski S, Gheysens O, Van Cleemput J, Bormans G, Nuyts J, Belmans A, Mortelmans L, Boogaerts M, Van de Werf F (2006) Autologous bone marrow-derived stem-cell transfer in patients with ST-segment elevation myocardial infarction: double-blind, randomised controlled trial. Lancet 367:113-121

11. Moelker AD, Baks T, van den Bos EJ, van Geuns RJ, de Feyter PJ, Duncker DJ, van der Giessen WJ (2006) Reduction in infarct size, but no functional improvement after bone marrow cell 
administration in a porcine model of reperfused myocardial infarction. Eur Heart J 27:30573064

12. de Bruijn JD, van den Brink I, Bovell YP, van Blitterswijk C (1998) Tissue engineering of goat bone: osteogenic potential of goat bone marrow cells. Bioceramics 11:497-500

13. Schop D, van Dijkhuizen-Radersma R, Borgart E, Janssen FW, Rozemuller H, Prins H-J, de Bruijn JD (2010) Expansion of human mesenchymal stromal cells on microcarriers: growth and metabolism. J Tissue Eng Regen Med in press

14. Nelson DL, Cox MM (2000) Lehninger Principles of Biochemistry. Vol. 3. Worth publishers, New York, NY

15. Hung SC, Chen NJ, Hsieh SL, Li H, Ma HL, Lo WH (2002) Isolation and characterization of sizesieved stem cells from human bone marrow. Stem Cells 20:249-258

16. Schop D, Janssen FW, Borgart E, de Bruijn JD, van Dijkhuizen-Radersma R (2008) Expansion of mesenchymal stem cells using a microcarrier-based cultivation system: growth and metabolism. J Tissue Eng Regen Med 2:126-135

17. Mendes SC, Tibbe JM, Veenhof M, Bakker K, Both S, Platenburg PP, Oner FC, de Bruijn JD, van Blitterswijk CA (2002) Bone tissue-engineered implants using human bone marrow stromal cells: effect of culture conditions and donor age. Tissue Eng 8:911-920

18. Phinney DG, Kopen G, Righter W, Webster S, Tremain N, Prockop DJ (1999) Donor variation in the growth properties and osteogenic potential of human marrow stromal cells. J Cell Biochem 75:424-436

19. Siddappa R, Licht R, van Blitterswijk C, de Boer J (2007) Donor variation and loss of multipotency during in vitro expansion of human mesenchymal stem cells for bone tissue engineering. $\mathrm{J}$ Orthop Res 25:1029-1041

20. Assmus B, Rolf A, Erbs S, Elsasser A, Haberbosch W, Hambrecht R, Tillmanns H, Yu J, Corti R, Mathey DG, Hamm CW, Suselbeck T, Tonn T, Dimmeler S, Dill T, Zeiher AM, Schachinger V Clinical outcome 2 years after intracoronary administration of bone marrow-derived progenitor cells in acute myocardial infarction. Circ Heart Fail 3:89-96

21. Zhang S, Sun A, Xu D, Yao K, Huang Z, Jin H, Wang K, Zou Y, Ge J (2009) Impact of timing on efficacy and safetyof intracoronary autologous bone marrow stem cells transplantation in acute myocardial infarction: a pooled subgroup analysis of randomized controlled trials. Clin Cardiol 32:458-466

22. Schop D, Van Dijkhuizen-Radersma R, Brans G, Prins H-J, Rozemuller H, Martens DE, de Bruijn JD (2010) Effect of oxygen tension on metabolism, expansion and differentiation of human mesenchymal stromal cells. Biotechnol Bioeng Submitted

168. 


\section{Summary}

Mesenchymal stem cells, MSCs, are a great potential source for clinical applications in the field of tissue regeneration. Either by applying cell based techniques or tissue engineering, clinically relevant numbers of MSCs are necessary as described in chapter 1. Although MSCa can be isolated from several tissues of the human body, bone marrow is one of the most investigated sources as relatively high numbers of MSCs can be enriched from this tissue. Unfortunately, a bone marrow aspirate does not contain clinically relevant amounts of MSCs for cell therapeutic use. The cells need to be multiplied ex vivo before they can be applied as a tissue regenerative basis. This dissertation describes the expansion of MSCs in a microcarrierbased bioreactor system. In addition, the metabolism of the MSCs is described as this directly influences cell growth efficiency.

Growth and metabolic experiments in conventional tissue culture flasks using MSCs from goat, rat and human donors showed that there is a species dependence on growth rate and metabolic utilization of glucose (chapter 2). Goat MSCs grew significantly faster compared to rat and human MSCs. Regarding the c-source metabolism, goat cells utilized glucose via the efficient oxidative phosphorylation pathway, while human and rat used the inefficient glycolysis pathway towards lactate. Moreover, it was shown that MSCs can tolerate relatively high lactate concentrations before growth inhibition occurs, while ammonia inhibits MSC growth at low levels that are faced during culture.

In chapter 3 and 4, we showed the possibility to expand goat and human MSCs on Cytodex 1 microcarriers in a spinner flask culture. By optimizing the feeding regime based on cellular metabolism, cell growth on microbeads was improved and clinically relevant numbers of MSCs per $\mathrm{cm}^{2}$ were reached, while maintaining stem cell characteristics and multipotency. In addition, we showed in chapter 5 that when controlling the $\mathrm{pH}$ at 7.2-7.3 and maintaining the oxygen tension at hypoxic levels of 3-4\% oxygen in a stirred vessel bioreactor, cell expansion and cell viability is improved. Results also showed a better maintenance of human stem cell multipotency with regard to chondrogenesis. Moreover, we found that human MSC metabolism shifted to a higher rate of glycolysis to generate energy for growth and cellular maintenance when expanded at low oxygen tensions. Chapter 6 showed a detailed insight in the amino acid metabolism of the human MSCs expanded at a low oxygen tension in a 
controlled stirred culture. A batch culture for 6 days showed no limitations in amino acid concentrations.

In addition to cell culture characteristics, in vivo studies with MSCs expanded in a microcarrier-based bioreactor system were initiated to examine the preservation of stem cell characteristics during expansion in vivo. The Appendix chapter described an efficient method of MSC enrichment and expansion of porcine MSCs mimicking the clinical situation.

Overall, we indicated the feasibility of expanding MSC on Cytodex 1 microcarriers and gained more knowledge on the effect of expansion conditions on cellular metabolism. We showed that expansion can be improved by investigating the metabolism of the cells and by controlling the cell culture for $\mathrm{pH}$ and oxygen tension. Nevertheless, there are still topics that need to be addressed to further improve expansion, such as the fatty acid metabolism, growth factor concentrations or the shear in a microcarrier based stirred culture. Before implementation into the clinical settings, a disposable bioreactor should be developed according to good manufacturing practice (GMP) guidelines.

170. 


\section{Samenvatting}

Mesenchymale stamcellen, MSC's, hebben een hoge klinische potentie voor de regeneratie van weefsels. Echter voor het gebruik van klinische toepassingen door middel van celtherapie of weefselkweek is een groot aantal MSC's vereist, zoals beschreven in hoofdstuk 1. MSC's kunnen worden verkregen uit verschillende soorten weefsels van het menselijke lichaam. Beenmerg wordt gezien als een van de belangrijkste weefsels aangezien zich hier een relatief hoog aantal MSC's in bevinden. Helaas is het aantal cellen dat uit het beenmerg kan worden geïsoleerd lang niet genoeg voor de klinische toepassing en moeten ze dus nog vermenigvuldigd worden. Dit proefschrift beschrijft de vermenigvuldiging van MSC's op microcarriers (dragermateriaal), in een bioreactor systeem. Ook is het metabolisme van de cellen beschreven aangezien de efficiëntie van de celgroei hierdoor wordt beïnvloed.

Experimenten in traditionele kweekflessen met MSC's van geiten, ratten en menselijke donoren toonde aan dat MSC's van verschillende soorten verschillen in groei en glucosemetabolisme (hoofdstuk 2). Geiten MSC's groeiden significant sneller vergeleken met ratten- en menselijke MSC's. Met betrekking tot het glucosemetabolisme consumeerde geiten MSC's glucose via de efficiënte oxidatieve fosforylatie route, waar menselijke en ratten MSC's de inefficiënte glycolyseroute naar melkzuur gebruikten. Verder is er ook aangetoond dat MSC's bestand zijn tegen relatief hoge melkzuurconcentraties, maar dat de groei wordt geremd door de ammoniaconcentraties die in een kweek worden bereikt.

In hoofdstuk 3 en 4 hebben we laten zien dat het mogelijk is om geiten- en menselijke MSC's op microcarriers in een geroerde fles te kweken. Door het voerschema, gebaseerd op het metabolisme, dusdanig te optimaliseren, waren we in staat de celgroei op microcarriers te verbeteren. Hierdoor werden celhoeveelheden per $\mathrm{cm}^{2}$ bereikt die nodig zijn voor klinische toepassingen. Hierbij werden de eigenschappen van de stamcellen behouden. Hoofdstuk 5 beschrijft dat het controleren van de $\mathrm{pH}$ op 7.2-7.3 en de zuurstofconcentratie op 3-4\% tijdens een kweek in een geroerd vat de celgroei en vitaliteit verbeterd. Ook werd de differentiatiemogelijkheid, met name de kraakbeendifferentiatie, beter behouden wanneer een kweek werd gecontroleerd. Verder zagen we dat het behouden van een lage (3-4\%) zuurstofconcentratie het metabolisme van de menselijke MSC's verschoof naar een hogere consumptie van glucose via de glycolyse. Hoofdstuk 6 laat een meer gedetailleerd overzicht 
zien van het aminozuurmetabolisme voor menselijke MSC's, wanneer ze worden vermenigvuldigd op de microcarriers in een geroerd vat met een lage zuurstofconcentratie. Hieruit bleek dat, wanneer de cellen voor 6 dagen in batch worden gekweekt, er geen limiterende aminozuurconcentraties worden behaald.

Naast het verkrijgen van meer celkweekkennis zijn er ook in vivo experimenten opgestart, waarbij we kijken of de vermenigvuldigde cellen nog steeds stamceleigenschappen hebben wanneer teruggeplaatst in een dierlijk lichaam. De bijlage beschrijft een efficiënte methode om MSC's uit een varkensbeenmergbiopt te verkrijgen, zoals het ook in de kliniek toegepast kan worden.

Alles omvattend hebben we bewezen dat het mogelijk is om MSC's te vermenigvuldigen op Cytodex 1 microcarriers en hebben we meer kennis verkregen van de invloed van celkweekcondities op het celmetabolisme. We hebben laten zien dat de vermenigvuldiging kan worden verbeterd door het metabolisme van de cellen te bestuderen en door de kweekcondities te controleren. Toch zijn er nog steeds onderwerpen die bestudeerd moeten worden om de vermenigvuldiging verder te verbeteren, zoals het vetzuurmetabolisme, concentraties van groeifactoren en de invloed van wrijvingskrachten die optreden in een geroerde bioreactor met microcarriers. Voordat het vermenigvuldigingsproces in de kliniek toegepast kan worden, moet er een bioreactor voor eenmalig gebruik worden ontworpen volgens strikte richtlijnen.

172. 


\section{Dankwoord}

Met behulp van dit hoofdstuk wil ik iedereen bedanken die mij tijdens mijn promotieperiode heeft gesteund en geïnspireerd. Zonder jullie was ik niet tot dit resultaat gekomen!

In het bijzonder wil ik twee mensen bedanken die mij hebben gestimuleerd om de verkregen resultaten en ideeën tot een promotieonderzoek te vormen; mijn promotor Joost en assistent-promotor Riemke. Joost, bedankt voor de mogelijkheid om mijn promotieonderzoek binnen Xpand Biotechnology BV te hebben mogen uitvoeren. Ik heb in deze periode erg veel geleerd en ik heb met heel veel plezier gewerkt aan het onderzoek en de andere klusjes die binnen een klein bedrijf moeten gebeuren. Riemke, ik moet zeggen dat jij toch wel mijn grootste inspiratiebron bent geweest en dat jij de persoon bent geweest die mij heeft gestimuleerd om te promoveren in het stamcelonderzoek. Heel erg bedankt voor je input en de "dates" tijdens de afgelopen jaren! Traditiegetrouw wil ik mijn tweede promotor Clemens van de Universiteit Twente bedanken voor de mogelijkheid om op de Universiteit binnen de vakgroep Tissue Regeneration te promoveren.

Uiteraard ben ik dank verschuldigd aan mijn (ex)-collega's van Xpand; Davide, Elise, Florence, Frank, Frank-Jan, Jurren, Linda, Madelon, Paul, Rafaelle, Remco, Ruiqiung, Ulrike, Vincent, Viola, Yanling, Yuan en Yvonne. Het was een goede tijd bij Xpand Biotechnology en dat komt mede door jullie allen. Linda en Elise, mijn paranimfen, hartstikke bedankt voor de gezellige tijd en goede samenwerking bij Xpand. Ik ben jullie gaan zien als goede vriendinnen en ik hoop dat we dat nog lang zullen zijn. Ook wil ik de andere "collega's" van CellCoTec, Signifix en Applikon Biotechnology bedanken voor de goede en gezellige samenwerking.

Henk-Jan, Henk en Anton Martens van het UMC Utrecht: Ik vond het erg prettig samenwerken met jullie. Helaas konden de microcarriers en het plaatjes lysate niet samen, maar misschien vinden we daar nog een oplossing voor. Bedankt dat ik gebruik heb kunnen maken van de FACS. 
André, ik vond het helemaal super om na onze studie in Wageningen weer samen met je te werken. Ons onderzoek naar de in vivo toepassing van de geëxpandeerde stamcellen wordt doorgezet bij het Erasmus MC en ik ben erg benieuwd naar de resultaten.

I also want to thank the "Bilthoven" PhD-students and TNW members from the University of Twente. Thanks for guiding me around in the lab when I started working for Xpand Biotechnology (or Progentix at that moment) and thanks for the nice times during conferences where we still met each other after the department moved from Bilthoven to Enschede. Hugo, I want to thank you for your help with rat MSCs isolations and your input in the publication where you are one of the co-authors. Gustavo, I want to thank you for our cooperation during the STEX project. We obtained very nice results and publications together! And, you're almost there! Frank, thanks for your input at the beginning of the STEX project. I missed you when you started working for another company.

Als voorlaatste, maar zeker erg belangrijk, wil ik mijn vrienden en familie bedanken. Jay en Sas, bedankt voor jullie interesse in het onderzoek en dat jullie altijd luisterden naar de bekende AIO frustraties. Joep en Alies, bedankt voor de afleiding in de weekenden als we weer gezellig bij elkaar waren ergens in een vakantiehuisje of gewoon lekker bij jullie of bij ons thuis. Verder wil ik mijn ouders, zusjes, schoonouders, Johan en Lil bedanken voor hun liefde en steun tijdens de promotieperiode en natuurlijk ook voor de interesse in het onderzoek, al was het voor jullie niet altijd te volgen waar ik me nou mee bezig hield.....

Alex, in 2006 zijn we allebei aan onze promotieonderzoek begonnen. Het grote voordeel hiervan is dat we onze resultaten konden bespreken tijdens het avondeten en dat we van elkaar begrepen als we weer eens in de avonduurtjes of in het weekend moesten werken. Dit was erg fijn. Bedankt voor alles! Nu nog een mooi boekje van jouw onderzoek. Dat we maar lang een gezond en gelukkig getrouwd stel blijven en elkaar kunnen blijven inspireren.

Deborah

174. 


\section{Curriculum vitae Deborah Schop}

Deborah was born on the $28^{\text {th }}$ of November 1982 in Rotterdam, The Netherlands. She grew up in Barendrecht and obtained her Bachelor in biotechnology at Hogeschool Rotterdam. In 2004 she went to Wageningen University to extent her knowledge on biotechnology and received her Master in Medical Biotechnology in 2006. After that she started as a process engineer at Xpand Biotechnology BV (formerly known as Progentix BV). The aim of the company was to develop an automated and stand-alone bioreactor system for the expansion of bone marrow derived stem cells.

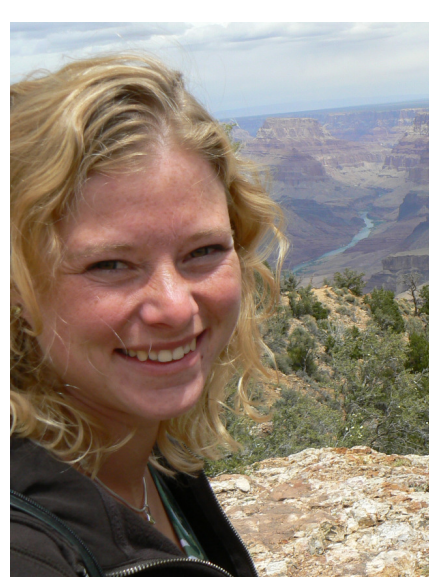
Within this project, her responsibility was to look into the process of mesenchymal stem cell expansion inside the bioreactor system. After one and a half year, this project was turned into a promotion project and the results are described in this thesis.

Since the $1^{\text {st }}$ of December 2009 she has been working at Synthon BV within the group of upstream processing, where she investigates fermentation conditions and scale up possibilities for the production of medicines using animal cell lines. 